Aus der Abteilung Gastroenterologie und Endokrinologie

(Prof. Dr. med. Dr. h.c. G. Ramadori)

im Zentrum Innere Medizin

der Medizinischen Fakultät der Universität Göttingen

\title{
Darmschädigung durch Photonen-Strahlung nach Einzeitbestrahlung der Leber
}

\author{
INAUGURAL - DISSERTATION \\ zur Erlangung des Doktorgrades \\ der Medizinischen Fakultät \\ der Georg-August-Universität zu Göttingen
}

vorgelegt von

Antonia Sophie Schwartz

aus Hamburg

Göttingen 2011 
Dekan:

1. Berichterstatter:

2. Berichterstatter/in:

3. Berichterstatter/in:

Tag der mündlichen Prüfung:
Prof. Dr. med. C. Frömmel

Prof. Dr. med. Dr. h.c. G. Ramadori

Prof. Dr. med. H. Christiansen

Prof. Dr. med. M. Oppermann

16.01.2012 


\section{INHALTSVERZEICHNIS}

EINLEITUNG

1.1 STRAHLENTHERAPIE

\section{2}

APOPTOSE

1.2.1 MORPHOLOGIE DER APOPTOSE

1.2 .2

APOPTOSE VERSUS NEKROSE

1.2 .3

CASPASEN: DiE SCHLÜSSELENZYME DER APOPTOSE

1.2 .4

SIGNALTRANSDUKTIONSWEGE DER APOPTOSE

1.3 ZYTOKINE: DiE REgULATION DER INTESTINALEN ZELLHOMÖOSTASE

1.4 ZIELSETZUNG

\section{MATERIAL UND METHODEN}

\section{1}

VERSUCHSAUFBAU

RNA-EXTRAKTION AUS GEWEBE MIT HILFE DER ULTRAZENTRIFUGE

\section{3}

GELELEKTROPHORESE ZUR DETEKTION VON APOPTOTISCHER DNA

\section{5}

STRIPPEN DER MEMBRANEN

3.1 DAS VERSUCHSTIER: RATTE

3.2 HiSTOLOGISCHE VERÄNDERUNG IN FOLGE VON BESTRAHLUNG 
3.2.3 ED1 ALS MARKER FÜR CD68-POSITIVE MAKROPHAGEN

3.2.4 CD3 ALS MARKER FÜR T-LYMPHOZYTEN

$\begin{array}{lll}3.2 .5 & \text { CD34-FÄRBUNG } & 42\end{array}$

3.2.6 CASPASE-3-FÄRBUNG

3.2.7 TUNEL-FÄRBUNG 46

$\begin{array}{lll}3.3 & \text { ERGEBNISSE DER RNA-ANALYSE }\end{array}$

3.3.1 PROINFLAMMATORISCHE ZYTOKINE 48

3.3.2 IP-10: DAS ETWAS ANDERE ZYTOKIN

3.3.3 FIBROSIERUNG IM DARM INITIIERT DURCH TGF- $\beta \quad 49$

3.3.4 DIE EXPRESSION VON CHEMOKINEN UND ADHÄSIONSMOLEKÜLEN 49

3.3.5 DIE EXPRESSION VON PRO- UND ANTIAPOPTOTISCHEN FAKTOREN 51

3.3.6 DIE EXPRESSION VON ENTZÜNDUNGSMEDIATOREN UND IMMUNZELLEN

3.3.7 DIE ANGIOGENESE BEEINFLUSSENDEN FAKTOREN: VEGF, VEGF-R UND SMA 52

3.4 ERGEBNISSE DER WESTERN BLOTS

3.4.1 $\quad \beta$-AKTIN, DAS HOUSE-KEEPING GEN $\quad 55$

3.4.2 CASPASE $8 \quad 55$

3.4.3 CASPASE $3 \quad 58$

3.4.4 DAS PROAPOPTOTISCHE BAX

3.4.5 DER GEGENSPIELER DER APOPTOSE: BCL-2

3.5 ANALYSE VON GENOMISCHER DNA MIT HILFE EINER GEL-ELEKTROPHORESE 61

3.6 ZUSAMMENFASSUNG DER ERGEBNISSE

$4 \quad$ DISKUSSION $\quad 67$

$\begin{array}{lll}4.1 & \text { BESTRAHLUNGSMODELLE } & 67\end{array}$

4.1.1 WAHL DER DARMABSCHNITTE UND ZEITPUNKTE NACH BESTRAHLUNG 68

$\begin{array}{lll}\text { 4.1.2 METHODISCHE DURCHFÜHRUNG } & 69\end{array}$

4.2 PATHOlogische Veränderungen AM DARM in Folge Von BeSTRAhlung 73

4.2.1 APOPTOSE: DiREKTE ANTWORT AUF BESTRAHLUNG

4.2.2 AKUTE UND CHRONISCHE STRAHLENENTERITIS

4.2.3 CHEMOTAXIS UND MIGRATION VON IMMUNZELLEN

4.2.4 ENDOTHELIALE DYSFUNKTION UND HYPOXIE $\quad 81$

4.2.5 STRAHLENINDUZIERTE FIBROSIERUNG AM DARM: LANGZEITSCHÄDEN 84

4.3 PARALLELEN ZU ANDEREN PATHOLOGISCHEN DARMVERÄNDERUNGEN

4.4 MögLiCHE THERAPIEANSÄTZE UND KLINISCHE RELEVANZ

$\begin{array}{lll}4.5 & \text { AUSBLICKE } & 90\end{array}$

5 ZUSAMMENFASSUNG $\quad 93$

6 LITERATURVERZEICHNIS $\quad 95$

$\begin{array}{lll}7 & \text { ANHANG: TABELLE } 7 \text { BIS } 15 & 108\end{array}$ 


\section{ABBILDUNGSVERZEICHNIS}

Abb. 1 Der intrinsische und extrinsische Signaltransduktionsweg der Apoptoseinduktion 8

Abb. 2 Planungscomputertomogramm und Rattensitus 12

Abb. 3 Beispielbild mit Ponceau-Rot 19

Abb. 4 a) Dünndarmsegment nach Bestrahlung und b) Dünndarmpräparat der bestrahlten Ratte im Vergleich zum unbestrahlten Versuchstier (kleiner Kasten) 32

Abb. $5 \quad$ Strahlenschädigungs-Score 34

Abb. 6 H.E.-Färbung (100-fache Vergrößerung) 36

Abb. 7 Masson-Goldner-Trichromfärbung (100-fache Vergrößerung) 37

Abb. 8 Absolute Anzahl von ED1-positiven Zellen im Gewebeausschnitt (1,3 $\left.\mathrm{mm}^{2}\right)$ dargestellt mit Standardabweichung 38

Abb. 9 ED1-Färbung (100-fache Vergrößerung) 39

Abb. 10 Exemplarische Zellzählung von CD3-positiven T-Lymphozyten 40

Abb. 11 CD3-Färbung (100-fache Vergrößerung) 41

Abb. 12 Prozentzahl der CD3-positiven T-Lymphozyten bezogen auf alle Zellen des Gewebeausschnittes $\left(=1,3 \mathrm{~mm}^{2}\right)$ dargestellt mit Standardabweichung 42

Abb. 13 CD34-Färbung (100-fache Vergrößerung) 43

Abb. 14 Prozentzahl der CD34-positiven Zellen bezogen auf alle Zellen des Gewebeausschnittes $\left(1,3 \mathrm{~mm}^{2}\right)$ dargestellt mit Standardabweichung $\quad 44$

Abb. 15 Caspase-3-Färbung (100-fache Vergrößerung) 45

Abb. 16 Prozentzahl der Caspase-3-positiven Zellen bezogen auf alle Zellen des Gewebeausschnittes $\left(1,3 \mathrm{~mm}^{2}\right)$ dargestellt mit Standardabweichung 46

$\begin{array}{lll}\text { Abb. } 17 & \text { TUNEL-Färbung } & 47\end{array}$

Abb. 18 Western Blot mit dem Antikörper $\beta$-Aktin inkubiert 55

Abb. 19 Caspase 8 dargestellt im Western Blot. Organ: Duodenum 56

Abb. 20 Caspase 8 dargestellt im Western Blot. Organ: Jejunum 56

Abb. 21 Caspase 8 dargestellt im Western Blot. Organ: Ileum 57

Abb. 22 Caspase 8 dargestellt im Western Blot. Organ: Colon 57

Abb. 23 Caspase 3 dargestellt im Western Blot 58

Abb. 24 Western Blots: 1. Bax bei $42 \mathrm{kDa}, 2$. Bax bei $21 \mathrm{kDa}, 3$. Bcl-2 bei $26 \mathrm{kDa}$ und 4. $\beta$-Aktin bei $46 \mathrm{kDa} \quad 60$

Abb. 25 Darstellung von genomischer DNA mit Hilfe einer Gelelektrophorese 62 


\section{TABELLENVERZEICHNIS}

Tabelle 1 Apoptose versus Nekrose modifiziert nach Kroemer et al. (1998) 5

$\begin{array}{lll}\text { Tabelle } 2 & \text { Zusammensetzung der Gele } & 18\end{array}$

Tabelle 3 Zusammensetzung der rTdT-Lösung 24

Tabelle 4 Kriterien der Strahlenschädigung des Darmgewebes 33

Tabelle 5 Fold changes $\quad 54$

Tabelle 6 Zusammenfassung aller Ergebnisse unter Berücksichtigung der Strahlenbelastung der Darmabschnitte 65

Tabelle $7 \quad$ Proteinbestimmung für 15er Slot, Proben C, D und E 108

Tabelle 8 Proteinbestimmung für 10er Slot, Proben A und B 109

Tabelle 9 Proteinstandardkonzentrationsreihe und Steigung des Graphen 110

Tabelle 10 Verwendete Chemikalien und Kits 110

Tabelle 11 Antikörperliste 112

Tabelle 12 Geräteliste $\quad 113$

Tabelle 13 Verbrauchsmaterialien 114

Tabelle 14 Sequenzen der Gen-spezifischen Primer für die quantitative RT-PCR-Analyse 115

Tabelle 15 Kriterien der Gewebeschädigung nach Radiotherapie mit Mittelwert (MW) und Standardabweichung (SD) 


\section{ABKÜRZUNGSVERZEICHNIS}

A

ADP Adenosindiphosphat

AEC 3-Amino-9-Ethyl-Carbazol

AIF Apoptosis-inducing factor

AK Antikörper

ANOVA Analysis of variance

APAF-1 Apoptosis protease activator protein-1

Apo-3 Apoptosis-antigen-3

ATP Adenosintriphosphat

Bad Bcl-2-associated death promotor

Bak Bcl-2 homologous antagonist killer

Bax Bcl-2-associated $X$ protein

Bcl B-cell-lymphoma

bp base pairs (Basenpaare)

CAD Caspase-activated DNAse

CARD Caspase recruitment domain

Caspase Cysteinyl-aspartate-specific proteinase

CCL Chemokine (C-C motif) ligand

CD Cluster of differentiation

CINC Cytokine-induced neutrophil chemo-attractant

COX Cyclooxygenase

CT Cycle threshold

DAB Diaminobenzidin

DD Death domain

DED Death effector domain

DEPC Diethylpyrocarbonat

DNA Deoxyribonuclein acid

dNTP Deoxyribonucleotide triphosphate

DTT Dithiothreitol

ED Ectodermal dysplasia

EDTA Ethylenediaminetetraacetic acid

FACS Fluorescence activated cell sorting 
FADD Fas-associated protein with death domain

5-FU 5-Fluoruracil

GALT Gut-associated lymphoid tissue

Gy $\quad$ Gray

h $\quad$ Stunde

H.E. Hämatoxylin-Eosin

HRP Horseradish peroxidase

HSP-27 Heat shock protein-27

ICAD Inhibitor of caspase-activated DNAse

ICAM Inter-cellular adhesion molecul

IFN- $\gamma \quad$ Interferon gamma

IgG Immunglobulin G

IL Interleukin

IL-1ra Interleukin-1-Rezeptorantagonist

i.p. intraperitoneal

IP-10 Human interferon-inducible protein-10

ISEL In situ end-labeling

kDa Kilodalton

LARC Liver activation regulated chemokine

LT- $\alpha \quad$ Lymphotoxin alpha

M. Morbus

MAdCAM Mucosal addressin cell adhesion molecule

MALT Mucosa-associated lymphatic tissue

MCP Monocyte chemotactic protein

$\mathrm{MeV} \quad$ Mega-Elektronenvolt

MG Molekulargewicht

MIP Macrophage inflammatory protein

M-MLV Moloney murine leukaemia virus

MW Mittelwert

NSAR Nicht-steroidales Antirheumatikum

PARP Poly-ADP-ribose polymerase

PECAM Platelet-endothelial cell adhesion molecule

PBS Phosphate buffered saline

PCR Polymerase chain reaction 


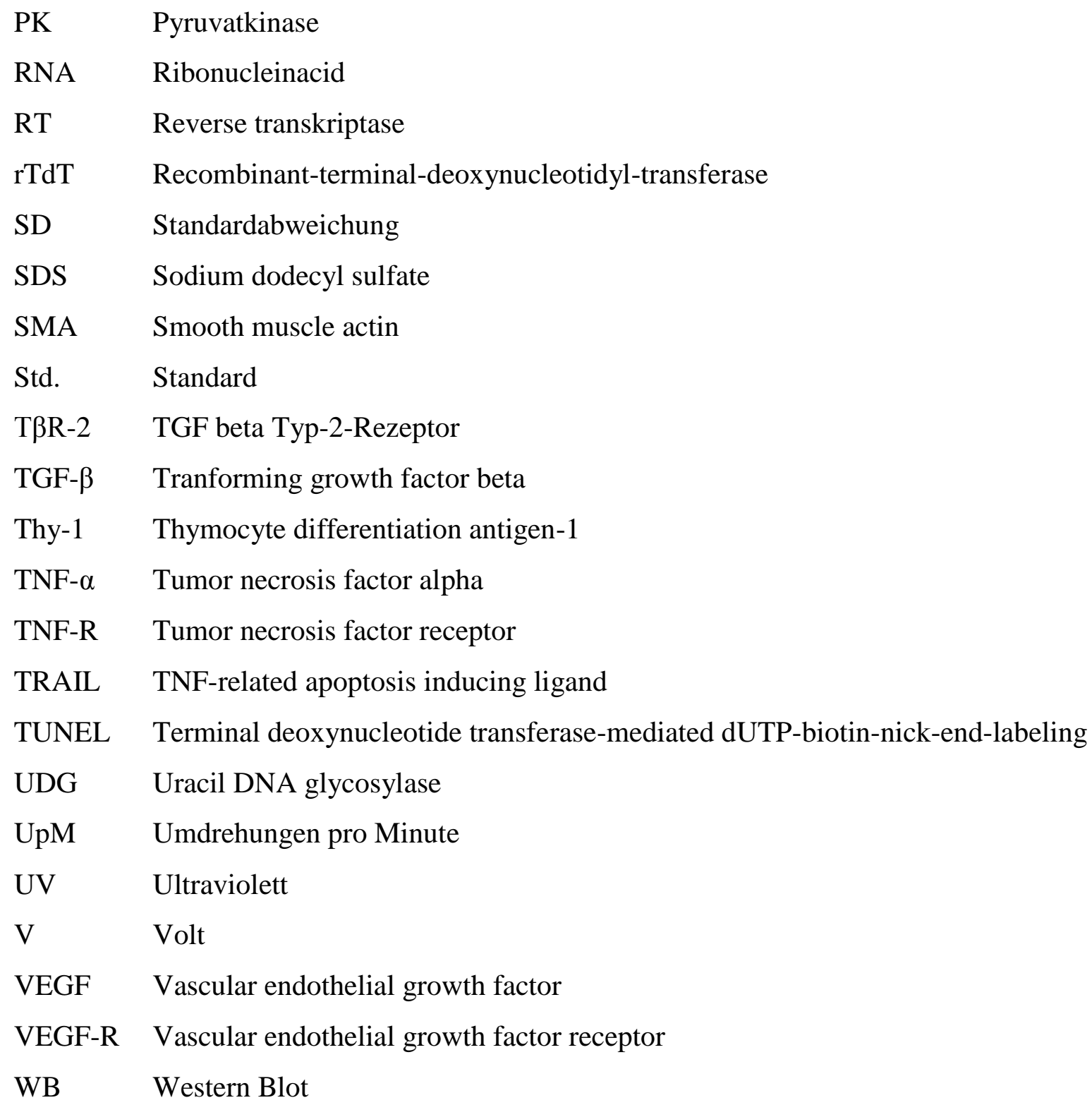




\section{EINLEITUNG}

Strahlentherapie ist eine wichtige Säule für die lokale Tumorkontrolle. Dabei ist die Kombination mit Chemotherapeutika und Radiosensitizern von zunehmender Bedeutung (Weichselbaum 2005). Die bei der Bestrahlung auftretende Schädigung von gesundem Gewebe, besonders im Dünndarm, ist ein dosislimitierender Faktor in der radiotherapeutischen Behandlung von Tumoren in der Abdominal- und Beckenregion (Arango et al. 2000).

\subsection{Strahlentherapie}

Schon 18 Monate, nachdem Wilhelm Conrad Röntgen 1895 die Photonenstrahlung entdeckt hatte, beschrieb Walsh bereits einen Fall, bei dem ein Patient nach abdomineller Strahlenexposition gastrointestinale Symptome entwickelte (Walsh 1897). Experimentelle Untersuchungen am Hund konnten 1912 zeigen, dass es zu histologischen Veränderungen im Darm nach Röntgenstrahlungsexposition kommt (Brennan 2005; Regaud et al. 1912; Warren und Whipple 1923).

Bei der Strahlenbehandlung von Tumoren des Oberbauchs (Magenkarzinom, Pankreaskarzinom, retroperitoneale Lymphknotenmetastasen) und des Beckens (insbesondere bei der Therapie von Rektumkarzinomen, Prostatakarzinomen oder Tumoren des weiblichen Genitals) werden signifikante Anteile von Dünndarm und Dickdarm radiogen belastet. Nach Lehrmeinung zeigt das Duodenum des Menschen die höchste Strahlenempfindlichkeit, gefolgt vom Jejunum, dem Ileum, dem Colon transversum, dem Sigma und dem Rektum (Gervaz et al. 2009; Hermann et al. 1996).

Enorme Fortschritte in der Technologie ermöglichen heute eine spezifische radiotherapeutische Intervention. Diese beinhaltet die Optimierung der Bestrahlungsdosis, eine drei-dimensionale und fraktionierte Bestrahlungstechnik. In der klinischen Praxis wird versucht, die radiogene Belastung weniger Dünndarmanteile auf 45-50 Gy zu beschränken. Dabei ist die Variabilität des locker am Mesenterium aufgehängten Organs zu berücksichtigen. Die Wahrscheinlichkeit, dass dabei immer dieselbe Darmschlinge von der Strahlung getroffen wird, ist sehr gering. Ausnahmen stellen hier postoperative Vernarbungen und Adhäsionen dar, die im Rahmen der Bestrahlungsplanung besonders berücksichtigt werden müssen. Die drei-dimensionale Radiotherapie ist als großer Fortschritt in der Bestrahlungstechnik anzusehen. Diese erlaubt, z.B. bei der Bestrahlung von Lebermetastasen, spezifisch hohe Dosen bei dem zu bestrahlenden Lebergewebe anzuwenden, ohne eine signifikante Dosiserhöhung für die anderen intra-abdominellen Organe zu riskieren (Cheng et al. 2002; Ten Haken et al. 1991). Die Anwendung von fraktionierten Bestrahlungseinheiten 
ermöglicht eine Regeneration der intestinalen Mukosa. Mit Hilfe dieser Methoden werden die Strahlenschäden insgesamt deutlich verringert (Horwhat und Dubois 1999).

Trotzdem entwickeln ca. $80 \%$ aller Patienten, die in der Abdomen- und Beckenregion bestrahlt werden während und nach der Bestrahlung mindestens eine milde Form von Nebenwirkungen. Akute Symptome manifestieren sich dabei zum einen in Form von Diarrhoen (großvolumige Durchfälle) als Reaktion des Dünndarms und zum anderen die klinisch davon abzugrenzende Strahlenproktitis, die sich mit Stuhldrang, Schleimabgängen und Blutauflagerungen äußert (Andreyev 2005). Die akute physiologische Reaktion des Darms auf eine stattgehabte Bestrahlung besteht zunächst in einer Steigerung der Motilität, die anschließend in einen atonischen Zustand übergeht (Linard et al. 2004). Auf Zellebene zeigt sich zunächst eine Teilungshemmung der Zellen in den Darmkrypten. Es entsteht eine Nachschubinsuffizienz, da die normalerweise stattfindende Progression der Zellen entlang der Krypten-Zotten-Achse ausbleibt (Hermann et al. 1996; Potten 2004). Schließlich atrophiert das Zottenepithel (Horwhat und Dubois 1999). Folgen der Zerstörung der Epithelschranke sind Wasser-, Elektrolyt- und Eiweißverlust in das Darmlumen, Resorptionsstörungen und Penetration von bakteriellen Toxinen (Potten 1990; Potten 2004). Letztendlich entleeren sich die Becherzellen bereits ab einer Dosis von $5 \mathrm{~Gy}$, so dass es zu einer vermehrten Ausscheidung von Mukus kommt (Hermann et al. 1996).

Chronische Strahlenschäden im Bereich des Darms sind Ergebnis einer komplexen Interaktion von radiogenen Epithelläsionen, mechanischen und peptischen Faktoren, Bindegewebes- und Gefäßveränderungen der Darmwand und enterogenen Infektionen (Dörr und Hendry 2001; Hermann et al. 1996; Paris et al. 2001). Als Folgen können chronische Geschwüre mit geringer Granulationsneigung und damit erhöhter Perforationsgefahr auftreten (Coia et al. 1995). Im Falle einer narbigen Umwandlung können zudem Stenosen vorkommen, die bei Passageverlegung einen Ileus provozieren können. Außerdem treten Fisteln, Strikturen, chronische Malabsorption und schwere transmurale Fibrosen auf, die die Lebensqualität der Patienten stark beeinträchtigen (Linard et al. 2004). Solche Folgen treten mit einer Wahrscheinlichkeit von $5 \%$ innerhalb von 5 Jahren nach Therapie auf, wenn circa ein Drittel des Dünndarms mit 50 Gy belastet wurde (Abbasakoor et al. 2006; Hermann et al. 1996). Oft ist bei diesen Nebenwirkungen eine symptomatische Therapie, bzw. eine chirurgische Intervention unabdinglich (Donner 1998; Hayne et al. 2001).

\subsection{Apoptose}

Anfang der 70iger Jahre wurde erstmals von Kerr et al. eine Form des Zelltodes beschrieben, die sich deutlich von der Nekrose unterscheidet. Für diesen zunächst als „schrumpfende Nekrose“ 
benannten Prozess wurde 1972 der Begriff Apoptose eingeführt (Kerr et al. 1972). Das Wort Apoptose setzt sich aus dem griechischen Wort apo (weg) und ptosis (fallen) zusammen und kann mit Blättern, die im Herbst von den Bäumen fallen, verglichen werden (Hug 2000; Levine 2000).

Die Apoptose gehört zu den physiologischen Vorgängen, die bei der Differenzierung von Gewebe eine große Rolle spielen. Bereits in der Embryogenese ist die Apoptose ein wesentlicher Prozess: das Verschwinden von Schwimmhäuten und die Enddifferenzierung von Organen werden der Apoptose zugesprochen (Saunders 1966; Wyllie et al. 1980). Außerdem ist Apoptose zur Aufrechterhaltung der Gewebehomöostase notwendig, denn jede Mitose wird durch Apoptose kompensiert (Haimovitz-Friedman et al. 1994; Kroemer et al. 1998). Letztendlich dient Apoptose als Schutzmechanismus zur Beseitigung infizierter, mutierter und destruierter Zellen (Levine 2000; Gupta 2001). Unter physiologischen Bedingungen ist das mikroskopisch-morphologisch nachweisbare Auftreten von Apoptose auch in Geweben mit hohem Zellumsatz, wie dem Darm, ein kontrolliertes Ereignis. Folglich ist zu jedem Zeitpunkt nur eine kleine Anzahl von apoptotischen Zellen zu finden (Saraste und Pulkki 2000).

\subsubsection{Morphologie der Apoptose}

Apoptose ist charakterisiert durch einen Verlust des Zell-Zell-Kontaktes, durch Zytoplasmakontraktion, Chromatinkondensation, Plasmamembranschwellung und DNAFragmentierung (Levine 2000; Gupta 2001).

Der Verlauf der Apoptose ist energieabhängig und wird in drei Phasen unterteilt: Die Initialphase, auch signalgebende Phase genannt, die Ausführungsphase, auch als Effektorphase oder Exekutionsphase bezeichnet, und die Degenerationsphase (Saraste und Pulkki 2000).

Die Initialphase der Apoptose wird durch zellinterne oder zellexterne Stimuli wie Hormone, Zytokine oder chemische bzw. physikalische Komponenten z.B. Photonenstrahlung ausgelöst. Sie ist gekennzeichnet durch eine Kondensation des Kernmaterials und eine ausgeprägte Darstellung des verdichteten Chromatins in der nukleären Hülle. Gefolgt von diesem Prozess wird eine Fragmentierung des Nukleus und eine spiralig-gewundene Faltung der nukleären Membran beobachtet. Zu frühen Zeitpunkten der Apoptose zeigt sich eine Trennung der apoptotischen Zelle von den Nachbarzellen, ein Verlust der Mikrovilli und die Bildung einer vorgewölbten zytoplasmatischen Blase.

In der Effektorphase ist die zelluläre Signalkaskade, die über die Caspasen zur Apoptose führt, aktiviert. Der Ablauf der Apoptose ist bis zu dieser Phase reversibel. Im Verlauf der Apoptose unterlaufen die zytoplasmatischen Organellen eine Kondensierung. Dabei werden Ionen, vor allem $\mathrm{K}^{+}$-Ionen, nach außen gepumpt. 
Im Spätstadium der Apoptose bzw. Degenerationsphase fragmentieren sich die Zellen und formen membrangebundene Apoptosekörperchen, welche nukleäres Material, intakte Organellen und kondensiertes Zytoplasma enthalten. Letztendlich werden die Apoptosekörperchen von angrenzenden parenchymalen Zellen oder Makrophagen phagozytiert (Compton 1992). Bei diesem Vorgang kommt es zu keiner inflammatorischen Begleitreaktion mit Zeichen einer exsudativen Entzündungsreaktion oder Einwanderung von neutrophilen Granulozyten (Wyllie et al. 1980).

Insgesamt wird die Dauer der Apoptose, abhängig von der jeweiligen Zelle, auf 6-24 h geschätzt (Kerr et al. 1972). Dabei laufen die apoptotischen Prozesse in einem Gewebe nie synchron ab.

\subsubsection{Apoptose versus Nekrose}

Während Apoptose als streng regulierter, programmierter Zelltod beschrieben wird, handelt es sich bei der Nekrose um einen akzidentellen Zelltod, der durch chemische und physikalische Noxen, Bakterien und Viren, aber auch durch Ischämie ausgelöst wird (Majno und Joris 1995). Bei der Nekrose sind immer ganze Zellgruppen betroffen, deren Zytoplasma und Mitochondrien anschwellen (Kroemer et al. 1998). Im Verlauf geht die gesamte Zellarchitektur zu Grunde. Die Zelle verliert ihre Basophilität und schließlich zerfällt sie vollständig durch Aufhebung der Membranpotentiale. Das umliegende Gewebe wird durch Entzündungszellen wie Leukozyten infiltriert und es findet eine Demarkierung des nekrotischen Gewebes mit Randsaumbildung und Bildung von Granulationsgewebe statt (Compton 1992; Kerr et al. 1972).

$\mathrm{Zu}$ beachten ist, dass Apoptose und Nekrose keine starren Gegebenheiten sind. Sie können ineinander übergehen. Beispielsweise wird beobachtet, dass es zu einer sekundären Zytolyse bei Apoptose kommen kann, die einer sekundären Nekrose entspricht (Hug 2000; Saraste 1999).

Apoptotischer Zelltod unterscheidet sich von nekrotischem Zelltod in Struktur, Mechanismus und Folgen, dies wird in Tabelle 1 zusammenfassend dargestellt (Kroemer et al. 1998; Trump et al. 1997; Wyllie et al. 1980) 
Tabelle 1 Apoptose versus Nekrose modifiziert nach Kroemer et al. (1998)

\begin{tabular}{|c|c|}
\hline Apoptose & primäre Nekrose \\
\hline physiologisches und/oder pathologisches Vorkommen & immer pathologisches, zufälliges Auftreten \\
\hline empfindlich hoch reguliert & unreguliert bzw. wenig reguliert \\
\hline Plasmamembran lange intakt & Plasmamembran zu frühen Zeitpunkten zerstört \\
\hline heterophagozytäre Elimination & Fehlen von Zellkontakten \\
\hline keine Entzündungsreaktion & Entzündungsreaktion \\
\hline $\begin{array}{l}\text { Mitwirken von zellulären Enzymen, selektive } \\
\text { Proteindegradation durch spezifische Proteasen } \\
\text { (Caspasen) } \\
\text { Chromatinkondensation (Pyknosis) } \\
\text { Kernfragmentierung (Karyorrhexis) } \\
\text { DNA-Fragmentierung (Endonukleasen) }\end{array}$ & - keine spezifischen Enzyme, die Nekrose unterstützen \\
\hline Zellschrumpfung und keine mitochondriale Schwellung & $\begin{array}{l}\text { Schwellung des gesamten Zytoplasmas (Onkosis), inklusive } \\
\text { der Mitochondrien }\end{array}$ \\
\hline $\begin{array}{l}\text { feine Änderungen der Plasmamembran: erst Verlust der } \\
\text { Membranasymmetrie, dann Verlust der Membranintegrität }\end{array}$ & $\begin{array}{l}\text { Sektundäre Nekrose: } \\
\text { sekundäre Zytolyse bei Apoptose, wenn die sterbenden } \\
\text { Zellen nicht durch heterophagozytäre Zellen eliminiert } \\
\text { werden }\end{array}$ \\
\hline
\end{tabular}

\subsubsection{Caspasen: Die Schlüsselenzyme der Apoptose}

Die Gruppe der Caspasen nimmt im Rahmen der Apoptose eine wichtige Schlüsselfunktion ein. Caspasen sind Cystein-Proteasen (Cysteinyl-aspartate-specific-proteinase), die ihre ProteinSubstrate spezifisch und sehr effizient an der Carboxyseite eines Aspartats schneiden. Derzeit sind 15 humane Caspasen bekannt, jedoch sind nicht alle an apoptotischen Prozessen beteiligt (Hug 2000; Kidd et al. 2000). Caspasen werden als Proenzyme (Zymogene) gebildet, die keine oder nur eine geringe intrinsische Aktivität besitzen. Die Aktivierung der Caspasen erfolgt durch andere Caspasen, Caspase-Kaskade genannt, oder durch eine Aggregation von Procaspasen. Außerdem können Caspasen durch autolytische Prozesse aktiviert werden (Strasser et al. 2000). Die Procaspasen bestehen aus einem einzelnen Polypeptidstrang mit einer N-terminalen Prodomäne und einer intermediären großen und einer $\mathrm{C}$-terminalen kleineren Untereinheit. Während der Aktivierung wird dieser Peptidstrang zunächst zwischen der kleinen und der großen Untereinheit proteolytisch gespalten. Anschließend wird die N-terminale Prodomäne abgespalten (Nicholson et al. 1995; Wilson et al. 1994). Die aktiven Caspase-Enzyme sind Heterodimere, die sich aus zwei identischen großen und zwei identischen kleineren Untereinheiten zusammensetzen. Basierend auf 
der Substratspezifität und der biologischen Funktion werden Caspasen in drei Gruppen unterteilt. Dabei werden Initiatorcaspasen, Effektorcaspasen und Zytokin-abhängige Caspasen, die proinflammatorisch wirksam sind, unterschieden (Cohen 1997; Levine 2000; Salvesen und Dixit 1997). Die Initiatorcaspasen (Caspase 2, 8, 9, 10) weisen eine längere Prodomäne auf und starten eine Lawine von aktivierten Caspasen, sogenannten Effekorcaspasen (Caspase 3, 6, 7), die eine kürzere Prodomäne enthalten (Marshman et al. 2001). Die Initiatorcaspasen und die proinflammatorischen Caspasen enthalten zwei besondere Protein-Protein-Sequenzen, die Death effector domain (DED) und die Caspase recruitment domain (CARD). Diese ermöglichen eine Interaktion zwischen den extrinsischen (z.B. TNF- $\alpha$, Fas-Liganden etc.) und den intrinsischen Signalwegen (z.B. DNA-Schädigung etc.) der Apoptose (Levine 2000). An die im Zytosol gelegene Death domain (DD) des Rezeptors koppelt sich das Adapterprotein FADD (Fas-associated protein with death domain). Das FADD-Molekül wiederum bindet über die DED Caspase 8 mit ihrer DED (Yoo et al. 2002). Ein Apoptosom entsteht. Durch autolytische Spaltung wird die Initiatorcaspase -Caspase 8- aktiviert, dabei wird die Prodomäne DED abgespalten. Die Initiatorcaspasen 8 induzieren über den extrinsischen Weg die Caspase-Kaskade. Diese Signalkaskade ist in Abb. 1 dargestellt. Die aktivierten Effektorcaspasen verursachen eine endonukleolytische Spaltung der DNA. Es kommt zu der Teilung mehrerer zellulärer Substrate wie z.B. der poly-ADP-ribose polymerase (PARP), einem Enzym, welches bei der DNA-Reparatur mitwirkt (Lazebnik et al. 1994), der DNA-Pyruvatkinase (DNA-PK), zuständig für den Zellzyklus, der Inhibitor of caspaseactivated DNAse (ICAD), die durch Spaltung zu Caspase-activated DNAse (CAD) wird, und Lamin B als Zellmembranbestandteil (Schulze-Osthoff et al. 1998; Szabo und Tarnawski 2000).

\subsubsection{Signaltransduktionswege der Apoptose}

Es ist eine Reihe von Prozessen bekannt, die Apoptose triggern. Dabei werden zwei zentrale Wege unterschieden, die zur Apoptose führen. Von besonderer Bedeutung ist die positive Induktion von Liganden (Todesfaktoren), die über den Todesrezeptor-Signal-Weg vermittelt zu Apoptose führen. Demgegenüber steht der Todesrezeptor-unabhängige bzw. mitochondriale Signaltransduktionsweg (Szabo und Tarnawski 2000; Gupta 2001). Zu beachten ist, dass die Rezeptor-vermittelte Apoptose nicht streng von dem mitochondrialen Signaltransduktionsweg getrennt ist. Die beiden Signaltransduktionswege können sich gegenseitig stimulieren bzw. verstärken (Saraste und Pulkki 2000). Caspase 3 bildet die gemeinsame Endstrecke des intrinsischen und extrinsischen Signaltransduktionsweges der Apoptose (Yoo et al. 2002). In Abb. 1 sind der Rezeptor-vermittelte extrinsiche Signaltransduktionsweg der Apoptose und der mitochondriale intrinsische Weg gemeinsam dargestellt. 


\subsubsection{Apoptose auslösende Rezeptoren und ihre Liganden}

Einer der potentesten Auslöser der Apoptose ist die Stimulierung des Todesrezeptors CD95. Eine Bindung des CD95-Liganden an den Rezeptor kann innerhalb weniger Minuten Apoptose irreversibel stimulieren. Die Todesrezeptoren, auch Tumornekrosefaktor-Rezeptoren (TNF-R) genannt, gehören zu einer Familie der Typ-I-Membranproteine (Oehm et al. 1992). Sie vermitteln die proapoptotischen Signale von der extrazellulären Seite zum intrazellulären Milieu (Gupta 2001). Die TNF-R besitzen jeweils eine extrazelluläre cysteinreiche Domäne zur Liganden-Bindung und eine intrazelluläre DD zur Weiterleitung des apoptotischen Signals (siehe Abb. 1). Die Liganden für diese Rezeptoren gehören zur Gruppe verwandter Zytokine, benannt als TNF-Familie. Diese beinhaltet unter anderem TNF- $\alpha$, LT- $\alpha$, Fas-Ligand, Apo3-Ligand und TRAIL (Rossi und Gaidano 2003).

\subsubsection{Der mitochondriale Signalweg der Apoptose: Die Bcl-2 Familie}

Neben der rezeptorvermittelten Signaltransduktion spielen die Mitochondrien eine bedeutende Rolle in der intrinsischen bzw. nicht-rezeptorvermittelten Signaltransduktion der Apoptose. Von besonderer Bedeutung ist hierbei die Bcl-2-Protein-Familie. Die Mitglieder der Bcl-2-Familie werden in proapoptotische Proteine z.B. Bax, Bad und Bak und in antiapoptotische Proteine z.B. Bcl-2 und Bcl- $\mathrm{x}_{\mathrm{L}}$ eingeteilt (Szabo und Tarnawski 2000). Die Proteine der Bcl-2 Familie regulieren die Permeabilität der Mitochondrienmembran für Ionen und die Freisetzung von Cytochrom $\mathrm{C}$ aus dem Mitochondrium (Nicholson und Thornberry 2003).

Das proapoptotisch wirksame Bax wird während der Apoptose vom Zytosol an die äußere Mitochondrienmembran verlagert. Dort bildet es Dimere oder sogar Oligomere. Durch Induktion von Ionenkanälen wird die direkte Freisetzung von Cytochrom C, Apoptosis-inducing-factor (AIF) oder bestimmten Pro-Caspasen aus dem intermembranären Spalt der Mitochondrien veranlasst (siehe Abb. 1). AIF wandert in den Nukleus. Dort initiiert es die Kondensation des Kernmaterials und leitet schließlich den Abbau der DNA ein (Green 1998; Gupta 2001; Susin et al. 1999). Cytochrom $\mathrm{C}$ bindet an Apoptosis protease activator protein-1 (APAF-1). In Anwesenheit von ATP akkumuliert das Adapterprotein und eine CARD wird demaskiert. An die CARD koppelt sich die Procaspase 9, die ebenfalls eine CARD aufweist. Dieser oligomere Initiatorkomplex wird ebenfalls Apoptosom genannt (Slee et al. 1999).

Die antiapoptotischen Mitglieder der Bcl-2-Familie sind an der inneren Mitochondrienmembran lokalisiert. Ihre Aufgabe ist es, das mitochondriale Membranpotential aufrecht zu erhalten. Bcl-2 kann zum einen als Ionenkanal agieren, indem es die Freisetzung von Cytochrom $\mathrm{C}$ hemmt (siehe Abb. 1). Zum anderen wirkt es als Adapterprotein, indem es Proteine, die den Zelltod regulieren, 
bindet (Gupta 2001; Reed 1997). Bei einem Überschuss von Bcl-2 kann der intrinsische Signaltransduktionsweg der Apoptose gehemmt werden (Szabo und Tarnawski 2000).

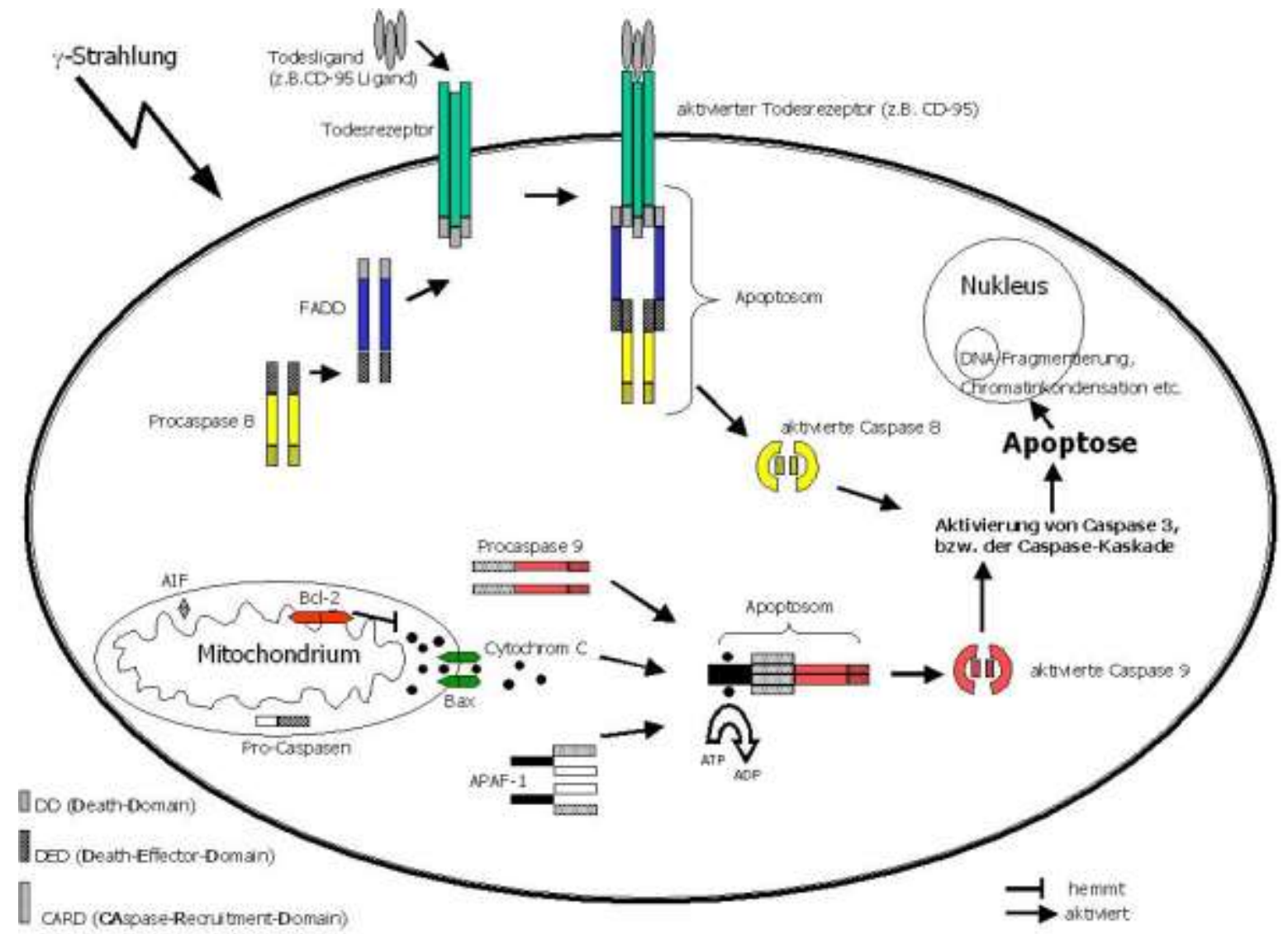

Abb. 1 Der intrinsische und extrinsische Signaltransduktionsweg der Apoptoseinduktion

\subsection{Zytokine: Die Regulation der intestinalen Zellhomöostase}

Der physiologische intestinale Epithelzellumsatz wird von einem sehr empfindlichen Gleichgewicht aus Zellproliferation, Zelldifferenzierung, Zellreifung und Apoptose bestimmt. Diese Homöostase wird durch ein Wechselspiel von wachstumsstimulierenden und inhibierenden Faktoren wie Zytokinen, Wachstumsfaktoren, Hormonen, luminalen Nährstoffen und mesenchymalen Strukturen aufrechterhalten (Ferretti et al. 1996; Podolsky 1993). Besonders die Zytokine spielen bei der Immunantwort auf strahleninduzierte Darmschädigung eine herausragende Rolle (Linard et al. 2004). Zytokine sind regulierende Glykoproteine, die von allen kernhaltigen Zellen, insbesondere von immunkompetenten Zellen wie Leukozyten produziert werden können. Eine individuelle Zelle kann dabei unterschiedliche Zytokine produzieren. Mehr noch, es können sich Zellpopulationen gruppieren, die dieselben Zytokine bilden und damit die Funktion und Interaktion der Zellen maßgeblich beeinflussen (Jung et al. 1995). Außerdem können Zytokine den Impuls zur Bildung von anderen Zytokinen geben. Zytokine wirken sowohl parakrin, als auch endokrin und können 
funktionell im Hinblick auf Entzündungsprozesse in proinflammatorische und antiinflammatorische Zytokine eingeteilt werden (Ruemmele und Seidman 1998). $\mathrm{Zu}$ den proinflammatorischen Zytokinen werden unter anderem IL-1 $\beta$, IL-6, IL-8 (CINC), MCP-1 und TNF- $\alpha$ gerechnet, während IL-4, IL-10, IL-1-Rezeptorantagonist (IL-1ra) und TGF- $\beta$ zu der Gruppe der antiinflammatorischen Zytokinen gezählt werden (Jung et al. 1995; Linard et al. 2004). 


\section{$1.4 \quad$ Zielsetzung}

Das Ziel in der Anwendung von therapeutischen Photonen-Strahlen ist das Erreichen einer letalen Dosis für die Tumorzellen unter geringstmöglicher Schädigung des normalen Gewebes. Dennoch sind es nach wie vor die akuten und chronischen Strahlenschäden, die den Einsatz einer Strahlentherapie limitieren. Bisherige Modelle zur Untersuchung radiogener Darmschädigung verwandten eine homogene Bestrahlung des Darms und entsprachen damit nicht der klinischen Situation.

Im Rahmen dieser Arbeit sollen daher erstmalig die Darmschäden nach Einzeitbestrahlung eines parenchymatösen Organes mit 25 Gy am Rattenmodell untersucht werden. Als Zielorgan wird die Leber gewählt, da diese bei der Ratte ein einfaches Bestrahlungsziel darstellt, und da die Leberbestrahlung zur Behandlung sowohl von primären Lebertumoren, als auch von Metastasen zunehmende Bedeutung gewinnt. Der Darm wird entsprechend seiner anatomischen Struktur in Duodenum, Jejunum, Ileum und Colon eingeteilt und im Zeitraum von 1 Stunde bis 3 Monate nach Leberbestrahlung untersucht. Sham-behandelte Tiere dienen als Kontrollen. Unser Interesse gilt insbesondere den Mechanismen, die einerseits ursächlich für die akuten, frühen und andererseits chronischen, späten Strahlenschäden sind. Weiter soll untersucht werden, ob und inwieweit die Lagebeziehung der einzelnen Darmabschnitte zum Bestrahlungszielvolumen mit der Strahlenschädigung korreliert.

Neben mikroskopisch-morphologischen Veränderungen sollen sowohl Apoptose-auslösende und hemmende Faktoren, der Einfluss von Nekrose, als auch die Rolle von Immunzellen und inflammatorischen Prozessen beleuchtet werden. Das Verständnis der pathophysiologischen Mechanismen dieser Schädigungsprozesse trägt maßgeblich zur Erklärung von intestinalen Strahlenschäden bei und ermöglicht Ansatzpunkte einer klinischen Intervention zur Minderung der Strahlenschäden zu identifizieren. 


\section{MATERIAL UND METHODEN}

Als Versuchstiere wurden männliche Ratten (rattus norvegicus) vom Stamm Wistar (Harlan Winkelmann, Borchen, D) mit einem Durchschnittsgewicht von $220 \mathrm{~g} \pm 20$ g verwendet. Die Ratten hatten ad libitum Zugang zu Nahrung und Wasser und es wurde ihnen ein Tag-Nacht-Rhythmus ermöglicht. Die Untersuchungen an den Tieren wurden den Tierschutzbeauftragten der Fakultät vorgelegt und von diesen befürwortet. Die Genehmigung durch den Herrn Regierungspräsidenten von Braunschweig vom 28.03.2003 (AZ 509.42502/01-09.03) «Untersuchung der Strahlenreaktion der Leber in vivo (Ratte)» liegt vor. Die Herkunft der Chemikalen, Geräte und Verbrauchsmaterialien ist im Anhang aufgelistet. Vereinzelt hatte die Wahl des Herstellers eine Bedeutung für den Versuch. In diesen Fällen wird auf den Hersteller direkt im Text verwiesen.

\subsection{Versuchsaufbau}

Die Tierexperimente wurden in zwei Untersuchungsphasen durchgeführt. Zunächst wurden in einem Vorversuch 10 Ratten zu den Zeitpunkten 0 h, 1 h, 6 h, 24 h und 96 h nach Bestrahlung in zwei Serien A und B gruppiert, um an einer kleinen Versuchstierkohorte die Durchführbarkeit der Versuche zu prüfen. Im Hauptversuch wurden dann nochmals 21 Ratten verwendet, die zu sieben Zeitpunkten nach Bestrahlung ( 0 h, 1 h, 6 h, 24 h, 96 h, 1,5 Monaten und 3 Monaten) in jeweils drei Rattenserien C, D und E eingeteilt wurden.

Zur Bestrahlung wurden die Ratten i.p. mit 90 mg/kg Ketamin und 7,5 mg/kg $2 \%$ Xylazin betäubt. Um die Leber der Ratten darzustellen, wurde ein Planungscomputertomogramm erstellt. Die Umgrenzung der Leber wurde auf dem Fell der Ratten markiert. Der Bestrahlungsplan wurde von den Physikern der Abteilung Strahlentherapie und Radioonkologie berechnet (Abb. 2 b). Daraufhin erfolgte eine selektive perkutane Bestrahlung der Leber mit $6 \mathrm{MeV}$-Photonen (Dosisrate von 2.4 Gy/min) mit Hilfe eines Varian-Clinac-600-C-Beschleunigers. Eine Dosis von 25 Gy wurde mit einer anteroposterioren und posteroanterioren Bestrahlungstechnik unter der Verwendung eines speziell entwickelten „,half-beam“-Verfahrens erreicht. Die Kontrolltiere wurden simultan betäubt und mit den zu bestrahlenden Tieren transportiert, selbst aber nicht bestrahlt.

Anschließend wurden die Tiere zu den Zeitpunkten 0 h, 1 h, 6 h, 24 h, 96 h, 1,5 Monate und 3 Monate nach der Bestrahlung getötet. Zuvor erfolgte eine i.p.-Sedierung mit 0,176 g/kg Pentobarbital-Natrium. Das Versuchstier E $0 \mathrm{~h}$ verstarb leider noch vor der Organentnahme im Käfig. Die Organentnahme erfolgte, nachdem die Tiere ausgeschüttelt wurden. Hiermit sollte eine vergleichbare Lage der Organe, insbesondere des Darms, erreicht werden. Der Darm wurde sofort nach Entnahme makroskopisch und auf Grund der anatomischen Anordnung im Bauchraum in 
Duodenum, Jejunum (ab $1 \mathrm{~cm}$ distal vom Duodenum gemessen), Ileum (aboral des Coecums gelegen) und Colon eingeteilt (Abb. 2 a).

Der Darm wurde mit einer 1-ml-Spritze vorsichtig mit $0,9 \% \mathrm{NaCl}$ gespült. Die Darmabschnitte wurden separat in ca. 4x4 mm große Stücke geschnitten, mit 0,9\% $\mathrm{NaCl}$ gewaschen, in flüssigem Stickstoff tiefgefroren und bei $-80^{\circ} \mathrm{C}$ gelagert. Des Weiteren wurden Organstückchen in einer Formalinlösung (siehe 2.6) fixiert.

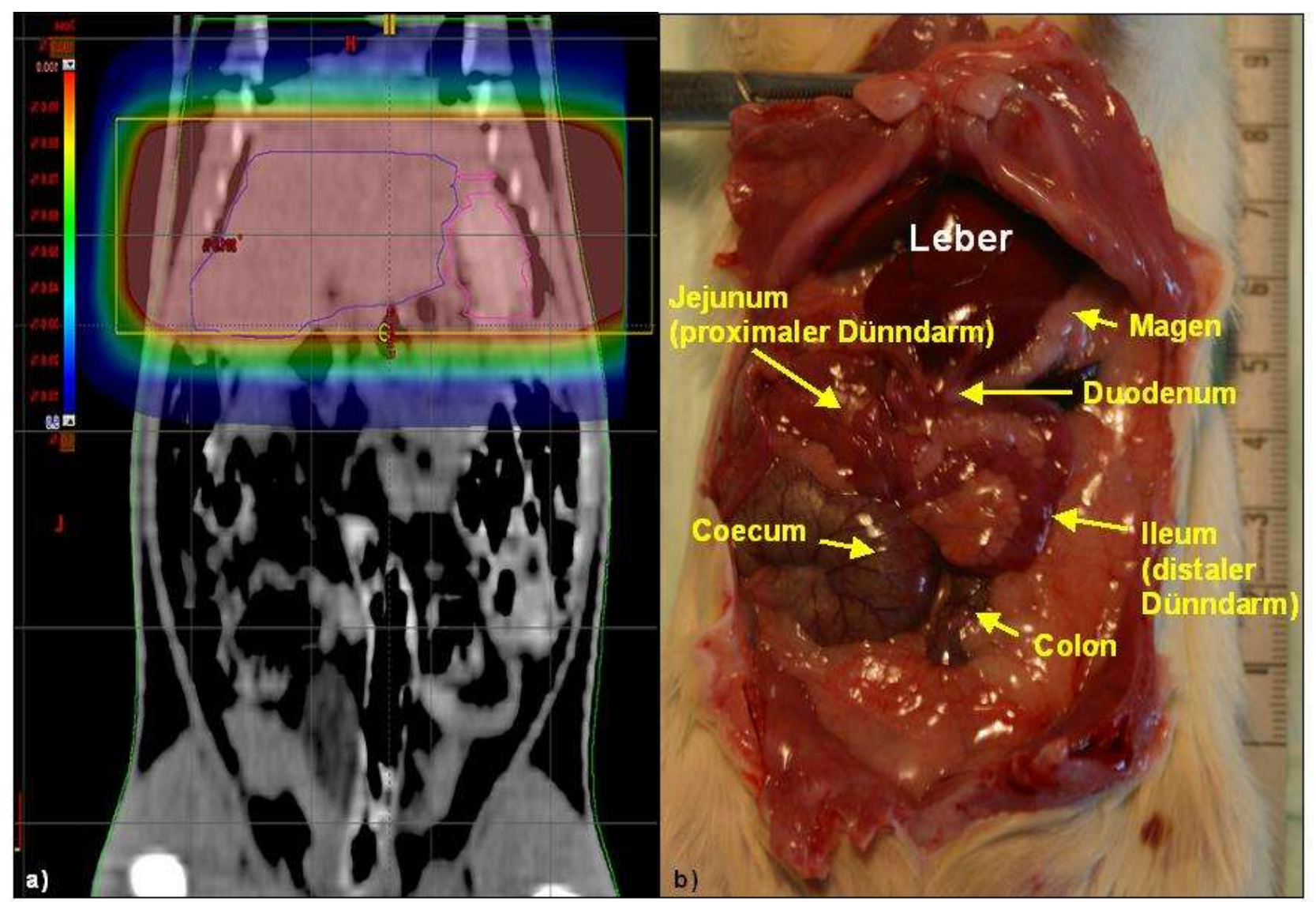

Abb. 2 Planungscomputertomogramm und Rattensitus

a) Planungscomputertomogramm mit Markierung des Bestrahlungsfeldes: Rot: 25 Gy, grün: bis 12 Gy, blau: bis 2,5 Gy, im übrigen Tier Streustrahlung möglich b) Rattensitus mit der anatomischen Lage von Leber, Magen, Duodenum, Jejunum, Ileum, Coecum und Colon

\section{$2.2 \quad$ RNA-Nachweis}

Zum RNA-Nachweis erfolgte zunächst die RNA-Isolation der einzelnen Darmabschnitte nach der Ultrazentrifugationsmethode von Chirgwin modifiziert nach Ramadori et al. (Chirgwin et al. 1979; Ramadori et al. 1985).

Im Weiteren diente die Real-Time-PCR als Methode zur Quantifizierung kleiner Mengen einer bekannten RNA-Sequenz. Die RNA wurde dazu zuerst in cDNA umgeschrieben und anschließend 
mit Hilfe von SYBR-Green und den passenden Primern im ABI-Prism ${ }^{\circledR}$-7000-PCR-Cycler vervielfältigt und quantifiziert.

\subsubsection{RNA-Extraktion aus Gewebe mit Hilfe der Ultrazentrifuge}

Bei dieser Methode wurden die Gewebestücke in $3 \mathrm{ml}$ Guanidinlösung mit dem Potter lysiert. Dabei war darauf zu achten, dass der Lysierstab nach jeder Probe in zunächst DEPC I, dann DEPC II und schließlich in Ampuwa gewaschen wurde. Mit dem Lysat überschichtete man 2 ml, einer im Ultrazentrifugenröhrchen vorgelegten Cäsiumchloridlösung. Anschließend wurde das Ultrazentrifugenröhrchen bis $1 \mathrm{~mm}$ unter den Rand mit der Guanidin-Lösung aufgefüllt. In dem durch Cäsiumchlorid und Ultrazentrifugation (35000 UpM, bei $20^{\circ} \mathrm{C}$ für mind. $12 \mathrm{~h}$ ) erzeugten Dichtegradienten konnte die RNA separiert werden. Anschließend wurden die Röhrchen vorsichtig aus den Einsätzen herausgeholt und mit einer separaten Pipette wurde der Überstand bis kurz über dem Boden abgesaugt. An der Schweißnaht des Ultrazentrifugenröhrchens wurde dieses mit einem Skalpell abgeschnitten. Nun wurden die Proben vorsichtig je zweimal mit $200 \mu 170 \%$ igem Ethanol gewaschen. Oft wurde dabei das Pellet erst nach dem zweiten Waschen sichtbar. Zur RNAResuspendierung wurde das Pellet zunächst in $100 \mu$ l Ampuwa gelöst, in ein Eppendorfgefäß überführt und für 5 min auf einem Heizblock erwärmt. Anschließend wurde nochmals $100 \mu 1$ Ampuwa hinzugegeben. Die Lösung wurde durch mehrfaches Aufziehen einer Pipette gemischt und in ein neues Eppendorfgefäß gegeben. Danach wurden die Proben kurz 1-2 min bei maximaler Upm zentrifugiert, dabei blieb die wasserlösliche RNA in der Lösung und der Schmutz setzte sich als Pellet ab. Jetzt wurde der Überstand $(200 \mu \mathrm{l})$ abpipettiert und zur Präzipitation der RNA wurden die Proben mindestens über Nacht bei $-20^{\circ} \mathrm{C}$ oder eine halbe Stunde bei $-80^{\circ} \mathrm{C}$ unter der Zugabe von $400 \mu 1$ Ethanol (absolut) und $20 \mu 12 \mathrm{M}$ Natriumacetatlösung (pH 5,2) gekühlt. Die entstandene Lösung wurde daraufhin für $30 \mathrm{~min}$ mit $12000 \mathrm{UpM}$ bei $4^{\circ} \mathrm{C}$ zentrifugiert. Der Überstand wurde verworfen und das Pellet abschließend wieder in $100 \mu 1$ Ampuwa gelöst. Wenn sich das Pellet nicht sofort in dem Ampuwa löste, wurde dieses bei $65^{\circ} \mathrm{C}$ im Heizblock erwärmt und damit gelöst. Zur weiteren Verwendung konnte die isolierte RNA bei $-80^{\circ} \mathrm{C}$ gelagert werden.

\subsubsection{RNA-Konzentrationsbestimmung}

Zur Bestimmung der Konzentration der isolierten RNA wurde ein Biophotometer verwendet. Für die Messung wurde die RNA-Probe 1:100 mit Ampuwa verdünnt (1 $\mu$ l Probe auf $99 \mu 1$ Ampuwa). Die Probe wurde in eine Küvette pipettiert und bei einer Wellenlänge von $260 \mathrm{~nm}$ (RNA-Faktor 40) gemessen. 


\subsubsection{Reverse Transkription}

Die reverse Transkription der RNA erfolgte unter der Verwendung eines M-MLV-reverseTranskriptase-Kits. Dabei wurde $1 \mu \mathrm{g}$ RNA-Probe eingesetzt. Das Gesamtvolumen der einzusetzenden Probe betrug $9 \mu$ l. Die anfallende Differenz wurde mit Ampuwa aufgefüllt. Die Proben wurden zunächst kurz bei $14000 \mathrm{UpM}$ anzentrifugiert und bei $4^{\circ} \mathrm{C}$ auf Eis gestellt, dann für $10 \mathrm{~min}$ bei $65^{\circ} \mathrm{C}$ zur Denaturierung mit $1 \mu \mathrm{RNAse-Inhibitor} \mathrm{inkubiert} \mathrm{und} \mathrm{schließlich} \mathrm{wieder} \mathrm{auf}$ Eis gestellt. Anschließend wurden $\mathrm{zu}$ jeder RNA-Probe die folgenden Volumina der Systemkomponenten pipettiert: $8 \mu$ First-Strand-Puffer (M-MLV 5x RT-Puffer), $8 \mu 1$ p(dT) ${ }_{15^{-}}$ Primer, $8 \mu \mathrm{l}$ dNTP-Mix, $4 \mu \mathrm{l}$ DTT und $2 \mu \mathrm{l}$ M-MLV-Reverse-Transkriptase. Dieser Ansatz wurde in einem 1,5-ml-Mikrozentrifugenröhrchen vermischt und für $1 \mathrm{~h}$ bei $38^{\circ} \mathrm{C}$ inkubiert. Um die entstandenen RNA-cDNA-Doppelstränge wieder zu denaturieren und die reverse Transkriptase zu inaktivieren, wurde der Ansatz im Folgenden für 10 min auf $72^{\circ} \mathrm{C}$ erhitzt. Das Reaktionsgefäß mit der fertigen cDNA der isolierten RNA konnte nun auf Eis gelagert abkühlen. Schließlich wurden die Proben mit $120 \mu \mathrm{l}$ Ampuwa versehen und bis zur weiteren Verwendung bei $-20^{\circ} \mathrm{C}$ eingefroren.

\subsubsection{Real-time-PCR}

Die Real-Time-PCR-Analyse der RNA wurde an einem ABI-Prism ${ }^{\circledR}$-7000-PCR-Cycler unter Verwendung des Platinum ${ }^{\circledR}$-SYBR ${ }^{\circledR}$-Green-qPCR-SuperMix-UDG-Kits durchgeführt. Alle verwendeten Primer wurden von der Firma Invitrogen bezogen. Die Sequenzen der genspezifischen Primer sind in Tabelle 13 dargestellt. Als Referenz wurde für jede Probe das House-keeping Gen $\beta$ Aktin verwendet. Damit wurde sichergestellt, dass die Gen-Expression in den unterschiedlichen Proben vergleichbar war. Von jeder cDNA der drei Serien zu den Zeitpunkten 0 h, 1 h, 6 h, 24 h, 96 h, 1,5 Monate und 3 Monate wurde eine Doppelbestimmung durchgeführt. Es wurde ein PlattenBelegungsschema mit dem Programm Abiprism erstellt. In jedes Loch der 96-Lochplatte wurden $2 \mu 1$ cDNA-Probe und $23 \mu 1$ Master-Mix pipettiert. Der Master-Mix wurde aus den Reagenzien des oben genannten Kits folgendermaßen zusammengesetzt: $13 \mu$ SYBR-Green, $7 \mu 1$ Ampuwa, 1,5 $\mu 1$ Primer (sense forward), 1,5 $\mu$ l Primer (sense reverse). Um Luftblasen aus den einzelnen Löchern zu entfernen, wurde die Platte vor Beginn der PCR kurz zentrifugiert. Die relative Quantifizierung der RNA erfolgte unter folgenden RT-PCR-Bedingungen: $50^{\circ} \mathrm{C}$ für $2 \mathrm{~min}, 95^{\circ} \mathrm{C}$ für $2 \mathrm{~min}$, 45 Zyklen bei $95^{\circ} \mathrm{C}$ für 15 sek und dann bei $60^{\circ} \mathrm{C}$ für 30 sek. Ein RT-PCR-Lauf dauerte ca. zwei Stunden. Die relative Quantifikation stützte sich dabei auf die relativen Expressionen der Ziel-RNA und der Referenz-RNA (in unserem Versuch das House-keeping Gen $\beta$-Aktin). 


\subsubsection{Statistische Analyse der PCR-Daten}

Die PCR-Daten wurden als Mittelwerte mit Standardabweichung dargestellt. Zur Erhebung der signifikanten Unterschiede zwischen den Mittelwerten wurde eine Varianzanalyse (engl. analysis of variance, ANOVA) durchgeführt, gefolgt von dem Student-t-Test. Die Expressionen der Zielgene wurde auf die Expression des House-keeping Gens $\beta$-Aktin normiert und die relative Genexpression wurden berechnet, indem der CT-Wert (engl. Cycle threshold $=$ Schwellenwert-Zyklus) verwendet wurde. Hierfür wurde folgende arithmetische Formel verwendet: Relativer Anstieg $=2^{-\Delta \mathrm{CT}}$, wobei $\Delta \mathrm{CT}=\mathrm{CT}-$ Zielgen $-\mathrm{CT}-$ Referenzgen bedeutet (Holzapfel und Wickert 2007; Pfaffl 2001). Ein PWert von $<0,01$ galt hierbei als statistisch signifikant. Die PCR-Daten wurden außerdem mit dem Mann-Whitney-U-Test für zwei unpaare Gruppen mit $\mathrm{p}<0,01$ als signifikant analysiert.

\subsection{Gelelektrophorese zur Detektion von apoptotischer DNA}

Die gelelektrophoretische Analyse von DNA auf einem Agarose-Gel zeigte die für Apoptose spezifische, durch Endonukleasen verursachte internukleosomale DNA-Fragmentierung in ca. 180200 große Basenpaar-Stücke (Compton 1992). Für diesen Versuch wurde ein Quick-ApoptoticDNA-Ladder-Detections-Kit der Firma BioCat und als Marker eine 123 bp-DNA-Ladder von Invitrogen verwendet.

Zum Nachweis von DNA-Fragmentierung als Beweis für apoptotische Prozesse wurden folgende Gewebeproben verwendet: Jejunum, Ileum und Colon mit jeweils C $0 \mathrm{~h}$ (Kontrolle), D $0 \mathrm{~h}$ (Kontrolle), C 1 h, D 1 h, E 1 h, C 6 h, D 6 h, E 6 h, C 24 h, D 24 h und E 24 h.

Die Proben wurden aus dem $-80^{\circ} \mathrm{C}$-Schrank herausgesucht, ein ganz kleines Stück Gewebematerial wurde entnommen und mit dem Potter in dem dazugehörigen Reagenzglas unter der Zugabe von $500 \mu \mathrm{l}$ PBS zerkleinert. Anschließend wurde diese Probe bei $14000 \mathrm{UpM}$ für 15 min bei $4^{\circ} \mathrm{C}$ zentrifugiert. Der Überstand wurde verworfen und auf das Pellet wurden $40 \mu$ l Lyse-Puffer gegeben. Nun wurde die Probe vorsichtig mit einer Pipette lysiert. Daraufhin wurden $5 \mu$ Enzym-B auf jede Probe gegeben. Die Proben wurden gevortext und für $30 \mathrm{~min}$ bei $50^{\circ} \mathrm{C}$ inkubiert. Im Folgenden wurde $5 \mu \mathrm{l}$ Ammonium Acetate Solution auf jede Probe gegeben und diese wieder gevortext. Die Proben wurden mit $50 \mu$ I Isopropanol überschichtet, gevortext und über Nacht bei $-20^{\circ} \mathrm{C}$ eingefroren. Zur Präzipitation der DNA wurden die Proben für 10 min bei $14000 \mathrm{UpM}$ und $4^{\circ} \mathrm{C}$ zentrifugiert. Der Überstand wurde entfernt und das DNA-Pellet mit 0,5 $\mathrm{ml} 70$ \%igem Ethanol gewaschen. Im Anschluss wurden die Proben wiederum für 10 min zentrifugiert, um das Ethanol anschließend mit dem Überstand zu entfernen. Anschließend wurden die Proben für 15 min bei Raumtemperatur getrocknet. Im folgenden Arbeitsschritt konnte das DNA-Pellet in $30 \mu$ DNA- 
Suspensions-Puffer aufgelöst werden. Daraufhin wurden ein 1,2\% Agarose-Gel mit 0,5 $\mu \mathrm{g} / \mathrm{ml}$ Ethidiumbromid und ein TBE-Lauf-Puffer ebenfalls mit $0,5 \mu \mathrm{g} / \mathrm{ml}$ Ethidiumbromid hergestellt. In dieses Gel wurden in die erste Tasche $3 \mu 1$ der DNA-Ladder und in die folgenden Taschen ca. $30 \mu 1$ der jeweiligen Proben pipettiert. Der Gellauf wurde für ca. drei Stunden bei $50 \mathrm{~V}(5 \mathrm{~V} / \mathrm{cm})$ angesetzt. Die mit Ethidiumbromid gefärbte DNA konnte anschließend durch eine Transillumination mit UV-Licht fotografiert werden.

Nach beendetem Versuch war darauf zu achten, dass alle mit Ethidiumbromid-kontaminierten Materialien in einem gesonderten Abfall entsorgt wurden.

\subsection{Western Blot: Nachweis von Proteinen}

Zum Nachweis der Caspasenaktivität und der pro- bzw. antiapoptotischen Mitglieder der Bcl-2Familie erfolgte die Bestimmung der Proteine mit Hilfe des Western Blots. Als House-keeping Protein wurde, wie bei der PCR, $\beta$-Aktin mitgeführt. Zunächst wurde ein Proteinlysat aus den Gewebestücken hergestellt. Die Proteine wurden in einem SDS-Gel elektrophoretisch der Größe nach aufgetrennt und anschließend auf eine Nitrozellulosemembran transferiert. Nach dem Blotten der Proteine auf die Membran wurde diese mit den gewünschten primären Antikörpern inkubiert. Durch anschließende Zugabe eines gegen den Primärantikörper gerichteten Sekundärantikörper konnte eine Detektion der zu untersuchenden Proteinbanden mittels des ChemiluminescentDetektions-Verfahrens auf einem Röntgenfilm erfolgen. Die Bindung des ChemiluminescentSubstrates an den sekundären Antikörper ermöglichte durch Schwärzung des Röntgenfilms das Sichtbarmachen der untersuchten Banden.

\subsubsection{Proteinisolation}

Um die Proteinexpression zu untersuchen, wurde zunächst die Proteinisolierung aus dem Gewebe vorgenommen. 56 Proben wurden wie folgt zusammengesetzt: Duodenum, Jejunum, Ileum und Colon zu den Zeitpunkten 0 h, 1 h, 6 h, 24 h und 96 h der Tiere C, D, E. Diese Gewebeproben wurden aus dem $-80^{\circ} \mathrm{C}$-Schrank entnommen und jeweils ein etwa gleich großes Organstückchen in ein 2-ml-E-Cup überführt. Zu den Proben wurden jeweils $500 \mu$ Lyse-Puffer pipettiert und eine kleine Metallkugel hinzugegeben. Die Proteinlysierung erfolgte dann mit dem Tissue Lysec. Die Proben wurden für 4 min bei einer Frequenz von 26,6 r/s homogenisiert. Die Metallkugel wurde anschließend mit einer sterilen Pipette entfernt, die Proben wurden mit $14.000 \mathrm{UpM}$ bei $4^{\circ} \mathrm{C}$ zentrifugiert und nach Abpipettierung des Überstandes wurden die Proteinproben bis zur weiteren Verwendung bei $-80^{\circ} \mathrm{C}$ eingefroren. 


\subsubsection{Bestimmung der Proteinkonzentration von Einzelproben}

Um die Proben für Western Blot verwenden $\mathrm{zu}$ können, wurde zunächst eine Konzentrationsbestimmung des Gesamtproteins durchgeführt. Die lysierten Gewebeproben wurden dem $-80^{\circ} \mathrm{C}$-Schrank entnommen und auf Eis aufgetaut. Es erfolgte eine 1:20 Verdünnung der Proben mit PBS, um im Messbereich der Proteinstandards (bis 1,44 g/l) zu bleiben. Jeweils $20 \mu \mathrm{l}$ der Proben und der Proteinstandards wurden in ein E-Cup pipettiert. Zunächst wurden $100 \mu$ eines Gemisches aus Lösung A und 10 \%igem SDS (98 $\mu$ l Lösung A und $2 \mu 110$ \%iges SDS) hinzugegeben und anschließend $900 \mu \mathrm{l}$ der Lösung B. Die Proben und Standards wurden gevortext und für 15 min bei Raumtemperatur inkubiert. Die Extinktion der Proben wurde bei $750 \mathrm{~nm}$ innerhalb einer Stunde in einem Photometer gemessen.

Zunächst wurde die Standardproteinkonzentrationsreihe im Bereich von 0,09-1,44 g/l bei einer Wellenlänge von $750 \mathrm{~nm}$ mit einer Halbmikro-Einmalküvette gemessen. Zwischen den Proben wurde die Küvette mit Bidest gespült. Anschließend wurden die Extinktionen der Proteinproben photometrisch bestimmt. Mittels der Proteinstandardkonzentrationsreihe konnte eine Standardkurve mit Hilfe des Graphikprogramms Kaleida-Graph erstellt werden und schließlich die Proteinkonzentration in $\mu \mathrm{g} / \mu \mathrm{l}$ der eingesetzten Proben berechnet werden (die Rechenschritte hierzu finden sich im Anhang).

\subsubsection{Herstellung der Polyacrylamidgele}

Zur Durchführung des Western Blots musste zunächst ein Polyacrylamidgel (siehe Tabelle 2) hergestellt werden. Je nach Molekulargewicht des abzubildenden Proteins wurden unterschiedlich prozentuierte Gele verwendet. Dabei war zu berücksichtigen, dass je höher der Acrylamid-Anteil ist, desto kleinmaschiger wird das Gel (Frey 2002). Der Proteingröße in kDa des zu untersuchenden Proteins wurde die jeweilige Gelprozentuierung wie folgt zugeordnet:

Proteingröße $(\mathrm{kDa})$ :

$10 \rightarrow 40$

$12 \rightarrow 45$

$15 \rightarrow 100$
Gelprozentuierung (\%):

$17,5 \%$

$15 \%$

$10 \%$ 
Tabelle 2 Zusammensetzung der Gele

\begin{tabular}{|l|c|c|c|c|}
\hline Chemikalien & \multicolumn{3}{|c|}{ Trenngel } & Sammelgel \\
& $10 \%$ & $\mathbf{1 5} \%$ & $\mathbf{1 7}, \mathbf{5} \%$ & $\mathbf{2} \%$ \\
\hline Acrylamid/Bis $\mathbf{3 0} \%$ & $5 \mathrm{ml}$ & $6 \mathrm{ml}$ & $\mathbf{7 m l}$ & $1 \mathrm{ml}$ \\
\hline Bidest & $4 \mathrm{ml}$ & $3 \mathrm{ml}$ & $2 \mathrm{ml}$ & $4 \mathrm{ml}$ \\
\hline Trenngel-Puffer & $3 \mathrm{ml}$ & $3 \mathrm{ml}$ & $3 \mathrm{ml}$ & - \\
\hline Sammelgel-Puffer & - & - & - & $1,67 \mathrm{ml}$ \\
\hline TEMED & $6 \mu l$ & $6 \mu l$ & $6 \mu l$ & $6,67 \mu l$ \\
\hline APS 15 \% & $60 \mu \mathrm{l}$ & $60 \mu \mathrm{l}$ & $60 \mu \mathrm{l}$ & $100 \mu \mathrm{l}$ \\
\hline
\end{tabular}

Um eine optimale Transfereigenschaft des Gels zu erreichen, wurden $1 \mathrm{~mm}$ dicke Gele verwendet, denn je dünner das Gel ist, desto effizienter gestaltet sich der Transfer (Frey 2002). Zur Herstellung der Gele wurde eine Apparatur von $B I O-R A D$ benutzt. Das Trenngel wurde mit den dazu benötigten Reagenzien unter dem Abzug hergestellt und mit einer $1000 \mu l$ Eppendorf-Pipette zwischen die Glasplatten pipettiert. Luftblasen wurden entfernt und das noch flüssige Gel wurde mit Isopropanol überschichtet. Für 20-30 min konnte das Gel bei Raumtemperatur aushärten. Im Anschluss wurde das Isopropanol wieder vorsichtig entfernt und das $2 \%$ ige Sammelgel (siehe Tabelle 2) wurde mit einer $1000 \mu \mathrm{l}$ Eppendorf-Pipette bis zur Oberkante der Glasplatten eingefüllt. Schließlich wurde der Kamm mit den jeweils gewünschten Slots (10er Slot oder 15er Slot) eingesetzt, dabei waren Luftblasen zu vermeiden. Das Sammelgel mit den Kämmen musste ebenfalls ca. 20-30 min bei Raumtemperatur aushärten. Anschließend konnten die Kämme entfernt werden. Für den Vorversuch mit den Versuchstieren der Serien A und B galt dabei eine Probenanordnung im 10er Slot-Gel. Für den folgenden Versuch der Serien C, D und E wurden 15 Slot-Gele eingesetzt.

\subsubsection{Gelelektrophoretische Trennung des Proteingemisches}

Die Trennung des unterschiedlichen Proteingemisches erfolgte mittels der diskontinuierlichen SDSGelelektrophorese. Zur Durchführung des Versuches wurden die vorbereiteten Proben aus dem $-80^{\circ} \mathrm{C}-$ Schrank entnommen, auf Eis aufgetaut und bei Bedarf gevortext. Anschließend wurden die Proben aliquotiert (die Berechnung hierfür findet sich im Anhang) und mit Spalt-Puffer auf $20 \mu 1$ für 10er Slot-Gele bzw. auf $10 \mu$ für 15er Slot-Gele aufgefüllt. Nach Zugabe des Spalt-Puffers in die E-Cups wurden die Proben 30 sek mit $14000 \mathrm{UpM}$ bei $4^{\circ} \mathrm{C}$ (im Kühlraum) zentrifugiert und anschließend bei $95^{\circ} \mathrm{C}$ für 5 min zur Denaturierung der Proteine erhitzt. Nun wurde die LaufgelApparatur zusammengesetzt und bis zur Markierung mit Lauf-Puffer aufgefüllt. Nach kurzem Abkühlen der Proben konnten diese für den Vorversuch in folgenden Reihenfolgen in die 10er Slots pipettiert werden: $10 \mu \mathrm{l}$ Standard in die erste Tasche und daraufhin jeweils $20 \mu \mathrm{l}$ der Proben A $1 \mathrm{~h}$, 
B 1 h, A 6 h, B 6 h, A 24 h, B 24 h, A 96 h, B 96 h und der Kontrolle A. Für den Hauptversuch wurden die Proben folgendermaßen in die Taschen 1-15 pipettiert: $10 \mu 1$ Standard und jeweils $15 \mu 1$ der Proben C 1 h, D 1 h, E 1 h, C 6 h, D 6 h, E 6 h, C 24 h, D 24 h, E 24 h, C 96 h, D 96 h, E 96 h und der Kontrollen C und D. Schließlich wurde die Apparatur verschlossen und der Gellauf für ca. zwei Stunden bei $30 \mathrm{~mA}$ und $200 \mathrm{~V}$ gestartet.

\subsubsection{Gel-Blot: Semi-dry-Verfahren}

Unmittelbar nach Abschluss der Gelelektrophorese erfolgte der Transfer der getrennten Proteine auf eine proteinbindende $0,45 \mu \mathrm{m}$ dicke Nitrozellulosemembran entsprechend der Methode von Towbin et al. (Towbin et al. 1979). Das Gel wurde in eine mit Blot-Puffer gefüllte Schale überführt und auf der Nitrozellulosemembran platziert. Danach wurde die Membran mit dem Gel zwischen zwei mit Blot-Puffern getränkten Filtern in die Blotapparatur gelegt. Mit einer Glaspipette wurde der Stapel luftblasenfrei gerollt. Geblottet wurde für eine Stunde bei einer konstanten Spannung von $15 \mathrm{~V}$ und einer Stromstärke von 0,2 A.

\subsubsection{Proteinbandennachweis mit Ponceau-Rot}

Um den Erfolg des Blotvorganges und der vorherigen Schritte zu prüfen, wurde die Membran nach dem Blotten kurz in einer Schale mit Ponceau-Rot geschwenkt und anschließend vorsichtig unter laufendem Wasser abgespült. Mittels des Ponceau-Rotes wurden alle geblotteten unspezifischen Proteinbanden angefärbt. Links zeigte sich der blaue Proteinstandard mit seinen Banden. Dieser Arbeitsschritt diente dem Versuch als Verlaufskontrolle. Dabei konnte ein mögliches Bandendefizit bei der Ponceau-Färbung zum Abbruch des Versuches führen bzw. bei der Interpretation des endgültigen Ergebnisses von Bedeutung sein. Die Membran mit der Ponceau-Färbung wurde mit einer Digitalkamera fotografiert.

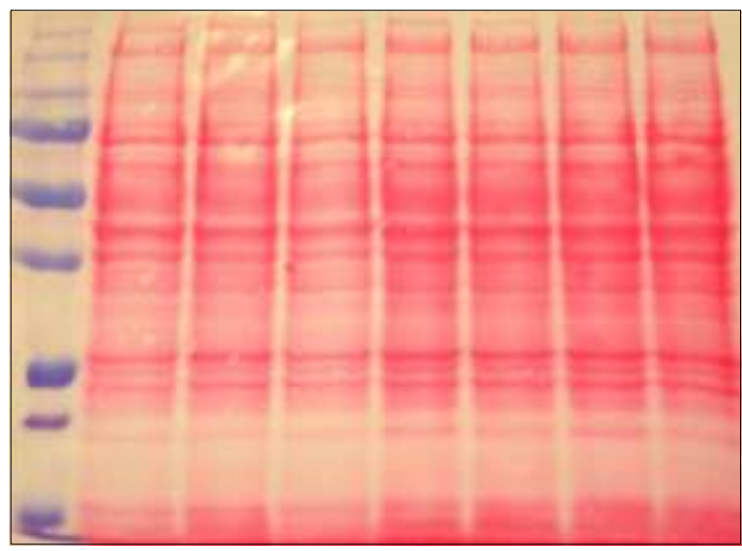

Abb. 3 Beispielbild mit Ponceau-Rot 


\subsubsection{Blocking}

Nun wurden die Membranen, jeweils in einem Schälchen, auf den Schüttler gestellt und mit jeweils $10 \mathrm{ml}$ Blockingsolution für $30 \mathrm{~min}$ bei Raumtemperatur geblockt, um die unspezifischen Bindungsstellen der Proteine zu blockieren und dadurch das Hintergrundrauschen zu minimieren. Für diesen und die folgenden Schritte wurde ein Chemiluminescent-Western-BlotImmunodetection-Kit von der Firma Invitrogen verwendet. Anschließend wurden die Membranen zwei Mal für 5 min mit Bidest gewaschen.

\subsubsection{Antikörper}

Für den Western Blot wurden Antikörper von den Firmen Santa Cruz Biotechnology, Calbiochem und Chemicon international by Millipore verwendet (Tabelle 11). Die monoklonalen anti-mouse oder anti-rabbit Antikörper wurden, entsprechend der Empfehlungen der Hersteller 1:25, 1:50, 1:100, 1:200, 1:500 oder 1:1000 mit $10 \mathrm{ml}$ Blockingsolution (siehe 2.6) verdünnt. Die Membranen wurden mit dem primären Antikörper über Nacht auf dem Schüttler bei $4^{\circ} \mathrm{C}$ inkubiert. Am folgenden Tag wurde der primäre Antikörper für weitere Verwendungen in einem Reagenzglas aufgefangen und im Kühlschrank aufbewahrt. Die Membranen wurden mit $20 \mathrm{ml}$ Antibody-Wash (siehe 2.6) drei Mal gewaschen, um den nicht gebundenen primären Antikörper zu entfernen. Im Folgenden wurden $10 \mathrm{ml}$ des zweiten Antikörpers, ebenfalls dem Kit entstammend, für 30 min auf die Membran gegeben. Dabei war darauf zu achten, dass der zweite Antikörper aus dem gleichen Tier wie der zuvor angewandte erste Antikörper stammte. In den durchgeführten Western Blots wurden Antikörper aus Mäusen oder Kaninchen verwendet. Schließlich wurden die Membranen noch drei Mal für je 5 min mit $20 \mathrm{ml}$ Antibody-Wash und zwei Mal für 2 min mit $20 \mathrm{ml}$ Bidest gereinigt.

\subsubsection{Entwicklungsprozess}

Nach sorgfältigem Waschen der Membranen wurden diese aus der Schale genommen, abgetropft und zwischen zwei Klarsichtfolien gelegt. 2,5 ml Chemiluminescent-Substrat (siehe 2.6) wurden unter Lichtschutz hergestellt und mit einer Glaspipette gleichmäßig auf die beiden Membranen verteilt. Anschließend wurden die Membranen vorsichtig luftblasenfrei mit der zweiten Klarsichtfolie bedeckt und für 5 min mit dem Chemiluminescent-Substrat inkubiert. Danach wurden die Membranen sorgfältig mit einem Filterpapier abgetupft, mit der Klarsichtfolie in eine Röntgenmappe gelegt und mit Leukosilk befestigt. In einer mit einer Infrarot-Lampe beleuchteten 
Dunkelkammer wurde ein Entwicklungsfilm auf die Membranen gelegt und für wenige Sekunden bis einige Minuten, abhängig von dem zuvor verwendeten Antikörper, in der geschlossenen Röntgenmappe inkubiert. Schließlich wurde der Röntgenfilm in einer Filmentwicklermaschine entwickelt. Es wurden immer mehrere Filme mit unterschiedlicher Expositionszeit (z.B. nach $10 \mathrm{sek}, 15 \mathrm{sek}, 30 \mathrm{sek}, 1 \mathrm{~min}, 2 \mathrm{~min}, 3 \mathrm{~min}, 5 \mathrm{~min}, 7 \mathrm{~min}, 10 \mathrm{~min}, 12 \mathrm{~min}, 15 \mathrm{~min}, 20 \mathrm{~min}, 25 \mathrm{~min}$ oder $30 \mathrm{~min}$ ) entwickelt, um später den bestmöglichen Film mit einer guten Bandendarstellung und wenig Hintergrund zu erhalten. Der Proteinstandard, der stets auf den Membranen sichtbar war, wurde mit einem wasserfesten Stift auf dem Röntgenfilm markiert, um die Größe der abgebildeten Banden in kDa festlegen zu können. Anschließend wurden die Membranen in der Klarsichtfolie im $-20^{\circ} \mathrm{C}$-Gefrierschrank bis zur nächsten Verwendung eingefroren.

\subsubsection{Strippen der Membranen}

Um die Membranen für einen weiteren Antikörper zu verwenden oder um einen eindeutigen Vergleich mit dem House-keeping Gen $\beta$-Aktin gewährleisten zu können, mussten die Membranen „gestrippt“ werden. Dies bedeutet, dass der zuvor verwendete Antikörper ,abgewaschen“ werden musste, damit ein neuer Antikörper an den Bindungsstellen andocken konnte. Hierfür wurde ein Antikörper-Stripping-Puffer hergestellt (siehe 2.6). Die Membranen wurden jeweils in eine wasserdichte verschließbare Plastiktüte gegeben und mit $25 \mathrm{ml}$ der Stripping-Solution versehen. Anschließend wurde die Plastiktüte luftblasenfrei verschlossen und für $30 \mathrm{~min}$ in einem $55-60^{\circ} \mathrm{C}$ warmen Wasserbad unter Bewegung inkubiert. Im Folgenden wurden die Membranen mehrfach mit $20 \mathrm{ml}$ PBS für ca. weitere $30 \mathrm{~min}$ auf dem Schüttler gewaschen. Nach dem Waschvorgang mit PBS konnte wiederum ein neuer primärer Antikörper auf die Membran pipettiert werden. Alle folgenden Schritte verliefen wie unter 2.4.8 und 2.4.9 bereits beschrieben.

\subsection{Histologie}

Direkt bei der Organentnahme wurden Organstückchen für eine spätere Paraffineinbettung in einer Formalinlösung „Bouin's Fixativ“ (siehe 2.6) fixiert. In $4 \mathrm{ml}$ dieser Lösung wurden jeweils mindestens zwei 4x4 mm Organstückchen jedes Darmabschnittes (Duodenum, Jejunum, Ileum, Colon) für max. $24 \mathrm{~h}$ inkubiert. Am folgenden Tag wurden die Proben in einer aufsteigenden Alkoholreihe von $70 \%, 80 \%, 90 \%, 100 \%$ (siehe 2.6) dehydriert und zweimalig in Xylol jeweils für $1 \mathrm{~h}$ unter dem Abzug gewaschen. Dabei war stets unter dem Abzug ein Xylolabfall bereit zu halten. Daraufhin wurden die Probengefäße mit ca. $4 \mathrm{ml} 66^{\circ} \mathrm{C}$-heißem Paraffin befüllt. Die endgültige Einbettung in einen Paraffinblock erfolgte mittels einer Paraffin-Ausgießstation, die freundlicherweise von der Routinepathologie im Hause zur Verfügung gestellt wurde. Es wurde 
jeweils ein Organstückchen eines Darmabschnittes der Tiere C, D und E zum gleichen Zeitpunkt gemeinsam in einen Block eingebettet, so dass es beim späteren Schneiden und Einfärben der Präparate möglich war, jeweils alle drei Proben der Tiere C, D, E auf einem Objektträger zu mikroskopieren. Dies erleichterte und beschleunigte die mikroskopische Auswertung, da die Tiere eines Zeitpunktes unmittelbar unter dem Mikroskop verglichen werden konnten. Nach der Einbettung wurden die Paraffinblöcke an einem Mikrotom geschnitten. Zuvor wurden diese noch auf einer Gefrierplatte gekühlt und gehärtet, um das Schneiden zu erleichtern. Es wurden Serienschnitte in einer Dicke von $2 \mu \mathrm{m}$ erstellt und in einem $37^{\circ} \mathrm{C}$ warmen Wasserbad auf Silanobjektträger (siehe 2.6) gezogen. Die Silanobjektträger gestalteten sich hierbei als vorteilhaft, da die Schnitte besser auf dem Objektträger hafteten.

Anschließend erfolgte eine H.E.- und Masson-Goldner-Trichromfärbung, als Standardfärbung und die immunhistochemischen Färbungen von CD3, ED1, Caspase-3, CD34 und TUNEL.

\subsubsection{Hämatoxylin-Eosin-Färbung}

In der Histologie wird die Hämatoxylin-Eosin-Färbung als Routinefärbung verwendet. Die H.E.Färbung ermöglicht einen guten Überblick über die Beschaffenheit des Gewebes zu gewinnen (Welsch 2003). Mikroskopisch-morphologische Veränderungen können festgestellt werden, die dann mit Spezialfärbungen bzw. immunhistologischen Färbungen noch genauer untersucht werden können. Das alkalische Hämatoxylin färbt die Zellkerne und Zytoplasmaanteile, die reich an rauem endoplasmatischen Retikulum sind, blau-violett. Eosin färbt andere Zytoplasmaanteile, sowie viele faserige extrazelluläre Komponenten rot (Welsch 2003).

Die Objektträger wurden zunächst zweimal zur Entferung des Paraffins für 10 min in Xylol gewaschen. Darauf folgte eine absteigende Alkoholreihe von $100 \%, 90 \%, 80 \%$ und $70 \%$ zu je 1 min (siehe 2.6). Der 100 \%ige Alkohol sorgte dabei dafür, dass das zuvor verwendete Xylol aus den Schnitten gelöst wurde und die anderen Alkoholstufen dienten der Hydratration der Schnitte. Im Folgenden wurden die Objektträger zwei Mal kurz in $\mathrm{H}_{2} \mathrm{O}$ geschwenkt und anschließend für 7 min in einer Küvette mit Hämalaun inkubiert. Danach erfolgte das „Bläuen“ der Schnitte unter fließendem Wasser für ca. $7 \mathrm{~min}$. Die Objektträger wurden für $1 \mathrm{~min}$ in eine Küvette mit Eosin gestellt. Zum Schluss mussten die Objektträger noch zwei Mal in $100 \%$ Alkohol geschwenkt, ein Mal für 5 min in Xylol und dann für 10 min in Xylol getaucht werden. Abschließend konnten die Objektträger nach kurzem Abtropfen mit DePeX-Mounting Medium eingedeckt werden.

\subsubsection{Masson-Goldner-Trichromfärbung}


Ergänzend zu der H.E.-Färbung wurde die Masson-Goldner-Trichromfärbung zur Darstellung von Kollagenfasern, Muskelfasern, Fibrin und Erythrozyten als Übersichtfärbung durchgeführt. Bei dieser Färbung wurden durch den Einsatz dreier unterschiedlicher Färbelösungen Zellkerne braunschwarz, Zytoplasma und Muskulatur ziegelrot, Erythrozyten leuchtend orange, Bindegewebe und saure Mukosubstanzen grün angefärbt (Welsch 2003). Die Durchführung dieser Färbung erfolgte wie die zuvor beschriebene H.E.-Färbung unter Verwendung eines Masson-GoldnerFärbekits. Die Schnitte wurden in Xylol entparaffiniert, in einer absteigenden Alkoholreihe hydriert, mit Eisehämatoxylin nach Weigert gefärbt und unter fließendem Leitungswasser gebläut. Nach kurzem Spülen mit 1 \%iger Essigsäure wurden die Schnitte mit Azophloxin-Lösung für 10 min inkubiert. Anschließend folgte erneutes Spülen mit Essigsäure und Hinzugabe der Phosphorwolframsäure-Orange-G-Lösung für $1 \mathrm{~min}$. Im nächsten Schritt wurden die Schnitte für 2 min mit Lichtgrün-SF-Lösung bedeckt, mit Eisessig gewaschen und abschließend mit einer aufsteigenden Alkoholreihe entwässert, mit Xylol geklärt und mit DePeX-Mounting Medium eingedeckt.

\subsubsection{TUNEL-Färbung}

Die von Gavrieli et al. entwickelte TUNEL-Methode (Terminal-deoxynucleotidyltransferasemediated-d-LETP-ñick-end-labeling) erlaubt die in-situ-Markierung von DNA-Brüchen in histologischen Gewebeproben, die bei Apoptose charakteristischerweise auftreten (Gavrieli et al. 1992). Die morphologischen Veränderungen, welche im Kern einer apoptotischen Zelle beobachtet werden, sind Ausdruck einer, durch Endonukleasen verursachten DNA-Fragmentierung. Dabei entstehen typischerweise DNA-Bruchstücke von 180-200 Basenpaaren (Compton 1992). Diese DNA-Bruchstücke weisen 3'-OH-Enden auf, deren Anwesenheit ein spezifisches Merkmal von apoptotischen, nicht hingegen von nekrotischen Zellkernen ist (Didenko und Hornsby 1996). Bei der TUNEL-Färbung werden diese 3-'OH-Enden mit Hilfe einer terminalen DeoxynucleotidylTransferase (rTdT) gebunden und mittels Streptavidin-HRP detektiert. Nach der Verwendung von Peroxidase-Substrat, Hydrogen-Peroxidase und Diaminobenzidin (DAB) werden diese sichtbar gemacht.

Für die TUNEL-Färbung wurde ein Kit der Firma Promega verwendet. Dies enthielt alle nötigen Reagenzien, deren Zusammensetzung unter 2.6 aufgeführt ist. Es wurden insgesamt 28 Schnitte gefärbt, die sich folgendermaßen zusammensetzten: Duodenum, Jejunum, Ileum und Colon jeweils zu den Zeitpunkten 0 h, 1 h, 6 h, 24 h, 96 h, 1,5 Monate und 3 Monate. Zunächst erfolgte die Entfernung des Paraffins und die Hydratration der Schnitte für jeweils 3 min wie zuvor unter 2.5.1 beschrieben. Im Anschluss wurden die Schnitte erst mit 0,9\% $\mathrm{NaCl}$ zur Entfernung des Alkohols 
und dann mit PBS für jeweils 5 min gereinigt. Nun wurden diese in 4 \%iger Paraformaldehydlösung für 15 min fixiert. Der Fixierung folgte das zweimalige Waschen in einer PBS-Küvette für jeweils 5 min. Anschließend wurden die Objektträger in einer feuchten Kammer platziert und mit $100 \mu l$ Proteinase $\mathrm{K}$ für 15 min inkubiert. Zu beachten war hierbei, dass Proteinase $\mathrm{K}$ das Gewebe durchlässiger macht. Eine zu lange Inkubation konnte daher eine Lösung der Schnitte vom Objektträger verursachen. Erneut wurden die Schnitte in PBS für 5 min gewaschen, gefolgt von einer zweiten Fixierung der Schnitte in der 4 \% Paraformaldehydlösung für 5 min, Waschen in PBS für 5 min und Überführung der Objektträger in die feuchte Kammer zur Inkubation mit $100 \mu 1$ Äquilibrations-Puffer für 10 min. Währenddessen wurde die rTdT-Lösung, wie in Tabelle 3 dargestellt, auf Eis vorbereitet.

Tabelle 3 Zusammensetzung der rTdT-Lösung

\begin{tabular}{|c|c|c|c|c|}
\hline Puffer Komponenten & $100 \mu \mathrm{l}$ Volumen/Slide & Zahl der Reaktionen & Volumen insg. & Kontrolle \\
\hline Äquilibration-Puffer & $98 \mu \mathrm{l}$ & 28 & $2744 \mu \mathrm{l}$ & $98 \mu \mathrm{l}$ \\
\hline Biotinylated Nucleotid Mix & $1 \mu \mathrm{l}$ & 28 & $28 \mu \mathrm{l}$ & $1 \mu \mathrm{l}$ \\
\hline RTdT-Emzym & $1 \mu \mathrm{l}$ & 28 & $28 \mu \mathrm{l}$ & $1 \mu \mathrm{l}$ Bidest \\
\hline
\end{tabular}

Nach Inkubation wurde der Äquilibration-Puffer vorsichtig abgetupft. Dabei durfte der Objektträger nicht austrocknen. Jetzt konnten $100 \mu \mathrm{l}$ rTdT auf jeden Objektträger gegeben werden. Für die Negativkontrolle wurde statt $1 \mu \mathrm{l}$ rTdT-Enzym $1 \mu$ l Bidest verwendet. Die Objektträger wurden mit einem Plastik-Cover bedeckt und bei $37^{\circ} \mathrm{C}$ für $60 \mathrm{~min}$ in den Wärmeschrank gestellt. Zum Stoppen der Reaktion wurden die Plastik-Cover entfernt und die Objektträger in einer Küvette für 15 min mit 2x SSC (siehe 2.6) bei Raumtemperatur inkubiert. Es folgte wiederum zweimal fünfminütiges Waschen mit PBS. Danach konnten die Schnitte mit 0,3\% Hydrogen-Peroxid in PBS, bei Raumtemperatur für 3-5 min geblockt werden. Nach dreimaligem Waschen der Schnitte in einer PBS-Küvette für jeweils 5 min wurden diese mit $100 \mu$ l Streptaverdin-HRP-Lösung, die 1:500 mit PBS verdünnt wurde, für $30 \mathrm{~min}$ bei Raumtemperatur inkubiert. Im Anschluss an dreifaches Waschen, wurde das Färben der Schnitte für ca. 10 min im Dunklen mit $100 \mu$ DAB-Lösung vorgenommen bis sich ein leicht brauner Hintergrund zeigte (siehe 2.6). Jetzt wurden die Schnitte wieder in Bidest gewaschen und daraufhin kurz mit Hämatoxylin gegengefärbt. In einer aufsteigenden Alkoholreihe (50\%, $70 \%, 85 \%, 95 \%, 100 \%, 100 \%)$ wurden die Objektträger kurz zur Dehydrierung geschwenkt. Der Alkohol wurde anschließend durch Schwenken der Objektträger 
in zwei Xylol-Küvetten ausgewaschen. Zum Eindecken der Objektträger wurde DePeX-Mounting Medium verwendet.

\subsubsection{Immunhistochemie}

Immunhistochemische Färbungen wurden von ED1 zur Darstellung von Lymphozyten, CD3 zur Darstellung von Makrophagen, CD34 zur Markierung von hämatopoetischen Progenitorzellen und Caspase 3 zum Nachweis von Apoptose hergestellt. Das Ziel dieser Färbemethoden war es, eine definierte Gewebe- bzw. Zelldeterminante mittels einer Antigen-Antikörper-Reaktion sichtbar zu machen. Eine Liste der verwendeten Antikörper findet sich im Anhang.

Es wurden wie bei den vorangegangenen Färbungen jeweils 28 Schnitte verwendet, die sich wie folgt zusammensetzten: Duodenum, Jejunum, Ileum und Colon jeweils zu den Zeitpunkten 0 h, 1 h, 6 h, 24 h, 96 h, 1,5 Monate und 3 Monate.

Die immunhistochemische Färbung von ED1 wurden mit einem AEC-Kit der Firma Bio Genex durchgeführt. Die Vorbereitung der Schnitte erfolgte wie bereits unter 2.5.1 beschrieben. Zur Antigen-Wiedererlangung wurden die Schnitte in Citrat-Puffer (10 mM, pH 6) für 45 min in einem Dampfkocher gekocht. Nach ca. 20-minütigem Abkühlen der Schnitte wurden diese mehrmals in einer PBS-Küvette gewaschen. Dann wurden die Gewebestücke entsprechend ihrer Größe mit ca. $100 \mu 1$ Peroxid-Block-Reagenz bedeckt und für $10 \mathrm{~min}$ bei Raumtemperatur inkubiert. Anschließend wurden die Schnitte mehrmals in einer PBS-Küvette gewaschen. Es folgte die Applikation von $100 \mu 1$ Power Block ${ }^{\mathrm{TM}}$ und eine Inkubation für 5-10 min bei Raumtemperatur. Nun wurden die Schnitte mit dem primären Antikörper versehen. Als primärer Antikörper wurde MouseAnti-Rat-CD68 von Serotec verwendet. Der Antikörper wurde 1:100 mit PBS verdünnt und bei $4^{\circ} \mathrm{C}$ über Nacht inkubiert. Anschließend wurden die Schnitte mehrfach gründlich in einer PBS-Küvette gewaschen. Die Schnitte wurden mit ca. $100 \mu$ l Super Enhancer ${ }^{\mathrm{TM}}$ Reagenz bedeckt, für 20 min bei Raumtemperatur inkubiert und dann mit PBS gewaschen. Abschließend erfolgte die Applikation von Poly-HRP-Reagenz mit einer Inkubationszeit von $30 \mathrm{~min}$ und anschließendem Waschen mit PBS.

Für die CD3-Färbung wurde ein polyklonaler Antikörper 1:100 verdünnt der Firma DAKO verwendet. Die Färbung von CD3 wurde wie die zuvor beschriebene Färbung von ED1 durchgeführt. Nach dem Schritt der Antigen-Wiedererlangung durch das Dampfkochen wurde folgendermaßen weiter verfahren: Die Schnitte wurden mit Bidest für 5 min gewaschen, mit TBS (7,4 \% ohne Tween) für 5 min bedeckt, und abschließend für 30 min mit dem primären Antikörper inkubiert. Zur Visualisierung der Antikörper-Antigen-Bindung wurde das ACE-Kit verwendet. 
Für die CD34-Färbung wurde ein monoklonaler Antikörper von Immunotech mit einer Verdünnung von 1:20 verwendet. Die Durchführung erfolgte ensprechend den Empfehlungen des Herstellers. Eine Vorbehandlung der Schnitte mit Citrat-Puffer und eine Erwärmung im Dampfkocher war für die CD34-Färbung nicht notwendig.

Auch die Caspase-3-Färbung wurde wie die zuvor beschriebenen Färbungen von ED1 und CD3 vorgenommen. Als Antikörper für die Caspase-3-Färbung wurde gespaltene Caspase 3 von Cell Signaling Technology verwendet, die Caspase 3 nur in aktivierter Form nachweist. Der Antikörper wurde 1:200 mit PBS verdünnt und über Nacht bei $4^{\circ} \mathrm{C}$ inkubiert.

Für alle Färbungen wurde als Negativkontrolle ein Objektträger mit Serum mitgeführt. Bei der CD3-, CD34- und der Caspase-3-Färbung wurden die Zellkerne mit Hämatoxylin gegengefärbt. Dabei wurden diese für wenige Sekunden in eine Hämatoxylin-Küvette getaucht und unter fließendem Wasser ,gebläut“. Eine Gegenfärbung mit Hämatoxylin sollte bei der späteren Auswertung eine prozentuale Darstellung der Antikörper-gebundenen Zellen versus übrige Zellen des Gewebes ermöglichen. Die Schnitte aller immunhistochemischen Färbungen wurden mit Kaisers Glyceringelatine eingedeckt.

\subsection{Puffer und verwendete Lösungen}

Die verwendeten Chemikalien zur Herstellung der Reagenzien und Lösungen wurden, falls nicht anders angegeben, von den Firmen Bio-Rad, Invitrogen, Merk, Serva und Sigma bezogen. Eine genaue Auflistung der Chemikalien, Geräte und Verbrauchsmaterialien ist im Anhang zu finden.

\section{Gewebefixierung:}

Alkoholreihe:

$100 \%$ Alkohol (unverdünnt)

$90 \%$ Alkohol: $10 \mathrm{ml}$ Bidest auf $90 \mathrm{ml}$ Alkohol

$80 \%$ Alkohol: $20 \mathrm{ml}$ Bidest auf $80 \mathrm{ml}$ Alkohol

$70 \%$ Alkohol: $30 \mathrm{ml}$ Bidest auf $70 \mathrm{ml}$ Alkohol

Bouin's Fixativ (neongelbe Lösung):

$75 \mathrm{ml}$ gesättigte $(1,2 \%)$ wässrige Pikrinsäure

$25 \mathrm{ml}$ Formalin (ca. $37 \%$ Formaldehyd)

$5 \mathrm{ml}$ Eisessig (kurz vor Gebrauch zusetzen)

\section{RNA-Nachweis:}

$\underline{0,25 \mathrm{M} \text { Citronensäure: }}$

2,4 g Citric acid auf $50 \mathrm{ml} \mathrm{H}_{2} \mathrm{O}$ 
$\underline{0,25 \mathrm{M} \mathrm{Na}-C i t r a t}(\mathrm{pH} 7,0)$ :

7,36 g Sodium-Citrat in $100 \mathrm{ml}$ Ampuwa lösen

$\rightarrow$ mit 0,25 M Citronensäure den pH-Wert einstellen

Guanidin-Lösung (200 ml):

$4 \mathrm{M}$ Guanidin 85,52 $\mathrm{g}$

$25 \mathrm{mM} \mathrm{Na}$-Citrat $20 \mathrm{ml}$

$0,5 \%$ Sarcosyl $1 \mathrm{~g}$

0,1 M $\beta$-Mercaptoethanol 1,35 ml

$\rightarrow$ unter Rühren lösen, autoklavieren, abgedunkelt in Alufolie bei $4^{\circ} \mathrm{C}$ lagern

M-MLV Reverse Transcriptase Kit:

1 Ampulle (40 $000 \mathrm{U}$ mit $200 \mathrm{U} / \mu \mathrm{l}$ ) M-MLV Reverse Transcriptase

1 Ampulle 5x First Stand Puffer (250 mM Tris-HCl (pH 8,3), $375 \mathrm{mM} \mathrm{KCl,} 15 \mathrm{mM} \mathrm{MgCl}$ )

1 Ampulle $(500 \mu \mathrm{l}) 100 \mathrm{mM}$ DTT

\section{Apototic DNA-Ladder Detection}

Quick-Apoptotic-DNA-Ladder-Detections-Kit (50 assays):

2 ml TE Lyse-Puffer

(0,25 ml Enzym-A-Solution $\rightarrow$ wurde für unseren Versuch nicht verwendet)

1 Ampulle Enzym-B-Solution (lyophilized)

$0,25 \mathrm{ml}$ Ammonium Acetat Solution

2 ml DNA-Suspensions-Puffer

Herstellung des 1,2\% Agarose-Gels:

$1,2 \mathrm{~g}$ Agarose abwiegen und mit $100 \mathrm{ml}$ TBE-Puffer in der Mikrowelle ca. 2 min zum Kochen bringen. Das Gemisch handwarm abkühlen lassen und in die Gelkammer gießen. Die Luftblasen vorsichtig mit einer Pipette entfernen. Anschließend in das Gel $5 \mu$ l Etidiumbromid geben und mit der Gellösung vermischen. Das Gel für 45 min bei Raumtemperatur unter dem Abzug aushärten lassen.

TBE-Lauf-Puffer (10-fach):

$108 \mathrm{~g}$ Tris (M 121,14 g/mol)

$55 \mathrm{~g}$ Borsäure (M 61,83 g/mol)

7,44 g EDTA (M 372,24 g/mol)

$\rightarrow$ ad $1000 \mathrm{ml}$ Ampuwa und $\mathrm{pH}$ auf 8.0 einstellen 
TBE-Lauf-Puffer (1-fach):

$100 \mathrm{ml}$ TBE 10x $+900 \mathrm{ml}$ Bidest

$\rightarrow$ TBE-Lauf-Puffer mit 0,5 $\mu \mathrm{g} / \mathrm{ml}$ Ethidiumbromid versehen

\section{Western Blot:}

Lyse-Puffer:

$20 \mathrm{mM}$ Tris $\mathrm{HCl}(\mathrm{pH}=7,5)(\mathrm{MG} 157,6) \quad \rightarrow \quad 0,0315 \mathrm{~g} / 100 \mathrm{ml}$

$150 \mathrm{mM} \mathrm{NaCl}(\mathrm{MG} \mathrm{58,6)} \quad \rightarrow \quad 0,0876 \mathrm{~g} / 100 \mathrm{ml}$

$1 \mathrm{mM} \mathrm{MgCl}_{2}(\mathrm{MG} 203,3) \quad \rightarrow \quad 0,0020 \mathrm{~g} / 100 \mathrm{ml}$

$1 \mathrm{mM} \mathrm{CaCl}_{2}(\mathrm{MG} \mathrm{147,02)} \quad \rightarrow \quad 0,0014 \mathrm{~g} / 100 \mathrm{ml}$

$1 \% \mathrm{NP}-40 \quad \rightarrow \quad 1 \mathrm{ml}$

$10 \%$ Glycerol $\quad \rightarrow \quad 10 \mathrm{ml}$

$\rightarrow$ Kurz vor Gebrauch Proteinase-Inhibitor-Cocktail (1 Tablette auf $10 \mathrm{ml}$ Puffer) hinzugeben

Proteinstandardkonzentrationsreihe (siehe Anhang):

\begin{tabular}{|l|l|}
\hline Probe & Konzentration [g/l] \\
\hline Standard & 1,44 \\
\hline $\mathrm{V}_{1}$ & 0,72 \\
\hline $\mathrm{V}_{2}$ & 0,36 \\
\hline $\mathrm{V}_{3}$ & 0,18 \\
\hline $\mathrm{V}_{4}$ & 0,09 \\
\hline
\end{tabular}

Trenngel-Puffer:

45,5 g Tris-Base (MG 121.1)

1,0 g SDS (MG 288.4)

$\rightarrow$ ad $250 \mathrm{ml}$ Bidest und auf $\mathrm{pH}=8,8$ einstellen

Sammelgel-Puffer:

15,1 g Tris-Base (MG 121.1)

1,0 g SDS (MG 288.4)

$\rightarrow$ ad 250 ml Bidest und auf $\mathrm{pH}=6,8$ einstellen

\section{APS 15\%:}

1,5g APS (MG 228.2)

$\rightarrow$ in 10 ml Bidest lösen

SDS-Spalt-Puffer:

$0,363 \mathrm{~g} / 100 \mathrm{ml}$ Tris-Base $(30 \mathrm{mM}) \quad \rightarrow \quad \mathrm{pH}$ von 7,4 einstellen 
$9 \% \operatorname{SDS}$

$15 \%$ Glycerin

0,04\% Bromphenolblau $\rightarrow \quad 9 \mathrm{~g} / 100 \mathrm{ml}$ Bidest

$\rightarrow \quad 15 \mathrm{~g} / 100 \mathrm{ml}$ Bidest

$\rightarrow \quad 40 \mathrm{mg} / 100 \mathrm{ml}$ Bidest

$\rightarrow$ direkt vor Gebrauch $10 \% \beta$-Mercaptoethanol zugeben

Lauf-Puffer:

28,8 g Glycin (0,192 M)

$6,0 \mathrm{~g}$ Tris-Base $(0,025 \mathrm{M})$

$2,0 \mathrm{~g} 0,1 \% \mathrm{w} / \mathrm{v}$ SDS

$\rightarrow$ in 21 Bidest lösen

Chemiluminescent Western Blot Immunodetektions-Kit:

80 ml Blocker / Diluent Part A

80 ml Blocker / Diluent Part B

2 x $100 \mathrm{ml}$ Washing Solution (16x)

2 x $100 \mathrm{ml}$ Secondary Antibody Solution (je nach Kit rabbit oder mouse)

$50 \mathrm{ml}$ Chemiluminescent Substrat

2,5 ml Chemiluminescent Substrat Enhancer

10 Filterpapiere (ca. $10 \times 20 \mathrm{~cm}$ )

2 Klarsichtfolien (ca. 14 x $20 \mathrm{~cm}$ )

2 Inkubationsschälchen mit Deckel (ca. 10 x 10 x 1,5 cm)

Blocking-Solution $(10 \mathrm{ml})$ :

$7 \mathrm{ml}$ Bidest

2 ml Blocker / Diluent Part A

$1 \mathrm{ml}$ Blocker / Diluent Part B

Primary Antibody Diluent (10ml):

$7 \mathrm{ml}$ Bidest

2 ml Blocker / Diluent Part A

$1 \mathrm{ml}$ Blocker / Diluent Part B

Anti-mouse oder Anti-rabbit-Antikörper je nach erforderlicher Verdünnung 1:25, 1:50, 1:100, 1:200, 1:500 oder1:1000 hinzugeben.

Antibody Wash $(160 \mathrm{ml})$ :

$150 \mathrm{ml}$ Bidest

$10 \mathrm{ml}$ Antibody Wash Solution (16x) 
Chemiluminescent Substrat (2,5 ml):

2,375 ml Chemiluminescent Substrat

0,125 ml Chemiluminescent Substrat Enhancer

$\rightarrow$ unter Lichtschutz herstellen

Antikörper-Stripping Solution $(50 \mathrm{ml})$ :

$345 \mu 1 \beta$-Mercaptoethanol

$10 \mathrm{ml} 10 \%$ iges SDS

$39,655 \mathrm{ml}$ Tris- $\mathrm{HCl}$

\section{Tris-HCl:}

0,9929 g Tris-HCl 63 mM (MG 157,6)

$\rightarrow$ mit 100 ml Bidest auffüllen

$\rightarrow \mathrm{pH}$ bei 6,7 einstellen

\section{Histologie:}

Silanobjektträger:

1. Küvette: $4 \mathrm{ml}$ Silan (gelagert bei $\left.4^{\circ} \mathrm{C}\right)+200 \mathrm{ml}$ Aceton

2. Küvette: $200 \mathrm{ml}$ Aceton

3. Küvette: $200 \mathrm{ml}$ Aceton

4. Küvette: $200 \mathrm{ml}$ Bidest

5. Küvette: $200 \mathrm{ml}$ Bidest

$\rightarrow$ Unter den Abzug wurden je 10 Objektträger für 20 sek in die Silanlösung gestellt. Anschließend wurden die Objektträger der Reihenfolge nach in den Küvetten 2-5 geschwenkt und schließlich für $24 \mathrm{~h}$ bei Raumtemperatur unter dem Abzug getrocknet.

\section{Masson-Goldner-Trichromfärbung:}

Masson-Goldner-Färbekit:

Lösung 1: Azophloxin-Lösung $500 \mathrm{ml}$

Lösung 2: Phosphorwolframsäure-Orange-G-Lösung $500 \mathrm{ml}$

Lösung 3: Lichtgrün-SF-Lösung $500 \mathrm{ml}$

Lösung 4: Essigsäure $10 \% 500 \mathrm{ml}, 1: 10$ mit dest. Aqua verdünnen

Weigerts Eisenhämatoxylin Lösung:

Weigerts Lösung A alkoholische Hämatoxylin-Lösung $500 \mathrm{ml}$

Weigerts Lösung B salzsaure Eisen(III)nitrit-Lösung $500 \mathrm{ml}$

$\rightarrow$ Weigerts Lösung A und B im Verhältnis 1:1 mischen 


\section{TUNEL-Färbung:}

\section{PBS (5 1):}

40 g Natriumchlorid (MG 58,44)

$1 \mathrm{~g}$ Kaliumchlorid (MG 74.56)

1,15 g Natriumhydrogenphosphat (MG 141.96)

$1 \mathrm{~g}$ Kaliumdihydrogenphosphat (MG 228.23)

$\rightarrow$ in 51 Bidest lösen

$4 \%$ Paraformaldehydlösung $(200 \mathrm{ml})$ :

8 g Paraformaldehyd

$200 \mathrm{ml}$ PBS

2-3 Tropfen Natronlauge

$\rightarrow$ In einer geschlossen Flasche $1,5-2 \mathrm{~h}$ bei $65^{\circ} \mathrm{C}$ auf Heizplatte mit magnetischem Rührstab auflösen. Sobald die Lösung nur noch etwas milchig ist, 2-3 Tropfen Natronlauge hinzufügen. Hierbei soll ein Umschlag zur klaren Lösung erfolgen.

Proteinase K-Puffer:

100 mM Tris-HCl (MG 157,6 g/l) (pH 8,0)

$50 \mathrm{mM}$ EDTA

$\underline{\operatorname{SSC}(20 \mathrm{x} \text { bzw. } 2 \mathrm{x}):}$

$87,7 \mathrm{~g} \mathrm{NaCl}$

44,1 g sodium citrat (MG 294.1)

$\rightarrow$ Auflösen in $400 \mathrm{ml}$ Bidest. Einstellung auf pH 7,2. Auffüllen auf $500 \mathrm{ml}$ Volumen mit Bidest. $\mathrm{Zu}$ beachten ist, dass das Salz gut gelöst ist.

$\rightarrow$ Kurz vor Gebrauch 1:10 mit Bidest verdünnen um 2x SSC zu erhalten.

DAB-Lösung:

$50 \mu 1$ DAB-Substrat 20 x Puffer mit $950 \mu$ l Bidest verdünnen und anschließend $50 \mu 1$ DAB $20 \mathrm{x}$ Chromogen und $50 \mu 1$ Hydrogen-Peroxid $20 \mathrm{x}$ hinzugeben.

$\rightarrow$ Erst kurz vor Gebrauch ansetzen und vor Licht schützen

\section{Immunhistochemie:}

Citrat-Puffer:

10 mM Citronensäure-Monohydrat (MG 210,14)

$\rightarrow 2,1 \mathrm{~g} / \mathrm{l}$ in PBS lösen

$\rightarrow$ pH bei 6,0 einstellen mit Hilfe von $2 \mathrm{~N} \mathrm{NaOH}$ 


\section{ERGEBNISSE}

Wie in der Darstellung des Planungscomputertomogamms vor Bestrahlung und des Rattensitus in Abb. 2 unter $2.1 \mathrm{zu}$ sehen ist, liegt neben der Leber und dem Magen ein Teil des Duodenums im Bestrahlungsfeld von 25 Gy. Eine geringe Strahlendosis von ca. 12 Gy bzw. ca. 2,5 Gy betrifft demnach nur einen Teil des Duodenums und des Jejunums. Das weitere Jejunum, das Ileum, das Coecum und das Colon liegen außerhalb des berechneten Bestrahlungsfeldes, Streustrahlung in geringen Dosen kann aber auch hier auftreten.

\subsection{Das Versuchstier: Ratte}

Während des Untersuchungszeitraumes verstarb keine der bestrahlten Ratten. Dennoch fiel nach der Bestrahlung eine mangelnde Gewichtszunahme der bestrahlten Versuchstiere im Vergleich zu den Kontrolltieren des jeweiligen Zeitpunktes auf. Außerdem wurde bei den bestrahlten Ratten eine Veränderung des Stuhlganges mit vermehrten Durchfällen beobachtet. Bei der Präparation der Tiere ließen sich makroskopisch deutliche Veränderungen des Darmgewebes im Vergleich zu den Kontrolltieren nachweisen. Abb. 4 a zeigt ein Dünndarmsegment des terminalen Ileums 2 Tage nach Bestrahlung mit Darstellung der Mesenterialgefäßarkade. Auffällig ist, dass der Dünndarm gerötet und ödematös verdickt erscheint. In Abb. 4 b ist das Dünndarmpräparat des terminalen Ileums im Vergleich zum Präparat des unbestrahlten Kontrolltieres (kleiner Kasten) dargestellt. Auch hier ist eine vermehrte Gefäßzeichnung auffallend.

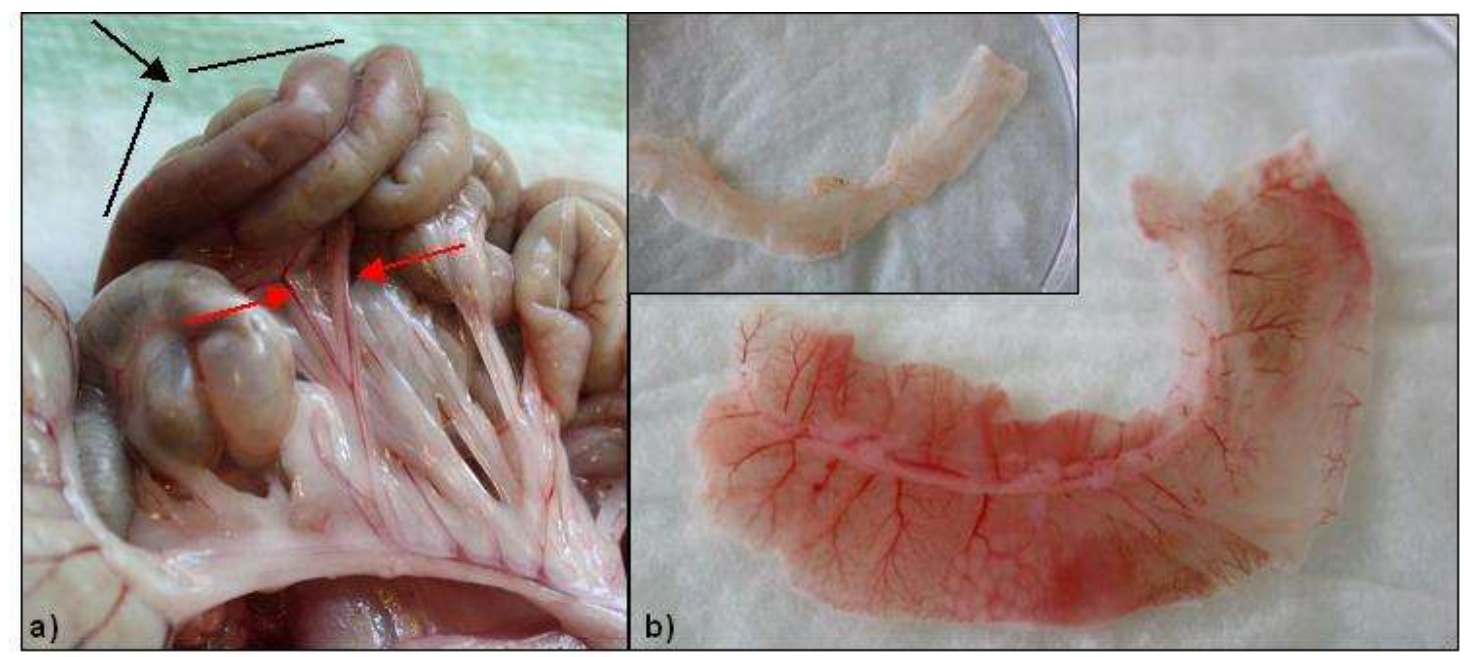

Abb. 4 a) Dünndarmsegment nach Bestrahlung und b) Dünndarmpräparat der bestrahlten Ratte im Vergleich zum unbestrahlten Versuchstier (kleiner Kasten) 


\subsection{Histologische Veränderung in Folge von Bestrahlung}

Es wurden histologische bzw. immunhistochemische Färbungen von den Organen Duodenum, Jejunum, Ileum und Colon zu den Zeitpunkten 0 h bis 3 Monate hergestellt. Als Übersichtfärbung wurde die H.E.-Färbung und die Masson-Goldner-Trichromfärbung durchgeführt. Makrophagen wurden mit der immunhistochemischen ED1-Färbung detektiert, Lymphozyten wurden mit der CD3-Färbung, hämatopoetische Vorläuferzellen mit Hilfe der CD34-Färbung, apoptotische Prozesse mit der Caspase-3-Färbung und spezifische DNA-Strangbrüche ebenfalls als Hinweis für Apoptose mittels der TUNEL-Färbung identifiziert.

\subsubsection{H.E.-Färbung: Die Übersichtsfärbung}

Die H.E.-Färbung wurde zur mikroskopischen Übersicht der anatomisch-morphologischen Gewebeveränderung erstellt. Um eine vergleichbare und quantifizierbare Auswertung der Organabschnitte zu den unterschiedlichen Zeitpunkten zu gewähren, wurde angelehnt an die Studien von Carr ein Strahlenschädigungs-Score erstellt (Carr 2001). Dieser beinhaltete fünf Kriterien, nach denen die morphologischen Veränderungen nach Bestrahlung beurteilt wurden (siehe Tabelle 4). Das Kriterium 1 bedeutet in diesem Fall, dass es zu keiner pathologischen Veränderung des Gewebes nach Bestrahlung gekommen ist, während das Kriterium 5 für die stärkste Strahlenschädigung des Gewebes steht. Hier ist es zu einer Schädigung bis in die Krypten des Epithels gekommen.

\section{Tabelle 4 Kriterien der Strahlenschädigung des Darmgewebes}

1: $\quad$ vitales Epithel, evtl. mechanische Alterationen durch die Aufarbeitung

2: $\quad$ abgeflachte Schleimhaut

3: $\quad$ Ödem der Zotten

4: $\quad$ avitales oder fehlendes Epithel (denudierte Zotten)

5: $\quad$ Krypten geschädigt

Die Organabschnitte der Tiere C, D und E wurden zu den jeweiligen Zeitpunkten nach den o.g. Kriterien miteinander verglichen und der Strahlenschädigungs-Score wurde erstellt, indem die Summe der Kriterien gemittelt und eine Standardabweichung berechnet wurde. Dies ermöglicht einen semiquantitativen Vergleich zwischen den einzelnen Organabschnitten und Zeitpunkten. Abb. 5 zeigt den Strahlenschädigungs-Score der jeweiligen Organabschnitte Duodenum, Jejunum, Ileum und Colon zu den Zeitpunkten 0 h (Kontrolle) bis 3 Monate nach Bestrahlung. 


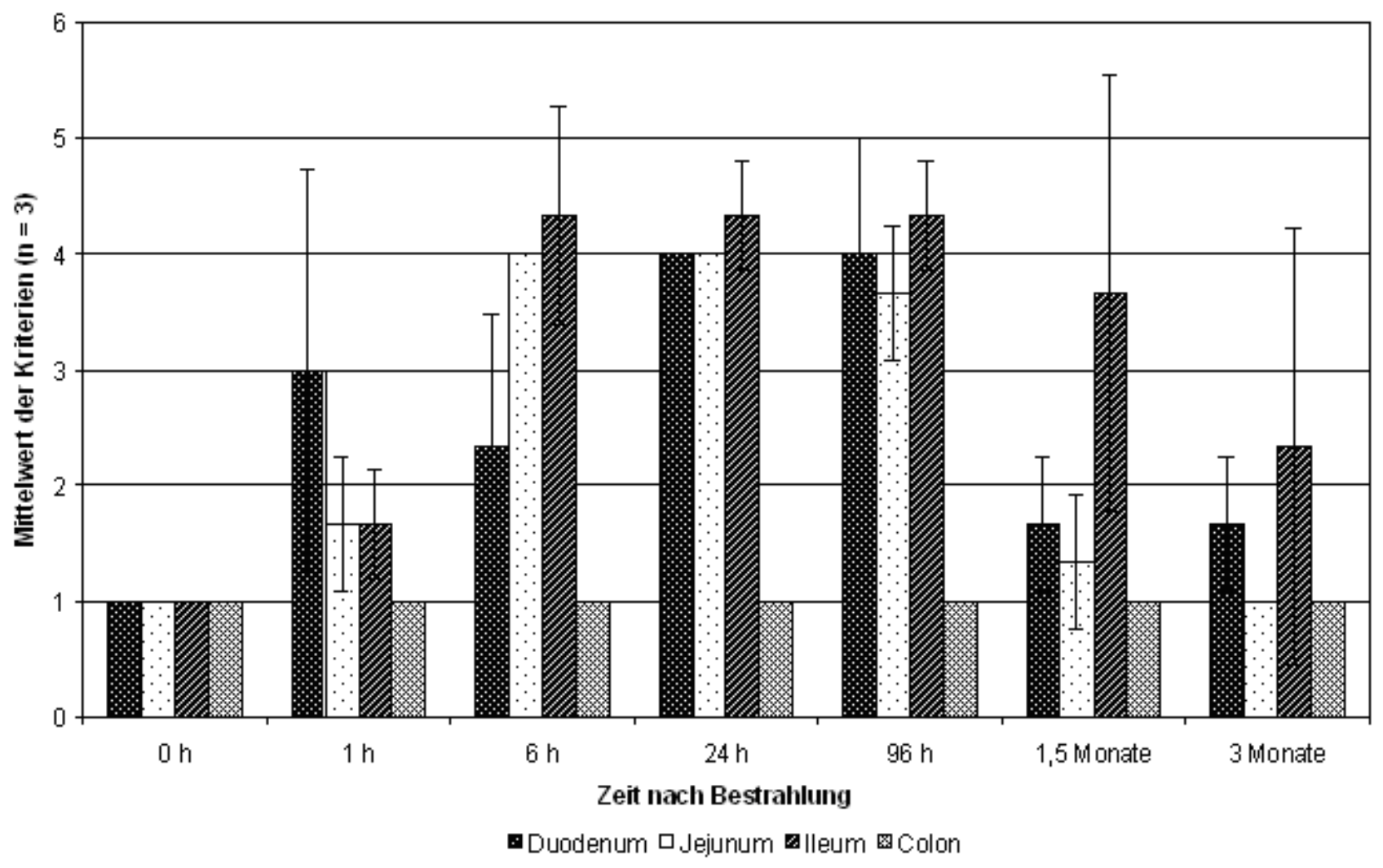

Abb. 5 Strahlenschädigungs-Score

Vergleichende graphische Darstellung der Gewebeschädigung von Duodenum, Jejunum, Ileum und Colon Die Mittelwerte der Kriterien $(n=3)$ und deren Standardabweichungen sind zu den unterschiedlichen Zeitpunkten nach Radiotherapie abgebildet.

Aus der graphischen Darstellung wird ersichtlich, dass es zwischen $6 \mathrm{~h}$ und $96 \mathrm{~h}$ zu einem deutlichen Peak der Darmschädigung in den Organabschnitten Duodenum, Jejunum und Ileum durch Bestrahlung kommt. Im Duodenum sind bereits eine Stunde nach Bestrahlung akute histologische Veränderungen des Gewebes auffallend (Abb. 6). Hier kommt es zu einem Verlust der Gewebeintegrität auf Höhe der Zotten, während die Krypten zu diesem Zeitpunkt noch intakt erscheinen. Nach $6 \mathrm{~h}$ wird eine ödematöse Aufwerfung der Zotten und eine zunehmende Zerstörung der Zottenarchitektur beobachtet. Zum Zeitpunkt 24 h bzw. 96 h aggravieren sich die Schäden des Duodenums noch. Nun zeigen sich die Zotten deutlich verkürzt und bei $96 \mathrm{~h}$ ist eine Skalpellierung der Zotten mit intraluminalen Zelldebris führend. Nach 1,5 Monaten bzw. nach 3 Monaten kommt es zu einer deutlichen Normalisierung des Gewebes. Eine komplette Regeneration wird hier jedoch nicht erreicht. $\mathrm{Zu}$ den späten Zeitpunkten ist noch eine abgeflachte Schleimhaut zu sehen (Abb. 6). Auch bei der H.E.-Färbung des Jejunums fallen deutliche Darmschädigungen zu den Zeitpunkten $6 \mathrm{~h}$ bis $96 \mathrm{~h}$ auf (Abb. 6). Zum 6 h-Zeitpunkt fällt ein Verlust der Epithelzelllinie an den Zotten auf. Die Villi sind auch in diesem Darmabschnitt 24 h nach Bestrahlung abgeflacht, breiter und reduziert in ihrer Anzahl, während die Krypten nur leicht verkürzt erscheinen. Nach 96 h findet ein Rückgang der Schädigung statt. Die Epithelzelllinie läßt sich nun wieder eindeutig vom Stroma der Zotten differenzieren. Als Folge von Bestrahlung ist nach 1,5 Monaten nur noch eine leicht abgeflachte 
Schleimhaut zu beobachten, während es nach 3 Monaten zu einer vollständigen Regeneration des Gewebes kommt. Die stärksten Strahlenschäden zeigen sich in der H.E.-Übersichtsfärbung, wie in Abb. 6 zu sehen ist, im Ileum. Direkt nach Bestrahlung kommt es zu einer ödematösen Aufwerfung der Epithelzelllinie und damit dezenter Abhebung vom Stroma. Bereits nach $6 \mathrm{~h}$ sind die Zotten zerstört, die Krypten nicht mehr eindeutig zu differenzieren und durch große vakuolenartige Hohlräume ersetzt. Während nach $24 \mathrm{~h}$ die Zotten in diesem Darmabschnitt weiterhin destruiert sind, können auf Kryptenniveau vereinzelt intakte Kryptenepithelzellen erfasst werden. 96 h nach Bestrahlung lässt sich eine Kryptzelllinie nachvollziehen. Die Zotten sind jedoch weiterhin verkürzt, unstrukturiert und ohne eine eindeutige Epithelschicht. Außerdem treten im Ileum erhebliche Spätschäden nach 1,5 Monaten und auch noch nach 3 Monaten auf. Diese äußern sich mit persistierenden Vakuolen im Stroma der weiterhin reduzierten Zotten. Im Colon findet sich $24 \mathrm{~h}$ nach Bestrahlung lediglich eine Auflockerung des Gewebes. Bereits nach 96 h erscheint diese rückläufig. Spätschäden nach 1,5 Monaten und 3 Monaten können hier nicht gezeigt werden (Abb. 6). Die Alterationen entsprechen den natürlichen Umbauprozessen, denen das Colon ständig unterliegt. 

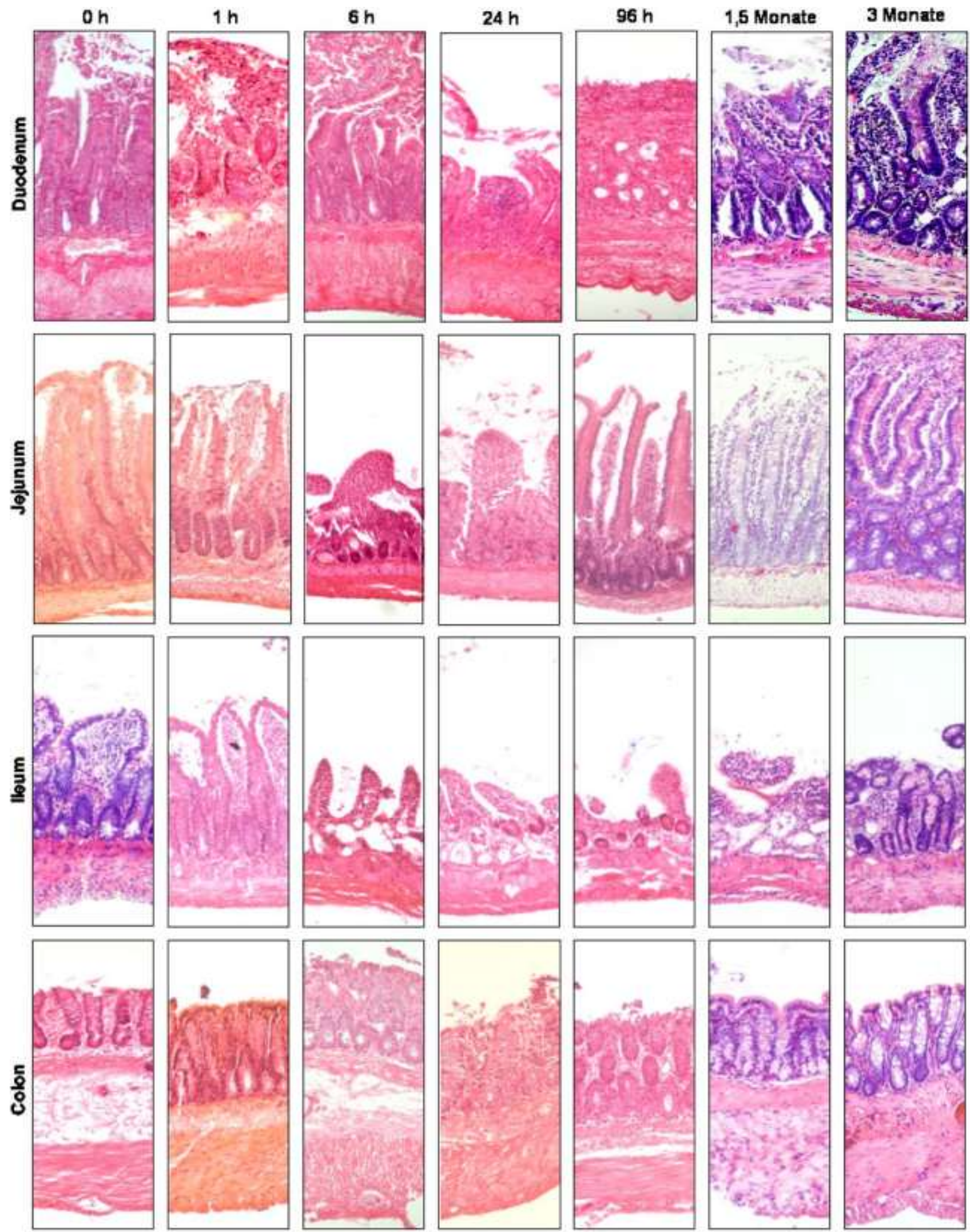

Abb. 6

H.E.-Färbung (100-fache Vergrößerung) 


\subsubsection{Masson-Goldner-Trichromfärbung}

Die Masson-Goldner-Trichromfärbung wurde ergänzend zu der H.E.-Färbung durchgeführt. Während die H.E.-Färbung für das Duodenum und Jejunum einen frühen Zerfall der Epithelintegrität zum 1 h-Zeitpunkt zeigt, so ist das Ileum nur durch ödematöse Villi auffällig. Nach $6 \mathrm{~h}$ erscheinen in der H.E.-Färbung die Zotten des Jejunums und Ileums deutlicher zerstört und verkürzt. In der Masson-Goldner-Trichromfärbung sind exemplarisch das Jejunum $6 \mathrm{~h}$ nach Bestrahlung und das Ileum zum 6 h-Zeitpunkt und 3-Monatszeitpunkt abgebildet. Abb. 7 a zeigt das Jejunum nach 6 h. Hier kommen neben Apoptosekörperchen in der Zellposition 4-5 der Krypten mitotische Zellkonfigurationen zur Darstellung. Hyalines Material und Zelldebris als Hinweis für Nekrose erscheint in Richtung des Lumens und nimmt teilweise die Position der Zotten ein. In der Submukosa des Jejunums findet sich außerdem in den Blutgefäßen eine Erythrozytenkongestion. Das Ileum stellt auch in der Masson-Goldner-Trichromfärbung die stärksten Strahlenschäden dar. Hier zeigt sich ein kompletter Verlust der Epithelzelllinie, eine Schädigung der Kryptenzellen, ein Auftreten von großen Vakuolen, eine reduzierte Anzahl von Blutgefäßen und eine vermehrte Kollageneinlagerung in der Submukosa (Abb. 7 b). Selbst nach 3 Monaten hat sich das Gewebe des Ileums noch nicht komplett regeneriert. Die Villi sind immer noch deutlich verkürzt, jedoch ist es zu einer Erholung der Krypten gekommen (Abb. 7 c).

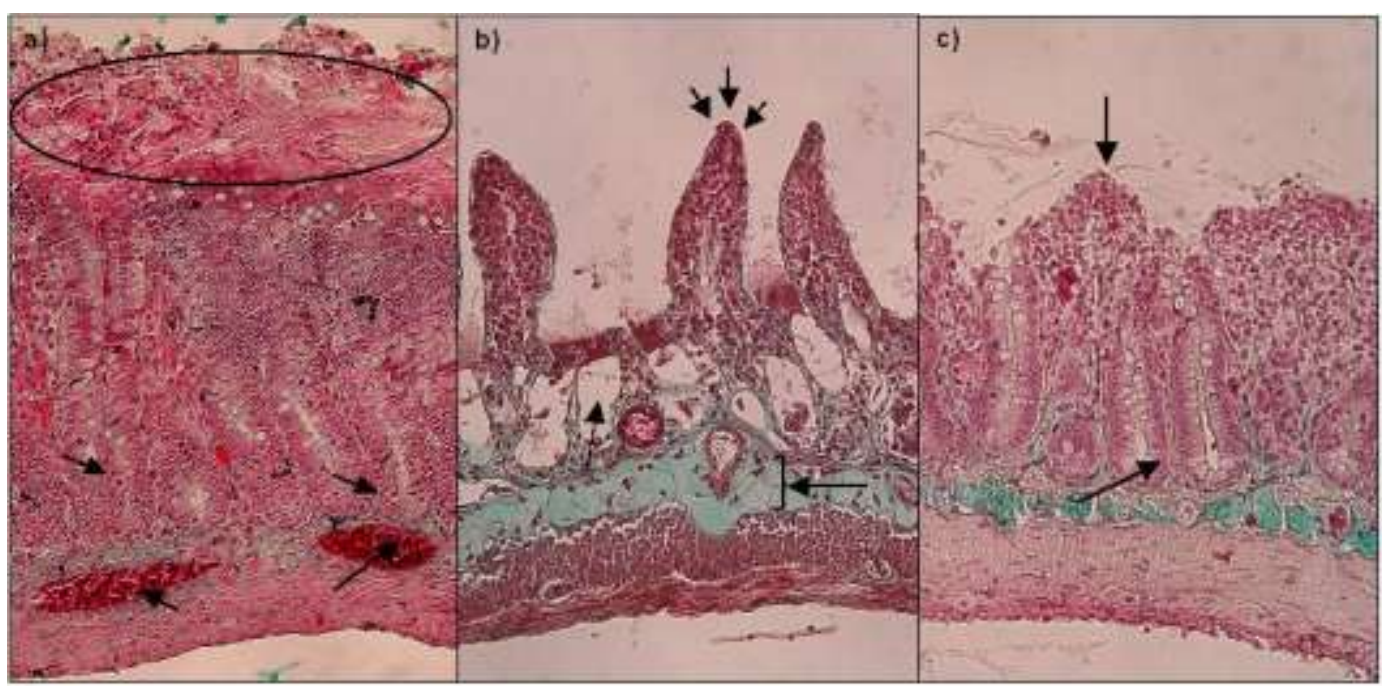

Abb. 7 Masson-Goldner-Trichromfärbung (100-fache Vergrößerung)

a) Jejunum 6 h nach Bestrahlung b) Ileum 6 h nach Bestrahlung c) Ileum 3 Monate nach Bestrahlung

\subsubsection{ED1 als Marker für CD68-positive Makrophagen}

Um die Bedeutung von Makrophagen im bestrahlten Darmgewebe zu untersuchen, führten wir die ED1-Färbung durch. Die ED1-Färbung eignet sich besonders zur Darstellung von Monozyten und eingewanderter Makrophagen im abdominellen Gewebe von Ratten (Heuff et al. 1993; Sminia und 
Jeurissen 1986). Der Antikörper ED1 ist dabei das rattenspezifische Homolog für humanes CD68 (Damoiseaux et al. 1994). In der immunhistologischen Färbung zeigt sich für ED1, dass im Gegensatz zum Duodenum (35 \pm 1 ED1-positive Zellen) und Colon (28 \pm 9 ED1-positive Zellen) im Jejunum $(87 \pm 10)$ und Ileum $(85 \pm 28)$ bereits im gesunden Gewebe $(0$ h-Zeitpunkt $)$ deutlich mehr Makrophagen nachgewiesen werden können (siehe Abb. 8 und Abb. 9).

Während im Duodenum $6 \mathrm{~h}$ nach Bestrahlung ED1-positive Zellen besonders an der Basis der Krypten aufgezeigt werden können, wandern diese im Jejunum und Ileum vom Zeitpunkt $1 \mathrm{~h}$ bis 96 h entlang der Krypten-Zotten-Achse im Stroma der Villi in Richtung des Darmlumens und treten dann an der Spitze der Villi auf. Eine Repopulation der Makrophagen kann bei 1,5 Monaten und 3 Monaten besonders im Ileum nachgewiesen werden (Abb. 8). Im Colon wird kein Unterschied zwischen den Zeitpunkten $0 \mathrm{~h}$ bis $96 \mathrm{~h}$ deutlich. Außergewöhnlich ist ein signifikanter Rückgang ED1-positiver Zellen 1,5 und 3 Monate nach Bestrahlung (26 \pm 9 ED-1-positive Zellen in der Kontrolle, $6 \pm 3$ nach 1,5 Monaten und $6 \pm 4$ nach 3 Monaten), wie in Abb. 8 und Abb. 9 zu sehen ist. Insgesamt ist festzuhalten, dass sich bei der Zellzählung von ED1-positiven Zellen hohe Standardabweichungen für alle Organabschnitte und Zeitpunkte ergeben.

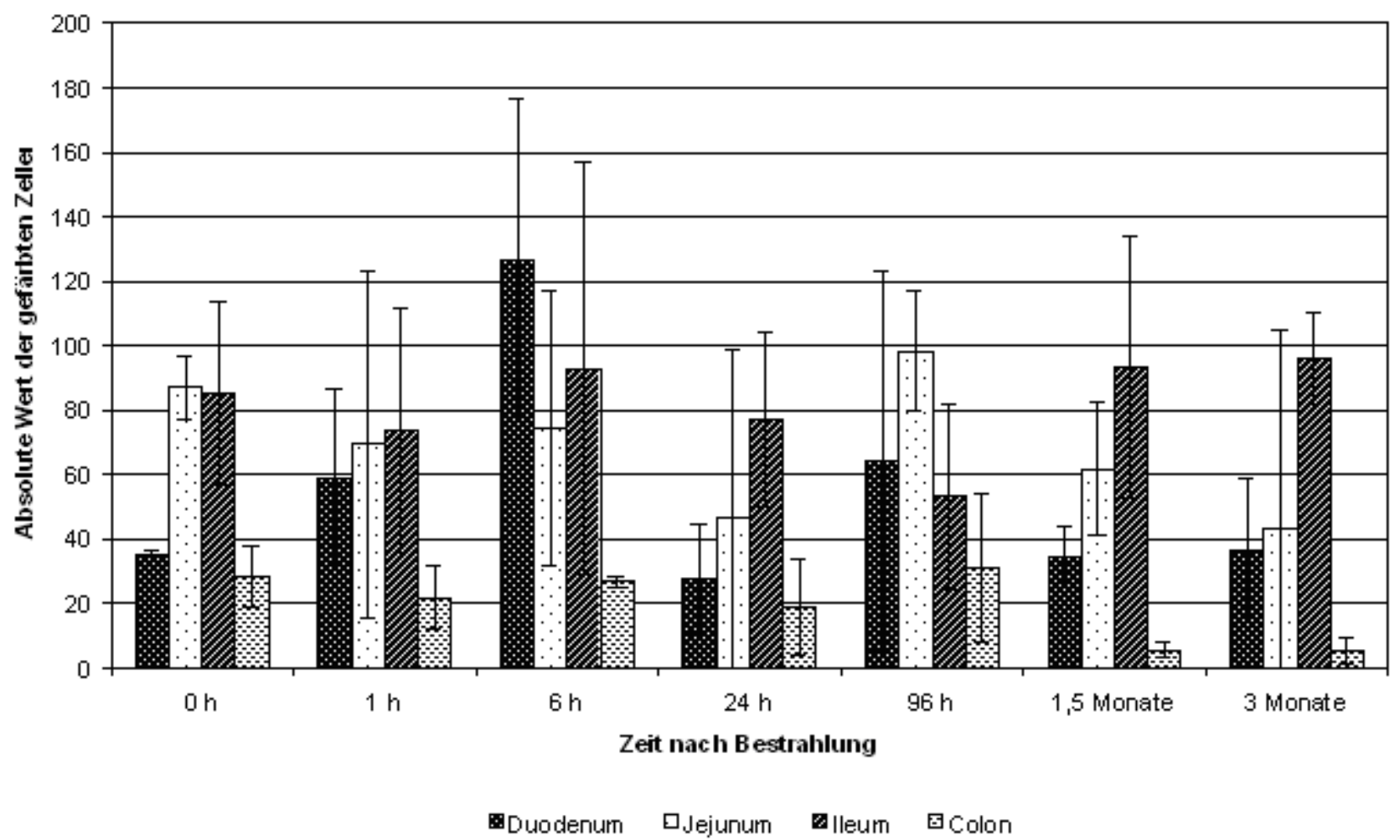

Abb. 8 Absolute Anzahl von ED1-positiven Zellen im Gewebeausschnitt (1,3 $\left.\mathrm{mm}^{2}\right)$ dargestellt mit Standardabweichung 


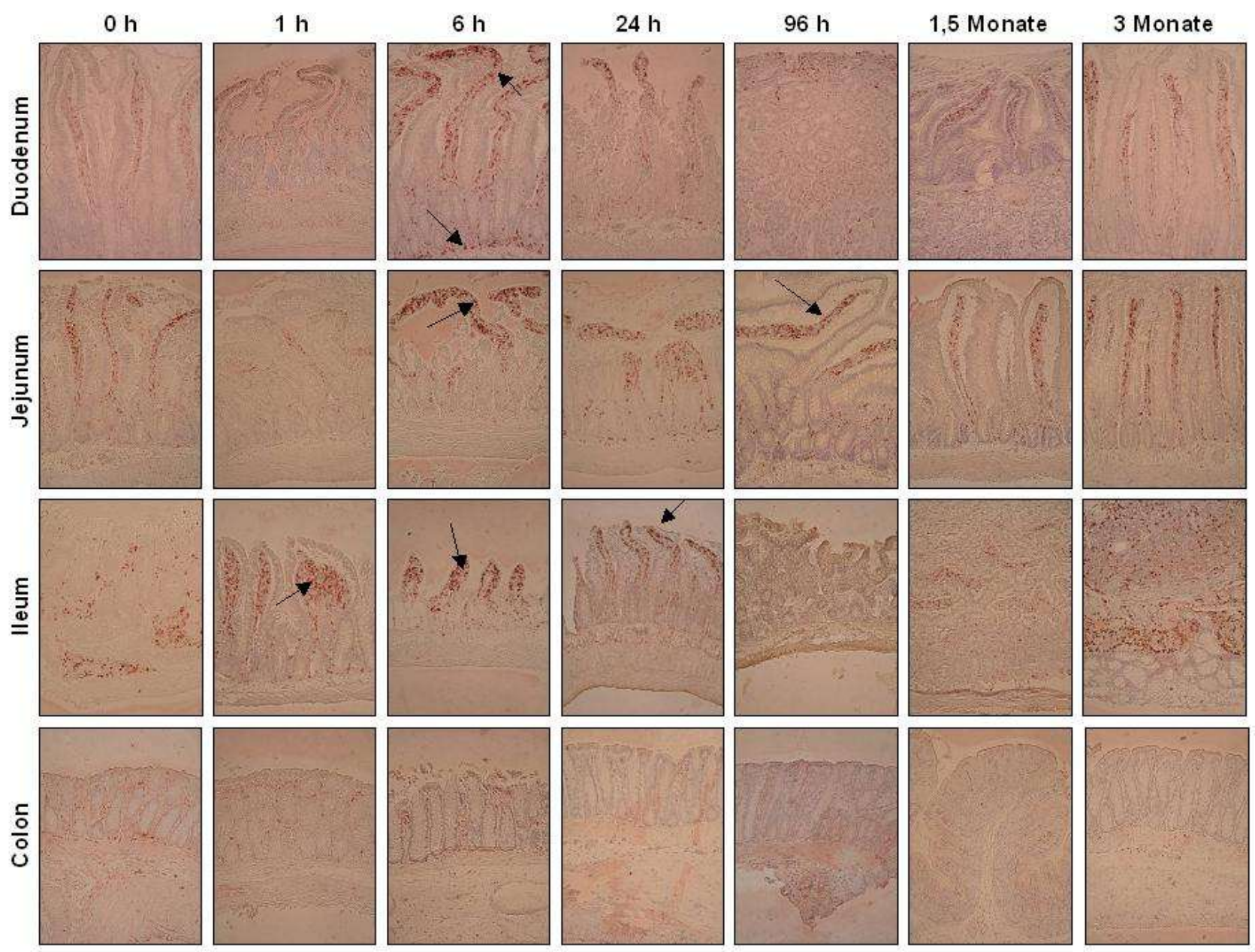

Abb. 9 ED1-Färbung (100-fache Vergrößerung)

\subsubsection{CD3 als Marker für T-Lymphozyten}

Der anti-CD3-Antikörper eignet sich zur Differenzierung zwischen T-Zellen und B-Zellen (Mason et al. 1989). Dabei sind T-Lymphozyten an der inflammatorischen Reaktion als Folge von bestrahlungsinduziertem oxidativen Stress beteiligt. Um die Anzahl der CD3-positiven TLymphozyten zu erfassen, wurde eigens hierfür ein Zellzähl-Programm geschrieben (Cameron et al. 2008). Dies ermöglicht die CD3-positiven T-Lymphozyten, deren Zytoplasma sich in den mikroskopischen Aufnahmen rot zeigt, gegenüber den übrigen Zellen des Gewebes, deren Kerne sich durch eine Hämatoxylin-Gegenfärbung blau färben, abzugrenzen. Exemplarisch ist in Abb. 10 a-c das Duodenum zum Zeitpunkt C 0 h abgebildet. Die Zellzählung ergibt für dieses Beispiel 241 Zellen, deren Zytoplasma sich rot färbt (siehe Abb. 10 b) und 1378 blau-angefärbte Zellenkerne (siehe Abb. 10 c). Dies bedeutet, dass von insgesamt 1378 gezählten Zellenkernen ca. 17,5\% rot angefärbtes Zytoplasma als Merkmal für CD3-markierte T-Lymphozyten aufweisen. 

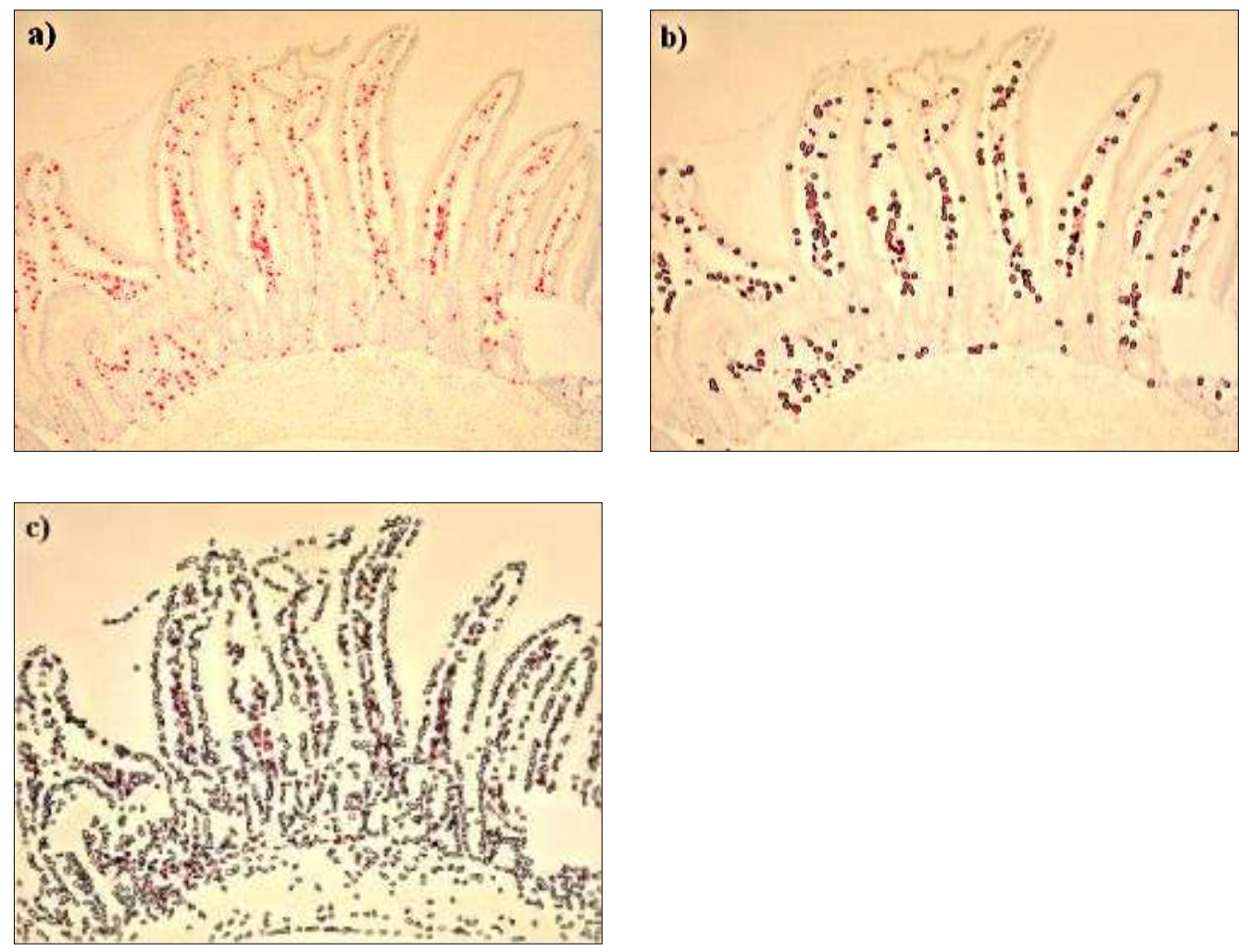

Abb. 10

Exemplarische Zellzählung von CD3-positiven T-Lymphozyten

a) Exemplarisch Tier C $0 \mathrm{~h}$ Duodenum in 100-facher Vergrößerung abgebildet b) Das rot angefärbte Zytoplasma von CD3-positiven T-Lymphozyten für Zellzählung markiert c) Alle blau-angefärbten Zellkerne des Gewebes für die Zellzählung markiert

Da sich diese Methode der Zellzählung gut eignet, das rot angefärbte Zytoplasma der CD3positiven T-Lymphozyten numerisch zu erfassen, wurden alle Schnitte dieser Färbung gezählt und die Prozentzahl der CD3-markierten T-Lymphozyten bezogen auf die Gesamtzellzahl des Gewebes ermittelt. Die quantitative Darstellung der einzelnen Darmabschnitte ist in Abb. 12 aufgeführt.

Für das Duodenum ergibt sich, dass es zu einem kleinen Anstieg von CD3-positiven TLymphozyten bis $6 \mathrm{~h}$ nach Bestrahlung im Vergleich zu den 0 h-Kontrolltieren kommt (siehe Abb. 11 und Abb. 12). Nach 24 h ist ein signifikanter Verlust von CD3-positiven Zellen im Duodenum nachweislich. Bereits nach $96 \mathrm{~h}$ kommt es wieder zu einem Anstieg der T-Lymphozyten im Duodenum. Im Jejunum sind konstant ca. $20 \%$ der Zellen CD3-positiv. Lediglich der 3-Monatswert zeigt eine leichte Erhöhung der CD3-positiven Zellen im Vergleich zu dem 0 h-Wert. Anhand der Abb. 11 und Abb. 12 wird deutlich, dass es besonders im Ileum zu einer frühen Einwanderung von T-Lymphozyten $1 \mathrm{~h}$ nach Bestrahlung kommt. Jedoch ist zu berücksichtigen, dass im Ileum auch beim unbestrahlten Tier die Anzahl von CD3-positiven Zellen im Vergleich zu den anderen Darmabschnitten erhöht ist. Auffällig ist, dass im Ileum bei $24 \mathrm{~h}$ und $96 \mathrm{~h}$ der prozentuale Wert der CD3-positiven Zellen unter den Wert der Kontrolle fällt und dann ein zweites Peak von CD3-positiven Zellen zum 3-Monatszeitpunkt registriert werden kann. Im Colon sind 
durchschnittlich nur 3-7 \% der Zellen CD3-positiv. Eine deutliche Veränderung der Zellzahl nach Bestrahlung kann im Colon nicht beobachtet werden.
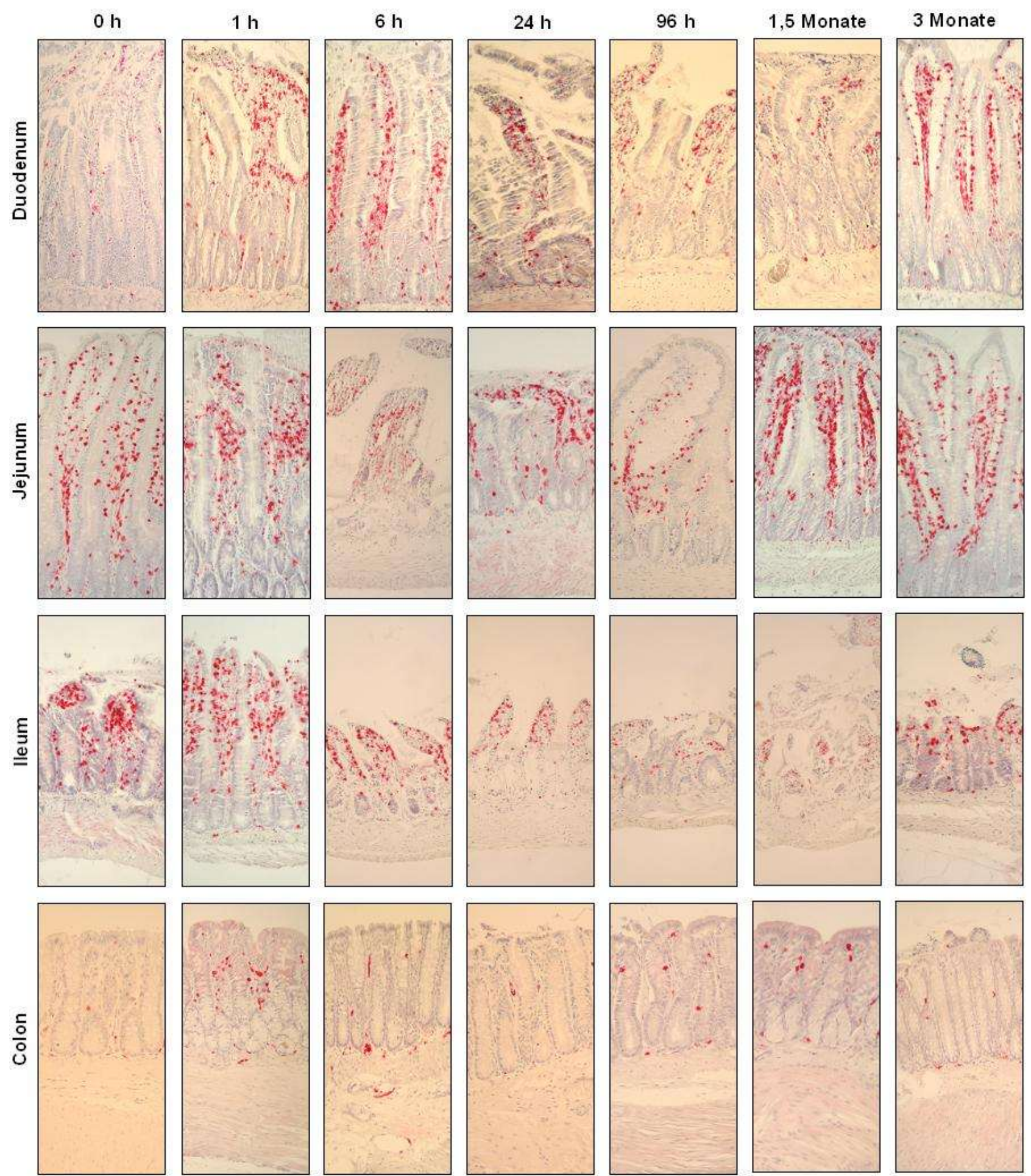

Abb. 11

CD3-Färbung (100-fache Vergrößerung) 


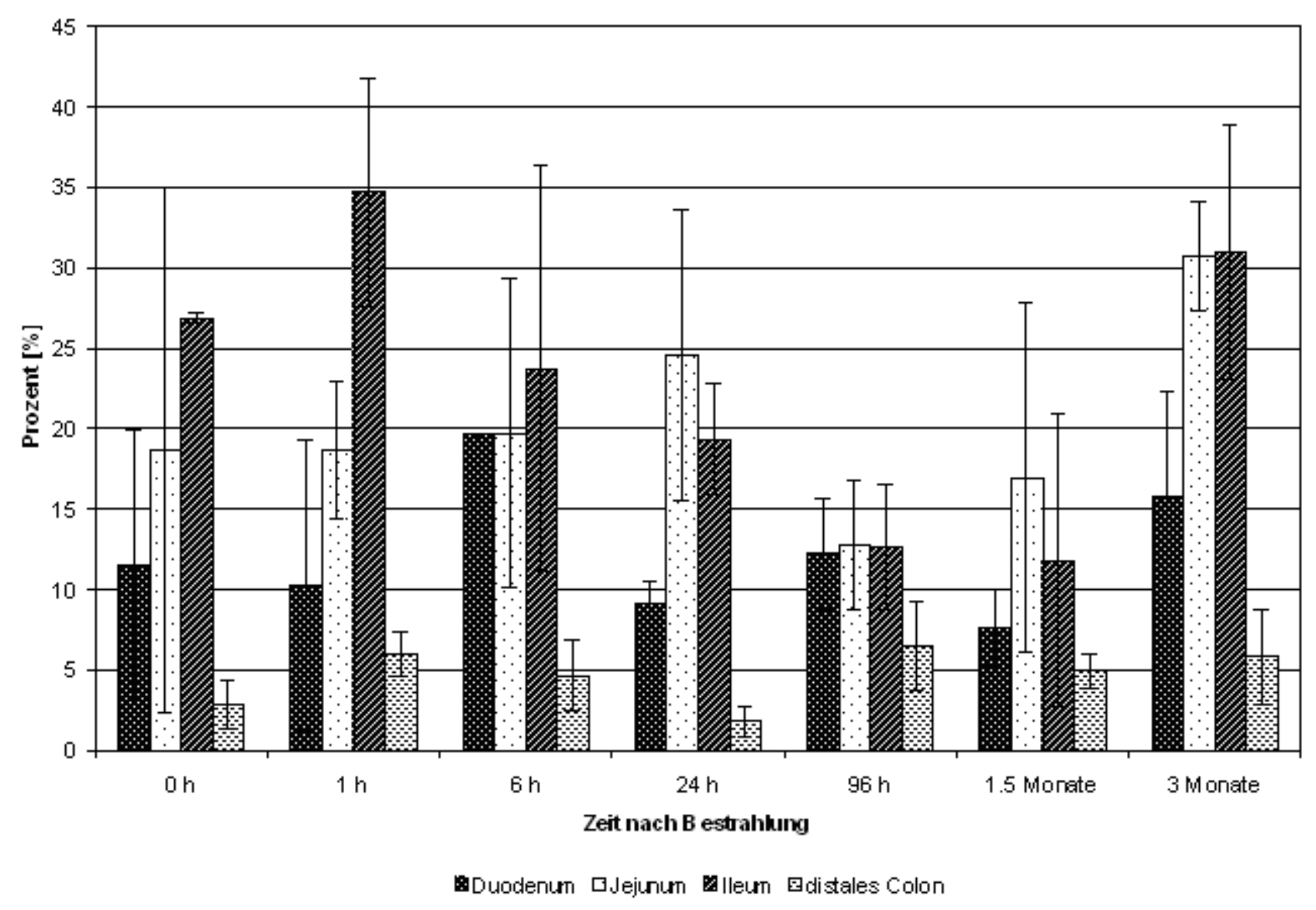

Abb. 12 Prozentzahl der CD3-positiven T-Lymphozyten bezogen auf alle Zellen des Gewebeausschnittes $\left(=1,3 \mathrm{~mm}^{2}\right)$ dargestellt mit Standardabweichung

\subsubsection{CD34-Färbung}

Zum Nachweis der Einwanderung von hämatopoetischen Progenitorzellen im bestrahlten Gewebe wurde die CD34-Färbung durchgeführt (siehe Abb. 13). Es erfolgte eine Gegenfärbung mit Hämatoxylin, um die CD34-positiven Zellen quantifizieren zu können (siehe Abb. 14). Die Abb. 14 zeigt einen signifikanten Anstieg von CD34-positiven Zellen nach $24 \mathrm{~h}$ im Duodenum von 54 CD34-positiven Zellen \pm 77 (3\% aller Zellen) auf 174 Zellen \pm 53 (14\% aller Zellen). Dies entspricht einem relativen Anstieg von $11 \%$. Im Jejunum findet ebenfalls ein signifikanter Anstieg von $2,5 \%$ auf $8,3 \%$ im Verlauf von $0 \mathrm{~h}$ bis $24 \mathrm{~h}$ statt. Nach einem Abfall auf 2,4\% nach 1,5 Monaten kommt es zu einem 2. Peak nach 3 Monaten auf $10 \%$ CD34-positiver Zellen. Diese zeigen sich sowohl an der Basis, als auch entlang der Zotte. Im Ileum sind 6,6 \% CD34-positive Zellen in den Kontrollen $(103$ Zellen \pm 29$)$ zu beobachten. Hier kommt es unerwarteterweise zu einer Abnahme von CD34-positiven Zellen bereits $1 \mathrm{~h}$ nach Bestrahlung auf $58 \pm 61$ Zellen (2,9\%), nach 6 h auf $15 \pm 13$ Zellen (1\%) und schließlich nach 1,5 Monaten auf 0,1\%. Nur nach 24 h lässt sich ein Anstieg der CD34-positiven Zellen auf 5,8 \% verzeichnen. Insgesamt ist auffällig, dass das Ileum Werte mit hohen Standardabweichungen beinhaltet. CD34-positive Zellen präsentieren sich 
bei $0 \mathrm{~h}$ und $24 \mathrm{~h}$, wie in Abb. 13 zu sehen ist, besonders entlang des unteren Drittels der Zotten. Für das Colon zeigt sich, dass die Anzahl CD34-positiver Zellen während der gesamten Periode von $0 \mathrm{~h}$ bis 3 Monate konstant bleibt. Es ist lediglich zu vermerken, dass CD34-positive Zellen zu den Zeitpunkten $1 \mathrm{~h}, 6 \mathrm{~h} 24 \mathrm{~h}$ und 3 Monaten vorrangig an der Basis der Krypten zu sehen sind, während sie sich bei $0 \mathrm{~h}$ und $96 \mathrm{~h}$ entlang der Zotten wiederfinden (Abb. 13).
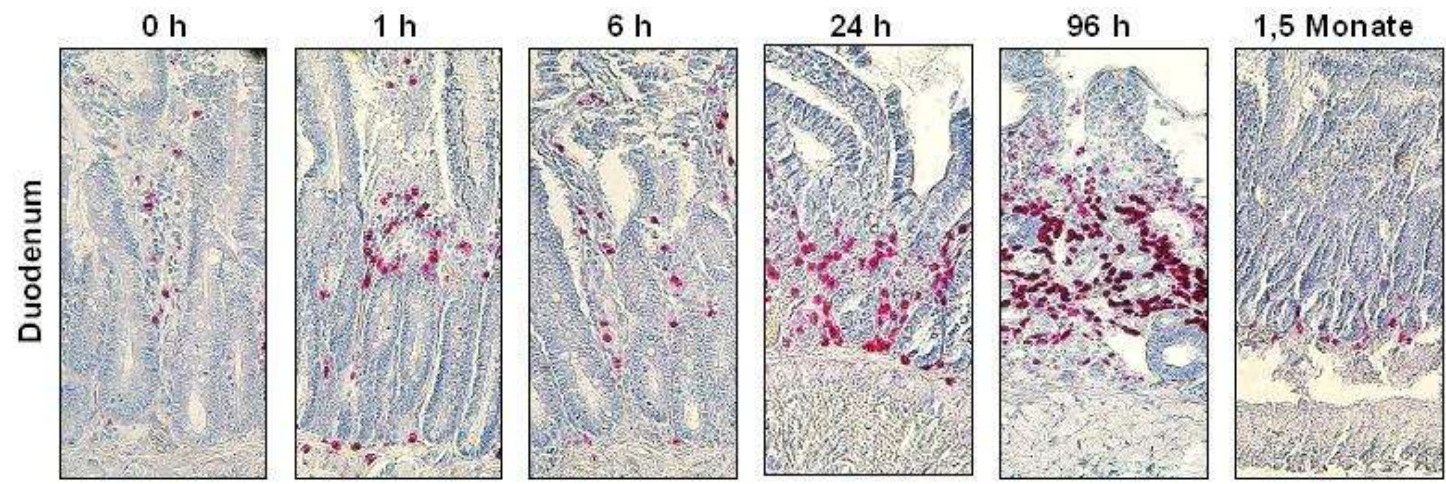

3 Monate
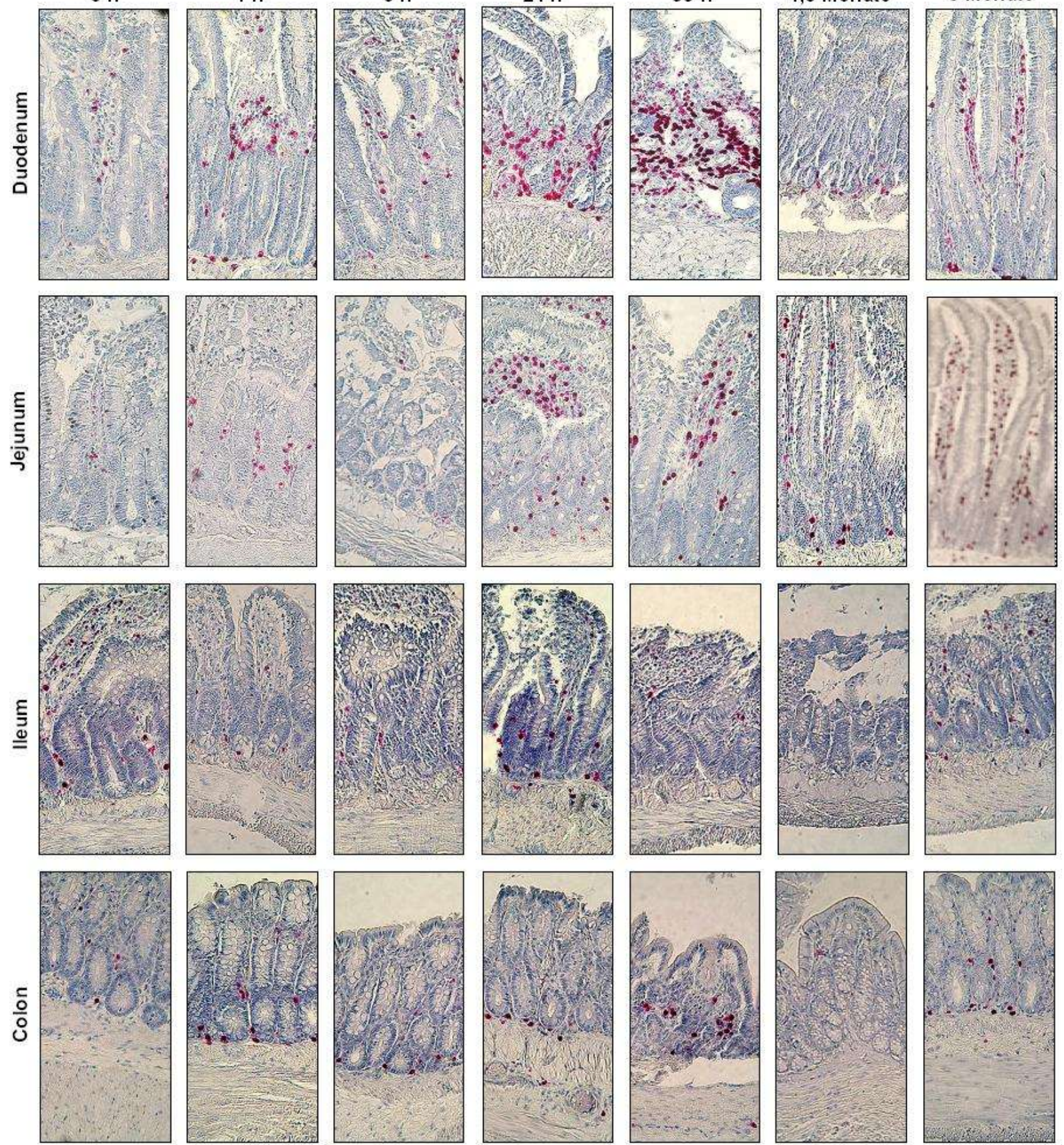

Abb. 13

CD34-Färbung (100-fache Vergrößerung)

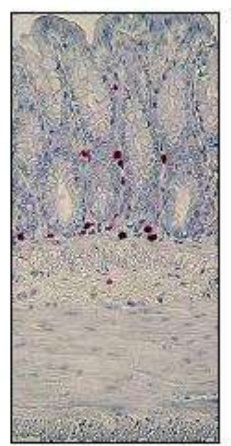




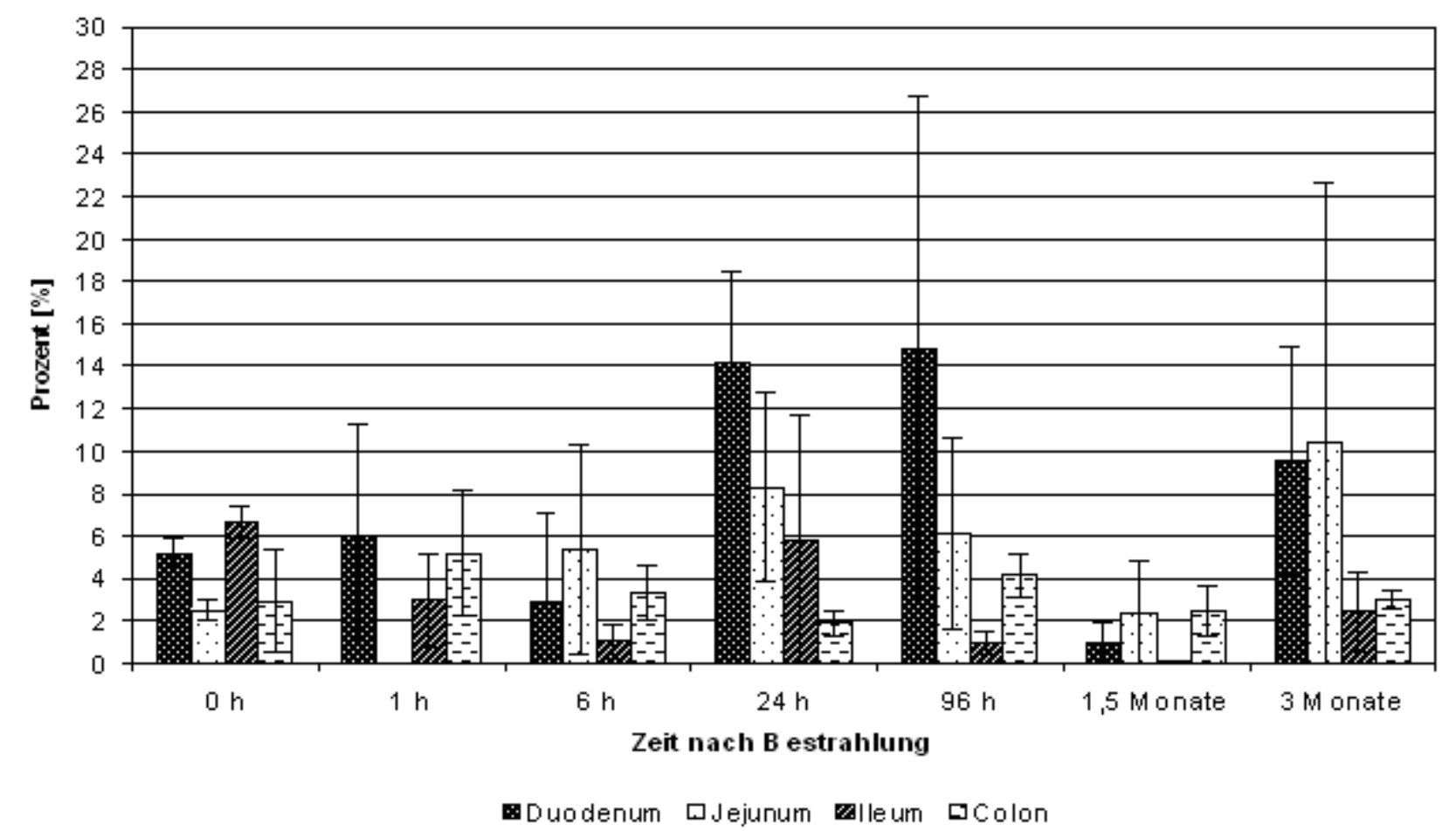

Abb. 14 Prozentzahl der CD34-positiven Zellen bezogen auf alle Zellen des Gewebeausschnittes (1,3 $\left.\mathrm{mm}^{2}\right)$ dargestellt mit Standardabweichung

\subsubsection{Caspase-3-Färbung}

Zur histologischen Sicherung der Apoptose wurde die Caspase-3-Färbung durchgeführt. Dies ermöglicht es einen Vergleich zwischen histologischen Veränderungen und denjenigen zu schaffen, die beim Western Blot mit dem Antikörper Caspase 3 untersucht worden sind. Wie auch bei der CD3- bzw. der CD34-Färbung wurde die Caspase-3-Färbung mit Hämatoxylin gegengefärbt. Dies lässt die prozentuale Berechnung der Caspase-3-positiven Zellen gegenüber allen angefärbten Zellen des Gewebes zu (siehe Abb. 16). In der Caspase-3-Färbung des Duodenums erscheinen bei $1 \mathrm{~h}, 6 \mathrm{~h}$ und $96 \mathrm{~h}$ besonders im mittleren Teil der Zotten, sowie vereinzelt an der Zottenbasis Caspase-3-positive Zellen (siehe Abb. 15 und Abb. 16). Im Jejunum lassen sich zu dem 1 hZeitpunkt vermehrt Caspase-3-positive Zellen entlang der gesamten Zotte nachweisen. Zum 6 hZeitpunkt kommt es zu einem Rückgang der Caspase-3-positiven Zellen. Erst ab 1,5 Monaten wird ein erneutes Peak bis einschließlich 3 Monate sichtbar. Das Ileum präsentiert bei $1 \mathrm{~h}$ und $6 \mathrm{~h} \mathrm{im}$ oberen Bereich der Zotten positive Zellen. Bei $24 \mathrm{~h}$ bis 1,5 Monate erscheint das Gewebe makroskopisch mit auffällig denudierten Zotten, wie es auch schon in der H.E.-Färbung beschrieben worden ist. Die Epithelschicht ist zu diesen Zeitpunkten fast vollständig zerstört, es treten lediglich vereinzelt Caspase-3-positive Zellen im Stroma auf. Im Ileum tritt der 3Monatszeitpunkt besonders hervor, hier finden sich Caspase-3-positive Zellen an der Basis der 
Krypten, während die Zotten zu Grunde gegangen sind (Abb. 15 und Abb. 16). Im Colon präsentieren sich Caspase-3-positive Zellen bei 1 h, 96 h und 3 Monaten an der Basis der Krypten.
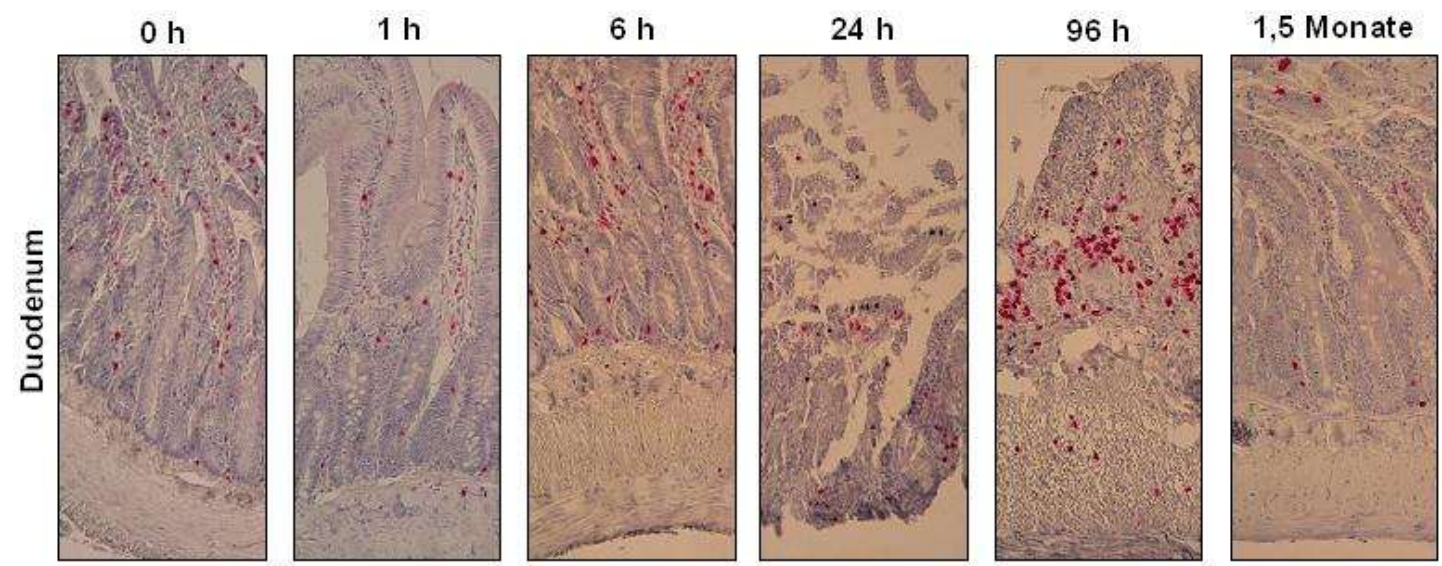

3 Monate
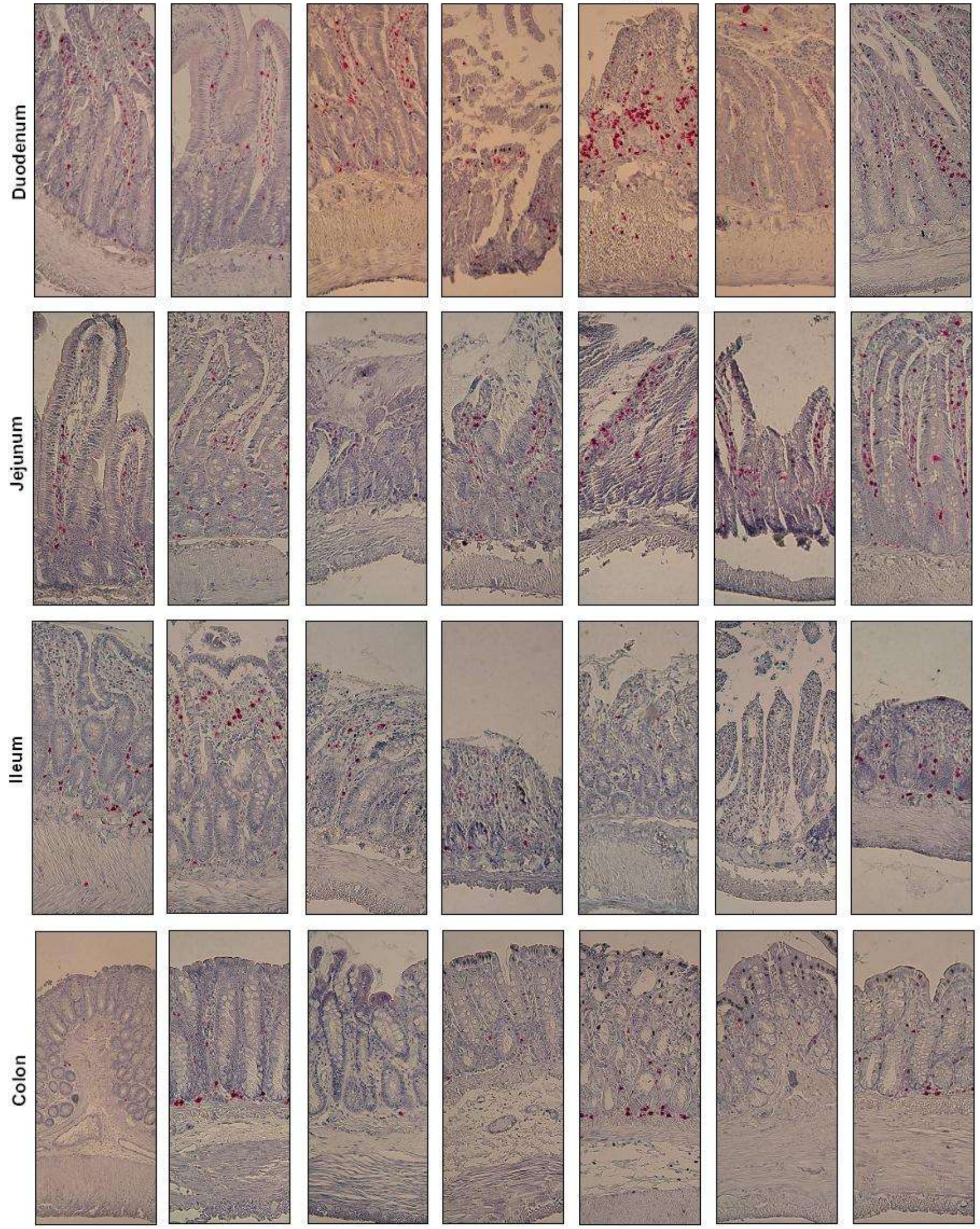

Abb. 15

Caspase-3-Färbung (100-fache Vergrößerung)

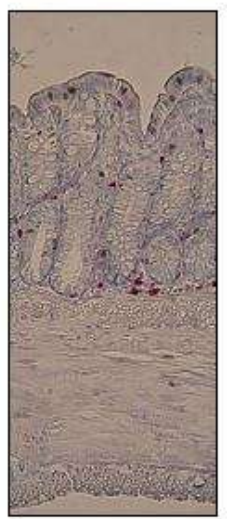




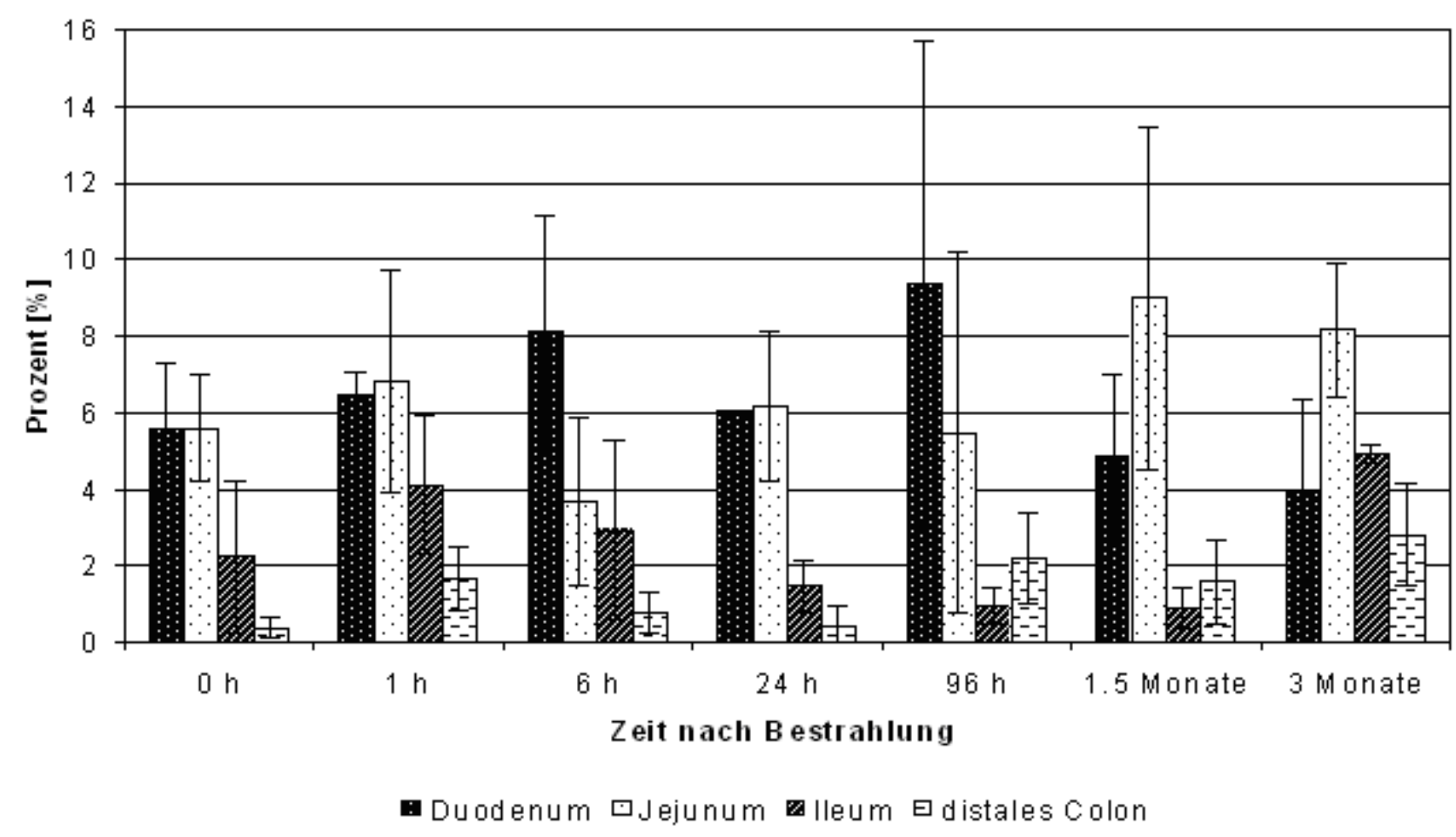

Abb. 16 Prozentzahl der Caspase-3-positiven Zellen bezogen auf alle Zellen des Gewebeausschnittes (1,3 $\left.\mathrm{mm}^{2}\right)$ dargestellt mit Standardabweichung

Für die Caspase-3-Färbung lässt sich zusammenfassend sagen, dass sich insgesamt ubiquitär im Gewebe entlang der Krypten-Zotten-Achse Caspase-3-positive Zellen zeigen. Dadurch, dass das Gewebe des Ileums stark zerstört erscheint, sind hier verhältnismäßig wenig Caspase-3-positive Zellen nachweisbar. Hervorzuheben ist das Auftreten von Caspase-3-positiven Zellen an der Basis der Krypten nach 3 Monaten im Ileum.

\subsubsection{TUNEL-Färbung}

Zur Darstellung von apoptotischen Zellen im Gewebe wurde die TUNEL-Färbung durchgeführt. Diese Färbung sollte dazu dienen, die Lokalisation der apoptotischen Zellen in den einzelnen Gewebeabschnitten zu detektieren. Exemplarisch für die TUNEL-Färbung sind in Abb. 17 a-c Schnitte vom Duodenum, Jejunum und Colon eine Stunde nach Einzeitbestrahlung der Leber vergleichend abgebildet. Bei den Ergebnissen der TUNEL-Färbung ist besonders zu berücksichtigen, dass das Duodenum und das Jejunum im direkten Bestrahlungsfeld liegen, während das Colon nur von indirekter Strahlung betroffen ist. Im Duodenum (Abb. 17 a) sind apoptotische Zellen besonders an der Basis der Krypten und im unteren Drittel der Zotten sichtbar. Dies bestätigt sich auch für das Jejunum. Auch hier ist Apoptose im unteren Teil der Zotten nachweisbar (Abb. 17 b). Das außerhalb des Bestrahlungsfeldes liegende Colon zeigt entlang der Krypten-Zotten-Achse keine apoptotischen Zellen. Hier präsentieren sich die apoptotischen Zellen lediglich an der Spitze der Zotten, wie in Abb. 17 c zu sehen ist. 

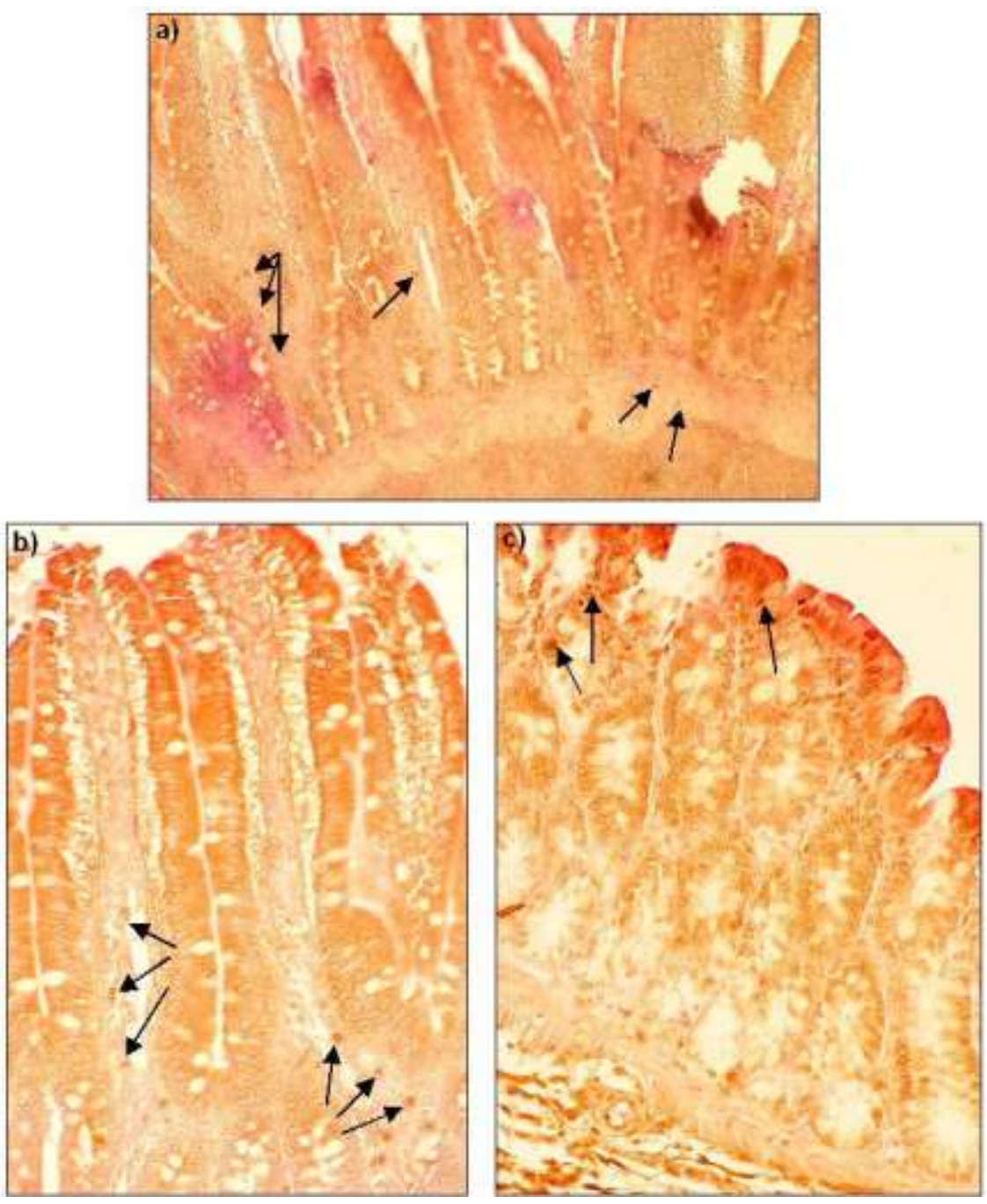

Abb. 17

\section{TUNEL-Färbung}

a) Duodenum (100-fache Vergrößerung) b) Jejunum (200-fache Vergrößerung) und c) Colon (200-fache Vergrößerung) jeweils $1 \mathrm{~h}$ nach Bestrahlung. Die Pfeile markieren die apoptotischen Zellen.

\subsection{Ergebnisse der RNA-Analyse}

In der RT-PCR wurde die Expression der mRNA von pro- und antiinflammatorischen Zytokinen, Akute-Phase-Faktoren, pro- und antiapoptotischen Proteinen, Oberflächenmarkern und Adhäsionsmolekülen quantifiziert. Hierfür wurden eine Reihe von Primern verwendet, die in Tabelle 13 im Anhang aufgelistet sind. Die Ergebnisse der PCR-Daten wurden auf $\beta$-Aktin (als House-keeping Gen) normiert. Zusammenfassend sind die Ergebnisse als ,fold changes" in Tabelle 5 dargestellt. Mit ,fold change" wird dabei das Verhältnis der Genexpression in Bezug auf das Grundniveau (Kontrolle) bezeichnet. 


\subsubsection{Proinflammatorische Zytokine}

TNF- $\alpha$, IL-1 $\beta$, IL-6 und IL-8 sind akute-Phase-Zytokine bzw. proinflammatorische Zytokine, die z.B. von aktivierten Makrophagen, Endothelzellen und Keratinozyten ausgeschüttet werden (Von Bültzingslöwen et al. 2006).

TNF- $\alpha$ verstärkt die Phagozytose und die Zytotoxizität in neutrophilen Granulozyten und moduliert die Expression von anderen Zytokinen wie IL-1 $\beta$ und IL-6 (Rübe et al. 2004). Für TNF- $\alpha$ ist im Organabschnitt Duodenum ein Anstieg direkt $1 \mathrm{~h}$ nach Bestrahlung nachweisbar, welcher signifikant bis 1,5 Monate erhöht bleibt. Im Jejunum fällt auch ein direkter Anstieg nach $1 \mathrm{~h}$ auf. Das Ileum zeigt lediglich zum 24 h-Wert eine Erhöhung um das 1,8-Fache im Verhältnis zur Ausgangsexpression. Die übrigen Zeitpunkte präsentieren ebenfalls einen Anstieg der TNF- $\alpha$ Expression im Ileum, jedoch kann auf Grund der hohen Standardabweichungen keine Signifikanz erreicht werden. Für das Colon lässt sich nach $1 \mathrm{~h}$ und $6 \mathrm{~h}$ ein signifikanter Abfall für TNF- $\alpha$ verzeichnen.

IL-1及 spielt eine Rolle in der Induktion von Endothelzelladhäsionsmolekülen und stimuliert die Produktion von Chemokinen in den Endothelzellen und Makrophagen (Liu W. et al. 2006). In unseren Proben können wir einen signifikanten 3-fachen Anstieg von IL-1 $\beta$ im Duodenum nach $1 \mathrm{~h}$ nachweisen. Das Jejunum fällt durch eine signifikante Herunterregulation ab $1 \mathrm{~h}$ bis einschließlich 3 Monaten nach Bestrahlung auf. Für das Ileum zeigt sich tendenziell auch ein Abfall im zeitlichen Verlauf bis 3 Monate, jedoch lassen sich keine signifikanten Werte verzeichnen. Im Colon kommt es nach $1 \mathrm{~h}$ und $6 \mathrm{~h}$ zu einer signifikanten Reduktion der IL-1 $\beta$-Expression.

IL-6 ist ein proinflammatorisch-wirksames Zytokin, welches ebenfalls von Makrophagen, Endothelzellen und Fibroblasten aktiviert durch IL-1und TNF- $\alpha$ synthetisiert wird (Indaram et al. 2000). Für IL-6 können wir zeigen, dass es im Ileum zu einer signifikanten Reduktion von IL-6 zum 1 h-Zeitpunkt kommt. Zum 96 h-Zeitpunkt des Colons findet sich ein signifikanter fast 2-fach erhöhter Anstieg im Verhältnis zu den Kontrollen.

IL-8 beziehungsweise CINC spielt eine herausragende Rolle bei der Induktion einer Infiltration von neutrophilen Granulozyten und somit bei akuten Entzündungsreaktionen (Harada et al. 1994; Linard et al. 2004). IL-8 zeigt eine frühe Zunahme der Expression in den proximalen Darmabschnitten. Das Jejunum erreicht dabei eine Signifikanz bei 24 h nach Bestrahlung. Nach $96 \mathrm{~h}$ kommt es jedoch hier wieder zu einem Rückgang. Das Ileum präsentiert keine signifikanten Werte. Im Colon ist der Zeitpunkt 1,5 Monate mit einer 2-fachen Erhöhung in Bezug zum Ausgangswert signifikant. 


\subsubsection{IP-10: Das etwas andere Zytokin}

Human interferon-inducible Protein 10 (IP-10) unterscheidet sich von den übrigen Zytokinen in seiner alleinigen Spezifität für aktivierte T-Lymphozyten (Gangur et al. 1998). IP-10 zeigt in den Kontrollen den höchsten Wert für das Ileum. Eine Stunde nach Radiatio kann ein signifikanter Anstieg für das Duodenum, Jejunum und Colon beschrieben werden. $6 \mathrm{~h}$ nach Bestrahlung imponiert besonders das Duodenum mit 23-fach höheren Werten im Vergleich zu den Kontrollen. Auch beim Jejunum ist eine signifikante Hochregulation (7-fach) nach $6 \mathrm{~h} \mathrm{zu}$ beobachten. Bei $24 \mathrm{~h}$ präsentieren sich das Duodenum und Jejunum weiterhin signifikant, jedoch mit fallenden Werten. Im Jejunum kommt es zum 1,5 Monatszeitpunkt nochmals zu einem signifikanten Anstieg von IP-10. Das Ileum zeigt keine eindeutig signifikanten Veränderungen in der IP-10-Expression. Hier ist nur bei 96 h eine geringfügige Abnahme der Expression als signifikant zu verzeichnen. Im Colon kommt es nach $1 \mathrm{~h} \mathrm{zu}$ einem 3,3-fachen Anstieg. Auch nach 96 h ist ein 2-facher Anstieg zu registrieren.

\subsubsection{Fibrosierung im Darm initiiert durch TGF- $\beta$}

TGF- $\boldsymbol{\beta}$ ist ein ubiquitäres multifunktionales Zytokin, welches insbesondere von aktivierten TZellen produziert wird. Seine Aufgabe ist es, die Proliferation und Differenzierung von T-Zellen und die Aktivierung von Makrophagen $\mathrm{zu}$ inhibieren. Außerdem wirkt es den Effekten proinflammatorischer Zytokine entgegen (Zheng et al. 2000). TGF- $\beta$ induziert wesentlich die Fibrosierung des Darmgewebes als Folge von abdomineller Bestrahlung (Haydont et al. 2007). In der PCR kann eine signifikante Hochregulation von TGF- $\beta 1 \mathrm{~h}$ nach Bestrahlung der Leber im Duodenum gezeigt werden. Im Verlauf münden die Werte von TGF- $\beta$ in den Darmabschnitten Duodenum und Jejunum zum 1,5 Monats- und 3 Monatszeitpunkt in einer signifikanten Herunterregulation. Das Ileum präsentiert sich direkt $1 \mathrm{~h}$ nach Bestrahlung mit einem signifikanten Abfall. Dieser bestätigt sich auch zum 96 h-Zeitpunkt. Für das Colon findet sich eine signifikante Herunterregulationen zu den frühen Zeitpunkten $1 \mathrm{~h}$ und $6 \mathrm{~h}$.

\subsubsection{Die Expression von Chemokinen und Adhäsionsmolekülen}

Monocyte chemotactic protein-1 (MCP-1) beziehungsweise auch Chemokine (C-C motif) ligand-2 (CCL-2) genannt aktiviert Monozyten und Makrophagen im Gewebe und ist an deren Transmigration beteiligt (Gremy et al. 2008). MCP-1 ist signifikant induziert nach $1 \mathrm{~h}$ im Duodenum und nach 1 h, 6 h, 24 h, 96 h und nach 1,5 Monaten im Jejunum. Im Ileum und Colon sind keine signifikanten Veränderungen festzuhalten. 
Das Chemokine Macrophage inflammatory protein-1 $\alpha$ (MIP-1 $\alpha$ ) beziehungsweise CLL-3 wird von Makrophagen und T-Lymphozyten ausgeschüttet und besitzt eine Reihe von proinflammatorischen Aktivitäten zu denen auch die Chemotaxis von Leukozyten gezählt wird (Cook 1996). Die Expression von MIP-1 $\alpha$ veranschaulicht in der PCR, dass es zu einem Anstieg $1 \mathrm{~h}$ nach Bestrahlung im Duodenum und Jejunum kommt. Beim 6 h-Wert des Duodenums ist weiterhin eine erhöhte Expression von MIP-1 $\alpha$ nachweislich. Im Jejunum finden sich im Verlauf nach 1,5 Monaten und 3 Monaten erneut deutlich signifikante Hochregulationen. Für das Ileum ist zu erwähnen, dass bei $96 \mathrm{~h}$ ein signifikanter Abfall von MIP-1 $\alpha$ auffällt. Das Colon zeigt bei 1,5 Monaten eine Hochregulation der MIP-1 $\alpha$-Expression.

MIP-3a, auch LARC, Exsodus-1 oder CLL-20 genannt, wird in Mukosa-assoziiertem lymphatischen Gewebe (MALT), Lymphknoten beziehungsweise in B- und T-Lymphozyten, eosinophilen Granulozyten, aber auch im normalen Colongewebe gebildet. MIP-3 $\alpha$ spielt sowohl bei der Migration von Gedächtniszellen (B-Lymphozyten) und unreifen dendritischen Zellen, als auch bei der Differenzierung von Monozyten zu Makrophagen im Rahmen von entzündlichen Ereignissen eine Rolle (Arango et al. 2000; Ghadjar et al. 2009; Williams 2006). In der PCR kann eine signifikante Hochregulation von MIP-3 $\alpha 1 \mathrm{~h}$ nach Bestrahlung im Duodenum (2,1-fach) und Jejunum (6,5-fach) festgestellt werden. Bei 96 h lässt sich ein signifikanter Abfall für diese Darmabschnitte verzeichnen. Die übrigen Darmabschnitte verhalten sich unauffällig in Bezug auf die MIP-3 $\alpha$-Expression.

PECAM-1 (Platelet-endothelial cell adhesion molecule-1), auch CD31 genannt, ist ein $130 \mathrm{kDa}$ großes Immunglobulin, welches an der Oberfläche von Epithelzellen, Thrombozyten, Monozyten, neutrophilen Granulozyten und selektiven T-Zellen präsentiert wird (Newman 1997). Mit Hilfe der PCR kann nachgewiesen werden, dass es zu einem signifikanten Anstieg von PECAM-1 im Jejunum $1 \mathrm{~h}$ und 1,5 Monate nach Bestrahlung kommt. Das Duodenum reagiert erst $96 \mathrm{~h}$ nach Bestrahlung mit einem knapp 3-fachen Anstieg. Im Ileum zeigt sich eine Reduktion der Expression nach 96 h. Das Colon reagiert nach 1 h und 6 h mit einem Abfall, während es nach 1,5 Monaten zu einem Anstieg der PECAM-1-Expression kommt.

ICAM-1 (Inter-cellular adhesion molecule-1), ebenso CD54 genannt, ist ein Endothelial- und Leukozyten-assoziiertes Transmembranprotein, welches eine besondere Bedeutung in der Stabilisierung von Zell-Zell-Interaktionen und der Migration von Leukozyten durch Endothelzellwände hat (Yang L. et al. 2005).

Für ICAM-1 kann gezeigt werden, dass es im Duodenum zu einem kontinuierlichen Anstieg der Expression bis 96 h kommt. Dabei ist der 1 h- und 96 h-Wert signifikant. Im Jejunum ist zu den Zeitpunkten 1 h, 6 h, 24 h und 1,5 Monate eine signifikante Hochregulation von ICAM-1 deutlich. 
Das Ileum und Colon zeigen keine wegweisenden Veränderungen in der ICAM-1-Expression nach Bestrahlung der Leber. Für das Colon fällt lediglich ein dezenter Abfall zum 1 h-Zeitpunkt auf.

MAdCAM-1 (Mucosal addressin cell adhesion molecule-1) wird selektiv von den Endothelzellen der intestinalen Mukosa und dem Darm-assoziierten lymphatischen Gewebe (engl. GALT= gutassociated lymphoid tissue) synthetisiert (Arihiro et al. 2002). In unserem Modell sticht die Expression von MAdCAM-1 im Ileum besonders hervor. Hier kommt es zu einem hoch signifikanten Anstieg von MAdCAM-1 nach 6 h. Dieser Anstieg hält bis 96 h nach Bestrahlung an, allerdings sind die Werte im Verlauf rückläufig. Bei $24 \mathrm{~h}$ zeigt sich im Duodenum und Jejunum ein signifikanter Abfall von MAdCAM-1, der für das Jejunum auch noch bei $96 \mathrm{~h}$ besteht.

Thy-1 (Thymocyte differentiation antigen-1)oder CD90 ist ein Adhäsionsmolekül, welches u.a. an der Aktivierung und Induktion von T-Zellen, Tumorsuppression, Apoptose, Wundheilung und Fibrose beteiligt ist (Rege und Hagood 2006 b). In der PCR können wir aufzeigen, dass es in den Kontrollproben bei $0 \mathrm{~h}$ zu der höchsten Expression von Thy-1 im Ileum und zu der geringsten Expression von Thy-1 im Jejunum kommt. Nach Bestrahlung der Leber zeigt sich ein signifikanter Anstieg der Thy-1-Expression im Duodenum nach $1 \mathrm{~h}$ und $96 \mathrm{~h}$. Im Jejunum lässt sich eine signifikante leichte Hochregulation 24 h, 1,5 Monate und 3 Monate nach Bestrahlung dokumentieren. Das Ileum fällt nur durch einen geringfügigen Abfall nach 96 h auf, während es im Colon zu den Zeitpunkten 1 h, 6 h, 96 h und 3 Monate zu einer Herunterregulation kommt.

\subsubsection{Die Expression von pro- und antiapoptotischen Faktoren}

In der PCR von dem proapoptotischen Bax lassen sich für alle Organabschnitte signifikante Werte erheben. Bezeichnend ist der zweigipfelige Verlauf des Ileums. Im Duodenum und Jejunum zeigen sich durchweg signifikante Hochregulationen von Bax bis einschließlich 3 Monate nach Bestrahlung. Im Colon sieht man nach 96 h und 1,5 Monaten einen geringfügigen signifikanten Anstieg.

Für das antiapoptotisch wirksame Bcl-2 fällt auf, dass es $1 \mathrm{~h}$ nach Bestrahlung im Duodenum und Jejunum zu einer signifikanten Hochregulation kommt. Beim Ileum präsentiert sich nur der 1,5 Monatswert als signifikant erhöht. Für das Colon ist festzuhalten, dass es nach $1 \mathrm{~h}$ und $6 \mathrm{~h} \mathrm{zu}$ einem deutlichen Abfall der Bcl-2-Expression kommt.

HSP-27 agiert als molekulares Chaperon in diversen Prozessen einer Zelle z.B. Inhibierung von Apoptose, Zelldifferenzierung und Thermoregulation (Sarto et al. 2000). In der PCR kann insbesondere im Ileum eine Hochregulation von HSP-27 nach 1 h, 24 h, 96 h und 3 Monaten nachgewiesen werden. Bei $24 \mathrm{~h}$ sind auch die Transkripte dieses Gens im Duodenum und Jejunum erhöht. Außerdem kommt es im Jejunum bei den späten Zeitpunkten 1,5 Monate und 3 Monate zu 
signifikanten Anstiegen der HSP-27-Expressionen. Für das Colon fällt ein Abfall nach 6 h, 96 h, 1,5 Monaten und 3 Monaten auf.

Interferon gamma (IFN- $\gamma$ ) wird von aktivierten Makrophagen und T-Zellen ausgeschüttet. $\mathrm{Zu}$ seiner Funktion wird u.a. die Induzierung von Apoptose gezählt (Kliem et al. 2009). Für IFN- $\gamma$ kann im Ileum eine signifikante Herunterregulation $1 \mathrm{~h}, 96 \mathrm{~h}$ und 1,5 Monate nach Bestrahlung beobachtet werden. $\mathrm{Zu}$ beachten sind hierbei allerdings große Standardabweichungen und die nicht aussagekräftigen Ergebnisse der Darmabschnitte Duodenum, Jejunum und Colon.

\subsubsection{Die Expression von Entzündungsmediatoren und Immunzellen}

ED1 ist ein Marker für CD68-positive Makrophagen (Doussis et al. 1993). Bei unbestrahlten Kontrolltieren lässt sich im Ileum die höchste Expression von ED1 zeigen. Im Duodenum kommt es zu einer Hochregulation der Expression von ED1 bis 96 h, allerdings ist hierbei nur der $1 \mathrm{~h}-$ Wert signifikant. Im Jejunum kommt es zu einer signifikanten Reduktion von ED1 nach 3 Monaten. Ein Abfall kann im Ileum nach $24 \mathrm{~h}$ und 96 h beschrieben werden. Im Colon ist zum 6 h-Zeitpunkt ebenfalls ein Abfall zu verzeichnen.

ED2 beziehungweise CD163 eignet sich als Marker zum Nachweis von gewebeständigen Makrophagen (Hori et al. 2008). Die Ergebnisse von ED2 zeigen enorm große Standardabweichungen. Dabei wird nur das Duodenum eindeutig nach $6 \mathrm{~h}$ und das Jejunum nach 1,5 Monaten mit einem signifikanten Anstieg abgebildet.

COX-2 ist für die Synthese von Prostaglandinen zuständig. Es ist beteiligt an der inflammatorischen Signalkaskade, die zu Ödemen und Gewebeschädigung nach Bestrahlung führt (Yeoh et al. 2007). In unserem Modell kann eine signifikante Hochregulation von COX-2 für das Duodenum $1 \mathrm{~h}$ nach Bestrahlung gezeigt werden. Der 96 h-Zeitpunkt präsentiert einen Abfall der Expression um das 0,3-Fache. Bei 1 h, 6 h, 24 h, 1,5 Monaten und 3 Monaten kann ein Anstieg für das Jejunum nachgewiesen werden. Im Ileum kommt es $\mathrm{zu}$ den späten Zeitpunkten $96 \mathrm{~h}$ und 3 Monaten zu einer leichten Hochregulation. Im Colon findet sich 1,5 Monate nach Bestrahlung ein leichter Abfall der COX-2-Expression.

\subsubsection{Die Angiogenese beeinflussenden Faktoren: VEGF, VEGF-R und SMA}

VEGF (Vascular endothelial growth factor) induziert Adhäsionsmoleküle auf Endothelzellen im Rahmen von Entzündungsprozessen (Kim et al. 2001). Außerdem zeichnet sich VEGF durch Regulation und Induktion von normaler und pathologischer Angiogenese aus (Ferrara 2001). In der PCR kann demonstriert werden, dass es zu einem signifikanten Anstieg von VEGF im Duodenum 
$1 \mathrm{~h}, 6 \mathrm{~h}$ und $96 \mathrm{~h}$ nach Bestrahlung kommt. Eine reduzierte Expression ist im Jejunum nach 3 Monaten zu sehen.

Für VEGF-R-1 zeigt die PCR zunächst einen signifikanten Abfall von VEGF-R-1 im Duodenum nach 6 h und im Verlauf einen Anstieg bei 96 h. Ein Abfall der Expression kann auch im Jejunum nach $1 \mathrm{~h}$ und $24 \mathrm{~h}$ und im Ileum nach $6 \mathrm{~h}$ verzeichnet werden. Bei $96 \mathrm{~h}$ und 3 Monaten kommt es im Ileum wieder zu einem signifikanten Anstieg. Das Colon zeigt als Bestrahlungsreaktion eindeutige Hochregulationen ab $24 \mathrm{~h}$ bis einschließlich 3 Monate.

SMA (Smooth muscle actin) ist ein bewährter Marker zur Identifizierung von Gefäßmuskelzellen (Chaponnier und Gabbiani 2004). SMA-Transkripte sind signifikant induziert im Duodenum $1 \mathrm{~h}$ nach Bestrahlung und erreichen ansteigende Werte bis einschließlich 96 h. Auch im Jejunum und Ileum ist eine Hochregulation von SMA beim 1 h-Wert zu sehen. Bei 24 h, 1,5 Monaten und 3 Monaten bleibt SMA im Jejunum signifikant hochreguliert. Im Ileum ist eine Hochregulation nach 96 h und 3 Monaten zu beobachten, während für das Colon zu den Zeitpunkten 96 h und 1,5 Monaten eine Herunterregulation beschrieben werden kann. 
Tabelle 5 Fold changes

\begin{tabular}{|c|c|c|c|c|c|c|c|c|c|c|c|c|c|c|c|c|c|c|c|c|c|c|c|c|}
\hline Organ & Zeitpunkt & 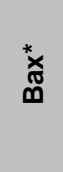 & 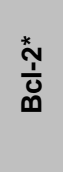 & $\begin{array}{l}\stackrel{*}{*} \\
\text { শั } \\
\text { O }\end{array}$ & 荌 & ثั้ & $\begin{array}{l}\stackrel{*}{*} \\
\stackrel{1}{1} \\
\stackrel{5}{1} \\
\text { T }\end{array}$ & 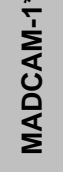 & $\begin{array}{l}\frac{*}{1} \\
\frac{1}{\delta} \\
\Sigma\end{array}$ & $\begin{array}{l}\frac{*}{0} \\
\frac{1}{\bar{\Sigma}} \\
\frac{1}{\Sigma}\end{array}$ & 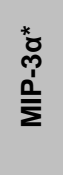 & 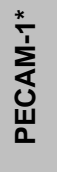 & $\sum_{\omega}^{*}$ & 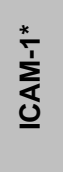 & $\begin{array}{l}\stackrel{*}{0} \\
\stackrel{0}{\underline{n}} \\
=\end{array}$ & $\stackrel{\text { بٌ }}{\stackrel{*}{=}}$ & $\stackrel{\text { ֻ }}{\stackrel{*}{=}}$ & $\begin{array}{l}\stackrel{*}{\vec{\lambda}} \\
\stackrel{\mathbf{u}}{\underline{z}}\end{array}$ & $\stackrel{*}{\stackrel{*}{\prime}}$ & 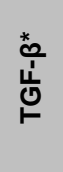 & 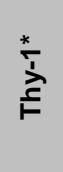 & $\begin{array}{l}\text { 苂 } \\
\text { ì } \\
\text { Ż }\end{array}$ & $\begin{array}{l}\text { 岕 } \\
\stackrel{\text { }}{>}\end{array}$ & 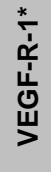 \\
\hline 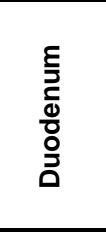 & $\begin{array}{l}1 \mathrm{~h} \\
6 \mathrm{~h} \\
24 \mathrm{~h} \\
96 \mathrm{~h} \\
1,5 \text { Monate } \\
3 \text { Monate } \\
\end{array}$ & $\begin{array}{l}1,6 \\
2,2 \\
2,3 \\
1,3 \\
1,4 \\
1,3 \\
\end{array}$ & 1,8 & 1,9 & 1,5 & 5,4 & 2,6 & 0,5 & 3,1 & $\begin{array}{l}4,8 \\
3,0\end{array}$ & $\begin{array}{l}2,1 \\
0,3\end{array}$ & 2,9 & $\begin{array}{l}1,8 \\
2,2 \\
2,5 \\
4,3\end{array}$ & $\begin{array}{l}1,5 \\
4,6\end{array}$ & $\begin{array}{l}2,6 \\
\\
0,3 \\
0,3 \\
\end{array}$ & & & & $\begin{array}{c}7,0 \\
23,0 \\
5,0\end{array}$ & $\begin{array}{l}1,3 \\
\\
0,7 \\
0,5 \\
\end{array}$ & $\begin{array}{l}1,7 \\
3,6\end{array}$ & $\begin{array}{l}4,2 \\
2,7 \\
2,4 \\
2,3 \\
3,5\end{array}$ & $\begin{array}{l}2,9 \\
2,7 \\
\\
3,8\end{array}$ & $\begin{array}{l}0,7 \\
2,5\end{array}$ \\
\hline 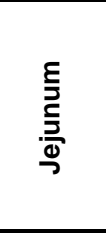 & $\begin{array}{l}1 \mathrm{~h} \\
6 \mathrm{~h} \\
24 \mathrm{~h} \\
96 \mathrm{~h} \\
1,5 \text { Monate } \\
3 \text { Monate } \\
\end{array}$ & $\begin{array}{l}1,8 \\
2,4 \\
2,2 \\
1,4 \\
1,7 \\
1,6 \\
\end{array}$ & 1,7 & $\begin{array}{l}2,1 \\
2,0 \\
2,0 \\
\\
3,3 \\
1,9 \\
\end{array}$ & 0,6 & 3,0 & $\begin{array}{l}3,0 \\
1,7 \\
2,9 \\
\end{array}$ & $\begin{array}{l}0,7 \\
0,5\end{array}$ & $\begin{array}{l}4,0 \\
2,6 \\
2,1 \\
1,8 \\
2,8\end{array}$ & $\begin{array}{r} \\
2,5 \\
2,0 \\
\end{array}$ & 0,4 & 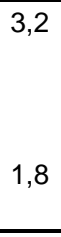 & $\begin{array}{l}2,5 \\
3,4 \\
2,1 \\
3,3 \\
\end{array}$ & $\begin{array}{l}5,1 \\
3,2 \\
1,8 \\
\\
2,7\end{array}$ & $\begin{array}{l}0,6 \\
0,4 \\
0,5 \\
0,5 \\
0,4 \\
0,3 \\
\end{array}$ & & $\begin{array}{l}2,2 \\
0,6\end{array}$ & & $\begin{array}{l}1,8 \\
6,8 \\
4,2 \\
\\
3,2\end{array}$ & 0,5 & $\begin{array}{l}2,3 \\
2,0 \\
2,4 \\
\end{array}$ & 1,9 & 0,6 & $\begin{array}{l}0,5 \\
0,6\end{array}$ \\
\hline$\stackrel{\underline{\xi}}{\underline{\Xi}}$ & $\begin{array}{l}1 \mathrm{~h} \\
6 \mathrm{~h} \\
24 \mathrm{~h} \\
96 \mathrm{~h} \\
1,5 \text { Monate } \\
3 \text { Monate } \\
\end{array}$ & $\begin{array}{r}1,4 \\
1,8 \\
1,7 \\
1,5 \\
\end{array}$ & 2,1 & $\begin{array}{r}2,3 \\
1,9 \\
\end{array}$ & $\begin{array}{l}0,4 \\
0,4\end{array}$ & & $\begin{array}{l}2,0 \\
\\
2,6 \\
1,6 \\
\\
1,6 \\
\end{array}$ & $\begin{array}{l}7,4 \\
5,3 \\
1,6\end{array}$ & & 0,3 & & 0,6 & $\begin{array}{l}2,6 \\
2,5 \\
\end{array}$ & & & 0,3 & & $\begin{array}{l}0,4 \\
\\
0,4 \\
0,2\end{array}$ & 0,6 & 0,7 & 0,6 & 1,8 & & $\begin{array}{r}0,5 \\
2,4 \\
2,5 \\
\end{array}$ \\
\hline 흥 & $\begin{array}{l}1 \mathrm{~h} \\
6 \mathrm{~h} \\
24 \mathrm{~h} \\
96 \mathrm{~h} \\
1,5 \text { Monate } \\
3 \text { Monate } \\
\end{array}$ & $\begin{array}{l}1,7 \\
1,4\end{array}$ & $\begin{array}{l}0,4 \\
0,4\end{array}$ & 0,6 & 0,5 & & $\begin{array}{l}0,5 \\
0,6 \\
0,5 \\
0,6 \\
\end{array}$ & & 0,7 & 4,4 & & $\begin{array}{l}0,6 \\
0,6\end{array}$ & $\begin{array}{l}0,6 \\
0,6\end{array}$ & 0,4 & $\begin{array}{l}0,2 \\
0,4\end{array}$ & 1,7 & 2,1 & & $\begin{array}{l}3,3 \\
2,0\end{array}$ & $\begin{array}{l}0,4 \\
0,5\end{array}$ & $\begin{array}{l}0,7 \\
0,6 \\
0,6 \\
0,6 \\
\end{array}$ & & & $\begin{array}{l}1,8 \\
2,2 \\
2,0 \\
1,4 \\
\end{array}$ \\
\hline
\end{tabular}

* fold change: Expression des untersuchten Gens im Verhältnis zum Grundniveau ( 0 h-Kontrolle) Die leeren Kästchen signalisieren, dass hier keine signifikanten Werte erreicht wurden 


\subsection{Ergebnisse der Western Blots}

Die Auswertung des Western Blots erfolgt semiquantitativ. Apoptotische Prozesse werden mit Hilfe der Antikörper Caspase 8, Caspase 3, Bax und Bcl-2 untersucht und im Vergleich zu dem House keeping Gen $\beta$-Aktin dargestellt.

\subsection{1 $\quad \beta$-Aktin, das House-keeping Gen}

Im Western Blot wurde $\beta$-Aktin als House-keeping Gen verwendet, da sich die Proteinexpression von $\beta$-Aktin nach Bestrahlung nicht ändert. Wie in Abb. 18 exemplarisch gezeigt wird, ist zu allen Zeitpunkten eine Bande bei $46 \mathrm{kDa}$ abgebildet. Außerdem sind die Proteinmengen und entsprechend die Dicke der jeweiligen Banden zu allen Zeitpunkten nach Bestrahlung vergleichbar.

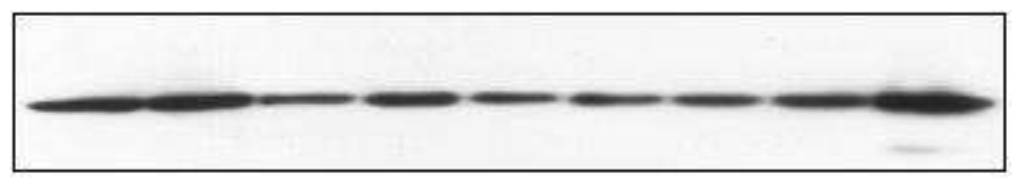

Abb. 18 Western Blot mit dem Antikörper $\beta$-Aktin inkubiert

Dargestellte Banden bei 46 kDa von links nach rechts: A 1 h, B 1 h, A 6 h, B 6 h, A 24 h, B 24 h, A 96 h, B 96 h, A Kontrolle. Exemplarisch ist hier das Jejunum abgebildet.

\subsubsection{Caspase 8}

Caspase 8 ist ein $55 \mathrm{kDa}$ großes, im Zytosol liegendes Protein, welches als inaktives Proenzym synthetisiert wird. Wie in Abb. 1 unter 1.2.4 präsentiert wird, leitet die Caspase 8 als Initiatorcaspase den extrinsischen Signaltransduktionweg der Apoptose in der Zelle weiter. Nach autolytischer Aktivierung am Apoptosom wird die 55 kDa-große Procaspase in zwei Schritten in die aktive heterodimere Caspase 8 gespalten. Zunächst entsteht eine $43 \mathrm{kDa}$-große Untereinheit und zwei $12 \mathrm{kDa}$-kleine Untereinheiten, die wiederum in $10 \mathrm{kDa}$-große Einheiten generiert werden. Das 43 kDa-große Proenzym wird erneut gespalten und es entsteht ein 26 kDa-großes Protein und die Freilegung des 18 kDa-großen aktiven Proteins.

Am Duodenum erkennt man eine deutliche zeitabhängige Spaltung und Aktivierung der Caspase 8 in Folge der Bestrahlung. Bereits nach 1 h ist, wie Abb. 19 zeigt, das 55 kDa-große Proenzym fast vollständig autolytisch in seine aktiven Untereinheiten gespalten worden. Bei $43 \mathrm{kDa}$ ist die aus der ersten autolytischen Spaltung entstandene Untereinheit schwach abgebildet. Bei $18 \mathrm{kDa}$ ist die aktive Untereinheit der Caspase $8 \mathrm{zu}$ erkennen. Im zeitlichen Verlauf kann gezeigt werden, dass zum Zeitpunkt $6 \mathrm{~h}$ ebenfalls eine leichte autolytische Spaltung in die Untereinheiten stattgefunden hat, allerdings ist hier das Proenzym bei $55 \mathrm{kDa}$ nicht vollständig lysiert. Bei der Probe D $6 \mathrm{~h}$ ist eine $10 \mathrm{kDa}$ aktive Untereinheit abgebildet. Bei $24 \mathrm{~h}$ und $96 \mathrm{~h}$ sind auch Untereinheiten der 
aktivierten Caspase 8 darstellbar, jedoch mit teils unspezifischen Banden und nicht vollständig lysiertem Proenzym. Die Kontrollen zeigen eine kräftige Bande des Proenzyms bei 55 kDa und nur sehr schwache Banden bei 43 und $18 \mathrm{kDa}$.

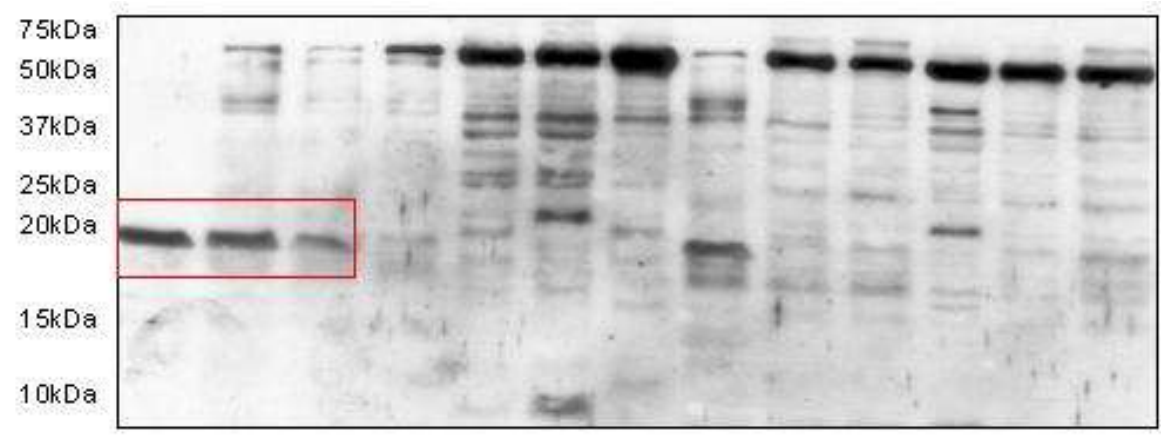

Abb. 19 Caspase 8 dargestellt im Western Blot. Organ: Duodenum

Linke Säule Bandengröße in Kilodalton (kDa). Proben von links nach rechts: C 1 h, D 1 h, E 1 h, C 6 h, D 6 h, E 6 h, C 24 h, D 24 h, E 24 h, C 96 h, D 96 h, E 96 h, C Kontrolle. Es zeigt sich deutlich die aktive Untereinheit bei 18 kDa bei allen 3 Proben $1 \mathrm{~h}$ nach Bestrahlung.

Das Jejunum zeigt durch alle Banden hinweg das 55 kDa-große Caspase-8-Proenzym (Abb. 20).

Die $43 \mathrm{kDa}-U n t e r e i n h e i t$ ist auch bei allen Proben zu sehen, jedoch zeigt sie sich zu den späteren Zeitpunkten und bei der Kontrolle etwas schwächer als bei $1 \mathrm{~h}$ und $6 \mathrm{~h}$. Die aktivierten Untereinheiten der Caspase 8 bei $18 \mathrm{kDa}$ und $10 \mathrm{kDa}$ sind ebenfalls besonders zu den frühen Zeitpunkten $1 \mathrm{~h}$ und $6 \mathrm{~h}$ sehr gut erkennbar. Bei $24 \mathrm{~h}$ sind diese nur noch schwächer zu sehen. Bei $96 \mathrm{~h}$ und der Kontrolle sind die $18 \mathrm{kDa}$ und die $10 \mathrm{kDa}$-große Untereinheit nur sehr schwach abgebildet.

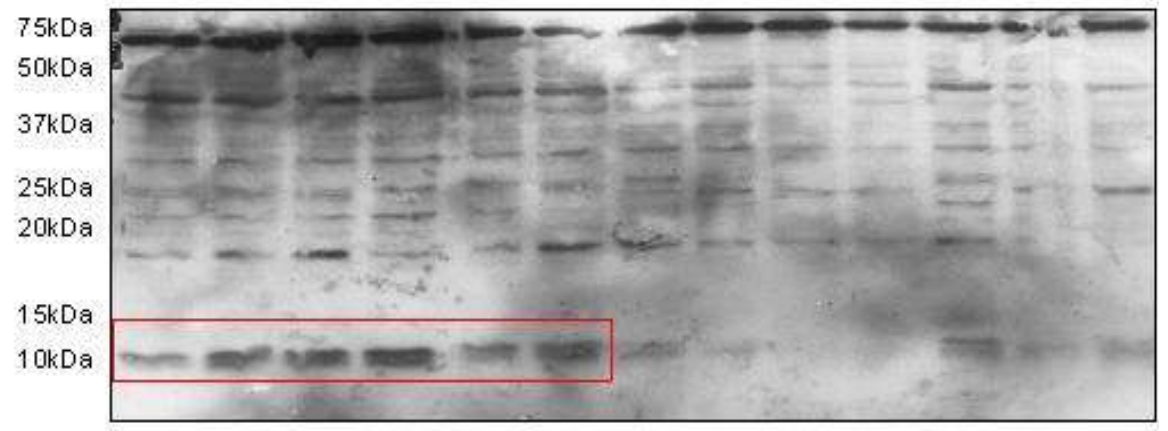

Abb. 20 Caspase 8 dargestellt im Western Blot. Organ: Jejunum

Linke Säule Bandengröße in Kilodalton (kDa). Proben von links nach rechts: C 1 h, D 1 h, E 1 h, C 6 h, D 6 h, E 6 h, C 24 h, D 24 h, E 24 h, C 96 h, D 96 h, E 96 h, C Kontrolle.

Der Western Blot des Ileums mit dem Antikörper Caspase 8 inkubiert ist in Abb. 21 dargestellt. Beim Ileum ist Apoptose anhand der Caspase-8-Aktivität bis 96 h nach Bestrahlung nachweisbar. Sowohl die Bande bei $55 \mathrm{kDa}$, als auch das Spaltprodukt aus der ersten autolytischen Spaltung der Caspase 8, die Bande bei $43 \mathrm{kDa}$ ist durch alle Proben hinweg gut zu erkennen. $\mathrm{Zu}$ den frühen Zeitpunkten $1 \mathrm{~h}$ und $6 \mathrm{~h}$ sind die aktiven Untereinheiten der Caspase 8, die 18 kDa-Einheiten bei 
den Proben A 1 h, B 1 h und A 6 h und die 10 kDa-Einheit bei Probe B 6 h gut erfassbar. Bei 24 h und auch bei $96 \mathrm{~h}$ sind nur noch deutlich schwächere Proteinexpressionen der aktivierten Untereinheiten der Caspase 8 im Western Blot sichtbar. Die Kontrolle zeigt keine aktiven Spaltprodukte der Caspase 8 als Hinweis für apototische Prozesse.

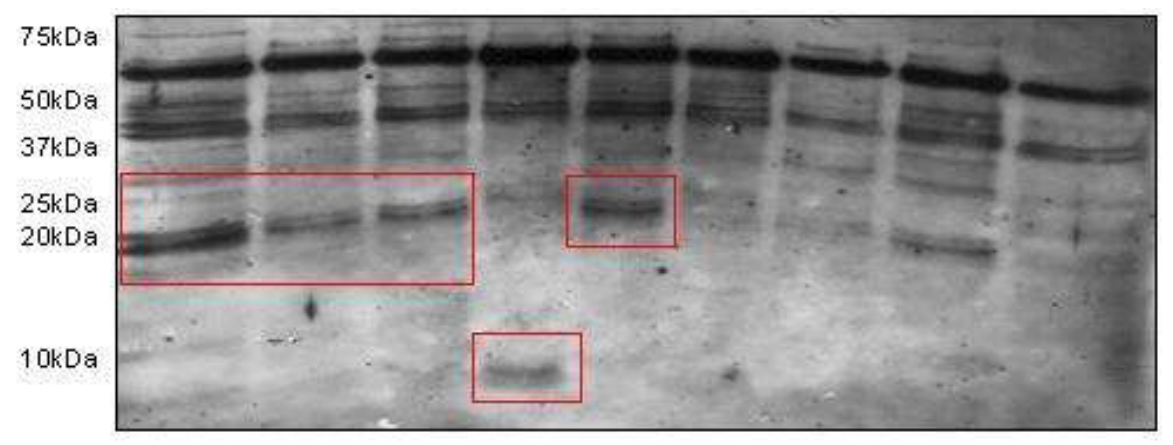

Abb. 21 Caspase 8 dargestellt im Western Blot. Organ: Ileum

Linke Säule Bandengröße in Kilodalton (kDa). Proben von links nach rechts: A 1 h, B 1 h, A 6 h, B 6 h, A 24 h, B 24 h, A 96 h, B 96 h, A Kontrolle.

Abb. 22 zeigt den mit Caspase 8 inkubierten Western Blot des Colons. Hier sind zu allen Zeitpunkten und bei der Kontrolle kräftige Banden des Proenzyms bei 55 kDa abgebildet. Auch die $43 \mathrm{kDa}-$ und die $18 \mathrm{kDa}-$ Bande ist bei allen Proben nachzuweisen. Bei D und E $1 \mathrm{~h}, \mathrm{C} 6 \mathrm{~h}$ und D 6 h kann eine schwache Bande bei 10 kDa vermutet werden.

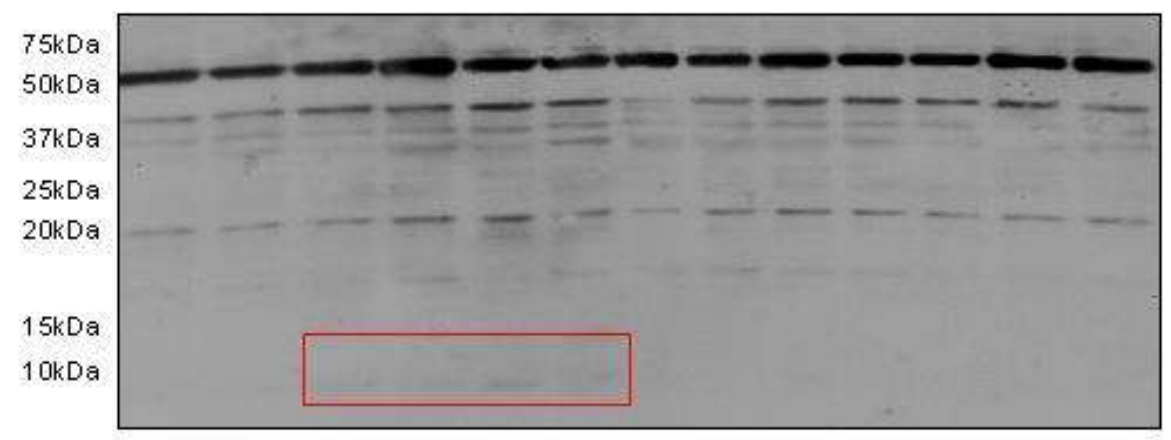

Abb. 22 Caspase 8 dargestellt im Western Blot. Organ: Colon

Linke Säule Bandengröße in Kilodalton (kDa). Proben von links nach rechts: C 1 h, D 1 h, E 1 h, C 6 h, D 6 h, E 6 h, C 24 h, D 24 h, E 24 h, C 96 h, D 96 h, E 96 h, C Kontrolle.

Zusammenfassend lässt sich sagen, dass Caspase 8 in allen 4 untersuchten Darmabschnitten anhand der aktiven Untereinheiten nachgewiesen werden kann. Am Duodenum ist die Spaltung des gesamten Proenzyms durch den Verlust der 55 kDa-Bande zu Gunsten der aktivierten Untereinheiten bei $18 \mathrm{kDa}$ zum Zeitpunkt $6 \mathrm{~h}$ besonders eindrücklich. Beim Jejunum sind die Banden bei $10 \mathrm{kDa}$ und $18 \mathrm{kDa}$ insbesondere zu den frühen Zeitpunkten $1 \mathrm{~h}$ und $6 \mathrm{~h}$ zu beachten. Das Ileum hat eine Caspase-Aktivität bis 96 h. Am Colon zeigen sich zu allen Zeitpunkten, insbesondere auch bei der Kontrolle sowohl das Proenzym bei $55 \mathrm{kDa}$, als auch die $43 \mathrm{kDa}-\mathrm{Bande}$ und das aktive Enzym bei $18 \mathrm{kDa}$. 


\subsubsection{Caspase 3}

Caspase 3 wird ebenfalls als inaktives $32 \mathrm{kDa}$-großes Proenzym synthetisiert. Durch Aktivierung anderer Caspasen wird es in sein aktives Enzym überführt, welches sich aus zwei 17 kDa-großen Untereinheiten und zwei 12 kDa-kleinen Untereinheiten zusammensetzt.

In Abb. 23 sind die Darmabschnitte Duodenum, Jejunum, Ileum und Colon im Vergleich dargestellt.

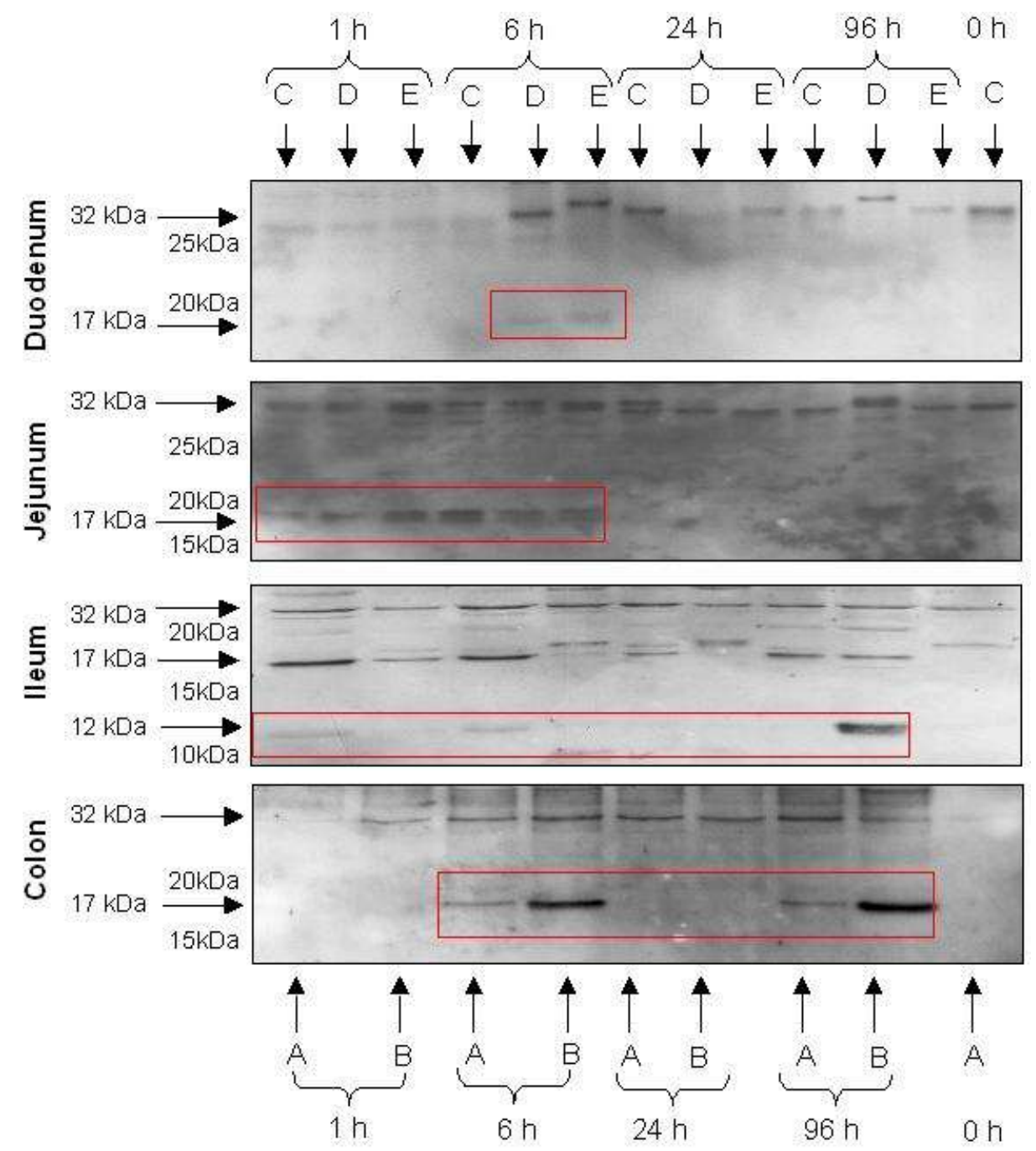

Abb. 23 Caspase 3 dargestellt im Western Blot

Linke Säule Bandengröße in Kilodalton (kDa). Bei 32 kDa wird das Proenzym, bei 17 kDa und 12 kDa die aktivierten Spaltprodukte der Caspase 3 abgebildet.

Im Duodenum sieht man zum 6 h-Zeitpunkt eine schwache Bande bei $17 \mathrm{kDa}$ als Hinweis für eine Caspase-3-Aktivität. Im Jejunum ist zu den Zeitpunkten $1 \mathrm{~h}$ und $6 \mathrm{~h}$ eine Bande bei $17 \mathrm{kDa} \mathrm{zu}$ erkennen. Im Ileum ist bis $96 \mathrm{~h}$ eine Bande bei $17 \mathrm{kDa}$ nachweisbar. Außerdem sind hier die Banden bei $12 \mathrm{kDa}$ bei den Proben A $1 \mathrm{~h}, \mathrm{~A} 6 \mathrm{~h}$ und B $96 \mathrm{~h}$ auffallend. Im Colon ist bei $6 \mathrm{~h}$ und bei $96 \mathrm{~h}$ die aktive Caspase 3 anhand der Bande bei $17 \mathrm{kDa}$ zu verzeichnen. 
In der Zusammenschau zeigt sich, dass auch die aktivierte Caspase 3 in allen 4 Darmabschnitten nachzuweisen ist. Im Duodenum und Jejunum ist eine Aktivierung zu den frühen Zeitpunkten $1 \mathrm{~h}$ und 6 h auffallend, während im Ileum und Colon die aktive Caspase 3 bis 96 h nach Bestrahlung zur Darstellung kommt.

\subsubsection{Das proapoptotische Bax}

Das 21 kDa-große Bax-Protein wirkt als proapoptotisches Protein des intrinsischen Signaltransduktionsweges der Apoptose. In der aktiven Form bildet Bax Dimere (siehe Abb. 1). Diese zeigen sich auf dem Gel mit einer ca. 42 kDa großen Bande. In Abb. 24 sind die Western Blots von Bax, Bcl-2 und $\beta$-Aktin vergleichend abgebildet. Im Duodenum lässt sich eine BaxProteinexpression zu allen Zeitpunkten mit besonders kräftigen Banden bei $1 \mathrm{~h}$ und $6 \mathrm{~h}$ nachweisen. Im Jejunum ist die deutlichste Bax-Aktivität während aller Zeitpunkte verglichen mit den anderen Darmabschnitten zu sehen. Auch hier sind die Proben $1 \mathrm{~h}$ und $6 \mathrm{~h}$ besonders eindrücklich. Im Ileum sind zu allen Zeitpunkten die Banden von Bax zu erkennen, jedoch deutlich schwächer als in den proximalen Darmabschnitten. Die 6 h- und 24 h-Zeitpunkte treten hier besonders hervor. Auch im Colon kann Bax zu diesen Zeitpunkten nachgewiesen werden.

Zusammenfassend lässt sich sagen, dass die Bax-Expression am deutlichsten in den proximalen Darmabschnitten zu sehen ist. Während hier bereits zu den frühen Zeitpunkten $1 \mathrm{~h}$ und $6 \mathrm{~h}$ nach Bestrahlung Bax-Banden hervortreten und die Bax-Expression bis $96 \mathrm{~h}$ anhält, fallen die distalen Darmabschnitte Ileum und Colon erst nach 6 h mit Bax-Banden auf. Im zeitlichen Verlauf bis $96 \mathrm{~h}$ sind die Banden rückläufig.

\subsubsection{Der Gegenspieler der Apoptose: Bcl-2}

Bcl-2 gehört zu den antiapoptotischen Mitgliedern der Bcl-2-Protein-Familie. Bcl-2 ist ein 26 kDagroßes Protein, welches an der Innenseite der Mitochondrien lokalisiert ist und den intrinsischen Weg der Apoptose hemmt. Die Western Blots von Bcl-2 sind ebenfalls in Abb. 24 zu sehen. Am Duodenum zeigt sich bei allen Proben eine Bcl-2-Protein-Expression mit besonders kräftigen Banden nach 6 h. Im Jejunum ist die 26 kDa-große Bande bis 96 h sichtbar. Dabei sind die Banden bei $1 \mathrm{~h}$ und $6 \mathrm{~h}$ am deutlichsten. Das Ileum zeigt eine Progredienz der Bandenstärke von $6 \mathrm{~h}$ bis $96 \mathrm{~h}$, bei insgesamt deutlich schwächeren Banden als bei den Darmabschnitten Duodenum und Jejunum. Im Colon sind Banden besonders ab $6 \mathrm{~h}$ mit abnehmender Intensität bis $96 \mathrm{~h} \mathrm{zu}$ vermerken. 
Die vergleichende Darstellung der Organabschnitte und der Zeitpunkte $0 \mathrm{~h}$ bis $96 \mathrm{~h}$ zeigt, dass das Duodenum und Jejunum bereits $1 \mathrm{~h}$ nach Bestrahlung mit einer Bcl-2-Expression reagieren, während diese im Ileum und Colon erst nach $6 \mathrm{~h}$ zu beobachten ist.

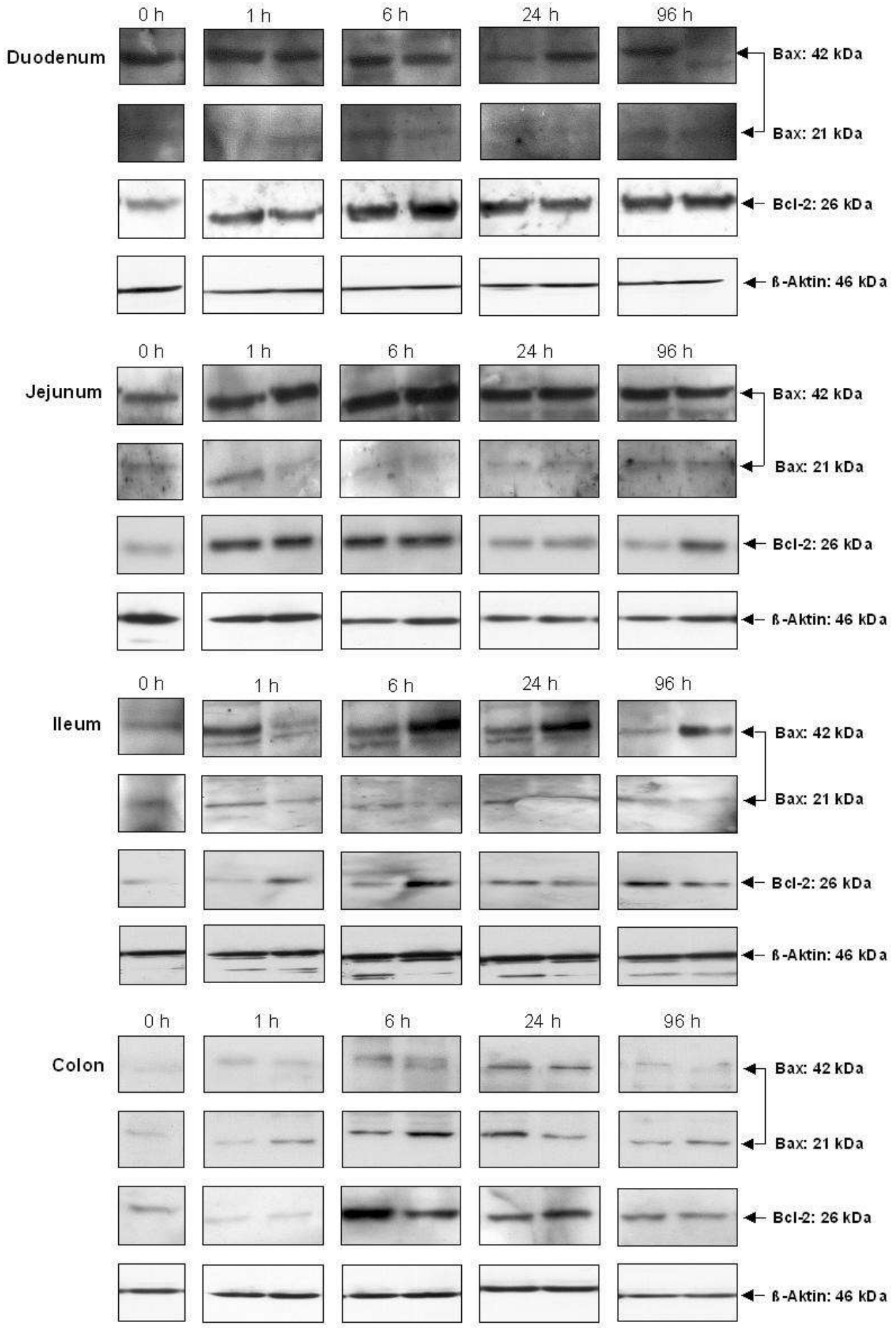

Abb. 24 Western Blots: 1. Bax bei $42 \mathrm{kDa}, 2$. Bax bei $21 \mathrm{kDa}, 3$. Bcl-2 bei $26 \mathrm{kDa}$ und 4. $\beta$-Aktin bei $46 \mathrm{kDa}$ 


\subsection{Analyse von genomischer DNA mit Hilfe einer Gel-Elektrophorese}

Internukleosomale DNA-Doppelstrangbrüche sind spezifische Erscheinungen bei apoptotischen Prozessen. Die Darstellung von Ethidiumbromid-markierter DNA auf einem Agarose-Gel dient der Differenzierung zwischen apoptotischer DNA und nekrotischer DNA. Eine DNA-Ladder wurde als Standard (Std.) bei jedem Gel in Position 1 mitgeführt. Sie ist geeignet, um die Größe von DNADoppelstrangbrüchen zwischen 123 und 3075 Basenpaaren zu detektieren. Dabei besteht die DNALadder aus einer Reihe von Fragmenten zwischen 123 und 4182 Basenpaarlängen. Bis zu 25 Banden können von der DNA-Ladder nach Ethidiumbromid-Färbung auf dem Gel erscheinen. Apoptotische DNA ist auf den Gelen als Bande zu erkennen, während bei nekrotischem DNAZerfall nur eine Schliere zu sehen ist. Es wurden Ethidiumbromid-Gele zur Analyse der genomischen DNA von den Organstücken Jejunum, Ileum und Colon erstellt. Dabei wurden jeweils 3 Proben der frühen Zeitpunkte $1 \mathrm{~h}$ bis $24 \mathrm{~h}$ und zwei Kontrollen mitgeführt. Zu beachten ist, dass es sich bei dieser Methode um keinen quantitativen Nachweis von DNA handelt, sondern nur eine durch Apoptose verursachte DNA-Segmentierung detektiert werden kann. In Abb. 25 a-c sind die Fotos der mit Ethidiumbromid gefärbten DNA nach gelelektrophoretischem Lauf von den Organen Jejunum, Ileum und Colon vergleichend abgebildet. Beim Jejunum (Abb. 25 a) ist deutlich zu erkennen, dass es weder bei den Kontrolltieren C und D zu einer spezifischen Aufspaltung der DNA als Hinweis für Apoptose kommt, noch ist eine Schliere als Merkmal des Abbaus von nekrotischer DNA sichtbar. Bei C, D und E zum Zeitpunkt 6 h sind bei ca. 180 Basenpaaren (bp) deutliche Banden sichtbar. Des Weiteren lässt sich bei den Proben 24 h C-D ebenfalls eine leichte Aufhellung am Gel als Hinweis für eine Spaltung der Basenpaare bei ca. 180 bp erkennen. Bei der Probe D $24 \mathrm{~h}$ ist außerdem eine Schliere im oberen Abschnitt des Gels zu vermerken. In Abb. 25 b ist das Ileum dargestellt. Hier sind bei C-E zu 1 h ganz schwache Banden bei 180 bp nachweisbar. Bei E 1 h ist ferner eine Schliere zu registrieren. Zum Zeitpunkt C 6 h ist ebenso eine ganz schwache Bande zu erfassen, wobei die Probe E $6 \mathrm{~h}$ in diesem Gel besonders hervortritt. Bei $24 \mathrm{~h}$ ist weitestgehend nur eine Schliere zu erkennen. Die Probe D 24 h lässt eine schwache Bande bei 180 bp vermuten. Die Abbildung des Colons (Abb. 25 c) zeigt bei den Proben C Kontrolle, D und E zu 1 h, E 6 h, C und E $24 \mathrm{~h}$ eine Schliere. Bei D-E zu 1 h, C-E 6 h und C 24 h ist außerdem eine leichte Aufhellung des Gels bei ca. 180 bp zu vermerken. 

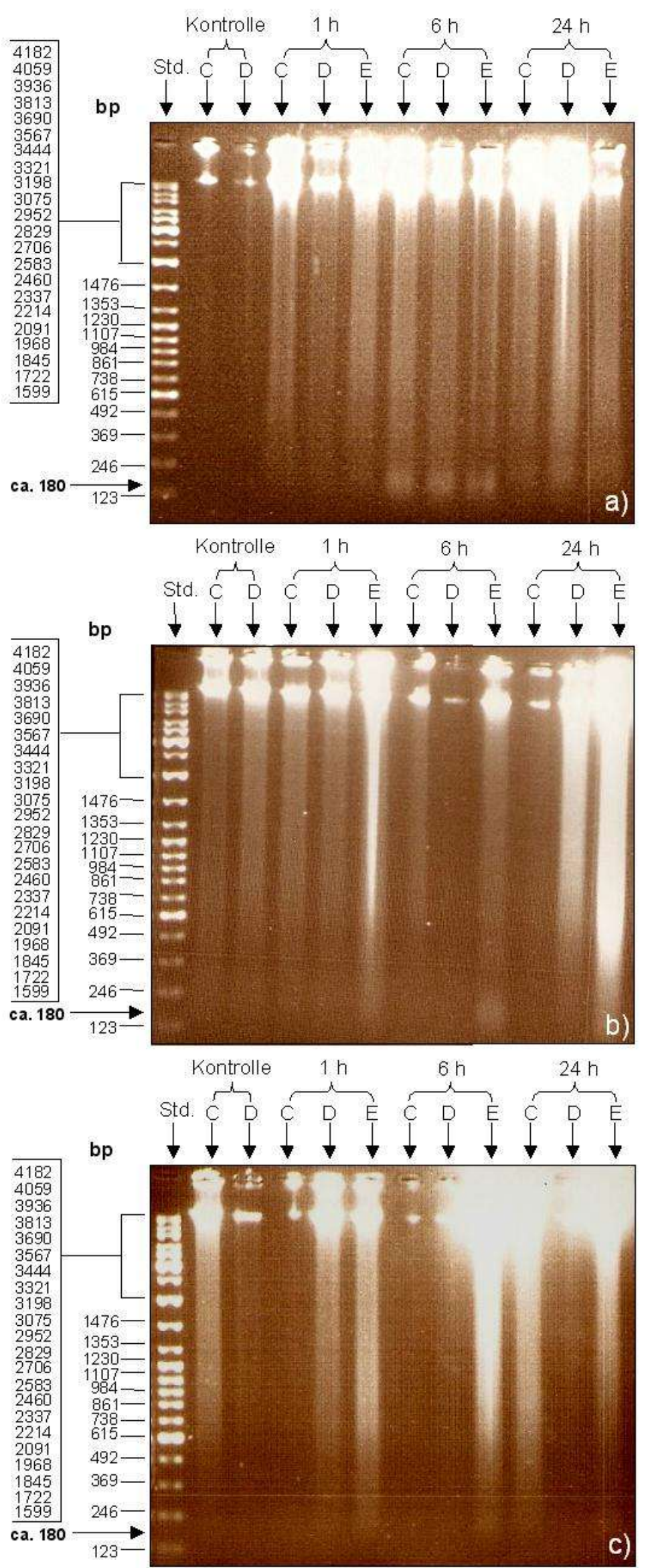

Abb. 25 Darstellung von genomischer DNA mit Hilfe einer Gelelektrophorese

Auf den Abbildungen a) Jejunum b) Ileum und c) Colon ist jeweils links die DNA-Ladder mit der Größe der Basenpaare (bp) angegeben. In den folgenden Slots sind die Proben in üblicher Reihenfolge pipettiert, wie es über dem Gel mit einem Pfeil markiert ist. 
Zusammenfassend lässt sich sagen, dass sich mit Hilfe der Ethidiumbromid gefärbten DNAElekrophorese apoptotische DNA-Fragmente anhand der Banden bei ca. 180 bp nachweisen lassen. Im Jejunum stechen besonders die Proben zum 6 h-Zeitpunkt hervor. Nekrose kann in diesem Gel nicht eindeutig festgestellt werden. Im Ileum sind sehr schwache Banden bei $1 \mathrm{~h}$ sichtbar. Eine Bande bei E $6 \mathrm{~h}$ hebt sich in diesem Gel besonders hervor. Eine Schliere als Hinweis für Nekrose bzw. DNA-Debris als Folge von Bestrahlung zeigt sich bei den 24 h-Werten. Im Colon ist auffallend, dass viele der Proben sowohl eine Schliere, als auch schwache Banden bei ca. $180 \mathrm{bp}$ abbilden. Bei $1 \mathrm{~h}$ und $6 \mathrm{~h}$ ist eine Aufhellung des Gels bei ca. $180 \mathrm{bp}$ als Hinweis für DNABruchstücke sichtbar.

\subsection{Zusammenfassung der Ergebnisse}

Alle Ergebnisse sind in Tabelle 6 zusammengefasst und vergleichend dargestellt. In der Zusammenschau der Ergebnisse lässt sich nachweisen, dass unmittelbar nach Bestrahlung in allen Teilen des Dünndarms eine direkte Strahlenreaktion auftritt, während im Colon nur milde und nachweislich reversible Schäden auftreten. $\mathrm{Zu}$ berücksichtigen ist dabei, dass ein Teil des Duodenums im Bestrahlungsfeld von 25 Gy liegt, während eine Strahlendosis von ca. 12 Gy bzw. ca. 2,5 Gy den übrigen Teil des Duodenums und des Jejunums trifft. Das weitere Jejunum, das Ileum, das Coecum und das Colon liegen außerhalb des berechneten Bestrahlungsfeldes. Hier muss jedoch mit einer Streustrahlung in geringen Dosen gerechnet werden. Histologisch zeigen sich zu den frühen Zeitpunkten noch intakt erscheinende Darmkrypten in den oberen Dünndarmabschnitten, während im Ileum bereits $6 \mathrm{~h}$ nach Bestrahlung eine Zerstörung auf Kryptenebene abläuft. Im Verlauf bis 1,5 Monate kommt es im Ileum zu einer Destruktion des Epithels. Eine komplette Regeneration kann hier bis 3 Monate nach Bestrahlung nicht erreicht werden. In den übrigen Darmabschnitten hingegen regeneriert sich - histologisch betrachtet - das Gewebe im Laufe des Untersuchungzeitraumes. Untermauert werden diese histologischen Ergebnisse auf molekularer Ebene durch die Resultate der Western Blots und der PCR. Auffallend ist auch hier, dass apoptotische Prozesse (Bax, Bcl-2, Caspase 3, Caspase 8, HSP-27 und IFN- $\gamma$ ) im Duodenum und Jejunum, die beide im direkten Bestrahlungsfeld liegen, unmittelbar nach Bestrahlung auftreten. Im Ileum kommt es zunächst bis zum 6 h-Zeitpunkt zu einer einheitlichen Hochregulation dieser Gene und Proteine. Nach 24 h kann dann zum Teil eine Herunterregulation beobachtet werden. Die Analyse der genomischen DNA mit Hilfe einer Gelelektrophorese bestätigt Apoptose im Jejunum bis $6 \mathrm{~h}$. Im Ileum kann zunächst Apoptose und bei $24 \mathrm{~h}$ auch Nekrose festgestellt werden. Mit Hilfe der TUNEL-Färbung können exemplarisch im Duodenum und Jejunum apototische Zellen an der Basis der Krypten und im unteren Drittel der Krypten-Zotten- 
Achse nachgewiesen werden, während diese im Colon an der Spitze der Zotten und Krypten auffallen. Neben Apoptose kommt es im Duodenum und Jejunum unmittelbar in Folge von Bestrahlung zu einer Hochregulation proinflammatorischer Zytokine, Adhäsionsmoleküle und zur Rekrutierung von Immunzellen. Das Ileum imponiert mit einer Herunterregulation von z.B. MIP1 $\alpha$, Thy-1 und PECAM-1 beziehungsweise einer mangelnder Expression der proinflammatorischen Zytokine nach Bestrahlung. Auffällig ist die Hochregulation des Adhäsionsmoleküls MAdCAM-1 im Ileum bis 24 h nach Radiatio. Für TGF- $\beta$, welches durch Aktivierung von T-Lymphozyten eine Fibrosierung im Darm initiiert, zeigen sich wider der Erwartung keine erhöhten Werte in den einzelnen Darmabschnitten. Vielmehr wird ein konsequenter Abfall beobachtet. Für das Ileum fällt insgesamt auf, dass in den Kontrollen die höchste Anzahl von Immunzellen im Vergleich zu den übrigen Darmabschnitten zu zählen sind. Bei der CD3-Färbung zur Darstellung von TLymphozyten und der CD34-Färbung zur Markierung von hämatopoetischen Progenitorzellen fallen ab $24 \mathrm{~h}$ die Anzahl der rekrutierten Immunzellen unter die Zellzahl der Kontrollen. Auch die Genexpression von IP-10 sinkt bei 96 h signifikant unter den Ausgangswert. Die ED1-Färbung veranschaulicht, dass die Immunzellen von $1 \mathrm{~h}$ bis $96 \mathrm{~h}$ im Jejunum und Ileum entlang der KryptenZotten-Achse wandern und schließlich ins Lumen abgeschilfert werden. Die Endothelzellmarker VEGF und SMA imponieren mit signifikanten Hochregulationen im Duodenum bis $96 \mathrm{~h}$. Hinzufügend präsentiert SMA, ein Marker zur Detektierung von Gefäßmuskelzellen, im Jejunum und Ileum auch zu den späten Zeitpunkten hoch signifikante Werte. Insgesamt kristallisieren sich im Bestrahlungsintervall von $0 \mathrm{~h}$ bis 3 Monate im Ileum die stärksten Schäden nach Bestrahlung heraus. 
Tabelle 6 Zusammenfassung aller Ergebnisse unter Berücksichtigung der Strahlenbelastung der Darmabschnitte

\begin{tabular}{|c|c|c|c|c|c|c|c|c|c|c|c|c|c|c|c|c|c|c|c|}
\hline Organabschnitt & Zeitpunkt & $\begin{array}{l}-\check{x} \\
\end{array}$ & $\stackrel{\sqrt[N]{x}}{\underset{\pi}{\infty}}$ & $\stackrel{\infty}{x}$ & พับ & ঙั & 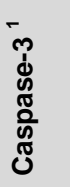 & 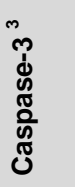 & 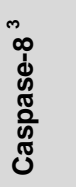 & סृ & 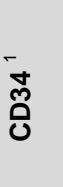 & $\begin{array}{l}\text { Ñ } \\
\text { ஸे } \\
\text { Ò }\end{array}$ & 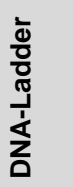 & $\bar{c}$ & 凅 & กั๊ & 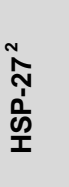 & 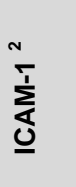 & 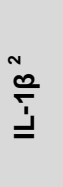 \\
\hline \multirow{6}{*}{$\begin{array}{l}\text { Duodenum } \\
\text { (Dosis bis } 25 \text { Gy) }\end{array}$} & $1 \mathrm{~h}$ & $\uparrow \uparrow \uparrow$ & $\uparrow \uparrow$ & $\uparrow \uparrow \uparrow$ & $\uparrow \uparrow$ & $\uparrow$ & $\bar{\uparrow}$ & $\rightarrow$ & $\bar{\uparrow}$ & $\downarrow$ & $\rightarrow$ & $\uparrow \uparrow$ & n.d. & $\uparrow \uparrow$ & $\uparrow \uparrow$ & $\rightarrow$ & $\rightarrow$ & $\uparrow \uparrow$ & $\uparrow \uparrow \uparrow$ \\
\hline & $6 \mathrm{~h}$ & $\uparrow \uparrow$ & $\uparrow \uparrow$ & $\uparrow \uparrow \uparrow$ & $\rightarrow$ & $\uparrow \uparrow$ & $\uparrow \uparrow$ & $\uparrow$ & $\uparrow \uparrow \uparrow \uparrow$ & $\uparrow \uparrow$ & $\downarrow$ & $\rightarrow$ & n.d. & $\uparrow \uparrow \uparrow$ & $\rightarrow$ & $\uparrow \uparrow \uparrow \uparrow \uparrow$ & $\rightarrow$ & $\rightarrow$ & $\rightarrow$ \\
\hline & $24 \mathrm{~h}$ & 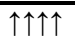 & $\uparrow \uparrow$ & $\uparrow \uparrow$ & $\rightarrow$ & $\uparrow \uparrow \uparrow \uparrow$ & $\bar{\uparrow}$ & $\rightarrow$ & $\bar{\uparrow}$ & $\downarrow$ & $\overline{\uparrow \uparrow}$ & $\rightarrow$ & n.d. & $\rightarrow$ & $\rightarrow$ & $\rightarrow$ & $\uparrow \uparrow \uparrow \uparrow$ & $\rightarrow$ & $\rightarrow$ \\
\hline & $96 \mathrm{~h}$ & 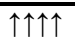 & $\bar{\uparrow}$ & $\overline{\uparrow \uparrow}$ & $\rightarrow$ & $\overline{\uparrow \uparrow \uparrow \uparrow}$ & $\overline{\uparrow \uparrow \uparrow \uparrow}$ & $\rightarrow$ & 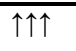 & $\rightarrow$ & $\overline{\uparrow \uparrow}$ & $\downarrow \downarrow \downarrow$ & n.d. & $\overline{\uparrow \uparrow}$ & $\rightarrow$ & $\rightarrow$ & $\rightarrow$ & $\overline{\uparrow \uparrow \uparrow \uparrow \uparrow}$ & $\rightarrow$ \\
\hline & 1,5 Monate & $\overline{\uparrow \uparrow}$ & $\bar{\uparrow}$ & n.d. & $\rightarrow$ & n.d. & $\overline{\uparrow \uparrow}$ & n.d. & n.d. & $\downarrow$ & $\downarrow \downarrow$ & n.d. & n.d. & $\rightarrow$ & $\rightarrow$ & $\rightarrow$ & $\rightarrow$ & n.d. & $\overline{\downarrow \downarrow \downarrow}$ \\
\hline & 3 Monate & $\overline{\uparrow \uparrow}$ & $\bar{\uparrow}$ & n.d. & $\rightarrow$ & n.d. & $\overline{\uparrow \uparrow}$ & n.d. & n.d. & $\bar{\uparrow}$ & $\uparrow$ & n.d. & n.d. & $\uparrow$ & $\rightarrow$ & $\rightarrow$ & $\rightarrow$ & n.d. & $\downarrow \downarrow \downarrow$ \\
\hline \multirow{6}{*}{$\begin{array}{c}\text { Jejunum } \\
\text { (Dosis bis } 12 \text { Gy) }\end{array}$} & $1 \mathrm{~h}$ & $\uparrow \uparrow$ & $\uparrow \uparrow$ & $\uparrow \uparrow \uparrow$ & $\uparrow \uparrow \uparrow \uparrow$ & $\uparrow \uparrow$ & $\bar{\uparrow}$ & $\bar{\uparrow}$ & $\uparrow \uparrow \uparrow \uparrow$ & $\rightarrow$ & $\downarrow$ & $\uparrow \uparrow$ & $\rightarrow$ & $\downarrow$ & $\rightarrow$ & $\rightarrow$ & $\rightarrow$ & $\uparrow \uparrow \uparrow \uparrow \uparrow$ & $\downarrow \downarrow$ \\
\hline & $6 \mathrm{~h}$ & $\overline{\uparrow \uparrow \uparrow \uparrow \uparrow}$ & $\overline{\uparrow \uparrow}$ & $\overline{\uparrow \uparrow \uparrow \uparrow \uparrow}$ & $\rightarrow$ & $\uparrow \uparrow$ & $\downarrow \downarrow$ & $\overline{\uparrow \uparrow}$ & 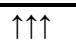 & $\rightarrow$ & $\bar{\uparrow}$ & $\uparrow \uparrow$ & $\overline{\uparrow \uparrow \uparrow \uparrow}$ & $\downarrow$ & $\rightarrow$ & $\rightarrow$ & $\rightarrow$ & $\uparrow \uparrow \uparrow$ & $\downarrow \downarrow \downarrow$ \\
\hline & $24 \mathrm{~h}$ & $\overline{\uparrow \uparrow \uparrow \uparrow}$ & $\overline{\uparrow \uparrow}$ & $\overline{\uparrow \uparrow \uparrow \uparrow}$ & $\rightarrow$ & $\bar{\uparrow}$ & $\bar{\uparrow}$ & $\bar{\uparrow}$ & $\bar{\uparrow}$ & $\bar{\uparrow}$ & $\overline{\uparrow \uparrow}$ & $\overline{\uparrow \uparrow}$ & $\uparrow$ & $\downarrow \downarrow$ & $\rightarrow$ & $\rightarrow$ & $\uparrow \uparrow \uparrow \uparrow$ & $\uparrow \uparrow$ & $\downarrow \downarrow$ \\
\hline & $96 \mathrm{~h}$ & $\overline{\uparrow \uparrow \uparrow \uparrow}$ & $\bar{\uparrow}$ & $\overline{\uparrow \uparrow \uparrow}$ & $\rightarrow$ & $\bar{\uparrow}$ & $\rightarrow$ & $\bar{\uparrow}$ & $\bar{\uparrow}$ & $\downarrow$ & $\bar{\uparrow}$ & $\rightarrow$ & n.d. & $\bar{\uparrow}$ & $\rightarrow$ & $\rightarrow$ & $\rightarrow$ & $\rightarrow$ & $\downarrow \downarrow$ \\
\hline & 1,5 Monate & $\uparrow$ & $\uparrow \uparrow$ & n.d. & $\uparrow \uparrow$ & n.d. & $\uparrow \uparrow \uparrow \uparrow$ & n.d. & n.d. & $\downarrow$ & $\rightarrow$ & $\uparrow \uparrow \uparrow \uparrow$ & n.d. & $\downarrow$ & $\rightarrow$ & $\uparrow \uparrow \uparrow \uparrow$ & $\uparrow \uparrow$ & $\uparrow \uparrow \uparrow \uparrow$ & $\downarrow \downarrow \downarrow$ \\
\hline & 3 Monate & $\rightarrow$ & $\bar{\uparrow}$ & n.d. & $\rightarrow$ & n.d. & $\uparrow \uparrow$ & n.d. & n.d. & $\begin{array}{c}\uparrow \uparrow \uparrow \\
\end{array}$ & $\uparrow \uparrow \uparrow$ & $\uparrow \uparrow$ & n.d. & $\downarrow \downarrow$ & $\downarrow \downarrow$ & $\rightarrow$ & $\overline{\uparrow \uparrow \uparrow \uparrow}$ & $\rightarrow$ & $\downarrow \downarrow \downarrow$ \\
\hline \multirow{6}{*}{$\begin{array}{c}\text { Ileum } \\
\text { (ggf.Streustrahlung) }\end{array}$} & $1 \mathrm{~h}$ & $\uparrow \uparrow$ & $\rightarrow$ & $\uparrow \uparrow$ & $\rightarrow$ & $\bar{\uparrow}$ & $\uparrow \uparrow \uparrow \uparrow$ & $\uparrow \uparrow$ & $\uparrow \uparrow \uparrow \uparrow$ & $\uparrow \uparrow \uparrow \uparrow$ & $\downarrow$ & $\rightarrow$ & $\bar{\uparrow}$ & $\downarrow$ & $\rightarrow$ & $\rightarrow$ & $\uparrow \uparrow$ & $\rightarrow$ & $\rightarrow$ \\
\hline & $6 \mathrm{~h}$ & 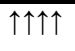 & $\bar{\uparrow}$ & 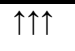 & $\rightarrow$ & $\overline{\uparrow \uparrow}$ & $\overline{\uparrow \uparrow}$ & $\overline{\uparrow \uparrow}$ & $\uparrow \uparrow \uparrow$ & $\downarrow$ & $\downarrow \downarrow$ & $\rightarrow$ & $\uparrow \uparrow \uparrow$ & $\bar{\uparrow}$ & $\rightarrow$ & $\rightarrow$ & $\rightarrow$ & $\rightarrow$ & $\rightarrow$ \\
\hline & $24 \mathrm{~h}$ & 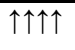 & $\uparrow \uparrow$ & $\uparrow \uparrow \uparrow$ & $\rightarrow$ & $\bar{\uparrow}$ & $\downarrow \downarrow$ & $\bar{\uparrow}$ & $\uparrow \uparrow$ & $\downarrow \downarrow$ & $\downarrow$ & $\rightarrow$ & $\rightarrow$ & $\downarrow$ & $\downarrow \downarrow \downarrow$ & $\rightarrow$ & $\uparrow \uparrow \uparrow \uparrow$ & $\rightarrow$ & $\rightarrow$ \\
\hline & $96 \mathrm{~h}$ & $\overline{\uparrow \uparrow \uparrow \uparrow}$ & $\rightarrow$ & $\uparrow$ & $\rightarrow$ & $\overline{\uparrow \uparrow}$ & $\downarrow \downarrow$ & $\uparrow$ & $\uparrow \uparrow \uparrow$ & $\downarrow \downarrow \downarrow$ & $\downarrow \downarrow \downarrow \downarrow$ & $\uparrow \uparrow$ & n.d. & $\downarrow \downarrow$ & $\downarrow \downarrow \downarrow$ & $\rightarrow$ & $\uparrow \uparrow$ & $\rightarrow$ & $\rightarrow$ \\
\hline & 1,5 Monate & $\uparrow \uparrow \uparrow$ & $\uparrow \uparrow$ & n.d. & $\overline{\uparrow \uparrow}$ & n.d. & $\downarrow \downarrow \downarrow$ & n.d. & n.d. & $\downarrow \downarrow \downarrow$ & $\downarrow \downarrow \downarrow$ & $\rightarrow$ & n.d. & $\uparrow$ & $\rightarrow$ & $\rightarrow$ & $\rightarrow$ & $\rightarrow$ & $\rightarrow$ \\
\hline & 3 Monate & $\overline{\uparrow \uparrow}$ & $\overline{\uparrow \uparrow}$ & n.d. & $\rightarrow$ & n.d. & $\uparrow \uparrow \uparrow \uparrow$ & n.d. & n.d. & $\overline{\uparrow \uparrow}$ & $\downarrow$ & $\uparrow \uparrow$ & n.d. & $\uparrow$ & $\rightarrow$ & $\rightarrow$ & $\uparrow \uparrow$ & $\rightarrow$ & $\rightarrow$ \\
\hline \multirow{6}{*}{$\begin{array}{c}\text { Colon } \\
\text { (ggf.Streustrahlung) }\end{array}$} & $1 \mathrm{~h}$ & $\rightarrow$ & $\rightarrow$ & $\uparrow$ & $\downarrow \downarrow \downarrow$ & $\rightarrow$ & $\uparrow \uparrow$ & $\rightarrow$ & $\uparrow$ & $\uparrow \uparrow$ & $\uparrow$ & $\rightarrow$ & $\uparrow$ & $\downarrow$ & $\rightarrow$ & $\rightarrow$ & $\rightarrow$ & $\downarrow \downarrow \downarrow$ & $\downarrow \downarrow \downarrow \downarrow$ \\
\hline & $6 \mathrm{~h}$ & $\rightarrow$ & $\rightarrow$ & $\uparrow$ & $\downarrow \downarrow \downarrow$ & $\uparrow \uparrow \uparrow$ & $\uparrow \uparrow$ & $\uparrow \uparrow$ & $\uparrow \uparrow$ & $\uparrow$ & $\rightarrow$ & $\rightarrow$ & $\uparrow$ & $\rightarrow$ & $\downarrow \downarrow$ & $\rightarrow$ & $\downarrow \downarrow$ & $\rightarrow$ & $\downarrow \downarrow \downarrow$ \\
\hline & $24 \mathrm{~h}$ & $\rightarrow$ & $\rightarrow$ & $\bar{\uparrow}$ & $\rightarrow$ & $\uparrow \uparrow$ & $\bar{\uparrow}$ & $\rightarrow$ & $\bar{\uparrow}$ & $\downarrow$ & $\rightarrow$ & $\rightarrow$ & $\rightarrow$ & $\downarrow$ & $\rightarrow$ & $\rightarrow$ & $\rightarrow$ & $\rightarrow$ & $\rightarrow$ \\
\hline & $96 \mathrm{~h}$ & $\rightarrow$ & $\overline{\uparrow \uparrow}$ & $\bar{\uparrow}$ & $\rightarrow$ & $\bar{\uparrow}$ & $\begin{array}{c}\uparrow \uparrow \uparrow \\
\end{array}$ & $\overline{\uparrow \uparrow}$ & $\bar{\uparrow}$ & $\overline{\uparrow \uparrow}$ & $\bar{\uparrow}$ & $\rightarrow$ & n.d. & $\rightarrow$ & $\rightarrow$ & $\rightarrow$ & $\downarrow \downarrow$ & $\rightarrow$ & $\rightarrow$ \\
\hline & 1,5 Monate & $\rightarrow$ & $\bar{\uparrow}$ & n.d. & $\rightarrow$ & n.d. & $\overline{\uparrow \uparrow}$ & n.d. & n.d. & $\bar{\uparrow}$ & $\rightarrow$ & $\downarrow \downarrow$ & n.d. & $\downarrow \downarrow \downarrow$ & $\rightarrow$ & $\rightarrow$ & $\downarrow \downarrow$ & $\rightarrow$ & $\rightarrow$ \\
\hline & 3 Monate & $\rightarrow$ & $\rightarrow$ & n.d. & $\rightarrow$ & n.d. & $\uparrow \uparrow \uparrow$ & n.d. & n.d. & $\uparrow \uparrow$ & $\rightarrow$ & $\rightarrow$ & n.d. & $\downarrow \downarrow \downarrow$ & $\rightarrow$ & $\rightarrow$ & $\downarrow \downarrow$ & $\rightarrow$ & $\rightarrow$ \\
\hline
\end{tabular}




\begin{tabular}{|c|c|c|c|c|c|c|c|c|c|c|c|c|c|c|c|c|c|}
\hline Organabschnitt & Zeitpunkt & $\stackrel{\sim}{\stackrel{\varphi}{\Perp}}$ & $\stackrel{\sim}{\infty}$ & $\begin{array}{l}\text { N } \\
\text { ż } \\
\underline{\underline{z}}\end{array}$ & $\stackrel{2}{\stackrel{1}{1}}$ & 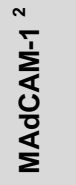 & $\begin{array}{l}\text { N } \\
\bar{\Delta} \\
\text { Ù }\end{array}$ & $\frac{\sim}{\sigma}$ & 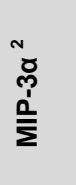 & 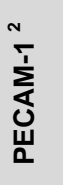 & $\sum_{\omega}^{\infty}$ & $\begin{array}{l}\text { o } \\
\stackrel{0}{1} \\
\dot{1} \\
\stackrel{0}{r}\end{array}$ & $\stackrel{\sim}{\vec{T}}$ & 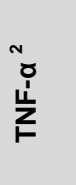 & 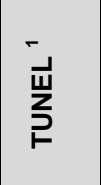 & 峁 & 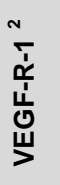 \\
\hline \multirow{6}{*}{$\begin{array}{l}\text { Duodenum } \\
\text { (Dosis bis } 25 \text { Gy) }\end{array}$} & $1 \mathrm{~h}$ & n.d. & $\rightarrow$ & $\rightarrow$ & 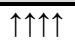 & $\rightarrow$ & 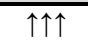 & $\overline{\uparrow \uparrow \uparrow \uparrow}$ & $\uparrow \uparrow$ & $\rightarrow$ & $\overline{\uparrow \uparrow}$ & $\uparrow$ & 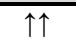 & $\overline{\uparrow \uparrow \uparrow \uparrow \uparrow}$ & \multirow{6}{*}{ 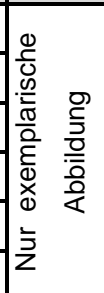 } & 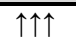 & $\rightarrow$ \\
\hline & $6 \mathrm{~h}$ & n.d. & $\rightarrow$ & $\rightarrow$ & $\begin{array}{c}\uparrow \uparrow \uparrow \uparrow \\
\end{array}$ & $\rightarrow$ & $\rightarrow$ & $\begin{array}{c}\uparrow \uparrow \uparrow \\
\end{array}$ & $\rightarrow$ & $\rightarrow$ & $\overline{\uparrow \uparrow}$ & $\rightarrow$ & $\rightarrow$ & $\overline{\uparrow \uparrow}$ & & $\begin{array}{c}\uparrow \uparrow \uparrow \\
\quad\end{array}$ & $\downarrow$ \\
\hline & $24 \mathrm{~h}$ & n.d. & $\rightarrow$ & $\rightarrow$ & 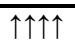 & $\downarrow$ & $\rightarrow$ & $\rightarrow$ & $\rightarrow$ & $\rightarrow$ & $\overline{\uparrow \uparrow \uparrow \uparrow}$ & $\rightarrow$ & $\rightarrow$ & $\overline{\uparrow \uparrow}$ & & $\rightarrow$ & $\rightarrow$ \\
\hline & $96 \mathrm{~h}$ & n.d. & $\rightarrow$ & $\rightarrow$ & $\rightarrow$ & $\rightarrow$ & $\rightarrow$ & $\rightarrow$ & $\downarrow \downarrow \downarrow \downarrow$ & $\uparrow \uparrow \uparrow \uparrow$ & $\uparrow \uparrow \uparrow \uparrow \uparrow$ & $\rightarrow$ & $\uparrow \uparrow \uparrow \uparrow \uparrow$ & $\uparrow$ & & $\uparrow \uparrow \uparrow \uparrow \uparrow$ & $\uparrow \uparrow \uparrow \uparrow$ \\
\hline & 1,5 Monate & n.d. & $\rightarrow$ & $\rightarrow$ & n.d. & n.d. & n.d. & n.d. & n.d. & n.d. & n.d. & $\downarrow$ & n.d. & 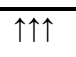 & & n.d. & n.d. \\
\hline & 3 Monate & n.d. & $\rightarrow$ & $\rightarrow$ & n.d. & n.d. & n.d. & n.d. & n.d. & n.d. & n.d. & $\downarrow \downarrow$ & n.d. & $\rightarrow$ & & n.d. & n.d. \\
\hline \multirow{6}{*}{$\begin{array}{c}\text { Jejunum } \\
\text { (Dosis bis } 12 \text { Gy) }\end{array}$} & $1 \mathrm{~h}$ & $\rightarrow$ & $\rightarrow$ & $\rightarrow$ & $\uparrow \uparrow$ & $\rightarrow$ & $\uparrow \uparrow \uparrow \uparrow$ & $\uparrow \uparrow \uparrow \uparrow$ & $\uparrow \uparrow \uparrow \uparrow$ & $\uparrow \uparrow \uparrow$ & $\uparrow \uparrow \uparrow$ & $\rightarrow$ & $\rightarrow$ & $\uparrow \uparrow$ & \multirow{6}{*}{ 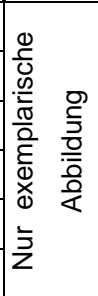 } & $\rightarrow$ & $\downarrow \downarrow$ \\
\hline & $6 \mathrm{~h}$ & $\rightarrow$ & $\rightarrow$ & $\rightarrow$ & 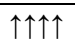 & $\rightarrow$ & $\begin{array}{c}\uparrow \uparrow \uparrow \\
\end{array}$ & $\rightarrow$ & $\rightarrow$ & $\rightarrow$ & $\rightarrow$ & $\rightarrow$ & $\rightarrow$ & $\rightarrow$ & & $\rightarrow$ & $\rightarrow$ \\
\hline & $24 \mathrm{~h}$ & $\rightarrow$ & $\uparrow \uparrow$ & $\rightarrow$ & 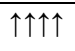 & $\downarrow$ & $\uparrow \uparrow$ & $\rightarrow$ & $\rightarrow$ & $\rightarrow$ & 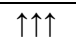 & $\rightarrow$ & $\uparrow \uparrow$ & $\rightarrow$ & & $\rightarrow$ & $\downarrow \downarrow$ \\
\hline & $96 \mathrm{~h}$ & $\rightarrow$ & $\downarrow \downarrow$ & $\rightarrow$ & $\rightarrow$ & $\downarrow$ & $\uparrow \uparrow$ & $\rightarrow$ & $\downarrow \downarrow \downarrow$ & $\rightarrow$ & $\rightarrow$ & $\rightarrow$ & $\rightarrow$ & $\rightarrow$ & & $\rightarrow$ & $\rightarrow$ \\
\hline & 1,5 Monate & $\rightarrow$ & $\rightarrow$ & $\rightarrow$ & $\uparrow \uparrow \uparrow \uparrow$ & n.d. & $\uparrow \uparrow \uparrow$ & $\uparrow \uparrow \uparrow$ & $\rightarrow$ & $\uparrow \uparrow$ & $\uparrow \uparrow$ & $\rightarrow$ & $\uparrow \uparrow$ & $\rightarrow$ & & $\rightarrow$ & $\rightarrow$ \\
\hline & 3 Monate & $\rightarrow$ & $\rightarrow$ & $\rightarrow$ & $\rightarrow$ & n.d. & $\rightarrow$ & $\uparrow \uparrow$ & $\rightarrow$ & $\rightarrow$ & $\uparrow \uparrow \uparrow \uparrow$ & $\downarrow \downarrow$ & $\uparrow \uparrow$ & $\rightarrow$ & & $\downarrow \downarrow$ & $\rightarrow$ \\
\hline \multirow{6}{*}{$\begin{array}{c}\text { Ileum } \\
\text { (ggf.Streustrahlung) }\end{array}$} & $1 \mathrm{~h}$ & $\downarrow \downarrow \downarrow$ & $\downarrow \downarrow$ & $\downarrow \downarrow \downarrow$ & $\rightarrow$ & $\rightarrow$ & $\rightarrow$ & $\rightarrow$ & $\rightarrow$ & $\rightarrow$ & $\uparrow \uparrow \uparrow$ & $\downarrow$ & $\rightarrow$ & $\rightarrow$ & n.d. & $\rightarrow$ & $\rightarrow$ \\
\hline & $6 \mathrm{~h}$ & $\rightarrow$ & $\rightarrow$ & $\rightarrow$ & $\rightarrow$ & $\uparrow \uparrow \uparrow \uparrow \uparrow$ & $\rightarrow$ & $\rightarrow$ & $\rightarrow$ & $\rightarrow$ & $\rightarrow$ & $\rightarrow$ & $\rightarrow$ & $\rightarrow$ & n.d. & $\rightarrow$ & $\downarrow \downarrow$ \\
\hline & $24 \mathrm{~h}$ & $\rightarrow$ & $\rightarrow$ & $\rightarrow$ & $\rightarrow$ & $\begin{array}{c}\uparrow \uparrow \uparrow \uparrow \\
\end{array}$ & $\rightarrow$ & $\rightarrow$ & $\rightarrow$ & $\rightarrow$ & $\rightarrow$ & $\rightarrow$ & $\rightarrow$ & $\begin{array}{c}\uparrow \uparrow \uparrow \uparrow \\
\end{array}$ & n.d. & $\rightarrow$ & $\rightarrow$ \\
\hline & $96 \mathrm{~h}$ & $\rightarrow$ & $\rightarrow$ & $\downarrow \downarrow \downarrow$ & $\downarrow \downarrow$ & $\uparrow$ & $\rightarrow$ & $\downarrow \downarrow \downarrow \downarrow$ & $\rightarrow$ & $\downarrow \downarrow$ & $\uparrow \uparrow \uparrow \uparrow$ & $\downarrow \downarrow$ & $\downarrow \downarrow$ & $\rightarrow$ & n.d. & $\rightarrow$ & 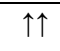 \\
\hline & 1,5 Monate & $\rightarrow$ & $\rightarrow$ & $\downarrow \downarrow \downarrow \downarrow \downarrow$ & $\rightarrow$ & n.d. & $\rightarrow$ & $\rightarrow$ & $\rightarrow$ & $\rightarrow$ & $\rightarrow$ & $\rightarrow$ & $\rightarrow$ & $\rightarrow$ & n.d. & $\rightarrow$ & $\rightarrow$ \\
\hline & 3 Monate & $\rightarrow$ & $\rightarrow$ & $\rightarrow$ & $\rightarrow$ & n.d. & $\rightarrow$ & $\rightarrow$ & $\rightarrow$ & $\rightarrow$ & 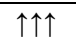 & $\rightarrow$ & $\rightarrow$ & $\rightarrow$ & n.d. & $\rightarrow$ & 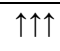 \\
\hline \multirow{6}{*}{$\begin{array}{c}\text { Colon } \\
\text { (ggf.Streustrahlung) }\end{array}$} & $1 \mathrm{~h}$ & $\rightarrow$ & $\rightarrow$ & $\rightarrow$ & $\uparrow \uparrow \uparrow \uparrow$ & n.d. & $\rightarrow$ & $\rightarrow$ & $\rightarrow$ & $\downarrow \downarrow$ & $\rightarrow$ & $\downarrow \downarrow \downarrow$ & $\downarrow$ & $\rightarrow$ & \multirow{6}{*}{ 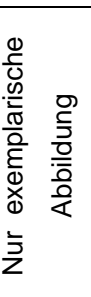 } & $\rightarrow$ & $\rightarrow$ \\
\hline & $6 \mathrm{~h}$ & $\rightarrow$ & $\rightarrow$ & $\rightarrow$ & $\rightarrow$ & n.d. & $\rightarrow$ & $\rightarrow$ & $\rightarrow$ & $\downarrow \downarrow$ & $\rightarrow$ & $\downarrow \downarrow$ & $\downarrow \downarrow$ & $\rightarrow$ & & $\rightarrow$ & $\rightarrow$ \\
\hline & $24 \mathrm{~h}$ & $\rightarrow$ & $\rightarrow$ & $\rightarrow$ & $\rightarrow$ & n.d. & $\rightarrow$ & $\rightarrow$ & $\rightarrow$ & $\rightarrow$ & $\rightarrow$ & $\rightarrow$ & $\rightarrow$ & $\rightarrow$ & & $\rightarrow$ & $\overline{\uparrow \uparrow}$ \\
\hline & $96 \mathrm{~h}$ & 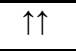 & $\rightarrow$ & $\rightarrow$ & $\uparrow \uparrow \uparrow$ & n.d. & $\rightarrow$ & $\rightarrow$ & $\rightarrow$ & $\rightarrow$ & $\downarrow \downarrow$ & $\rightarrow$ & $\downarrow \downarrow$ & $\rightarrow$ & & $\rightarrow$ & $\overline{\uparrow \uparrow}$ \\
\hline & 1,5 Monate & $\rightarrow$ & $\uparrow \uparrow$ & $\rightarrow$ & $\rightarrow$ & n.d. & $\downarrow$ & 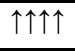 & $\rightarrow$ & $\uparrow \uparrow$ & $\downarrow \downarrow$ & $\rightarrow$ & $\rightarrow$ & $\rightarrow$ & & $\rightarrow$ & $\uparrow \uparrow$ \\
\hline & 3 Monate & $\rightarrow$ & $\downarrow$ & $\rightarrow$ & $\rightarrow$ & n.d. & $\rightarrow$ & $\rightarrow$ & $\rightarrow$ & $\rightarrow$ & $\rightarrow$ & $\rightarrow$ & $\downarrow \downarrow$ & $\rightarrow$ & & $\rightarrow$ & $\uparrow$ \\
\hline
\end{tabular}

${ }^{1}=$ histologische/immunhistochemische Färbung; ${ }^{2}=\mathrm{PCR} ;{ }^{3}=$ Western Blot. Für H.E.-Schnitte Kriterien der Gewebeschädigung nach Carr 2001 und für PCR fold changes verwendet $\uparrow=$ leichte Hochregulation, $\uparrow \uparrow=$ mittlere Hochregulation, $\uparrow \uparrow \uparrow=$ starke Hochregulation, $\uparrow \uparrow \uparrow \uparrow=$ extreme Hochregulation

$\downarrow=$ leichte Herunterregulation, $\downarrow \downarrow=$ mittlere Herunterregulation, $\downarrow \downarrow \downarrow=$ starke Herunterregulation, $\downarrow \downarrow \downarrow \downarrow=$ extreme Herunterregulation

$\rightarrow=$ keine signifikanten Veränderungen (PCR), bei Histologie normale Erscheinung / physiologischen Alterationen entsprechend 


\section{DISKUSSION}

Ionisierende Strahlen werden als Routineverfahren in der Therapie maligner Tumore angewandt. Bei der Bestrahlung abdomineller Organe kommt es häufig zum Auftreten von Akut- und Spätschäden im Darmbereich, die einen dosislimitierenden Faktor für die Bestrahlung darstellen. Da experimentelle Untersuchungen zu Strahlenschäden am humanen Darm nicht möglich sind, und hierzu lediglich Fallberichte vorliegen, müssen Studien am Tiermodell erfolgen. Im Rahmen dieser Arbeit wurden erstmals Strahlenschäden an einzelnen Darmabschnitten nach perkutaner Einzeitbestrahlung der Leber an einem Rattenmodell untersucht.

\subsection{Bestrahlungsmodelle}

Als Bestrahlungsmodell wurde die perkutane Einzeitleberbestrahlung gewählt. Zum einen stellt die Leber der Ratte ein einfaches Bestrahlungsziel dar, zum anderen hat die Leberbestrahlung beim Menschen in den letzten Jahren mit der Entwicklung neuer selektiver Bestrahlungstechniken erneut an Bedeutung gewonnen. Sie ermöglicht sowohl bei bösartigen Lebertumoren, als auch bei Metastasen neben der nebenwirkungsreichen Chemotherapie eine weitere Behandlungsoption zur lokalen Therapie. Bisher wird ihr Einsatz durch die Nebenwirkungen am Darm limitiert (Berbeco et al. 2005; Christiansen et al. 2006; Christiansen et al. 2007; Schefter et al. 2005; Wang S. et al. 1995). Genauere Untersuchungen zur Leberbestrahlung und ihrer Wirkung innerhalb der Leber werden von Christiansen und Kollegen erforscht (Christiansen et al. 2006; Christiansen et al. 2007; Moriconi et al. 2008; Qesaraku et al. 2009). Wir fokussierten unser Interesse auf die akuten frühen Strahlenschäden (1 h, 6 h, 24 h und 96 h), sowie die späten Strahlenschäden (1,5 Monate und 3 Monate) der verschiedenen Dünn- und Dickdarmabschnitte (Duodenum, Jejunum, Ileum und Colon). Durch ihre anatomische Lage sind die proximalen Dünndarmabschnitte, insbesondere das Duodenum und das Jejunum, direkter Strahlung ausgesetzt, während das Ileum und das Colon außerhalb dieses Bestrahlungsfeldes liegen (siehe Abb. 2). Mit diesem Bestrahlungsmodell wurden zum ersten Mal Nebenwirkungen am Darm untersucht, während ein parenchymatöses Organ das Ziel der Bestrahlung war.

In den bisher beschriebenen Modellen sind zwar vielfach die Darmschäden nach Bestrahlung untersucht worden, allerdings wurde entweder eine Ganzkörperbestrahlung (Paris et al. 2001), eine Bestrahlung des gesamten Abdomens (Olgaç et al. 2006) oder eine Bestrahlung nach Exkorporation des Darms (Haydont et al. 2007; Rubio und Jalnäs 1996) bzw. nach chirurgisch angelegter, artifizieller Skrotalhernie im Tierexperiment durchgeführt (Denham et al. 2000). Diese Modelle dienen einem grundsätzlichen Verständnis der Effekte ionisierender Strahlen. Für die bisherige 
klinische Anwendung ist der Darm jedoch, mit Ausnahme des Rektums, ,innocent Bystander“ vergleichbar mit unserem Modell. Auch eine Gegenüberstellung der einzelnen Darmabschnitte bezüglich ihrer Reaktion auf die Bestrahlung ist in den direkten Bestrahlungsmodellen bisher nicht untersucht worden.

\subsubsection{Wahl der Darmabschnitte und Zeitpunkte nach Bestrahlung}

Die Wahl der Darmabschnitte und Zeitpunkte ging aus einem Vorversuch hervor. Zunächst wurden für den ersten Versuch Gewebeproben zu den Zeitpunkten 0 h, 0,5 h, 1 h, 3 h, 6 h, 24 h, 48 h und $96 \mathrm{~h}$ nach Bestrahlung aufgearbeitet. Im Laufe der Untersuchungen zeigte sich, dass keine signifikanten Unterschiede zwischen den sehr dicht beieinanderliegenden frühen Zeitpunkten erhoben werden konnten, so dass wir auf eine weitere Datenerhebung zu den Zeitpunkten 0,5 h, $3 \mathrm{~h}$ und $48 \mathrm{~h}$ verzichteten. Basierend auf den Erfahrungen von Potten, sollten mit den Zeitpunkten bis 24 h die akuten, frühen Strahlenschäden untersucht werden (Potten 1992). Außerdem fokussierte sich unser Interesse auf die Zeitpunkte 1,5 Monate und 3 Monate, um prolongierte Strahlenschäden zu erfassen. Carr beschreibt dabei den „,cutoff point“ für Langzeitschäden bei 4 Wochen nach Radiatio (Carr 2001).

Bei den Untersuchungen des Darms haben wir, anders als die Forschungsgruppen von Forsberg, Black, Jensen, Rubio, Liu Y., Carr und deren Kollegen, sowohl den Dünndarm, als auch den Dickdarm untersucht (Black et al. 1980; Carr 2001; Forsberg et al. 1979; Jensen et al. 1983; Liu Y. et al. 2009; Rubio und Jalnäs 1996). Die meisten Ergebnisse der oben genannten Forschungsgruppen wurden in einem Strahlenschädigungs-Score, basierend auf den Daten von bestrahltem Dünndarm, zusammengefasst. Hervorzuheben sind die Untersuchungen von Black und Liu Y.. Diese untersuchten die späten Strahlenschäden ab 4 Wochen bzw. ab 90 Tagen nach Bestrahlung im Dickdarm (Black et al. 1980; Liu Y. et al. 2009).

Angelehnt an die o.g. Forschungsprojekte wählten wir als Darmabschnitte des Dünndarms das Duodenum, Jejunum und Ileum und das terminale Colon. Da sich die einzelnen Darmabschnitte in ihrem anatomischen Aufbau, ihrer Struktur und Funktion unterscheiden, war uns eine getrennte Beurteilung wichtig. Beim Menschen wird der Dünndarm in drei Abschnitte unterteilt, die man auch bei der Ratte wiederfindet. Das Duodenum wird durch das Treitz'sche Band vom Jejunum abgegrenzt. Das Jejunum nimmt etwa $40 \%$ und das Ileum $60 \%$ des Dünndarms ein (Nakshabendi et al. 1999). Als Dünndarmabschnitte wurden zum einen das Duodenum und Jejunum gewählt, da diese auf Grund ihrer anatomischen Position angrenzend an der Leber zu liegen kommen, und somit einer Strahlendosis bis 25 Gy bzw. 12 Gy ausgesetzt sind. Wir erwarteten in diesen Darmabschnitten direkte Nebenwirkungen der Leberbestrahlung. Zum anderen wurden das Ileum 
und das Colon entnommen. Die Untersuchungen dieser Darmabschnitte fokussierten sich auf indirekte Schäden oder solche, die durch sehr kleine Dosen (Streustrahlung) nach Bestrahlung der Leber verursachtet worden sind. Anatomisch zeigt sich, dass der äußere Umfang des Dünndarms nach distal abnimmt und die zirkulären Falten der Mukosa (Kerckring'sche Falten) flacher werden. Auch die Peyer'schen Plaques unterscheiden sich. Die jejunalen Peyer'schen Plaques haben mehr intraepitheliale Lymphozyten als die ilialen Peyer'schen Plaques (Pabst und Rothkotter 1999; Po Po et al. 2005; Wolf et al. 1981). Dabei gelten die Peyer'schen Plaques des Ileums als größtes primäres lymphoides Organ (Po Po et al. 2005). An der Konfiguration der Dünndarmzotten zeigen sich ebenfalls Unterschiede: Im Duodenum sind die Zotten breiter und fast blattähnlich, im Jejunum schmal und im Ileum kürzer, etwas breiter und fingerartig (Nakshabendi et al. 1999). Die Durchblutung und Mikrozirkulation ist im Jejunum insgesamt besser als im Ileum, berücksichtigend, dass auch im Jejunum die Resorption von Nahrung erhöht ist (Floch et al. 1966; Ottaway und Parrott 1980). Bezüglich des Colons ist festzuhalten, dass die Colonkrypten nach distal tiefer werden und die Mukusproduktion zunimmt (Bufill 1990; Glebov et al. 2003).

\subsubsection{Methodische Durchführung}

Strahlentoxizität, oxidativer Stress und Apoptose sind eng miteinander gekoppelte Prozesse. Schon milde Oxidationsprozesse können Apoptose triggern, während es bei erhöhtem oxidativen Stress zu Nekrose kommen kann (Lennon et al. 1991). Fest steht, dass Apoptose an sich im Gegensatz zur Nekrose keine entzündliche Reaktion induziert (Haanen und Vermes 1995). Zur Untersuchung der Darmschäden nach Radiatio eines parenchymatösen Organs wurde die perkutane Einzeitbestrahlung mit 25 Gy der Leber gewählt. Das Probenmaterial wurde mit Hilfe von vier Methoden untersucht, deren Ziel es war, Apoptose, Nekrose, Entzündungsreaktionen, Veränderungen an den Gefäßen und Fibrosierung des Darms zu untersuchen. Dabei wurden histopathologische Veränderungen im zeitlichen Verlauf an den einzelnen Darmabschnitten verglichen. Die Durchführung des Western Blots stellte die Protein-Expression von pro- und antiapoptotischen Proteinen gegenüber, die wiederum durch die PCR-Ergebnisse und denen der immunhistochemischen Färbungen untermauert werden konnten. Außerdem sollten durch die RT-PCR neben apoptotischen Prozessen, Zytokine als Hinweis für inflammatorische Ereignisse, Chemokine als Mediatoren der Migration von Immunzellen und Adhäsionsmoleküle detektiert werden. Um strahleninduzierte Apoptose beweisen zu können, wurde immunhistochemisch hinzufügend die TUNEL-Methode verwendet. Die eindeutige Differenzierung von Apoptose und Nekrose erfolgte durch eine DNA-Elektrophorese. 
Hall et al. konnten mit Hilfe der ISEL-Färbe-Methode (In situ end-labeling) zeigen, dass es bei unterschiedlicher Präparation und Fixation zu Alterationen in der Zellmorphologie des Gewebes kommen kann. Hierfür eröffneten sie zunächst den Darm longitudinal und fixierten diesen sofort. Dies zeigte in der ISEL-Färbe-Methode nur wenig ISEL-positive Zellen zur Zottenspitze hin. Im Gegensatz dazu wurde demonstriert, dass Präparate, die mit 15-minütiger Verzögerung fixiert wurden, einen dramatischen Anstieg der ISEL-positiven Zellen besonders weiter unten an den Zotten aufwiesen. Die Präparate, die sowohl verzögert, als auch ohne vorherige Eröffnung des Lumens fixiert wurden, präsentierten die höchste Anzahl ISEL-positiver Zellen. Außerdem beschreibt Hall, dass es bei zu schwacher Fixierung, besonders wenn intraluminal noch Stuhlreste vorhanden waren, zu vermehrtem Zelldebris mit apoptotischen Veränderungen kommt (Hall et al. 1994).

Unter Kenntnisnahme dieser Ergebnisse wurden in unserem Versuch die Darmabschnitte zügig vom Rektum ausgehend separiert. Die Präparate wurden vorsichtig mit $0,9 \% \mathrm{NaCl}$ über eine 1-mlSpritze gespült, longitudinal eröffnet und in einem Becher mit 0,9\% $\mathrm{NaCl}$ geschwenkt um Stuhlreste zu entfernen. Zur Fixierung der zur Histologie gewonnenen Gewebeproben wurde in unserem Hauptversuch zum einen die klassische Formalinlösung, und zum anderen Bouin's Fixativ (siehe 2.6) verwendet. Für die übrigen Versuche wurden die Proben in flüssigem Stickstoff konserviert und bei $-80^{\circ} \mathrm{C}$ gelagert. Bei den in Formalin eingelegten Gewebestücken fiel schon nach kürzester Lagerung ein Zerfall und eine Entfärbung des Gewebes auf, so dass letztendlich alle Proben für histologische Untersuchungen mit Bouin’s Fixativ fixiert wurden.

Die genaue Identifizierung von apoptotischen Zellen im Gastrointestinaltrakt gestaltet sich als besonders schwierig. Apoptose lässt sich zwar anhand von Apoptosekörperchen erfassen, jedoch sind diese nur ca. eine Stunde nach Beginn des apoptotischen Prozesses in histologischen Färbungen zu detektieren (Hall et al. 1994). Diese schnelle Clearance der Apoptosekörperchen wird durch Phagozytose von Nachbarzellen oder von Makrophagen verursacht (David 1967). Hinzu kommt, dass sich apoptotische Zellen zwar in einer H.E.-Übersichtsfärbung identifizieren lassen, sie aber durch ihre ähnliche Färbeeigenschaft mit intraepithelialen Lymphozyten des Dünn- und Dickdarms verwechselt werden können, und dies zu einer Missinterpretation führen kann (Hall et al. 1994; Kerr et al. 1972). Um diese Problematik zu umgehen, führten wir die TUNEL-Färbung neben der ED1- und CD3-Färbung zur Darstellung von Lymphozyten und Makrophagen durch. Die H.E.-Färbung diente zur Beurteilung makrostruktureller Veränderungen am Gewebe nach Photonenbestrahlung. Unterstützend zur H.E.-Routinefärbung wurde die Masson-Goldner- 
Trichromfärbung zur Darstellung von Bindegewebe und zum Nachweis von Erythrozytenkongestionen im Blutgefäß durchgeführt.

Morphologische Veränderungen nach Bestrahlung treten in den unterschiedlichen Kompartimenten der Darmwand auf. Eine Möglichkeit, einen Überblick über die Komplexität der Gewebeschädigung zu gewinnen, ist, die unterschiedlichen Parameter in einem Score zusammenzufassen. Wir orientierten uns in unserem Versuch an den Studien von Carr, die sich wiederum auf die Daten von Forsberg, Jensen, Carr, Rubio, Black und Kollegen stützten (Black et al. 1980; Carr 2001; Forsberg et al. 1979; Jensen et al. 1983; Rubio und Jalnäs 1996). Während sich Forsberg nur auf epitheliale und stromale Veränderungen im Dünndarm nach Bestrahlung konzentrierte, stellte Jensen ein Multiparametersystem auf, den sogenannten „radiation injury score“, in dem mehrere strukturelle Veränderungen der Darmwand untersucht wurden (Forsberg et al. 1979; Jensen et al. 1983). 1996 präsentierten Rubio und Jalnäs erstmals eine genaue Klassifizierung der histologischen Veränderungen am Darm (Rubio und Jalnäs 1996). Dabei wurden dosis- und zeitabhängige Strahlenschäden mit nur zeitabhängigen Veränderungen nach Bestrahlung verglichen. Hierfür untersuchten sie 16 histologische Parameter an Paraffinschnitten. Dazu zählten als dosis- und zeitabhängig: Nekrose der Epithelzellen, Verlust von Becherzellen, Abszesse in den Krypten, strukturelle Veränderungen in den Krypten, Verlust von PanethKörnerzellen, erniedrigte Anzahl von Mitosen, Schleimhautulzerationen, Abnahme der Einwanderung von intraepithelialen und in der Lamina propria gelegenen Lymphozyten, vermehrt Kollagen in der Submukosa, der Muskularis propria und in der Subserosa und ektope Drüsenzellen, während als zeit- aber nicht dosisabhängig schlägerförmige oberflächliche Epithelzellen, Blutkongestion und erhöhte Anzahl von Stromazellen beobachtet wurden (Rubio und Jalnäs 1996). Unter Beachtung dieser Studien erstellten wir einen 5-Punkte-Score, der sich sowohl für die Auswertung des Dünndarms, als auch für die Beschreibung der Strahlenschäden am Dickdarm eignet. Entsprechend des Scores wird das Gewebe anatomisch entlang der Krypten-Zotten-Achse begutachtet. Während der erste Punkt ein vitales Epithel widerspiegelt, findet sich bei Punkt 2 abgeflachte Schleimhaut. Der dritte Punkte beinhaltet neben den Beobachtungen von Punkt 2 ödematöse Zotten. Außerdem treten hier Vakuolen auf. Chiu bezeichnet diese in seiner Publikation von 1970 als Grünhagen-Raum. Diese werden als Erscheinungen eines ischämischen Ereignisses interpretiert (Chiu et al. 1970). Punkt 4 beschreibt denudierte Zotten. Eine Epithelschicht ist nicht mehr darstellbar. Punkt 5 fasst die stärksten Strahlenschäden zusammen und zeigt neben den vorbeschriebenen Destruktionen geschädigte Krypten. 
Bei der TUNEL-Färbung fiel unter gleichen Untersuchungskonditionen eine deutliche Vielfalt der qualitativen Ergebnisse aufeinanderfolgender TUNEL-Färbungen auf. Die Validität eines TUNELAssays als eine Methode zur Detektion von Apoptose wird daher immer wieder diskutiert. Die Zerstörung von DNA ist nicht nur ein Merkmal von Apoptose, sondern kann auch bei Nekrose während der Reparatur von reversiblen DNA-Schäden und bei der post-mortem-Autolyse auftreten. Saraste und Pulkki beschreiben, dass die Kinetik einer TUNEL-Färbung von der Zugänglichkeit der DNA-Strangbrüche zur Färbelösung abhängig ist. Dabei spielt die Art des Gewebes und die Gewebepräparation eine wesentliche Rolle (Saraste und Pulkki 2000). Erschwerend kam bei unserem Versuch hinzu, dass nicht eine Zelllinie mit der TUNEL-Färbung untersucht werden konnte, sondern das heterogene Schleimhautgewebe des Dünn- und Dickdarms.

Auch beim Western Blot gestaltete es sich als schwierig, dass nicht nur eine Zelllinie untersucht wurde, sondern ein heterogenes Proteingemisch. $\beta$-Aktin wurde als House-keeping Gen für den Western Blot verwendet. Die Proteinexpression von $\beta$-Aktin erweist sich auch nach Bestrahlung als stabil. Zum Nachweis von Apoptose bedienten wir uns folgender Antikörper: Caspase 8, Caspase 3, Bax und Bcl-2. In den Western Blot Darstellungen von Caspase 8 und Caspase 3 werden, wie in Abb. 19, Abb. 20, Abb. 21, Abb. 22 und Abb. 23 zu sehen ist, je nach Aktivierung multiple Banden abgebildet. Dabei zeigt sich, dass das Proenzym teilweise nicht komplett gespalten wird. Dies lässt vermuten, dass sich die aktiven Untereinheiten der Caspasen während des Versuches wieder zu Dimeren verbunden haben. Daher haben wir versucht, durch eine längere Inkubationszeit der Proben im Heizblock eine stärkere Denaturierung der Proteine zu erreichen. Bei dem Antikörper Bax zeigen sich insgesamt nur schwache Banden im Western Blot. Trotz hoher AntikörperKonzentrationen 1:25, langer Belichtungszeiten zwischen 15-30 min und mehrfacher Durchführung des Versuches gestaltete es sich als schwierig, Bax als deutliche Bande im Western Blot darzustellen. Die Hypothese der Dimerbildung kann auch bei Bax vermutet werden. Oltvai und Yang E. bestätigen in ihren Veröffentlichungen von 1993 und 1995, dass Bax und Bcl-2 homogene oder sogar heterogene Dimere bilden können. Diese Dimere sind sowohl verstärkend, als auch hemmend wirksam (Oltvai et al. 1993; Yang E. et al. 1995). Ferner beschreibt Oltvai, dass wenn Bcl-2-Monomere im Überschuss vorhanden sind, Apoptose gehemmt wird. Im Gegensatz dazu wird Apoptose eingeleitet, wenn Bax-Homodimere überwiegend bestehen (Oltvai et al. 1993). Wie in Abb. 24 dargestellt ist, kann beim Western Blot von Bax häufig eine Bande bei $42 \mathrm{kDa}$ dargestellt werden. Dies lässt den Schluss zu, dass sich aus den $21 \mathrm{kDa}$-großen Banden Dimere mit einer Größe von 42 kDa gebildet haben. Der Gegenspieler der Apotose Bcl-2 lässt sich im Western Blot sehr gut abbilden. Zwar sind hohe Antikörperkonzentrationen von 1:50 notwendig, aber nur eine 
kurze Belichtungszeit führt zu klaren Bcl-2-Banden, so dass ein starkes Hintergrundrauschen vermieden werden kann.

Mit der Durchführung der DNA-Gelelektrophorese sollte apoptotische DNA als Folge von Bestrahlung im Gegensatz zu nekrotischem DNA-Material abgebildet werden. In der DNAGelelektrophorese können nur eindeutige Banden bei 180 bp gezeigt werden, jedoch keine Dimere oder Trimere der 180 Basenpaare. Außerdem ist durch eine Überbelichtung des Gels die Aufteilung der Banden bei Apoptose nicht eindeutig von den zu erwartenden Schlieren bei Nekrose zu differenzieren. Letztendlich gilt auch für diesen Versuch, dass nicht bestrahlte Zellkulturen verwendet wurden, sondern Gewebestücke heterogenen Materials.

\subsection{Pathologische Veränderungen am Darm in Folge von Bestrahlung}

Schon 1897 wurde von Walsh beobachtet, dass die Strahlenschäden dosisabhängig und gewebeabhängig sind. Er beschrieb, dass am Darm die Schädigungen stärker in den Lieberkühnkrypten als am Zottenepithel nachweisbar sind (Walsh 1897). Regaud et al. beobachteten 1912, dass die Mukosa des Dünndarms wesentlich strahlensensibler als die des Magens oder des Dickdarms ist (Regaud et al. 1912). Nachdem im Verlauf von fast hundert Jahren gezeigt werden konnte, dass DNA-Schäden und Apoptose einen wichtigen Vorgang im Gewebe nach Bestrahlung darstellen, gilt es nun die weiteren Mechanismen zu untersuchen.

In vorangegangenen Studien wurde vermutet, dass die Schwere der intestinalen Strahlentoxizität ausschließlich von dem Ausmaß der intestinalen Kryptzellschädigung abhängig ist (Potten 2004). Diesem Gedanken stehen die Forschungsergebnisse von Paris und Kollegen gegenüber. Sie konnten beweisen, dass sowohl Veränderungen der zellulären Funktion, insbesondere der Endothelzellen mit nachfolgender Hypoxie des Mukosagewebes, als auch sekundäre Veränderungen wie Entzündungsreaktionen ursächlich für die Strahlenschäden sind (Paris et al. 2001; Schefter et al. 2005).

In der Zusammenschau zeigt sich, dass die akute Strahlenreaktion des Gewebes durch Schädigung mitotischer Zellen an den intestinalen Krypten verursacht wird, und sich chronische Bestrahlungsschäden durch Schädigung weniger mitotisch aktiver Zellen, wie z.B. Endothelzellen äußern (Wang J. et al. 2007). So lassen sich heute Strahlenschäden nicht nur monokausal auf Apoptose zurückführen, vielmehr ist es eine komplexe Antwort des Gewebes, die sich durch Apoptose, Nekrose, entzündliche Prozesse, Veränderungen der Gefäße und letztendlich Fibrosierung des Darmgewebes erklärt. 


\subsubsection{Apoptose: Direkte Antwort auf Bestrahlung}

Apoptose ist ein wichtiger Mechanismus zur Aufrechterhaltung eines Gleichgewichts von Zellproliferation und Zellelimination (Potten et al. 1997). Unter physiologischen Bedingungen weisen die Krypten des Dünndarms ein spontanes Level von Apoptose von ungefähr einer programmiert sterbenden Zelle in jeder fünften Krypte auf (Potten 1992). Die Epithelschicht im Darm erneuert sich alle zwei bis drei Tage im Nage- und Säugetier (Hall et al. 1994). Der hohe Zellumsatz wird durch eine enorme Zellproduktion, Proliferation, Differenzierung und konstante Migration entlang der Krypten-Zotten-Achse ermöglicht (Potten 2004). Die schnelle Regeneration geht aus der Teilung von pluripotenten Stammzellen hervor. Diese sind im Dünndarm circa vier Zellen über der Kryptenbasis, oberhalb der Paneth-Körner-Zellen lokalisiert, während sie im Dickdarm an der Basis der Krypten platziert sind (Potten 1992). Des Weiteren beschreibt Potten, dass die im Dünndarm durch Bestrahlung oder zytotoxische Medikamente geschädigten Zellen, die in Apoptose übergehen, weitgehend übereinstimmend mit der Lokalisation von Stammzellen in Position 4 der Zellreihen sind. Im Colon hingegen sind apoptotischen Zellen in der siebten Zellreihe platziert, während die Stammzellen in der ersten oder der zweiten Reihe vermutet werden. Beim Überleben von nur einer Stammzelle kann sich die Krypte wieder vollständig erholen (Potten 1990). Außerdem kann sich ein gänzlich normal aussehendes Epithel aus $4 \%$ der überlebenden Krypten regenerieren (Potten 2004).

Ergänzend zeigt Potten eine Zellzykluszeit im Dünndarm von 12 h, während es im Colon zu einem prolongierten Zellzyklus von über 24 h kommt. Diesen verlängerten Zellzyklus im Colon erklärt er durch eine besonders lange G1-Phase (Potten 1986). Er vermutet, dass Zellen, die eine lange G1Phase besitzen, möglicherweise unempfindlicher sind. Die Tendenz in Apoptose überzugehen ist bei Zellen in der G2-Phase höher. Dies lässt den Schluss zu, dass Stammzellen, die eine längere G1-Phase besitzen, resistenter auf apoptotische Signale reagieren (Ijiri und Potten 1990). Potten sieht unter anderem hierin eine Erklärung dafür, dass Mutationen im Dünndarm durch Apoptose schneller eliminiert werden, und pathologische Veränderungen der Zellen z.B. die Entwicklung von Tumoren wesentlich seltener als im Colon sind (Ijiri und Potten 1990; Potten et al. 1992). Für unseren Versuch sind diese Erkenntnisse von Potten insofern von Bedeutung, als sie einen Ansatz der Erklärung bieten, warum das Ileum im Gegensatz zum Colon eine stärkere Reaktion auf Bestrahlung aufweist, obwohl sie beide außerhalb des Bestrahlungsfeldes liegen. Hinzufügend beschreiben Nakshabendi et al., dass die Zellerneuerung innerhalb des Dünndarms in den proximalen Abschnitten am schnellsten ist (Nakshabendi et al. 1999). So erklärt sich, warum es im Duodenum und Jejunum nach Ablauf von 3 Monaten zu einer Restitution kommt, während die Reparaturmechanismen im Ileum prolongiert erscheinen. 
In vorangegangenen Studien wurden erste Anzeichen für Apoptose bereits $1 \mathrm{~h}$ nach Bestrahlung mit Dosen zwischen 0,15 und 9 Gy beobachtet. Außerdem konnten Potten et al. zeigen, dass durch Bestrahlung induzierte Apoptose einen Peak nach 3-6 h erreicht. Danach erfolgt eine Abnahme der Apoptoserate diagnostiziert anhand der Apoptosekörperchen bis zum 24 h-Zeitpunkt. Dieser Rückgang in der Anzahl der Apoptosekörperchen wird darauf zurückgeführt, dass die apoptotischen Fragmente phagozytiert werden und von benachbarten, intakten Zellen verdaut werden. Die benachbarten Zellen wandern ihrerseits wiederum entlang der Krypten nach oben und werden schließlich ins Lumen abgeschieden (Potten 1992). Diese Migration entlang der Krypten-ZottenAchse spielt besonders eine Rolle, denn bestrahlungsinduzierte Apoptose tritt im Wesentlichen an der Basis der Krypten und nur teilweise entlang der Krypten-Zotten-Achse auf (Ijiri und Potten 1990). Mit der Zeit werden reife Zellen ins Darmlumen abgeschilfert. Es kommt aber zu keiner Wanderung der Zellen entlang der Krypten-Zotten-Achse mehr, da die Zellen durch die Bestrahlung in den Krypten zu Grunde gegangen sind (Brown 2008). Diese Nachschubinsuffizienz zeigt sich auch in unseren Versuchen. Abb. 6 verdeutlicht, dass hierbei besonders das Ileum betroffen ist. Diese Abbildung belegt, dass die Zeitpunkte $6 \mathrm{~h}$ bis $96 \mathrm{~h}$ am stärksten geschädigt sind. Hier erscheint die Epithelschicht komplett destruiert. Es lässt sich eine Verkürzung der Zotten und eine Schädigung des Dünndarmgewebes an der Kryptenbasis darstellen. Potten zeigt, dass Schädigungen im Dünndarm, besonders 3-6 h nach Bestrahlung, in deutlicher Abhängigkeit zur Strahlendosis stehen. Dies lässt ihn schlussfolgern, dass der Dünndarm zu den sensitivsten Organen der Säugetiere bei Versuchen in vivo gehört (Potten 1992).

Bei der perkutanen Bestrahlung der Leber können wir darstellen, dass es in den Dünndarmabschnitten Duodenum und Jejunum bereits $1 \mathrm{~h}$ nach Bestrahlung zu einer deutlichen Schädigung des Gewebes kommt. Olgaç schildert, dass es bei abdomineller Einzeitbestrahlung der Ratte zu einer signifikanten Abnahme der Anzahl und der Höhe der Villi kommt (Olgaç et al. 2006). Entgegen der Vermutung, dass die stärksten Strahlenschäden in den im unmittelbaren Bestrahlungsfeld der Leber liegenden Darmabschnitten (Duodenum und Jejunum) auftreten, beobachten wir, dass es im Ileum zur stärksten Schädigung kommt, obwohl es außerhalb des Bestrahlungsfeldes liegt. Das Ileum zeigt in den H.E.-Schnitten einen kompletten Zerfall der Darmzotten und eine Zerstörung der Krypten bereits $6 \mathrm{~h}$ nach Bestrahlung. Auch im Verlauf von 3 Monaten nach Bestrahlung ist es im Gewebe des Ileums noch nicht zu einer kompletten Regeneration gekommen. Das Duodenum und das Jejunum zeigen zwar eine sofortige Schädigung nach Bestrahlung, jedoch kommt es hier nach Ablauf von 3 Monaten zu einer Wiedererlangung der Gewebeintegrität. 
Unterstützend $\mathrm{zu}$ den histologischen Ergebnissen werden zur Diagnostik von Apoptose die Caspasen hinzugezogen. Der extrinische bzw. Rezeptor-vermittelte Weg der Apoptose kann anhand der Proteinexpression von Caspase 8 dargestellt werden. Auch hier fällt auf, dass es im Duodenum und Jejunum früh nach Bestrahlung $\mathrm{zu}$ Apoptose kommt. Während in diesen beiden Darmabschnitten ein Rückgang der Caspase-8-Aktivität nach 6 h beschrieben werden kann, ist im Ileum eine Caspase-8-Expression bis 96 h nach Bestrahlung nachvollziehbar. Ähnliche Ergebnisse zeigen sich für die Haupt-Effektor-Caspase 3. Caspase 3 ist wie Abb. 1 zeigt, sowohl am extrinsischen, als auch am intrinsischen Weg der Signalkaskade der Apoptose beteiligt. Auch hier präsentieren sich das Duodenum und Jejunum bis $6 \mathrm{~h}$ nach Bestrahlung mit Caspase-3-positiven Banden. Im Ileum erscheinen diese bis einschließlich 96 h. Die Caspase-3-Färbung zeigt hinzufügend, dass im Ileum 3 Monate nach Bestrahlung noch Apoptose nahe der Basis der Krypten auftritt. Ein persistierender apoptotischer Untergang an dieser Lokalisation bedeutet also, dass das Gewebe bis dato noch keinen gesunden Aufbau erreicht hat. Im Colon kann nach $6 \mathrm{~h}$ und nach $96 \mathrm{~h}$ eine Caspase-3-Expression als Hinweis für apoptotische Prozesse nachgewiesen werden.

Ergänzend zu den Caspasen wurden sowohl die pro-, als auch die antiapoptotischen Mitglieder der Bcl-2-Familie untersucht. Während $\mathrm{Bcl}-2$ den intrinsischen Weg der apoptotischen Signaltransduktion hemmt, ist Bax proapoptotisch wirksam (Szabo und Tarnawski 2000). Vorbeschrieben ist dabei, dass die Bcl-2-Protein-Expression im Gesunden nur in den Zellen an der Basis der Colonkrypten vorliegt, während sie in den Krypten vom unbestrahlten Dünndarm nicht nachgewiesen werden kann. Merritt präzisiert diese Aussage noch, indem er darstellt, dass Bcl-2positive Zellen im Dünndarm nicht in der Zellposition vier bis fünf (der Stammzellregion) nachgewiesen werden können (Merritt et al. 1995). Pritchard beschreibt, dass bei Bcl-2-NullMäusen ein hohes Level von spontaner, $\gamma$-Strahlen- oder 5-FU-induzierter Apoptose besonders an der Basis der Colonkrypten zu sehen ist (Pritchard et al. 2000). Zwar kann die anatomische Lokalisation der Bcl-2-Proteinexpression im Western Blot und in der PCR nicht dargestellt werden, jedoch lässt sich eine kräftige Bande von Bcl-2 am Colon bei $26 \mathrm{kDa}$ besonders zum Zeitpunkt $6 \mathrm{~h}$ bis 96 h nachvollziehen (siehe Abb. 24). Damit werden die Ergebnisse der Caspase 3 für das Colon bestätigt. Kontrovers hierzu beschreibt Merrit, dass im Colon Apoptose fast vollständig durch eine Überexpression von Bcl-2 verhindert wird (Merritt et al. 1995). In unserem Versuch scheinen das Duodenum und das Jejunum zunächst durch eine erhöhte Expression von Bcl-2 dem apoptotischen Untergang entgegenzuwirken (siehe Abb. 24). Die parallel auftretenden Bax-Banden dieser Darmabschnitte bis $96 \mathrm{~h}$ weisen aber auf deutliche proapoptotische Signale hin. Rudner stellt in seiner Versuchsreihe dar, dass Bcl-2 bis ca. $48 \mathrm{~h}$ nach Bestrahlung den Zusammenbruch des Membranpotentials der Mitochondrien verhindert. Danach kommt es zu einem Ausstrom von 
Cytochrom C aus der Mitochondrienmembran und die Signalkaskade der Apoptose wird initiiert. Ferner beschreibt er, dass Zellen, die Bcl-2 überexprimieren, kurzfristig einen Überlebensvorteil besitzen, jedoch letztendlich das antiapoptotische Protein Bcl-2 die Strahlensensitivität nicht beeinflusst (Rudner et al. 2001). Die Daten der PCR untermauern jene der Western Blots und veranschaulichen, dass sich auch im Ileum ein signifikantes, proapoptotisches Signal ab $6 \mathrm{~h}$ bis einschließlich 96 h zeigt. Da jedoch die Wirkung der Mitglieder der Bcl-2-Familie teils reziprok sein kann, lässt sich neben der antiapoptotischen Komponente von Bcl-2 auch Bax als proapoptotsches Mitglied nachweisen. So ist Bcl-2 im Ileum zum Zeitpunkt 1,5 Monate vergleichbar hochreguliert wie Bax. Dies legt nahe, wie komplex der Mechanismus der ApoptoseInduktion und deren Inhibierung ist (Pritchard et al. 2000).

Insgesamt zeigt sich, dass apoptotische Prozesse in allen von uns untersuchten Darmabschnitten bewiesen werden können. Pritchard beschreibt, dass der Dünndarm viel anfälliger für Apoptose als der Dickdarm ist (Pritchard et al. 2000). Dennoch lässt sich die prolongierte Schädigung des Dünndarms nicht einzig und allein durch Apoptose erklären. Ferner ist es notwendig neben Apoptose weitere Pathomechanismen wie z.B. Nekrose und entzündliche Prozesse zu beleuchten, die grundlegend für die Strahlenschäden am Darm sind.

\subsubsection{Akute und chronische Strahlenenteritis}

Bestrahlungsinduzierte Enteritis wird in eine frühe, akute und eine verzögerte, chronische Form eingeteilt. Kurz nach Bestrahlung kommt es zum Absterben der schnell proliferierenden Kryptenepithelzellen und daraus resultierend $\mathrm{zu}$ einem Zusammenbruch der epithelialen Barrierefunktion und zur Entzündung der Schleimhaut. Mikroskopisch findet sich als akute Reaktion eine Schädigung der Mukosa (Coia et al. 1995). Die chronische, bestrahlungsinduzierte Enteritis wird charakterisiert durch Sklerosierung der Gefäße und progressive, intestinale Wandfibrosierung (Wang J. et al. 2007). Hier präsentiert sich mikroskopisch die chronische Veränderung in der Submukosa (Coia et al. 1995). Zur Erklärung dieser Pathomechanismen werden in unserem Modell im Wesentlichen die Daten der PCR herangezogen. Die Akute-Phase-Zytokine TNF- $\alpha$, IL-1 $\beta$, IL-6 und IL-8 werden von aktivierten Makrophagen und Endothelzellen ausgeschüttet (Von Bültzingslöwen et al. 2006). TNF- $\alpha$ wurde ursprünglich als Zytokin definiert, welches zuständig für Nekose bei Tumoren in vivo ist (Munker und Koeffler 1987). Die Studien von Haimovitz et al. schlagen vor, dass TNF- $\alpha$ in den meisten Fällen die apoptotische Form des Zelltodes initiiert (Haimovitz-Friedman et al. 1997). Außerdem wird beschrieben, dass es für die Regulation, Differenzierung und Proliferation von Immunzellen zuständig ist und dabei eine Reihe von proinflammatorischen Prozessen induziert (Ao et al. 2009). IL-1 $\beta$ ist ebenfalls ein potentes 
proinflammatorisches Zytokin. Für IL-1 $\beta$ wird berichtet, dass es eines der wenigen Zytokine ist, dass direkt durch Bestahlung hochreguliert wird (Liu W. et al. 2006). Die Ausschüttung von IL-6 wird durch IL-1 und TNF- $\alpha$ veranlasst (Indaram et al. 2000). In unserem Versuch lässt sich darstellen, dass IL-1 $\beta$ nur im Duodenum direkt $1 \mathrm{~h}$ nach Bestrahlung in eine Hochregulation mündet. Anschließend kommt es ab 1,5 Monaten im Duodenum und zu allen Zeitpunkten des Jejunums zu einer Herunterregulation. Für das Ileum können diese frühen Veränderungen nicht nachgewiesen werden. Nur zum 1 h-Zeitpunkt nach Bestrahlung kann ein Abfall von IL-6 gezeigt werden. Das für T-Lymphozyten spezifische Chemokin IP-10 zeigt zunächst in den Kontrollen einen deutlich erhöhten Wert für das Ileum. Direkt nach Bestrahlung imponieren das Duodenum, Jeunum und Colon mit erhöhten Expressionen. Im Ileum spiegelt sich stattdessen zum 96 hZeitpunkt eine Reduktion der Expression wieder. Auch die immunhistochemischen Färbungen bestätigen, dass im Ileum im Gegensatz zu den proximalen Darmabschnitten eine Abnahme der Immunzellen nachweislich ist. Die ED1-Färbung zur Markierung von CD68-positiven Makrophagen zeigt, dass im Duodenum schon $1 \mathrm{~h}$ nach Radiatio eine deutliche Infiltration des Gewebes mit Makrophagen stattgefunden hat. Eine vergleichbare Einwanderung von Makrophagen kann weder im Jejunum, noch im Ileum nachvollzogen werden. Die PCR-Ergebnisse für ED1 bestätigen jene, die sich in der immunhistochemischen Färbung zeigen. Unterstützend fällt in der Genexpression von ED2 auch eine signifikante Zunahme nach $6 \mathrm{~h}$ im Duodenum auf. In der immunhistochemischen Färbung für CD3-positive Lymphozyten ist im Ileum nach einem primären Anstieg $1 \mathrm{~h}$ nach Bestrahlung ein signifikanter Abfall bis 1,5 Monate bezeichnend. Darüber hinaus zeigt die CD34-Färbung eine Repopulation von CD34-positiven Zellen 3 Monate nach Bestrahlung im Duodenum und Jejunum, während dieser Effekt im Ileum fehlt. Diese zu beobachtenden morphologischen Veränderungen lassen sich zum einen durch eine Abschilferung der Immunzellen in das Lumen nach $96 \mathrm{~h}$ im Ileum erklären. Zum anderen scheint es in diesem Zusammenhang erneut von Bedeutung zu sein, dass das Jejunum im Gegensatz zum Ileum eine bessere Durchblutung aufweist und somit auch eine profundere Mikrozirkulation von Immunzellen ermöglicht (Ottaway und Parrott 1980).

Letztendlich ist es für das Ileum ebenfalls von Bedeutung, dass neben signifikanter Apoptose der schnell proliferierenden Epithelzellen auch Nekrose als Resultat maximaler Schädigung nachweisbar ist (siehe Abb. 25). Und so kommt es konsekutiv auch auf diesem Weg zu einer Abnahme der Immunzellen und damit geminderten Rekrutierung von Reparaturmechanismen. Zusammenfassend zeigen diese Daten, dass wir in unseren Versuchen nicht nur die von Rubio und Jalnäs beschriebene Abnahme von Lymphozyten bestätigen können, sondern ergänzend auch der zu Grunde liegende Pathomechanismus beleuchtet wird (Rubio und Jalnäs 1996). 
Vozenin-Brotons et al. können außerdem zeigen, dass sich bestrahlungsinduzierte Enteritis in einer erhöhten Expression vom Hitzeschockprotein (HSP-27) äußert (Vozenin-Brotons et al. 2004). Für HSP-27 lässt sich anhand unserer Versuchsreihe nicht wie bei den oben genannten Zytokinen ein direkter Anstieg der proximalen Darmabschnitte zeigen, hier ist es das Ileum, welches direkt nach Bestrahlung mit einer erhöhten Expression reagiert. Nach $24 \mathrm{~h}$ erreicht HSP-27 für alle Dünndarmabschnitte einen signifikanten Peak. So lassen sich frühe und späte, strahleninduzierte entzündliche Prozesse als ein multifaktorielles System darstellen. Die strahleninduzierte Entzündung führt letztendlich im Ileum trotz geringer Strahlenbelastung zu einer verzögerten Rekrutierung von Reparaturmechanismen, während diese im Duodenum und Jejunum deutlich suffizienter erscheinen. Wichtig ist hierbei sich erneut zu vergegenwärtigen, dass Apoptose und Entzündung zwar parallel in unserem Versuch beobachtet werden können, aber Apoptose für sich genommen keine Entzündungsreaktion auslöst (Hug 2000; Saraste und Pulkki 2000).

\subsubsection{Chemotaxis und Migration von Immunzellen}

Neben den zuvor beschriebenen Zytokinen stellen die Chemokine und Adhäsionsmoleküle wichtige Schnittstellen in der Zell-Zell-Interaktion nach Bestrahlung dar. Der Transfer von Leukozyten in das perivaskuläre Gewebe spielt eine wesentliche Rolle, sowohl in der Aufrechterhaltung der normalen Immunhomöostase, als auch in der Entstehung von entzündlichen Prozessen. Lymphozytenadhäsion und deren Migration durch die Gefäßwand wird zu einem großen Teil durch eine Interaktion zwischen Endothelzelladhäsionsmolekülen und den Glykoproteinliganden ermöglicht, die auf der Oberfläche von Leukozyten präsentiert werden (Wetzel et al. 2004).

$\mathrm{Zu}$ den Aufgaben des Adhäsionsmoleküls PECAM-1 gehört die interzelluläre Verbindung von Endothelzellen. Außerdem hat es Einfluss auf die Aktivität und das Überleben der Zelle, in der es exprimiert wird (Newman und Newman 2003). Auffällig ist, dass PECAM-1 nicht auf Fibroblasten, Epithelzellen, Muskelzellen oder anderen nicht-vaskulären Zellen nachgewiesen werden kann, dafür aber auf Leukozyten, Thrombozyten und Endothelzellen (Gao et al. 2003; Newman 1997). Gao et al. zeigen des Weiteren in ihren Versuchen, dass PECAM-1 den Zellen, in denen es exprimiert wird eine erhöhte Resistenz gegen apoptotischen Stress gewährt. Ferner weisen sie darauf hin, dass PECAM-1 ein potenter Inhibitor von Bax-induzierter Apoptose ist. Eine Hemmung des extrinsischen Signaltransduktionsweges der Apoptose kann jedoch durch PECAM-1 nicht erzielt werden (Gao et al. 2003). In unserem Versuch sind direkte Strahlenschäden und eine erhöhte Expression von Bax und Bcl-2 unmittelbar nach Bestrahlung im Bereich der Epithelzellen vergesellschaftet. Epithelzellen gehören jedoch nicht zu den Targetzellen von PECAM-1. Erst im Verlauf kommt es zu einer Einwanderung von Blutzellen, die PECAM-1 auf ihrer Oberfläche 
exprimieren. Lediglich im Jejunum zeigt sich bereits $1 \mathrm{~h}$ nach Bestrahlung ein 3-facher Anstieg von PECAM-1. Möglicherweise hat es hier seinen Ausgang von den Endothelzellen der zahlreichen Blutgefäße des Jejunums. Für das Ileum ist ein Abfall von PECAM-1 nach 96 h auffallend. Einen Erklärungsansatz bietet die Tatsache, dass die PECAM-1-tragenden Zellen auf Grund der starken Schädigung des Ileums zugrunde gegangen sind.

Neben PECAM-1 wird im vaskulären Endothel ein geringes Level von ICAM-1 exprimiert. ICAM-1 kann durch proinflammatorische Zytokine wie IL-1 und TNF- $\alpha$ hochreguliert werden (Yang L. et al. 2005). ICAM-1 wird insbesondere von Leukozyten und Endothelzellen, aber auch von Epithelzellen und dendritischen Zellen exprimiert (Dustin et al. 1986; Van De Stolpe und Van Der Saag 1996). Zu den Aufgaben von ICAM-1 gehört es, als Adhäsionsmolekül die Migration von Lymphozyten $\mathrm{zu}$ ermöglichen. Javaid et al. beschreiben, dass es bereits $1 \mathrm{~h}$ nach einem proinflammatorischen Ereignis zu einer ICAM-1-Stimulation kommt (Javaid et al. 2003). In unserem Versuch kann diese Aussage bestätigt werden. Es zeigt sich, dass ICAM-1, wie auch die anderen Adhäsionsmoleküle vorwiegend im Jejunum bereits nach $1 \mathrm{~h}$ detektiert werden kann.

Ein weiteres zu erwähnendes Adhäsionsmolekül ist MAdCAM-1. Die Expression von MAdCAM-1 wird ebenfalls durch TNF- $\alpha$ und IL-1 induziert. MAdCAM-1 ist ein Rezeptorprotein welches auf den Endothelzellen der intestinalen Mukosa, Submukosa und Peyer'schen Plaques präsentiert wird. MAdCAM-1 agiert als Hauptligand zur Rekrutierung von Lymphozyten im Rahmen von chronischen Entzündungen im Darm (Ogawa et al. 2005). Bei chronisch entzündlichen Darmerkrankungen wird sogar eine permanente Hochregulation von MAdCAM-1 beobachtet (Oshima et al. 2001). Interessanterweise zeigen unsere Ergebnisse eine deutliche Expression von MAdCAM-1 im terminalen Ileum bis $24 \mathrm{~h}$ nach Bestrahlung. Hier ist es also nicht im Rahmen eines chronischen Ereignisses exprimiert, sondern im Rahmen der akuten Strahlenreaktion. Anders als die übrigen Adhäsionsmoleküle ist MAdCAM-1 nicht in den proximal gelegenen Dünndarmabschnitten nachzuweisen, sondern im Ileum. Das terminale Ileum erweist sich auch bei der chronisch entzündlichen Darmerkrankung M. Crohn als präferierter Fokus der Entzündung (Watanabe et al. 2010). Dies lässt den Schluss zu, dass Strahlenschäden einen ähnlichen Pathomechanismus wie die chronisch entzündliche Darmerkrankung M. Crohn aufweisen, und sie sich daher vornehmlich im terminalen Ileum wiederfinden.

Thy-1 ist ein Adhäsionsmolekül, das abschließend auch an der Rekrutierung von Leukozyten im Rahmen von inflammatorischen Prozessen beteiligt ist. Des Weiteren soll es eine Rolle bei der Regeneration von Nerven, Apoptose, Tumorwachstum und Metastasierung, Entzündung und Fibrose spielen. Thy-1 ist einer der meist verwendeten Oberflächenmarker für Stammzellen, da es auf CD34-positiven Blutzellen exprimiert wird (Wetzel et al. 2004). Es wird unter anderem von T- 
Lymphozyten, Endothelzellen und Fibroblasten synthetisiert, jedoch nur im Rahmen von inflammatorischen Prozessen (Rege und Hagood 2006 a). So erklären sich für Thy-1 die erhöhten Expressionen in unseren Proben des Duodenums und Jejunums. Korrelierend hierzu bestätigt die CD34-Färbung eine Zunahme der hämatopoetischen Vorläuferzellen. Jene also, die verantwortlich

für die Thy-1-Produktion sind. Im Ileum und Colon kommt es bei allen signifikanten Zeitpunkten $\mathrm{zu}$ einer Herunterregulation. Parallel hierzu wird in diesen Abschnitten der Verlust von CD34positiven Zellen in Abb. 13 gezeigt.

Für die Chemokine MCP-1, MIP-1 $\alpha$ und MIP-3 $\alpha$ lässt sich zusammenfassend sagen, dass auch diese vorwiegend zu den frühen Zeitpunkten im Duodenum und Jejunum auftreten. MCP-1 kann eine Hochregulation von Adhäsionsmolekülen und die Produktion von Zytokinen in Monozyten bewirken. Außerdem ist es für die Einwanderung von Monozyten in geschädigtes Gewebe zuständig (Desai et al. 2003; Gremy et al. 2008; Hori et al. 2008). Das Chemokin MIP-1 $\alpha$ ist ebenso an der Chemotaxis von Leukozyten beteiligt (Cook 1996). Interessant ist, dass es im Jejunum neben einer fast 5-fachen Erhöhung zum 1 h-Zeitpunkt auch zu den späten Zeitpunkten (1,5 Monate und 3 Monate) eine deutliche Expression zeigt.

Matthijsen schildert, dass eine Abschilferung von nekrotischen Enterozyten eine persistierende oder sekundär entzündliche Reaktion abmildert. Es kommt nur zu einer verminderten Einwanderung von Immunzellen, während sich nekrotisches Material und Zellschrott im Lumen des Darms befindet (Matthijsen et al. 2009). Diese reduzierte Rekrutierung von Immunzellen haben wir zuvor bereits für das Ileum bestätigt. Konsekutiv ist es bei dem histologisch völlig destruierten Gewebe des Ileums naheliegend, dass es zu keiner erhöhten Expression der inflammatorischen Chemokine MCP-1, MIP-1 $\alpha$ und MIP-3 $\alpha$ kommt. Mehr noch, für MIP-1 $\alpha$ ist ein signifikanter Abfall zu vermerken. Diese Beobachtung korreliert mit den Daten beim Menschen: Eine 30-minütige Ischämie gefolgt von einer 4-stündigen Reperfusion, scheint nicht in eine eindeutige entzündliche Reaktion zu münden. Ursächlich hierfür ist der besondere Abschilferungsmechanismus der geschädigten Enterozyten im Dünndarm. Dieser wiederum kommt durch einen Verlust der ZellZell-Interaktion zustande (Matthijsen et al. 2009).

\subsubsection{Endotheliale Dysfunktion und Hypoxie}

Während die primären Pathomechanismen der strahleninduzierten Entzündung und Apoptose, sowie die Rolle der Adhäsionsmoleküle und Chemokine bereits in den vorherigen Abschnitten diskutiert worden sind, soll nun der Einfluss einer strahleninduzierten Hypoxie und den daraus sekundär resultierenden Schäden in den Vordergrund gestellt werden. Die Forschungsgruppe von Maj et al. und jene von Milliat et al. beleuchten, dass Bestrahlung eine Veränderung der 
rheologischen Eigenschaften des Blutes induziert. Es kommt zu einer Vasodilatation und konsekutiv zu einer Reduktion des Blutflusses (Maj et al. 2003; Milliat et al. 2006). Wang J. beschreibt, dass es zu mikrovaskulären Gefäßveränderungen sowohl bei den frühen, inflammatorischen Strahlenschäden, als auch bei den späten, fibroproliferativen Strahlenschäden kommt (Wang J. et al. 2007). Dabei steht zu den frühen Zeitpunkten die Apoptose der kapillären Endothelzellen im Vordergrund. Dies führt zu einer konsequenten Blockierung des kapillären Blutflusses und ist wesentlich für das Absterben von Kryptenzellen verantwortlich (Hendry et al. 2001; Suit und Withers 2001). Für die Spätschäden sind die Daten von Schuller et al. zu berücksichtigen. Diese stellten die kontrovers $\mathrm{zu}$ beurteilende Frage, ob eine endotheliale Dysfunktion durch Apoptose Folgen für das bestrahlungsinduzierte Gastrointestialsyndrom hat (Schuller et al. 2006). Schuller entwickelte eigens hierfür ein Modell, bei dem die Strahlendosis selektiv für Gefäßendothelzellen um den Faktor 3 im Vergleich zum restlichen Körper erhöht wurde. Damit zeigte er, dass endotheliale Apoptose nicht die Ursache für das Gastrointestinalsyndrom ist (Schuller et al. 2007). Potten veröffentlichte in einer Studie von 2004, dass eine frühe ( $4 \mathrm{~h}$ nach Bestrahlung) und eine späte (10 h nach Bestrahlung) Apoptose der epithelialen Kryptenzellen beobachtet werden kann, jedoch kaum Apoptose im Stroma und den endothelialen Zellen nachweisbar ist (Potten 2004). Diesen Forschungsergebnissen stehen die Aussagen von Paris, Gudkov und Hendry gegenüber, die behaupten, dass Apoptose von mikrovaskulären Endothelzellen zur primären Läsion nach Bestrahlung führt und dies in eine Dysfunktion der Stammzellen mündet (Gudkov und Gleiberman 2008; Hendry et al. 2008; Paris et al. 2001). Wir können in unseren Versuchen, wie schon unter 4.2.1 beschrieben ist, ebenfalls beweisen, dass es zu Apoptose der Kryptenzellen nach Bestrahlung kommt.

Wenn man sich hinzufügend vergegenwärtigt, dass strahleninduzierte Gewebeschädigung im unmittelbaren Verhältnis zu der Zellturnover-Kinetik steht, so erklärt sich, dass das schneller proliferierende intestinale Gewebe früher und aggressiver von der Bestrahlung geschädigt wird als das endotheliales Gewebe. Andererseits ist es wichtig zu berücksichtigen, dass jede funktionelle Zelle oder Stammzelle über ein Netzwerk von Blutgefäßen versorgt wird. Kommt es zu einer Schädigung dieser Gefäßzellen und damit zu einer Beeinträchtigung ihrer Sauerstoff- und Nährstofftransportfunktion, ist das Absterben der Zielzelle programmiert (Schuller et al. 2007).

Wie schon unter 4.2.2. beleuchtet wurde, kommt es zu einem deutlichen Rückgang der Immunzellen entlang der intestinalen Mukosa in Folge von Bestrahlung. Die Tatsache, dass das Jejunum besser als das Ileum durchblutet wird, lässt die Vermutung zu, dass die initiale Hypoxie in Folge von Apoptose der Endothelzellen in den proximalen Darmabschnitten effizienter überwunden werden kann als im Ileum (Paris et al. 2001). Die Masson-Goldner-Trichromfärbung bestätigt für 
das Jejunum, dass es $6 \mathrm{~h}$ nach Bestrahlung zu einem Blutandrang an der Basis der Krypten kommt (siehe Abb. 7). Darüber hinaus wird dieser empfindliche Mechanismus noch durch die Tatsache gestützt, dass durch die Hochregulierung der Adhäsionsmoleküle ebenfalls eine bessere Mikrozirkulation in den proximalen Dünndarmabschnitten erreicht wird.

Als Nachweis für eine erhöhte Angiogenese bzw. für die Veränderungen der Vaskularisation des Gewebes sollen die Transkripte von COX-2, VEGF, VEGF-R-1 und SMA herangezogen werden. COX-2 ist ein Enzym, das im Wesentlichen als Antwort auf eine Entzündung und zur Produktion von Prostaglandinen, die den inflammatorischen Prozess unterstützen, exprimiert wird. Die Expression von COX-2 wird von proinflammatorischen Zytokinen, wie z.B. TNF- $\alpha$ und IL-1 $\beta$ stimuliert (Keskek et al. 2006). Keskek et al. können nachweisen, dass es sowohl in vaskulären Endothelzellen, als auch in Fibroblasten zu einer erhöhten Expression von COX-2 nach Bestrahlung kommt. In histologischen Färbungen veranschaulichen sie, dass es $96 \mathrm{~h}$ nach Bestrahlung zum Höhepunkt der Epithelschäden kommt. Ein Peak von COX-2 wird in den vaskulären Endothelzellen 14 Tage nach Bestrahlung erreicht. Für die Expression in Fibroblasten kann ein Anstieg schon nach $2 \mathrm{~h}$ gezeigt werden. Der Höhepunkt der COX-2-Expression wird in Fibroblasten ebenfalls nach 14 Tagen beobachtet. Dies lässt Keskek et al. schlussfolgern, dass COX-2 sowohl bei der akuten, inflammatorischen Strahlenreaktion, als auch bei der verzögerten, fibrotischen Veränderung des Gewebes eine Rolle spielt (Keskek et al. 2006).

In unserem Versuch präsentieren sich vergleichbare Werte. Das Duodenum und Jejunum reagieren unmittelbar nach $1 \mathrm{~h}$ mit einer erhöhten COX-2-Expression. Eine weitere signifikante Hochregulation können wir bei 96 h nach Bestrahlung im Duodenum und Ileum finden. Im Jejunum und Ileum verzeichnen wir eine signifikante Erhöhung von COX-2 bezogen auf den 0 hKontrollwert nach 1,5 bzw. 3 Monaten. Somit lässt sich auch bei unseren Daten ein biphasischer Verlauf nachvollziehen. Ben-Av stellte in seiner Veröffentlichung von 1995 dar, dass es durch eine Hochregulation von VEGF in Fibroblasten zu einer Stimulation von Endothelzellen kommt, die wiederum die Angiogenese anregen und die Expression von COX-2 fördern (Ben-Av et al. 1995).

Unsere Ergebnisse weisen darauf hin, dass es bei 1 h, 6 h und 96 h zu einem signifikanten Anstieg von VEGF im Duodenum kommt. Der frühe Anstieg von VEGF könnte also unter anderem für die Hochregulation von COX-2 bei $96 \mathrm{~h}$ nach Bestrahlung verantwortlich sein. Für VEGF wird beschrieben, dass es einerseits als Mediator für Angiogenese und Revaskulisation fungiert, andererseits aber auch proinflammatorisch wirksam ist, indem es für eine erhöhte vaskuläre Permeabilität und folglich zu Ödemen und zur Einwanderung von Entzündungszellen beiträgt (Liu Y. et al. 2009). VEGF-R-1 zeigt $96 \mathrm{~h}$ nach Bestrahlung im Duodenum ebenfalls eine Hochregulation, während $6 \mathrm{~h}$ nach Bestrahlung ein signifikanter Abfall berücksichtigt werden muss. 
Im Verlauf kommt es im Ileum nach $96 \mathrm{~h}$ und 3 Monaten jedoch $\mathrm{zu}$ einer signifikanten Hochregulation.

SMA ist ein zuverlässiger Marker zur Detektierung von Gefäßmuskelzellen im Rahmen von pathologischen Gefäßveränderungen (Chaponnier und Gabbiani 2004). Von Bourgier et al. wird beschrieben, dass es zu einer deutlichen Hochregulation von SMA bei strahleninduzierter Enteritis kommt. Die erhöhte Expression von SMA geht außerdem mit erhöhten Kollagenablagerungen in der Muskularis propria einher und spielt damit auch eine Rolle bei der strahleninduzierten Fibrosierung im Darm (Bourgier et al. 2005). Die SMA-Transkripte unserer Versuchsreihe zeigen im Duodenum von $1 \mathrm{~h}$ bis $96 \mathrm{~h}$ signifikante Werte. Das Jejunum imponiert mit einer Hochregulation bis 3 Monate nach Bestrahlung. Im Ileum treten die signifikanten Werte nach $1 \mathrm{~h}$, $96 \mathrm{~h}$ und 3 Monaten hervor und verdeutlichen, dass SMA neben einer akuten Reaktion auf Bestrahlung auch wesentlich für die Spätschäden nach 96 h bis 3 Monaten verantwortlich ist.

\subsubsection{Strahleninduzierte Fibrosierung am Darm: Langzeitschäden}

Jensen et al. richteten in ihren Untersuchungen schon 1983 ein besonderes Augenmerk auf Strahlenschäden bis 4 Wochen nach Radiatio und solchen, die erst nach 4 Wochen auftreten. Während die frühen Bestrahlungsschäden weitgehend durch Apoptose, Nekrose und Entzündung erklärt werden können, zeichnen sich die Spätschäden durch Ulzerationen, Atypien der Epithelschicht, Verdickung der Serosa und makroskopische Veränderungen aus (Jensen et al. 1983). Als Langzeitschäden werden Sklerosierung der Gefäße, transmurale Fibrosierung der Epithelschicht, die bis zu einer intestinalen Obstruktion führen können, Lymphödeme und ektope Drüsenzellen beschrieben. Das Ausmaß dieser Veränderungen steigt einige Wochen nach Bestrahlung an und erreicht ein Plateau mehrere Monate nach Radiatio (Hauer-Jensen et al. 1998; Richter et al. 1997; Wang J. et al. 1999). Die intestinale Fibrosierung ist dabei permanent und irreversibel und stellt eine wesentliche Komponente der chronischen Strahlenschäden dar (Haydont et al. 2007). In dem vorherigen Abschnitt 4.2.4 wurde die Relevanz von Hypoxie im bestrahlten Gewebe beschrieben. Hervorzuheben ist dabei, dass strahleninduzierte Hypoxie auch wesentlich für die Entstehung der Fibrosierung des Gewebes ist, welche unter anderem durch profibrotische Zytokine wie TGF- $\beta$ induziert wird (Liu Y. et al. 2009). TGF- $\beta$ ist ein wichtiges Zytokin, das sowohl Reparaturmechanismen nach Schädigung des Gewebes initiiert, als auch terminiert. Eine dysregulierte Produktion kann daher in eine Fibrosierung des Gewebes münden. Die Studien von Skwarchuk und Travis demonstrieren, dass es im Sinne von Langzeitschäden nach 8 bis 26 Wochen zu einem Anstieg von TGF- $\beta$ kommt (Skwarchuk und Travis 1998). Auch Liu Y. et al. beobachteten, dass es sowohl auf mRNA, als auch auf Proteinebene zu einem signifikanten Anstieg 
der TGF- $\beta$-Expression 3 Monate nach Bestrahlung kommt. Somit sprechen beide Forschungsgruppen TGF- $\beta$ eine wesentliche Rolle in der bestrahlungsinduzierten Fibrosierung des Gewebes zu (Liu Y. et al. 2009). In unserem Versuch können wir nur eine Hochregulation von TGF- $\beta 1 \mathrm{~h}$ nach Bestrahlung im Duodenum finden. $\mathrm{Zu}$ diesem Zeitpunkt werden die ersten Reparaturmechanismen nach Bestrahlung initiiert (Skwarchuk und Travis 1998). Im Verlauf kommt es jedoch zu keiner weiteren Hochregulation von TGF- $\beta$. Vielmehr fallen in allen Darmabschnitten signifikante Herunterregulationen auf. Möglicherweise lassen sich diese Herunterregulationen durch den Verlust der TGF- $\beta$-produzierenden T-Lymphozyten erklären. Zu berücksichtigen ist jedoch auch die Aussage von Haydont et al. (Haydont et al. 2008). Diese beschreiben beim Menschen mit chronischen Erkrankungen z.B. strahleninduzierter Enteropathie oder Sklerodermie, dass, obwohl TGF- $\beta$ eine Schlüsselrolle in der Induktion und Aufrechterhaltung von Fibrosierung in geschädigtem Gewebe hat, es zu einer Abnahme der Expression von TGF- $\beta$ kommt (Haydont et al. 2008). Neben TGF- $\beta$ lässt sich anhand der Masson-Goldner-Trichromfärbung (siehe Abb. 7) mikroskopisch eine vermehrte Kollageneinlagerung in der Submukosa des Ileums bereits ab $6 \mathrm{~h}$ nach Bestrahlung nachvollziehen.

\subsection{Parallelen zu anderen pathologischen Darmveränderungen}

Die akuten klinischen Symptome, die auf eine Bestrahlung am Darm zurückzuführen sind, umfassen Diarrhoen (großvolumige Durchfälle) als Reaktion des Dünndarms und die Strahlenproktitis mit Stuhldrang, Schleimabgängen und blutigen Auflagerungen auf dem Stuhl als Antwort des Dickdarms (Andreyev 2005). Coia et al. zeigten, dass stärkere Schäden bei einer Koinzidenz mit arteriellem Hypertonus und Diabetes mellitus auftreten. Außerdem aggravieren sich Strahlenschäden am voroperierten Darm (Coia et al. 1995).

Die pathologischen Prozesse, die nach Bestrahlung beobachtet werden, weisen deutliche Parallelen zu anderen gastrointestinalen Erkrankungen auf. Mehr noch, bei Patienten, die an einer vorbestehenden intestinalen Erkrankung z.B. Zöliakie, Morbus Crohn oder Colitis ulercosa leiden, kann es zu einer Exazerbation durch Bestrahlung kommen (Andreyev 2005). Es wird vermutet, dass ein Großteil der Symptome durch Fibrosierung des Gewebes hervorgerufen wird. Diese hat zur Folge, dass es zu Stenosierungen und Narbenbildungen kommt. Dabei ist der Dünndarm auf Grund seines kleineren Lumens stärker als der Dickdarm betroffen (Coia et al. 1995).

Die meisten Fälle von chronisch entzündlichen Darmerkrankungen beim Menschen sind mit einem Zusammenbruch der normalen Immuntoleranz assoziiert (Williams 2006). Ähnlich wie bei Strahlenschäden am Darm spielt bei der Pathogenese chronisch entzündlicher Darmerkrankungen eine Dysbalance zwischen pro- und antiinflammatorischen Faktoren eine Schlüsselrolle (Sartor 
1995). Außerdem wird eine gesteigerte Expression und Produktion der proinflammatorischen Zytokine IFN- $\gamma$, TNF- $\alpha$, IL-1 $\beta$ und IL-6 innerhalb der intestinalen Schleimhaut im Rahmen von M. Crohn und Colitis ulcerosa beobachtet (Braegger et al. 1992; Macdermott et al. 1998; Reinecker und Podolsky 1995; Williams 2006). Auch ein Zusammenhang zwischen der Stärke der TNF- $\alpha$ bzw. IL-1 $\beta$-Expression im entzündlich infiltrierten Gewebe und der Erkrankungsschwere kann identifiziert werden (Brandtzaeg et al., 1997; Dionne et al., 1997; Sartor, 1995). Williams beschreibt für chronisch entzündliche Darmerkrankungen, dass eine erhöhte Expression von MIP$3 \alpha$ in Biopsien von Patienten beobachtet werden kann, während diese im gesunden Gewebe nicht nachvollziehbar ist (Williams 2006). Da sich in unserem Versuch die stärksten Strahlenschäden im Ileum herauskristallisiert haben, sind Parallelen insbesondere zur Pathogenese des M. Crohns, der sich auch vornehmlich im terminalen Ileum manifestiert, naheliegend. Unterstützt wird diese Korrelation durch die vergleichbare Expression von MAdCAM-1, wie sie unter 4.2.3 beschrieben ist. Um klinische Ansatzpunkte einer Therapie bei strahleninduzierter Enteritis zu eröffnen, sollten die Übereinstimmungen zu chronisch entzündlichen Darmerkrankungen und insbesondere zum M. Crohn berücksichtigt werden.

Neben den entzündlichen Darmerkrankungen lassen sich gleichermaßen auch zur Karzinogenese Analogien aufweisen. Der Entwicklung eines Karzinoms geht in den meisten Fällen ein chronisches Ungleichgewicht zwischen Apoptose und Proliferation voraus (Nardone 2003). Zellproliferation oder Mitosen werden positiv reguliert von Wachstumsfaktoren und Protoonkogenen, die den Zellzyklus stimulieren, und negativ kontrolliert von Tumorsupressorgenen, die die Aktivität der Protoonkogene inhibieren (Levine 2000). Hervorzuheben ist, dass der Dünndarm nur ca. 2 \% der Adenokarzinome des Gastrointestinaltraktes beinhaltet (Halfdanarson et al. 2010). Das Adenokarzinom des Kolons macht hingegen $95 \%$ aller Kolontumore aus und liegt auf Platz 2 der deutschen Krebsrangliste (Husmann et al. 2010). Hierbei spielt erneut die Position der Stammzellen eine entscheidene Rolle. Während die Stammzellen im Kolon an der Basis der Krypten lokalisiert sind, sind diese im Dünndarm in Position 4 unmittelbar oberhalb der Paneth-Zellen platziert. Kommt es jetzt durch exogene Noxen zu einer Schädigung der Zellen, so wird beobachtet, dass im Dünndarm die Stammzellen in Apoptose gehen, während im Dickdarm Apoptose nicht eindeutig entlang der Krypten-Zotten-Achse lokalisiert werden kann (Ijiri und Potten 1990; Merritt et al. 1994; Potten 1986; Potten et al. 1992). Dies lässt den Schluss zu, dass geschädigte Stammzellen im Dickdarm nicht erfolgreich eliminiert werden, und es bei fehlender oder inkompletter Reparatur leichter zur Entstehung von malignen Prozessen kommen kann. Selbstverständlich müssen zur Kazinogenese noch viele weitere Aspekte berücksichtigt werden. 


\subsection{Mögliche Therapieansätze und klinische Relevanz}

Da die Strahlenschäden am Darm immer wieder einer therapeutischen Strahlendosis entgegenstehen, gewinnt eine adäquate symptomatische und radioprotektive Therapie zunehmende Bedeutung. Zum einen hat eine Optimierung der Strahlenapplikation durch Fraktionierung und dreidimensionale Technik eine Reduzierung der Strahlendosis ermöglicht, zum anderen werden supportive Medikamente eingesetzt, die die Wirksamkeit der Strahlentherapie erhöhen und eine bessere Verträglichkeit zulassen (Horwhat und Dubois 1999; Widel et al. 2009).

Aus den Akut- und Spätreaktionen nach Bestrahlung eröffnen sich verschiedene Möglichkeiten einer medikamentösen Therapie. So werden radioprotektive Substanzen getestet, die die strahleninduzierte Zytotoxizität am Normalgewebe verhindern sollen. Strategien zur Zytoprotektion beinhalten die Hemmung der Bildung von freien Radikalen, sowie die Neutralisierung freier Radikale, die zu einer DNA-Schädigung führen können (Grdina et al. 2002). In vitro-Studien zeigen, dass der aktive Metabolit von Amifostine (WR-1065) sowohl den strahleninduzierten Zelltod, als auch die Mutagenese hemmt (Grdina et al. 2002). Dieser Effekt wird als selektiv für gesunde Zellen beschrieben, da durch die höhere Aktivität alkalischer Phosphatase im gesunden Gewebe, sowie die bessere Vaskularisierung und den höheren $\mathrm{pH}-\mathrm{Wert}$ eine bessere Aufnahme des aktiven Metaboliten in das Normalgewebe im Vergleich zum Tumorgewebe stattfindet (Nakshabendi et al. 1999; Plateroti et al. 1998).

Antioxidative Eigenschaften werden auch dem Heilmittel Curcumin zugesprochen. Es beseitigt die durch Bestrahlung entstehenden freien Radikale, inhibiert die Lipid-Peroxidation und schützt die zellulären Makromoleküle, insbesondere die DNA vor oxidativen Schäden. Neben der radioprotektiven Wirksamkeit zeigt Curcumin auch radiosensitivierende Effekte. So bestätigt sich im Tierexperiment, dass der Einsatz von Curcumin bei Zelllinien des humanen Prostatakarzinoms und Kolonkarzinoms zu einem inhibierenden Wachstum führt (Akpolat et al. 2009; Chendil et al. 2004).

Olgaç et al. beschreiben am Rattenmodell, dass die Behandlung mit dem synthetischen Somatostatin-Analogon Octreotid protektive Eigenschaften gegen oxidativen Stress nach abdomineller Bestrahlung hat (Olgaç et al. 2006). In klinischen Studien besticht Octreotid durch seine gute Verträglichkeit. Octreotid besitzt antiangiogenetische und antitumorale Effekte. Außerdem wirkt es inhibierend auf die gastrointestinale Motilität und Sekretion. Somit ist es auch in der symptomatischen Therapie zur Behandlung von Diarrhoen und Tenesmen eine sinnvolle Alternative zur bisherigen Medikation (Onal et al. 2011).

Eine genaue Beleuchtung der Ursachen für die beschriebenen Diarrhoen im Rahmen einer akuten und chronischen Strahlenenteritis eröffnet weitere Ansatzpunkte für eine Therapie. Neben der 
bereits beschriebenen, beschleunigten intestinalen Transitzeit des Dünn- und Dickdarms, müssen bakterielle Überwucherungen, Malabsorption von Gallensäuren und Fettsäuren, eine Pankreasinsuffizienz, physiologische Veränderungen des unteren Gastrointestinaltraktes, die Bildung von Strikturen und psychologische Faktoren berücksichtigt werden (Fuccio et al. 2009). So erscheint eine symptomatische Therapie mit z.B. Cholestyramin zur Bindung der Gallensäure, Metronidazol oder Vancomycin zur Unterbindung einer pathologischen Darmüberwucherung und Pankreatin bei Steatorrhoen sinnvoll (Andreyev 2005; Coia et al. 1995). Der Einsatz von Probiotika hat Einfluss auf das intestinale Ökosystem und stabilisiert die Integrität der Darmwand (Fuccio et al. 2009).

Neuere Studien schlagen vor, dass selektive COX-2-Hemmer postoperative peritoneale Adhäsionen reduzieren (Greene et al. 2005). Der Einsatz dieses Wirkstoffes wäre bei strahleninduzierten Strikturen also naheliegend, da der zu Grunde liegende Pathomechanismus vergleichbar ist mit denen der peritonealen Adhäsionen.

Hille und Kertesz haben bei Patienten mit bestrahlten Prostatakarzinomen zur Behandlung einer akuten und chronischen Strahlenproktitis die Wirksamkeit einer lokalen Therapie mit Misoprostolzäpfchen und Natriumbutyrat-Einläufen getestet. Während das Prostaglandin Misoprostol keine positiven Effekte erzielen kann, scheinen Natriumbutyrat-Einläufe in der Behandlung der akuten radiotherapieinduzierten Proktitis hilfreich zu sein. Langfristig haben sie jedoch keinen Einfluss auf die Häufigkeit und Schwere einer späteren Proktitis (Hille et al. 2008; Hille et al. 2005 b; Kertesz et al. 2009).

Die Anwendung von Melatonin veranschaulicht im bestrahlten Tiermodell, dass die histologischen Strukturen des Darms konserviert werden. Die Villi und Krypten erscheinen weniger beeinträchtigt durch Bestrahlung und folglich kommt es zu reduzierten Strahlenschäden. Dabei erweist sich das Hormon Melatonin durch seine kleine Molekülgröße gegenüber anderen Antioxidantien als vorteilhaft (Onal et al. 2011).

Einen weiteren nicht $\mathrm{zu}$ vernachlässigenden Ansatz zur Minimierung von Strahlenschäden verfolgen Arango et al.. Eine Vorbehandlung mit einem MIP-1 $\alpha$-Analogon zeigt im bestrahlten Versuchstier eine signifikant erhöhte Anzahl überlebender Zotten und Krypten im untersuchten Dünndarm. Das radioprotektive Potential von MIP-1 $\alpha$ wird auf eine Reduzierung der Mitosenanzahl während der Bestrahlung zurückgeführt, wissend, dass Zellen während der Mitose besonders sensibel auf Strahlenschäden reagieren. Durch den Einsatz des MIP-1 $\alpha$-Analogons kommt es zu einer substantiellen Reduktion der Nebenwirkungen von abdomineller Bestrahlung. Langfristig erhoffen sich Arango und Kollegen durch diese Radioprotektion, einen verstärkten Einsatz von Bestrahlung in der Abdominal- und Beckenregion zu ermöglichen (Arango et al. 2001). 
Zytokine und Prostaglandine sind essentielle Mediatoren in der Interaktion zwischen aktivierten Immunzellen und epithelialen bzw. mesenchymalen Zellen. Bei strahleninduzierter Enteritis kommt es zu signifikanten Änderungen der Expression von proinflammatorischen Zytokinen, Chemokinen und Prostaglandinen. Diese bieten in der klinischen Anwendung Ziele einer therapeutischen Intervention (Fantini et al. 2007). Infliximab ist ein chimärer monoklonaler Antikörper gegen TNF$\alpha$. In der Behandlung von chronisch entzündlichen Darmerkrankungen, insbesondere beim M. Crohn, hat sich Infliximab bei schweren Verläufen einen wichtigen Stellenwert in der Therapie verschafft. Infliximab entfaltet seine Wirkung, indem es lösliches TNF- $\alpha$ im Gewebe neutralisiert und die aktivierten Entzündungszellen, auf denen TNF- $\alpha$ exprimiert wird, in Apoptose überführt (Andoh et al. 2008). Durch eine Hemmung von TNF- $\alpha$ kommt es konsekutiv zu einer reduzierten Sekretion von TGF- $\beta$. Dies hat eine Minderung der Kollagensynthese zur Folge. Die experimentellen Studien von Staroslawska et al. schlagen vor, Infliximab bei Fibrosierungen in Folge von Strahlenschäden therapeutisch einzusetzen (Staroslawska et al. 2008).

Keskek et al. beleuchteten in ihrer Publikation von 2006, dass die Einnahme von selektiven Prostaglandin-Inhibitoren die Symptome einer strahleninduzierten Enteritis zu mildern vermögen (Keskek et al. 2006). In einem Rattenmodell demonstrierten sie, dass es bei einer Vor- und Nachbehandlung mit Refecoxib nur zu einem reduzierten Verlust der Anzahl und der Länge der ilialen Villi kommt. Des Weiteren konnte unter Refecoxibtherapie 14 Tage nach Bestrahlung eine signifikante Reduktion inflammatorischer Prozesse am Darm beobachtet werden (Keskek et al. 2006). Nebenbefundlich konnte eine Verringerung der Inzidenz von mesenterialen Lymphadenopathien festgestellt werden (Keskek et al. 2006).

Wie wir unter 4.2.4 beschrieben haben, kommt es durch Bestrahlung zu Endothel- und Gefäßschäden, die zu einer Hypoxie des Gewebes führen. In experimentellen Studien zeigt sich, dass es durch Inhibierung von VEGF zu einer Hemmung der Angiogenese kommt. Diese Eigenschaft machten sich Liu Y. et al. zu Nutze. Sie bewiesen, dass die Hemmung von VEGF und der Einsatz von anti-TGF- $\beta$ die Tumorantwort auf Bestrahlung verbessert, und eine bestrahlungsinduzierte Fibrose reduziert werden kann (Liu Y. et al. 2009). Diese Ergebnisse korrelieren mit den Aussagen von Zheng et al.. Hier führte der Einsatz von rekombiniertem löslichen TGF- $\beta$-Typ-2-Rezeptor (T $\beta$ R-2) zu einer Verbesserung der Strahlenenteropathie im Mausmodell (Zheng et al. 2000).

Des Weiteren wird einer Kombinationstherapie aus Pentoxifyllin und Tocopherol antioxidative und antifibrotische Wirksamkeit zugesprochen (Anscher 2005). Der Phosphodiesteraseinhibitor Pentoxifyllin zeichnet sich durch seine immunmodulativen Eigenschaften aus. Es kommt zu einer Herunterregulation zahlreicher Zytokine, die Mediatoren der inflammatorischen und 
fibrogenetischen Reaktion nach Bestrahlung sind. Da Strahlenschäden auch durch reaktive Sauerstoffmetabolite vermittelt werden, erscheint eine Komedikation mit dem antioxidativ wirksamen Tocopherol sinnvoll (Hille et al. 2005 a). Hille et al. beschreiben, dass bei Patienten mit Strahlenenteritis oder -proktitis die Symptome deutlich reduziert werden können (Hille et al. 2005 a). Bei einer zu kurzen Therapie besteht jedoch das Risiko eines Rebound-Effektes (Delanian et al. 2005). Nebenwirkungen der Pentoxifyllintherapie wie allergische Reaktionen, Blutungen, Hämatome, Thrombozytopenien, Schwindel oder Übelkeit mit Erbrechen limitieren jedoch den Einsatz einer Langzeittherapie (Hille et al. 2005 a).

Als Langzeitschäden der Strahlenenteritis sind Fibrosierungen des Schleimhautgewebes und Strikturen $\mathrm{zu}$ berücksichtigen, die konsekutiv $\mathrm{zu}$ einer Obstruktion des Darms führen. Histopathologisch zeigt sich eine schwere transmurale Fibrose mit Schleimhautulzerationen und Gefäßsklerosierungen. Bei diesen Komplikationen darf neben den bereits oben beschriebenen „modernen Präparaten“ die klassische symptomatische Therapie nicht vernachlässigt werden. So wird eine Inhibierung der Entzündung mit Corticosteroiden und nicht-steroidalen Antirheumatika (NSAR) erreicht (Hille et al. 2005 a). Eine parenterale Ernährung erweist sich in schweren Fällen als unabdingbar. Als Ultima ratio kann eine chirurgische Resektion erfolgen (Vozenin-Brotons et al. 2004). Eine chirurgische Sanierung birgt jedoch immer die Gefahr, dass es auf Grund des radiogen veränderten Gewebes vermehrt $\mathrm{zu}$ Wundheilungsstörungen, Anastomoseninsuffizienzen, Entwicklung von Fisteln und Wundinfektionen kommen kann (Larsen et al. 2007).

In der klinischen Praxis kommt es bei der Behandlung vom Rektum-, Prostata-, oder Cervixkarzinom, bzw. der Bestrahlung von paraaortaler Lymphknoten und intraabdominell gelegenem M. Hodgkin zu abdominellen Nebenwirkungen der Bestrahlung. Die oben genannten Medikamente sollen exemplarisch Möglichkeiten eines therapeutischen Ansatzes darlegen. Einige dieser Studien sind bisher nur im Tiermodell durchgeführt worden. So sind neben der Grundlagenforschung zur Bewältigung von Strahlenschäden weitere klinische Studien notwendig, um langfristig eine effektive nebenwirkungsarme Strahlentherapie anbieten zu können.

\subsection{Ausblicke}

Unsere Untersuchungen nach Einzeitbestrahlung der Ratte haben gezeigt, dass der distale Dünndarm trotz indirekter Bestrahlung oder Streustrahlung deutlich strahlensensitiver reagiert, als die im unmittelbaren Bestrahlungsfeld liegenden proximaleren Dünndarmabschnitte. Das Colon, ebenfalls außerhalb des Bestrahlungsfeldes liegend, kann ähnliche Veränderungen wie im Dünndarm aufweisen, jedoch sind diese deutlich schwächer ausgeprägt und es kommt im Verlauf des Untersuchungszeitraumes $\mathrm{zu}$ einer kompletten Regeneration. Die unterschiedlichen 
Abwehrmechanismen des Ileums und Colons müssen daher auf das lokal-spezifische Mikroenvironment zurückgeführt werden. Die persistierenden Schäden des Ileums resultieren möglicherweise in einer höheren Sensitivität für oxidativen Stress mit einer konsekutiven Schädigung der Regenerationsfähigkeit der Krypten-Zotten-Achse. So erscheint es insbesondere für das Ileum, bei dem es nach Ablauf des dreimonatigen Untersuchungszeitraums noch zu keiner kompletten Erholung des Gewebes gekommen ist, bedeutsam die Langzeitschäden in einem Follow up bis mindestens 1 Jahr nach Bestrahlung zu verfolgen.

Um die bei der selektiven Leberbestrahlung entstehende Streustrahlung am Darm in einem entsprechend weiten Spektrum zu simulieren, sollte in einem weiteren Versuch die perkutane Einzeitbestrahlung der Leber mit unterschiedlichen Einzeldosen (z.B. 2 Gy, 5 Gy, 10 Gy, 15 Gy, 25 Gy) erfolgen. Dieser Versuch würde gleichzeitig den Vergleich verschiedener Einzeldosen am Darm auch im Hinblick auf eine zukünftige Untersuchung mit fraktionierter Bestrahlung, d.h. einer sukzessiven kumulierten Bestrahlung mit kleinen Einzeldosen (2 Gy) ermöglichen.

Im distalen Dünndarm kommt es durch Bestrahlung der Leber zu einem Zusammenbruch der epithelialen Barriere. Dies führt zu einer vermehrten Einwanderung von Bakterien, die hier das septische Geschehen verstärken (Andoh et al. 2008; Haglund 1994). Daher sollen Stuhlproben aus den einzelnen Darmabschnitten gewonnen werden, um das intraluminale mikrobiologische Milieu zu untersuchen. Eine Stuhluntersuchung wäre insofern auch sinnvoll, da sowohl in der Pathogenese von chronisch entzündlichen Darmerkrankungen, als auch von Tumoren des Dünndarms anaerobe Organismen bedeutsam erscheinen (Cuffy et al. 2006; Sartor 1995). Als Marker für zelluläre entzündliche Prozesse könnten aus dem gewonnenen Stuhl, die bei chronisch entzündlichen Darmerkrankungen bereits etablierten Marker Calprotectin und Lactoferrin untersucht werden (Malik et al. 2010). Hille und Kollegen unserer Arbeitsgruppe haben diese bereits im Rahmen von chronischer Strahlenproktitis in Folge von Bestrahlung der Prostata untersucht (Hille et al. 2009). Es konnte eine signifikante Korrelation zwischen dem Auftreten einer chronischen Strahlenproktitis und dem Nachweis von Calprotectin und Lactoferrin gesehen werden.

Zudem wird von Haglund beschrieben, dass die vermehrte Anwesenheit von pankreatischen Proteasen zu einer Mukosaschädigung führt. Naheliegend ist, dass neben dem Dünndarm auch das im direkten Bestrahlungsfeld liegende Pankreas geschädigt wird. Folglich kommt es zu einer Freisetzung von Pankreasenzymen, die wiederum vermehrt im terminalen Ileum resorbiert werden und die lokale Schädigung aggravieren (Haglund 1994). In einem weiteren Versuchsaufbau gilt es daher, das im unmittelbaren Bestrahlungsfeld liegende Pankreas in Bezug auf seine exogene Funktion zu untersuchen. 
Abschließend soll zur Vorbeugung von Strahlenschäden am Darm ein aus der japanischen KampoTradition stammendes Arzneipflanzengesamtextrakt Hochu-ekki-to (TJ-41) untersucht werden. Die in Untersuchungen aus Japan und China bereits beschriebenen radioprotektiven Wirkungen sollen in einem weiteren Versuchsaufbau getestet werden. Besonderer Wert sollte hier auf die IFN- $\gamma$ Produktion gelegt werden, da bekannt ist, dass diese durch Hochu-ekki-to gesteigert wird (Ottaway und Parrott 1980; Rider et al. 1967). 


\section{ZUSAMMENFASSUNG}

Ionisierende Strahlen werden routinemäßig in der Behandlung von malignen Tumoren des Oberbauches, des Rektums, der Prostata und der weiblichen Geschlechtsorgane verwendet. Häufige Nebenwirkungen dieser Bestrahlung zeigen sich mit sowohl frühen, als auch späten Veränderungen im Gastrointestinaltrakt. Vorherige Studien, die die Strahlenenteropathie untersuchten, konzentrierten ihr Interesse auf direkte Strahlenschäden am Darm, die durch eine Ganzkörperbestrahlung oder Bestrahlung von chirurgisch exkorporierten Darm auftraten. Bisher bestehen keine Modelle bei denen der Darm direkter und indirekter Strahlenwirkung nach Radiatio eines parenchymatösen Organes ausgesetzt ist.

Wir entwickelten ein Modell bei dem die Leber des Versuchstieres Ratte im Fokus der Bestrahlung liegt. Mit einer Einzeldosis von $25 \mathrm{~Gy}$ wurde nach Erstellung eines PlanungsComputertomogramms die Leber perkutan bestrahlt. Die Ratten wurden 0 h (Kontrolle), 1 h, 6 h, 24 h, 96 h, 1,5 Monate und 3 Monate nach Bestrahlung getötet und seziert. Das Duodenum wurde vom Jejunum separiert. Das Colon wurde am Rektum abgesetzt und am Ileocoecalpol vom Ileum getrennt und dieses am Treitz'schen Band vom Jejunum differenziert. Anschließend wurden die Gewebeproben gewaschen, eröffnet, in flüssigem Stickstoff oder einer Formalinlösung fixiert und gelagert, bis sie für die Versuche RT-PCR, DNA-Gelelektrophorese, Western Blot, Histologie und Immunhistologie aufgearbeitet wurden.

Mit Hilfe der Versuche ließ sich zeigen, dass im Duodenum und Jejunum direkt nach Bestrahlung Epithelzellschäden auftreten. $6 \mathrm{~h}$ nach Bestrahlung erscheint die Zotten-Architekur unterbrochen. Nach $24 \mathrm{~h}$ finden sich in den proximalen Dünndarmabschnitten vermehrt Immunzellen an der Basis der Krypten. Parallel hierzu treten erhöhte Expressionen von Chemokinen, Adhäsionsmolekülen und Faktoren der Angiogenese auf. Insgesamt erreicht das Duodenum und Jejunum eine fast vollständige Regeneration der Krypten-Zotten-Achse nach Ablauf von 3 Monaten.

Im Ileum kommt es direkt nach Bestrahlung zu einer ödematösen Aufwerfung der Zotten. Bereits 6 h nach Radiatio erscheint das Gewebe des Ileums komplett destruiert. Denudierte Zotten und ein Untergang der Kryptenzelllinie mit ersatzweisem Auftreten von Vakuolen prägen das Gewebe. In der Lamina propria treten nur noch vereinzelte Blutgefäße auf, während eine vermehrte Kollagenablagerung auffällig ist. Innerhalb der 3 Monate kann im Ileum, histologisch betrachtet, keine komplette Regeneration erreicht werden. Diese fortbestehende Schädigung des Ileums geht mit einer Hochregulation von proapoptotischen Enzymen und nach $24 \mathrm{~h}$ mit nekrotischen Zellveränderungen einher. Auffällig ist, dass im Ileum initial die höchste Zahl von Immunzellen detektiert werden kann. Im Verlauf werden diese Zellen jedoch in das Lumen abgeschilfert oder 
gehen selbst in Apoptose über. Durch den Untergang der Blutgefäße kommt es zu einer reduzierten Einwanderung von Immunzellen, so dass diese bei den Reparaturmechanismen des Gewebes nicht unterstützend wirken können. Im Colon finden sich während des gesamten Untersuchungszeitraumes nur moderate Veränderungen als Folge der Leberbestrahlung. Hier kommt es nach 3 Monaten zu einer kompletten Restitution.

Zusammenfassend lässt sich sagen, dass der obere und untere Dünndarm sehr unterschiedlich auf die Bestrahlung der Leber reagiert. Während das Duodenum und Jejunum zwar unmittelbar nach Bestrahlung eine akute Schädigung des Gewebes zeigen, ist entgegen unserer Erwartung das außerhalb des Bestrahlungsfeldes liegende Ileum am stärksten betroffen. Seine Reparaturmechanismen sind nicht ausreichend, um die ausgeprägte Destruktion des Gewebes zu verhindern. Diese Tatsache muss in der klinischen Anwendung von Strahlen berücksichtigt werden, um strahleninduzierte Spätschäden am Dünndarm besser kontrollieren zu können. 


\section{LITERATURVERZEICHNIS}

Abbasakoor F, Vaizey CJ, Boulos PB (2006): Improving the morbidity of anorectal injury from pelvic radiotherapy. Colorectal Dis $\underline{8}, 2-10$

Akpolat M, Kanter M, Uzal MC (2009): Protective effects of curcumin against gamma radiationinduced ileal mucosal damage. Arch Toxicol $\underline{83}, 609-617$

Andoh A, Yagi Y, Shioya M, Nishida A, Tsujikawa T, Fujiyama Y (2008): Mucosal cytokine network in inflammatory bowel disease. World J Gastroenterol 14, 5154-5161

Andreyev J (2005): Gastrointestinal complications of pelvic radiotherapy: are they of any importance? Gut 54, 1051-1054

Anscher MS (2005): The irreversibility of radiation-induced fibrosis: fact or folklore? J Clin Oncol $\underline{23}, 8551-8552$

Ao X, Zhao L, Davis MA, Lubman DM, Lawrence TS, Kong FM (2009): Radiation produces differential changes in cytokine profiles in radiation lung fibrosis sensitive and resistant mice. $\mathrm{J}$ Hematol Oncol $\underline{2}, 6$

Arango D, Ettarh RR, Brennan PC (2000): Dose-effect relationship of BB-10010/MIP-1 alpha on proliferation in murine small intestinal epithelium: single and double administration protocols. Dig Dis Sci $\underline{45}, 2306-2312$

Arango D, Ettarh RR, Holden G, Moriarty M, Brennan PC (2001): BB-10010, an analog of macrophage inflammatory protein-1alpha, protects murine small intestine against radiation. Dig Dis Sci $\underline{46}, 2608-2614$

Arihiro S, Ohtani H, Suzuki M, Murata M, Ejima C, Oki M, Kinouchi Y, Fukushima K, Sasaki I, Nakamura S (2002): Differential expression of mucosal addressin cell adhesion molecule-1 (MAdCAM-1) in ulcerative colitis and Crohn's disease. Pathol Int 2, 367-374

Ben-Av P, Crofford LJ, Wilder RL, Hla T (1995): Induction of vascular endothelial growth factor expression in synovial fibroblasts by prostaglandin $\mathrm{E}$ and interleukin-1: a potential mechanism for inflammatory angiogenesis. FEBS Lett $\underline{372}, 83-87$

Berbeco RI, Neicu T, Rietzel E, Chen GT, Jiang SB (2005): A technique for respiratory-gated radiotherapy treatment verification with an EPID in cine mode. Phys Med Biol 50, 3669-3679

Black WC, Gomez LS, Yuhas JM, Kligerman MM (1980): Quantitation of the late effects of Xradiation on the large intestine. Cancer $\underline{45}, 444-451$

Bourgier C, Haydont V, Milliat F, Francois A, Holler V, Lasser P, Bourhis J, Mathe D, VozeninBrotons MC (2005): Inhibition of Rho kinase modulates radiation induced fibrogenic phenotype in intestinal smooth muscle cells through alteration of the cytoskeleton and connective tissue growth factor expression. Gut 54, 336-343

Braegger CP, Nicholls S, Murch SH, Stephens S, MacDonald TT (1992): Tumour necrosis factor alpha in stool as a marker of intestinal inflammation. Lancet $\underline{339}$, 89-91 
Brennan P (2005): Radiation effects on small intestine: macrostructual, ultrastructual, surface and functional observations. Radiography Ireland $\underline{9}, 64-72$

Brown M (2008): What causes the radiation gastrointestinal syndrome?: Overview. Int J Radiat Oncol Biol Phys $\underline{70}$, 799-800

Bufill JA (1990): Colorectal cancer: evidence for distinct genetic categories based on proximal or distal tumor location. Ann Intern Med 113, 779-788

Cameron S, Haller F, Dudas J, Moriconi F, Gunawan B, Armbrust T, Langer C, Fuzesi L, Ramadori G (2008): Immune cells in primary gastrointestinal stromal tumors. Eur J Gastroenterol Hepatol 20, 327-334

Carr KE (2001): Effects of radiation damage on intestinal morphology. Int Rev Cytol 208, 1-119

Chaponnier C, Gabbiani G (2004): Pathological situations characterized by altered actin isoform expression. J Pathol 204, 386-395

Chendil D, Ranga RS, Meigooni D, Sathishkumar S, Ahmed MM (2004): Curcumin confers radiosensitizing effect in prostate cancer cell line PC-3. Oncogene 23, 1599-1607

Cheng JC, Wu JK, Huang CM, Liu HS, Huang DY, Cheng SH, Tsai SY, Jian JJ, Lin YM, Cheng TI (2002): Radiation-induced liver disease after three-dimensional conformal radiotherapy for patients with hepatocellular carcinoma: dosimetric analysis and implication. Int J Radiat Oncol Biol Phys $\underline{54}, 156-162$

Chirgwin JM, Przybyla AE, MacDonald RJ, Rutter WJ (1979): Isolation of biologically active ribonucleic acid from sources enriched in ribonuclease. Biochemistry $\underline{18}, 5294-5299$

Chiu CJ, McArdle AH, Brown R, Scott HJ, Gurd FN (1970): Intestinal mucosal lesion in low-flow states. I. A morphological, hemodynamic, and metabolic reappraisal. Arch Surg 101, 478-483

Christiansen H, Batusic D, Saile B, Hermann RM, Dudas J, Rave-Fränk M, Hess CF, Schmidberger $\mathrm{H}$, Ramadori G (2006): Identification of genes responsive to gamma radiation in rat hepatocytes and rat liver by cDNA array gene expression analysis. Radiat Res $\underline{165}, 318-325$

Christiansen H, Sheikh N, Saile B, Reuter F, Rave-Fränk M, Hermann RM, Dudas J, Hille A, Hess CF, Ramadori G (2007): x-Irradiation in rat liver: consequent upregulation of hepcidin and downregulation of hemojuvelin and ferroportin-1 gene expression. Radiology $242,189-197$

Cohen GM (1997): Caspases: the executioners of apoptosis. Biochem J $\underline{326 \text { ( Pt 1) }}, 1-16$

Coia LR, Myerson RJ, Tepper JE (1995): Late effects of radiation therapy on the gastrointestinal tract. Int J Radiat Oncol Biol Phys $\underline{31}$, 1213-1236

Compton MM (1992): A biochemical hallmark of apoptosis: internucleosomal degradation of the genome. Cancer Metastasis Rev 11, 105-119

Cook DN (1996): The role of MIP-1 alpha in inflammation and hematopoiesis. J Leukoc Biol $\underline{59}$, 61-66

Cuffy M, Abir F, Longo WE (2006): Management of less common tumors of the colon, rectum, and anus. Clin Colorectal Cancer $\underline{5}, 327-337$ 
Damoiseaux JG, Dopp EA, Calame W, Chao D, MacPherson GG, Dijkstra CD (1994): Rat macrophage lysosomal membrane antigen recognized by monoclonal antibody ED1. Immunology $\underline{83}, 140-147$

David H (1967): On the mechanism of cell desquamation of the small intestine villi. (Electron microscopic studies). Virchows Arch Pathol Anat Physiol Klin Med 342, 19-25

Delanian S, Porcher R, Rudant J, Lefaix JL (2005): Kinetics of response to long-term treatment combining pentoxifylline and tocopherol in patients with superficial radiation-induced fibrosis. $\mathbf{J}$ Clin Oncol 23, 8570-8579

Denham JW, Hauer-Jensen M, Kron T, Langberg CW (2000): Treatment-time-dependence models of early and delayed radiation injury in rat small intestine. Int J Radiat Oncol Biol Phys $\underline{48}, 871-887$

Desai A, Miller MJ, Huang X, Warren JS (2003): Nitric oxide modulates MCP-1 expression in endothelial cells: implications for the pathogenesis of pulmonary granulomatous vasculitis. Inflammation 27, 213-223

Didenko VV, Hornsby PJ (1996): Presence of double-strand breaks with single-base 3' overhangs in cells undergoing apoptosis but not necrosis. J Cell Biol 135, 1369-1376

Donner CS (1998): Pathophysiology and therapy of chronic radiation-induced injury to the colon. Dig Dis $\underline{16}, 253-261$

Dörr W, Hendry JH (2001): Consequential late effects in normal tissues. Radiother Oncol $\underline{61}, 223-$ 231

Doussis IA, Gatter KC, Mason DY (1993): CD68 reactivity of non-macrophage derived tumours in cytological specimens. J Clin Pathol 느, 334-336

Dustin ML, Rothlein R, Bhan AK, Dinarello CA, Springer TA (1986): Induction by IL-1 and interferon-gamma: tissue distribution, biochemistry, and function of a natural adherence molecule (ICAM-1). J Immunol 137, 245-254

Fantini MC, Monteleone G, Macdonald TT (2007): New players in the cytokine orchestra of inflammatory bowel disease. Inflamm Bowel Dis $\underline{13}, 1419-1423$

Ferrara N (2001): Role of vascular endothelial growth factor in regulation of physiological angiogenesis. Am J Physiol Cell Physiol 280, C1358-1366

Ferretti E, Li S, Wang J, Post M, Moore A (1996): Mesenchymal regulation of differentiation of intestinal epithelial cells. J Pediatr Gastroenterol Nutr $\underline{23}$, 65-73

Floch MH, Van Noorden S, Spiro HM (1966): Differences in epithelial enzyme activity in the duodenum, jejunum, and ileum of the monkey. Am J Dig Dis $\underline{11}, 804-810$

Forsberg JO, Jiborn H, Jung B (1979): Protective effect of hypoxia against radiation induced fibrosis in the rat gut. Acta Radiol Oncol Radiat Phys Biol $\underline{18}$, 65-75

Frey A: Protein-Blotting und Nachweis membran-gebundener Proteine; in: Gentechnische Methoden: Eine Sammlung von Arbeitsanleitungen für das molekularbiologische Labor; Spektrum akademischer Verlag Gustav Fischer, Heidelberg 2002, 343-368 
Fuccio L, Guido A, Eusebi LH, Laterza L, Grilli D, Cennamo V, Ceroni L, Barbieri E, Bazzoli F (2009): Effects of probiotics for the prevention and treatment of radiation-induced diarrhea. J Clin Gastroenterol 43, 506-513

Gangur V, Simons FE, Hayglass KT (1998): Human IP-10 selectively promotes dominance of polyclonally activated and environmental antigen-driven IFN-gamma over IL-4 responses. FASEB $\mathrm{J} \underline{12}, 705-713$

Gao C, Sun W, Christofidou-Solomidou M, Sawada M, Newman DK, Bergom C, Albelda SM, Matsuyama S, Newman PJ (2003): PECAM-1 functions as a specific and potent inhibitor of mitochondrial-dependent apoptosis. Blood 102, 169-179

Gavrieli Y, Sherman Y, Ben-Sasson SA (1992): Identification of programmed cell death in situ via specific labeling of nuclear DNA fragmentation. J Cell Biol 119, 493-501

Gervaz P, Morel P, Vozenin-Brotons MC (2009): Molecular aspects of intestinal radiation-induced fibrosis. Curr Mol Med 9, 273-280

Ghadjar P, Rubie C, Aebersold DM, Keilholz U (2009): The chemokine CCL20 and its receptor CCR6 in human malignancy with focus on colorectal cancer. Int J Cancer $\underline{125}, 741-745$

Glebov OK, Rodriguez LM, Nakahara K, Jenkins J, Cliatt J, Humbyrd CJ, DeNobile J, Soballe P, Simon R, Wright G (2003): Distinguishing right from left colon by the pattern of gene expression. Cancer Epidemiol Biomarkers Prev $\underline{12}, 755-762$

Grdina DJ, Murley JS, Kataoka Y (2002): Radioprotectants: current status and new directions.

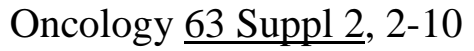

Green DR (1998): Apoptotic pathways: the roads to ruin. Cell $\underline{94}$, 695-698

Greene AK, Alwayn IP, Nose V, Flynn E, Sampson D, Zurakowski D, Folkman J, Puder M (2005): Prevention of intra-abdominal adhesions using the antiangiogenic COX-2 inhibitor celecoxib. Ann Surg 242, 140-146

Gremy O, Benderitter M, Linard C (2008): Acute and persisting Th2-like immune response after fractionated colorectal gamma-irradiation. World J Gastroenterol 14, 7075-7085

Gudkov AV, Gleiberman A (2008): In regard to Schuller et Al. (Int J Radiat Oncol Biol Phys 2007;68:205-210). Int J Radiat Oncol Biol Phys 므, 800-801; author reply 802-803

Gupta S (2001): Molecular steps of death receptor and mitochondrial pathways of apoptosis. Life Sci $\underline{69}, 2957-2964$

Haanen C, Vermes I (1995): Apoptosis and inflammation. Mediators Inflamm 4, 5-15

Haglund U (1994): Gut ischaemia. Gut $\underline{35}$, S73-76

Haimovitz-Friedman A, Kan CC, Ehleiter D, Persaud RS, McLoughlin M, Fuks Z, Kolesnick RN (1994): Ionizing radiation acts on cellular membranes to generate ceramide and initiate apoptosis. J Exp Med 180, 525-535

Halfdanarson TR, McWilliams RR, Donohue JH, Quevedo JF (2010): A single-institution experience with 491 cases of small bowel adenocarcinoma. Am J Surg 199, 797-803 
Hall PA, Coates PJ, Ansari B, Hopwood D (1994): Regulation of cell number in the mammalian gastrointestinal tract: the importance of apoptosis. J Cell Sci 107 (Pt 12), 3569-3577

Harada A, Sekido N, Akahoshi T, Wada T, Mukaida N, Matsushima K (1994): Essential involvement of interleukin-8 (IL-8) in acute inflammation. J Leukoc Biol 56, 559-564

Hauer-Jensen M, Richter KK, Wang J, Abe E, Sung CC, Hardin JW (1998): Changes in transforming growth factor beta 1 gene expression and immunoreactivity levels during development of chronic radiation enteropathy. Radiat Res $\underline{150}, 673-680$

Haydont V, Bourgier C, Pocard M, Lusinchi A, Aigueperse J, Mathe D, Bourhis J, VozeninBrotons MC (2007): Pravastatin Inhibits the Rho/CCN2/extracellular matrix cascade in human fibrosis explants and improves radiation-induced intestinal fibrosis in rats. Clin Cancer Res $\underline{13}$, 5331-5340

Haydont V, Riser BL, Aigueperse J, Vozenin-Brotons MC (2008): Specific signals involved in the long-term maintenance of radiation-induced fibrogenic differentiation: a role for CCN2 and low concentration of TGF-beta1. Am J Physiol Cell Physiol 294, C1332-1341

Hayne D, Vaizey CJ, Boulos PB (2001): Anorectal injury following pelvic radiotherapy. Br J Surg $\underline{88}, 1037-1048$

Hendry JH, Booth C, Potten CS (2001): Endothelial cells and radiation gastrointestinal syndrome. Science 294, 1411

Hendry JH, Dörr W, Hill RP, Potten CS (2008): No apoptotic endothelial cells in irradiated intestine: regarding Schuller et al. (Int J Radiat Oncol Biol Phys 2007;68:205-210). Int J Radiat Oncol Biol Phys 무, 801-802; author reply 803

Hermann T, Baumann M, Dörr W: Strahlenschäden an einzelnen Geweben und Organen Verdauungstrakt-; in: Klinische Strahlenbiologie -kurz und bündig-; 3. überarbeitete Auflage; Fischer-Verlag, Jena 1996, 108-112

Heuff G, van der Ende MB, Boutkan H, Prevoo W, Bayon LG, Fleuren GJ, Beelen RH, Meijer S, Dijkstra CD (1993): Macrophage populations in different stages of induced hepatic metastases in rats: an immunohistochemical analysis. Scand J Immunol $\underline{38}$, 10-16

Hille A, Christiansen H, Pradier O, Hermann RM, Siekmeyer B, Weiss E, Hilgers R, Hess CF, Schmidberger H (2005 a): Effect of pentoxifylline and tocopherol on radiation proctitis/enteritis. Strahlenther Onkol 181, 606-614

Hille A, Schmidberger H, Hermann RM, Christiansen H, Saile B, Pradier O, Hess CF (2005 b): A phase III randomized, placebo-controlled, double-blind study of misoprostol rectal suppositories to prevent acute radiation proctitis in patients with prostate cancer. Int J Radiat Oncol Biol Phys $\underline{63}$, $1488-1493$

Hille A, Herrmann MK, Kertesz T, Christiansen H, Hermann RM, Pradier O, Schmidberger H, Hess CF (2008): Sodium butyrate enemas in the treatment of acute radiation-induced proctitis in patients with prostate cancer and the impact on late proctitis. A prospective evaluation. Strahlenther Onkol 184, 686-692

Hille A, Rave-Fränk M, Christiansen H, Herrmann MK, Kertesz T, Hermann RM, Wolff HA, Schirmer M, Hess CF, Ramadori G (2009): Faecal calprotectin and lactoferrin values during 
irradiation of prostate cancer correlate with chronic radiation proctitis: results of a prospective study. Scand J Gastroenterol 44, 939-946

Holzapfel B, Wickert L (2007): Die quantitative Real-Time-PCR (qRT-PCR). BIUZ $\underline{37}, 120-126$

Hori M, Nobe H, Horiguchi K, Ozaki H (2008): MCP-1 targeting inhibits muscularis macrophage recruitment and intestinal smooth muscle dysfunction in colonic inflammation. Am J Physiol Cell Physiol 294, C391-401

Horwhat JD, Dubois A (1999): Radiation enteritis. Curr Treat Option Gastroenterol 2, 371-381

Hug H (2000): Apoptose: die Selbstvernichtung der Zelle als Überlebensschutz. BIUZ $\underline{\text { 30, }}$ 128-135

Husmann G, Kaatsch P, Katalinic A, Bertz J, Kraywinkel K, Wolf U: Krebs in Deutschland 2005/2006 Häufigkeit und Trends -Eine gemeinsame Veröffentlichung des Robert Koch-Instituts und der Gesellschaft der epidemiologischen Krebsregister in Deutschland e.V. (Hrsg); 7. Ausgabe; Robert Koch Institut, Berlin 2010

Ijiri K, Potten CS (1990): The circadian rhythm for the number and sensitivity of radiation-induced apoptosis in the crypts of mouse small intestine. Int J Radiat Biol $\underline{58}, 165-175$

Indaram AV, Visvalingam V, Locke M, Bank S (2000): Mucosal cytokine production in radiationinduced proctosigmoiditis compared with inflammatory bowel disease. Am J Gastroenterol 95, $1221-1225$

Javaid K, Rahman A, Anwar KN, Frey RS, Minshall RD, Malik AB (2003): Tumor necrosis factoralpha induces early-onset endothelial adhesivity by protein kinase $\mathrm{C} \zeta$-dependent activation of intercellular adhesion molecule-1. Circ Res 92, 1089-1097

Jensen MH, Sauer T, Devik F, Nygaard K (1983): Late changes following single dose roentgen irradiation of rat small intestine. Acta Radiol Oncol 22, 299-303

Jung HC, Eckmann L, Yang SK, Panja A, Fierer J, Morzycka-Wroblewska E, Kagnoff MF (1995): A distinct array of proinflammatory cytokines is expressed in human colon epithelial cells in response to bacterial invasion. J Clin Invest 95, 55-65

Kerr JF, Wyllie AH, Currie AR (1972): Apoptosis: a basic biological phenomenon with wideranging implications in tissue kinetics. Br J Cancer 26, 239-257

Kertesz T, Herrmann MK, Zapf A, Christiansen H, Hermann RM, Pradier O, Schmidberger H, Hess CF, Hille A (2009): Effect of a prostaglandin - given rectally for prevention of radiation-induced acute proctitis - on late rectal toxicity. Results of a phase III randomized, placebo-controlled, double-blind study. Strahlenther Onkol 185, 596-602

Keskek M, Gocmen E, Kilic M, Gencturk S, Can B, Cengiz M, Okten RM, Koc M (2006): Increased expression of cyclooxygenase-2 (COX-2) in radiation-induced small bowel injury in rats. J Surg Res $\underline{135}$, 76-84

Kidd VJ, Lahti JM, Teitz T (2000): Proteolytic regulation of apoptosis. Semin Cell Dev Biol 11, 191-201

Kim I, Moon SO, Kim SH, Kim HJ, Koh YS, Koh GY (2001): Vascular endothelial growth factor expression of intercellular adhesion molecule 1 (ICAM-1), vascular cell adhesion molecule 1 
(VCAM-1), and E-selectin through nuclear factor-kappa B activation in endothelial cells. J Biol Chem 276, 7614-7620

Kliem H, Berisha B, Meyer HH, Schams D (2009): Regulatory changes of apoptotic factors in the bovine corpus luteum after induced luteolysis. Mol Reprod Dev $\underline{76}, 220-230$

Kroemer G, Dallaporta B, Resche-Rigon M (1998): The mitochondrial death/life regulator in apoptosis and necrosis. Annu Rev Physiol 60, 619-642

Larsen A, Reitan JB, Aase ST, Hauer-Jensen M (2007): Long-term prognosis in patients with severe late radiation enteropathy: a prospective cohort study. World J Gastroenterol $\underline{13}$, 3610-3613

Lazebnik YA, Kaufmann SH, Desnoyers S, Poirier GG, Earnshaw WC (1994): Cleavage of poly(ADP-ribose) polymerase by a proteinase with properties like ICE. Nature $\underline{371}$, 346-347

Lennon SV, Martin SJ, Cotter TG (1991): Dose-dependent induction of apoptosis in human tumour cell lines by widely diverging stimuli. Cell Prolif $\underline{24}$, 203-214

Levine AD (2000): Apoptosis: implications for inflammatory bowel disease. Inflamm Bowel Dis $\underline{6}$, 191-205

Linard C, Marquette C, Mathieu J, Pennequin A, Clarencon D, Mathe D (2004): Acute induction of inflammatory cytokine expression after gamma-irradiation in the rat: effect of an NF-kappaB inhibitor. Int J Radiat Oncol Biol Phys $\underline{58}$, 427-434

Liu W, Ding I, Chen K, Olschowka J, Xu J, Hu D, Morrow GR, Okunieff P (2006): Interleukin 1 beta (IL-1 $\beta$ ) signaling is a critical component of radiation-induced skin fibrosis. Radiat Res $\underline{165}$, 181-191

Liu Y, Kudo K, Abe Y, Hu DL, Kijima H, Nakane A, Ono K (2009): Inhibition of transforming growth factor-beta, hypoxia-inducible factor-1alpha and vascular endothelial growth factor reduced late rectal injury induced by irradiation. J Radiat Res (Tokyo) 50, 233-239

MacDermott RP, Sanderson IR, Reinecker HC (1998): The central role of chemokines (chemotactic cytokines) in the immunopathogenesis of ulcerative colitis and Crohn's disease. Inflamm Bowel Dis $\underline{4}, 54-67$

Maj JG, Paris F, Haimovitz-Friedman A, Venkatraman E, Kolesnick R, Fuks Z (2003): Microvascular function regulates intestinal crypt response to radiation. Cancer Res $\underline{63}, 4338-4341$

Majno G, Joris I (1995): Apoptosis, oncosis, and necrosis. An overview of cell death. Am J Pathol $\underline{146}, 3-15$

Malik IA, Moriconi F, Sheikh N, Naz N, Khan S, Dudas J, Mansuroglu T, Hess CF, Rave-Fränk M, Christiansen H (2010): Single-dose gamma-irradiation induces up-regulation of chemokine gene expression and recruitment of granulocytes into the portal area but not into other regions of rat hepatic tissue. Am J Pathol 176, 1801-1815

Marshman E, Ottewell PD, Potten CS, Watson AJ (2001): Caspase activation during spontaneous and radiation-induced apoptosis in the murine intestine. J Pathol $\underline{195}, 285-292$ 
Mason DY, Cordell J, Brown M, Pallesen G, Ralfkiaer E, Rothbard J, Crumpton M, Gatter KC (1989): Detection of $\mathrm{T}$ cells in paraffin wax embedded tissue using antibodies against a peptide sequence from the CD3 antigen. J Clin Pathol $\underline{42}$, 1194-1200

Matthijsen RA, Derikx JP, Kuipers D, van Dam RM, Dejong CH, Buurman WA (2009): Enterocyte shedding and epithelial lining repair following ischemia of the human small intestine attenuate inflammation. PLoS One $\underline{4}$, e 7045

Merritt AJ, Potten CS, Kemp CJ, Hickman JA, Balmain A, Lane DP, Hall PA (1994): The role of p53 in spontaneous and radiation-induced apoptosis in the gastrointestinal tract of normal and p53deficient mice. Cancer Res $\underline{54}$, 614-617

Merritt AJ, Potten CS, Watson AJ, Loh DY, Nakayama K, Nakayama K, Hickman JA (1995): Differential expression of bcl-2 in intestinal epithelia. Correlation with attenuation of apoptosis in colonic crypts and the incidence of colonic neoplasia. J Cell Sci 108 (Pt 6), 2261-2271

Milliat F, Francois A, Isoir M, Deutsch E, Tamarat R, Tarlet G, Atfi A, Validire P, Bourhis J, Sabourin JC (2006): Influence of endothelial cells on vascular smooth muscle cells phenotype after irradiation: implication in radiation-induced vascular damages. Am J Pathol $\underline{169}, 1484-1495$

Moriconi F, Christiansen H, Raddatz D, Dudas J, Hermann RM, Rave-Fränk M, Sheikh N, Saile B, Hess CF, Ramadori G (2008): Effect of radiation on gene expression of rat liver chemokines: in vivo and in vitro studies. Radiat Res $\underline{169}, 162-169$

Munker R, Koeffler HP (1987): Tumor necrosis factor: recent advances. J Mol Med $\underline{65}$, 345-352

Nakshabendi IM, McKee R, Downie S, Russell RI, Rennie MJ (1999): Rates of small intestinal mucosal protein synthesis in human jejunum and ileum. Am J Physiol 277, E1028-1031

Nardone G (2003): Review article: molecular basis of gastric carcinogenesis. Aliment Pharmacol Ther 17 Suppl 2, 75-81

Newman PJ (1997): The biology of PECAM-1. J Clin Invest 100, S25-29

Newman PJ, Newman DK (2003): Signal transduction pathways mediated by PECAM-1: new roles for an old molecule in platelet and vascular cell biology. Arterioscler Thromb Vasc Biol 23, 953964

Nicholson DW, Ali A, Thornberry NA, Vaillancourt JP, Ding CK, Gallant M, Gareau Y, Griffin PR, Labelle M, Lazebnik YA (1995): Identification and inhibition of the ICE/CED-3 protease necessary for mammalian apoptosis. Nature $\underline{376}, 37-43$

Nicholson DW, Thornberry NA (2003): Apoptosis. Life and death decisions. Science 299, 214-215

Oehm A, Behrmann I, Falk W, Pawlita M, Maier G, Klas C, Li-Weber M, Richards S, Dhein J, Trauth BC (1992): Purification and molecular cloning of the APO-1 cell surface antigen, a member of the tumor necrosis factor/nerve growth factor receptor superfamily. Sequence identity with the Fas antigen. J Biol Chem 267, 10709-10715

Ogawa H, Binion DG, Heidemann J, Theriot M, Fisher PJ, Johnson NA, Otterson MF, Rafiee P (2005): Mechanisms of MAdCAM-1 gene expression in human intestinal microvascular endothelial cells. Am J Physiol Cell Physiol 288, C272-281 
Olgaç V, Erbil Y, Barbaros U, Oztezcan S, Giris M, Kaya H, Bilge H, Guler S, Toker G (2006): The efficacy of octreotide in pancreatic and intestinal changes: radiation-induced enteritis in animals. Dig Dis Sci $\underline{51}$, 227-232

Oltvai ZN, Milliman CL, Korsmeyer SJ (1993): Bcl-2 heterodimerizes in vivo with a conserved homolog, Bax, that accelerates programmed cell death. Cell $\underline{74}$, 609-619

Onal C, Kayaselcuk F, Topkan E, Yavuz M, Bacanli D, Yavuz A (2011): Protective Effects of Melatonin and Octreotide Against Radiation-Induced Intestinal Injury. Dig Dis Sci 56, 359-367

Oshima T, Jordan P, Grisham MB, Alexander JS, Jennings M, Sasaki M, Manas K (2001): TNFalpha induced endothelial MAdCAM-1 expression is regulated by exogenous, not endogenous nitric oxide. BMC Gastroenterol $\underline{1}, 5$

Ottaway CA, Parrott DM (1980): Regional blood flow and the localization of lymphoblasts in the small intestine of the mouse. I. Examination of normal small intestine. Immunology 41 , 955-961

Pabst R, Rothkotter HJ (1999): Postnatal development of lymphocyte subsets in different compartments of the small intestine of piglets. Vet Immunol Immunopathol $\underline{72}$, 167-173

Paris F, Fuks Z, Kang A, Capodieci P, Juan G, Ehleiter D, Haimovitz-Friedman A, Cordon-Cardo C, Kolesnick R (2001): Endothelial apoptosis as the primary lesion initiating intestinal radiation damage in mice. Science $\underline{293}$, 293-297

Pfaffl MW (2001): A new mathematical model for relative quantification in real-time RT-PCR. Nucleic Acids Res 29, 2002-2007

Plateroti M, Rubin DC, Duluc I, Singh R, Foltzer-Jourdainne C, Freund JN, Kedinger M (1998): Subepithelial fibroblast cell lines from different levels of gut axis display regional characteristics. Am J Physiol 274, G945-954

Po Po S, Zuki ABZ, Zamri-Saad M, Rahman-Omar A, Effendy AW (2005): Morphological Study of the Jejunal and Ileal Peyer`s Patches of Three-month Old Calves. J Anim Vet Adv $\underline{4}, 579-589$

Podolsky DK (1993): Regulation of intestinal epithelial proliferation: a few answers, many questions. Am J Physiol 264, G179-186

Potten CS (1986): Cell cycles in cell hierarchies. Int J Radiat Biol Relat Stud Phys Chem Med $\underline{49}$, 257-278

Potten CS (1990): A comprehensive study of the radiobiological response of the murine (BDF1) small intestine. Int J Radiat Biol $\underline{58}$, 925-973

Potten CS (1992): The significance of spontaneous and induced apoptosis in the gastrointestinal tract of mice. Cancer Metastasis Rev 11, 179-195

Potten CS (2004): Radiation, the ideal cytotoxic agent for studying the cell biology of tissues such as the small intestine. Radiat Res $\underline{161}$, 123-136

Potten CS, Li YQ, O'Connor PJ, Winton DJ (1992): A possible explanation for the differential cancer incidence in the intestine, based on distribution of the cytotoxic effects of carcinogens in the murine large bowel. Carcinogenesis $\underline{13}$, 2305-2312 
Potten CS, Wilson JW, Booth C (1997): Regulation and significance of apoptosis in the stem cells of the gastrointestinal epithelium. Stem Cells $\underline{15}, 82-93$

Pritchard DM, Print C, O'Reilly L, Adams JM, Potten CS, Hickman JA (2000): Bcl-w is an important determinant of damage-induced apoptosis in epithelia of small and large intestine. Oncogene 19, 3955-3959

Qesaraku B, Dudas J, Rave-Fränk M, Hess CF, Ramadori G, Saile B, Christiansen H (2009): Effect of tumour necrosis factor alpha and irradiation alone or in combination on the viability of hepatocellular and biliary adenocarcinoma cell lines in vitro. Liver Int $\underline{29}, 910-921$

Ramadori G, Sipe JD, Colten HR (1985): Expression and regulation of the murine serum amyloid A (SAA) gene in extrahepatic sites. J Immunol 135, 3645-3647

Reed JC (1997): Double identity for proteins of the Bcl-2 family. Nature 387, 773-776

Regaud C, Nogier T, Lacassagne A (1912): Sur les effets redoutables des irradiations etendues de l'abdomen et sur les lesions du tube digestif determinees par les rayons de Roentgen. Arch d'Electr Med $\underline{343}, 321-334$

Rege TA, Hagood JS (2006 a): Thy-1 as a regulator of cell-cell and cell-matrix interactions in axon regeneration, apoptosis, adhesion, migration, cancer, and fibrosis. FASEB J 20, 1045-1054

Rege TA, Hagood JS (2006 b): Thy-1, a versatile modulator of signaling affecting cellular adhesion, proliferation, survival, and cytokine/growth factor responses. Biochim Biophys Acta $\underline{1763}, 991-999$

Reinecker HC, Podolsky DK (1995): Human intestinal epithelial cells express functional cytokine receptors sharing the common gamma-c-chain of the interleukin-2-receptor. Proc Natl Acad Sci U S A $\underline{92}, 8353-8357$

Richter KK, Fagerhol MK, Carr JC, Winkler JM, Sung CC, Hauer-Jensen M (1997): Association of granulocyte transmigration with structural and cellular parameters of injury in experimental radiation enteropathy. Radiat Oncol Investig $\underline{5}$, 275-282

Rider AK, Schedl HP, Nokes G, Shining S (1967): Small intestinal glucose transport. Proximaldistal kinetic gradients. J Gen Physiol 무, 1173-1182

Rossi D, Gaidano G (2003): Messengers of cell death: apoptotic signaling in health and disease. Haematologica $\underline{88}, 212-218$

Rübe CE, Wilfert F, Palm J, König J, Burdak-Rothkamm S, Liu L, Schuck A, Willich N, Rübe C (2004): Irradiation induces a biphasic expression of pro-inflammatory cytokines in the lung. Strahlenther Onkol 180, 442-448

Rubio CA, Jalnäs M (1996): Dose-time-dependent histological changes following irradiation of the small intestine of rats. Dig Dis Sci $\underline{41}, 392-401$

Rudner J, Lepple-Wienhues A, Budach W, Berschauer J, Friedrich B, Wesselborg S, SchulzeOsthoff K, Belka C (2001): Wild-type, mitochondrial and ER-restricted Bcl-2 inhibit DNA damageinduced apoptosis but do not affect death receptor-induced apoptosis. J Cell Sci 114, 4161-4172 
Ruemmele FM, Seidman EG (1998): Cytokine - intestinal epithelial cell interactions: implications for immune mediated bowel disorders. Acta Paediatr Sin $\underline{39}, 1-8$

Salvesen GS, Dixit VM (1997): Caspases: intracellular signaling by proteolysis. Cell 91, 443-446

Saraste A (1999): Morphologic criteria and detection of apoptosis. Herz 24, 189-195

Saraste A, Pulkki K (2000): Morphologic and biochemical hallmarks of apoptosis. Cardiovasc Res $\underline{45}, 528-537$

Sarto C, Binz PA, Mocarelli P (2000): Heat shock proteins in human cancer. Electrophoresis 21, $1218-1226$

Sartor RB (1995): Current concepts of the etiology and pathogenesis of ulcerative colitis and Crohn's disease. Gastroenterol Clin North Am 24, 475-507

Saunders JW, Jr. (1966): Death in embryonic systems. Science 154, 604-612

Schefter TE, Kavanagh BD, Timmerman RD, Cardenes HR, Baron A, Gaspar LE (2005): A phase I trial of stereotactic body radiation therapy (SBRT) for liver metastases. Int J Radiat Oncol Biol Phys $\underline{62}, 1371-1378$

Schuller BW, Binns PJ, Riley KJ, Ma L, Hawthorne MF, Coderre JA (2006): Selective irradiation of the vascular endothelium has no effect on the survival of murine intestinal crypt stem cells. Proc Natl Acad Sci U S A $\underline{103}$, 3787-3792

Schuller BW, Rogers AB, Cormier KS, Riley KJ, Binns PJ, Julius R, Hawthorne MF, Coderre JA (2007): No significant endothelial apoptosis in the radiation-induced gastrointestinal syndrome. Int J Radiat Oncol Biol Phys $\underline{68}$, 205-210

Schulze-Osthoff K, Ferrari D, Los M, Wesselborg S, Peter ME (1998): Apoptosis signaling by death receptors. Eur J Biochem 254, 439-459

Skwarchuk MW, Travis EL (1998): Changes in histology and fibrogenic cytokines in irradiated colorectum of two murine strains. Int J Radiat Oncol Biol Phys $\underline{42}, 169-178$

Slee EA, Harte MT, Kluck RM, Wolf BB, Casiano CA, Newmeyer DD, Wang HG, Reed JC, Nicholson DW, Alnemri ES (1999): Ordering the cytochrome c-initiated caspase cascade: hierarchical activation of caspases-2, $-3,-6,-7,-8$, and -10 in a caspase-9-dependent manner. J Cell Biol 144, 281-292

Sminia T, Jeurissen SH (1986): The macrophage population of the gastro-intestinal tract of the rat. Immunobiology $\underline{172}, 72-80$

Staroslawska E, Czarnocki KJ, Koziol-Montewka M, Donica H, Magrys A (2008): Effect of infliximab on the levels of TNF-alpha and TGF-beta in the whole blood cultures of irradiated patients. Folia Histochem Cytobiol 46, 291-297

Strasser A, O'Connor L, Dixit VM (2000): Apoptosis signaling. Annu Rev Biochem $\underline{69}$, 217-245

Suit HD, Withers HR (2001): Endothelial cells and radiation gastrointestinal syndrome. Science $\underline{294}, 1411$ 
Susin SA, Lorenzo HK, Zamzami N, Marzo I, Snow BE, Brothers GM, Mangion J, Jacotot E, Costantini P, Loeffler M (1999): Molecular characterization of mitochondrial apoptosis-inducing factor. Nature $\underline{397}, 441-446$

Szabo I, Tarnawski AS (2000): Apoptosis in the gastric mucosa: molecular mechanisms, basic and clinical implications. J Physiol Pharmacol $\underline{51}$, 3-15

Ten Haken RK, Lawrence TS, Mc Shan DL, Tesser RJ, Fraass BA, Lichter AS (1991): Technical considerations in the use of 3-D beam arrangements in the abdomen. Radiother Oncol 22, 19-28

Towbin H, Staehelin T, Gordon J (1979): Electrophoretic transfer of proteins from polyacrylamide gels to nitrocellulose sheets: procedure and some applications. Proc Natl Acad Sci U S A $\underline{76}$, 43504354

Trump BF, Berezesky IK, Chang SH, Phelps PC (1997): The pathways of cell death: oncosis, apoptosis, and necrosis. Toxicol Pathol $\underline{25}, 82-88$

van de Stolpe A, van der Saag PT (1996): Intercellular adhesion molecule-1. J Mol Med 74, 13-33

von Bültzingslöwen I, Brennan MT, Spijkervet FK, Logan R, Stringer A, Raber-Durlacher JE, Keefe D (2006): Growth factors and cytokines in the prevention and treatment of oral and gastrointestinal mucositis. Support Care Cancer 14, 519-527

Vozenin-Brotons MC, Milliat F, Linard C, Strup C, Francois A, Sabourin JC, Lasser P, Lusinchi A, Deutsch E, Girinsky T (2004): Gene expression profile in human late radiation enteritis obtained by high-density cDNA array hybridization. Radiat Res $\underline{161}, 299-311$

Walsh D (1897): Deep tissue traumatism from roentgen ray exposure. Br Med J 1897,2, 272-273

Wang J, Richter KK, Sung CC, Hauer-Jensen M (1999): Upregulation and spatial shift in the localization of the mannose 6-phosphate/insulin-like growth factor II receptor during radiation enteropathy development in the rat. Radiother Oncol 50, 205-213

Wang J, Boerma M, Fu Q, Hauer-Jensen M (2007): Significance of endothelial dysfunction in the pathogenesis of early and delayed radiation enteropathy. World J Gastroenterol $\underline{13}$, 3047-3055

Wang S, Quadri SM, Tang XZ, Stephens LC, Lollo CP, Bartholomew RM, Vriesendorp HM (1995): Liver toxicity induced by combined external-beam irradiation and radioimmunoglobulin therapy. Radiat Res 141, 294-302

Warren SL, Whipple GH (1923): Roentgen ray intoxication: IV. Intestinal lesions and acute intoxication produced by radiation in a variety of animals. J Exp Med $\underline{38}, 741-752$

Watanabe J, Lin JA, Narasimha AJ, Shahbazian A, Ishikawa TO, Martin MG, Herschman HR, Reddy ST (2010): Novel anti-inflammatory functions for endothelial and myeloid cyclooxygenase2 in a new mouse model of Crohn's disease. Am J Physiol Gastrointest Liver Physiol 298, G842850

Weichselbaum R (2005): Radiation's outer limits. Nat Med 11, 477-478

Welsch U: Sobotta - Lehrbuch Histologie; Urban \& Fischer, Jena 2003 
Wetzel A, Chavakis T, Preissner KT, Sticherling M, Haustein UF, Anderegg U, Saalbach A (2004): Human Thy-1 (CD90) on activated endothelial cells is a counterreceptor for the leukocyte integrin Mac-1 (CD11b/CD18). J Immunol 172, 3850-3859

Widel M, Przybyszewski W, Rzeszowska-Wolny J (2009): Radiation-induced bystander effect: the important part of ionizing radiation response. Potential clinical implications. Postepy Hig Med Dosw (Online) $\underline{63}, 377-388$

Williams IR (2006): CCR6 and CCL20: partners in intestinal immunity and lymphorganogenesis. Ann N Y Acad Sci 1072, 52-61

Wilson KP, Black JA, Thomson JA, Kim EE, Griffith JP, Navia MA, Murcko MA, Chambers SP, Aldape RA, Raybuck SA (1994): Structure and mechanism of interleukin-1 beta converting enzyme. Nature $\underline{370}, 270-275$

Wolf JL, Rubin DH, Finberg R, Kauffman RS, Sharpe AH, Trier JS, Fields BN (1981): Intestinal M cells: a pathway for entry of reovirus into the host. Science $\underline{212}, 471-472$

Wyllie AH, Kerr JF, Currie AR (1980): Cell death: the significance of apoptosis. Int Rev Cytol $\underline{68}$, 251-306

Yang E, Zha J, Jockel J, Boise LH, Thompson CB, Korsmeyer SJ (1995): Bad, a heterodimeric partner for Bcl-XL and Bcl-2, displaces Bax and promotes cell death. Cell $\underline{80}$, 285-291

Yang L, Froio RM, Sciuto TE, Dvorak AM, Alon R, Luscinskas FW (2005): ICAM-1 regulates neutrophil adhesion and transcellular migration of TNF-alpha-activated vascular endothelium under flow. Blood 106, 584-592

Yeoh AS, Gibson RJ, Yeoh EE, Bowen JM, Stringer AM, Giam KA, Keefe DM (2007): A novel animal model to investigate fractionated radiotherapy-induced alimentary mucositis: the role of apoptosis, p53, nuclear factor-kappaB, COX-1, and COX-2. Mol Cancer Ther $\underline{6}$, 2319-2327

Yoo NJ, Kim HS, Kim SY, Park WS, Kim SH, Lee JY, Lee SH (2002): Stomach cancer highly expresses both initiator and effector caspases; an immunohistochemical study. APMIS $\underline{110}$, 825832

Zheng H, Wang J, Koteliansky VE, Gotwals PJ, Hauer-Jensen M (2000): Recombinant soluble transforming growth factor beta type II receptor ameliorates radiation enteropathy in mice. Gastroenterology 119, 1286-1296 


\section{$7 \quad$ ANHANG: Tabelle 7 bis 15}

Tabelle 7 Proteinbestimmung für 15er Slot, Proben C, D und E

\begin{tabular}{|c|c|c|c|c|c|c|}
\hline Organ & Probe & Extinktion (y) & $\begin{array}{c}\text { Protein (x) } \\
{[\mu \mathrm{g} / \mu \mathrm{l}]}\end{array}$ & $\begin{array}{c}\text { Lysat }[\mu \mathrm{g} / \mu \mathrm{ll}] \mathrm{x} \\
\text { Faktor } 20\end{array}$ & $40 \mu \mathrm{g}$ Protein & $\begin{array}{c}\text { Vol. } 10 \mu \mathrm{l} \\
\text { Spalt-Puffer }\end{array}$ \\
\hline Duodenum & $\mathrm{COh}$ & 0,3314 & 0,94 & 18,88 & 2,12 & 7,88 \\
\hline Duodenum & $\mathrm{DOh}$ & 0,2739 & 0,78 & 15,60 & 2,56 & 7,44 \\
\hline Duodenum & $\mathrm{C} 1 \mathrm{~h}$ & 0,3001 & 0,85 & 17,09 & 2,34 & 7,66 \\
\hline Duodenum & $\mathrm{D} 1 \mathrm{~h}$ & 0,303 & 0,86 & 17,26 & 2,32 & 7,68 \\
\hline Duodenum & $\mathrm{E} 1 \mathrm{~h}$ & 0,411 & 1,17 & 23,41 & 1,71 & 8,29 \\
\hline Duodenum & $\mathrm{C} 6 \mathrm{~h}$ & 0,3125 & 0,89 & 17,80 & 2,25 & 7,75 \\
\hline Duodenum & $\mathrm{D} 6 \mathrm{~h}$ & 0,2365 & 0,67 & 13,47 & 2,97 & 7,03 \\
\hline Duodenum & $\mathrm{E} 6 \mathrm{~h}$ & 0,2725 & 0,78 & 15,52 & 2,58 & 7,42 \\
\hline Duodenum & $\mathrm{C} 24 \mathrm{~h}$ & 0,1928 & 0,55 & 10,98 & 3,64 & 6,36 \\
\hline Duodenum & $\mathrm{D} 24 \mathrm{~h}$ & 0,322 & 0,92 & 18,34 & 2,18 & 7,82 \\
\hline Duodenum & $\mathrm{E} 24 \mathrm{~h}$ & 0,322 & 0,92 & 18,34 & 2,18 & 7,82 \\
\hline Duodenum & $\mathrm{C} 96 \mathrm{~h}$ & 0,2471 & 0,70 & 14,07 & 2,84 & 7,16 \\
\hline Duodenum & $\mathrm{D} 96 \mathrm{~h}$ & 0,1363 & 0,39 & 7,76 & 5,15 & 4,85 \\
\hline Duodenum & $\mathrm{E} 96 \mathrm{~h}$ & 0,1619 & 0,46 & 9,22 & 4,34 & 5,66 \\
\hline Jejunum & $\mathrm{COh}$ & 0,3103 & 0,88 & 17,67 & 2,26 & 7,74 \\
\hline Jejunum & $\mathrm{DOh}$ & 0,2507 & 0,71 & 14,28 & 2,80 & 7,20 \\
\hline Jejunum & $\mathrm{C} 1 \mathrm{~h}$ & 0,2433 & 0,69 & 13,86 & 2,89 & 7,11 \\
\hline Jejunum & $\mathrm{D} 1 \mathrm{~h}$ & 0,2009 & 0,57 & 11,44 & 3,50 & 6,50 \\
\hline Jejunum & $\mathrm{E} 1 \mathrm{~h}$ & 0,239 & 0,68 & 13,61 & 2,94 & 7,06 \\
\hline Jejunum & $\mathrm{C} 6 \mathrm{~h}$ & 0,3531 & 1,01 & 20,11 & 1,99 & 8,01 \\
\hline Jejunum & $\mathrm{D} 6 \mathrm{~h}$ & 0,3922 & 1,12 & 22,34 & 1,79 & 8,21 \\
\hline Jejunum & $\mathrm{E} 6 \mathrm{~h}$ & 0,2699 & 0,77 & 15,37 & 2,60 & 7,40 \\
\hline Jejunum & $\mathrm{C} 24 \mathrm{~h}$ & 0,2345 & 0,67 & 13,36 & 2,99 & 7,01 \\
\hline Jejunum & $\mathrm{D} 24 \mathrm{~h}$ & 0,1949 & 0,56 & 11,10 & 3,60 & 6,40 \\
\hline Jejunum & $\mathrm{E} 24 \mathrm{~h}$ & 0,2994 & 0,85 & 17,05 & 2,35 & 7,65 \\
\hline Jejunum & $\mathrm{C} 96 \mathrm{~h}$ & 0,2324 & 0,66 & 13,24 & 3,02 & 6,98 \\
\hline Jejunum & $\mathrm{D} 96 \mathrm{~h}$ & 0,3405 & 0,97 & 19,39 & 2,06 & 7,94 \\
\hline Jejunum & $\mathrm{E} 96 \mathrm{~h}$ & 0,1989 & 0,57 & 11,33 & 3,53 & 6,47 \\
\hline Ileum & $\mathrm{COh}$ & 0,2162 & 0,62 & 12,31 & 3,25 & 6,75 \\
\hline Ileum & $\mathrm{DOh}$ & 0,2124 & 0,60 & 12,10 & 3,31 & 6,69 \\
\hline Ileum & $\mathrm{C} 1 \mathrm{~h}$ & 0,1575 & 0,45 & 8,97 & 4,46 & 5,54 \\
\hline Ileum & $\mathrm{D} 1 \mathrm{~h}$ & 0,2379 & 0,68 & 13,55 & 2,95 & 7,05 \\
\hline Illeum & $\mathrm{E} 1 \mathrm{~h}$ & 0,1991 & 0,57 & 11,34 & 3,53 & 6,47 \\
\hline Ileum & $\mathrm{C} 6 \mathrm{~h}$ & 0,1938 & 0,55 & 11,04 & 3,62 & 6,38 \\
\hline Ileum & $\mathrm{D} 6 \mathrm{~h}$ & 0,3035 & 0,86 & 17,29 & 2,31 & 7,69 \\
\hline Ileum & $\mathrm{E} 6 \mathrm{~h}$ & 0,2391 & 0,68 & 13,62 & 2,94 & 7,06 \\
\hline Illeum & $\mathrm{C} 24 \mathrm{~h}$ & 0,3595 & 1,02 & 20,48 & 1,95 & 8,05 \\
\hline Illeum & $\mathrm{D} 24 \mathrm{~h}$ & 0,212 & 0,60 & 12,07 & 3,31 & 6,69 \\
\hline Ileum & $\mathrm{E} 24 \mathrm{~h}$ & 0,2295 & 0,65 & 13,07 & 3,06 & 6,94 \\
\hline Illeum & $\mathrm{C} 96 \mathrm{~h}$ & 0,2349 & 0,67 & 13,38 & 2,99 & 7,01 \\
\hline Ileum & $\mathrm{D} 96 \mathrm{~h}$ & 0,1766 & 0,50 & 10,06 & 3,98 & 6,02 \\
\hline lleum & $\mathrm{E} 96 \mathrm{~h}$ & 0,2324 & 0,66 & 13,24 & 3,02 & 6,98 \\
\hline
\end{tabular}




\begin{tabular}{|l|c|c|c|c|c|c|}
\hline Organ & Probe & Extinktion $(\mathbf{y})$ & $\begin{array}{c}\text { Protein }(\mathbf{x}) \\
{[\boldsymbol{\mu g} / \boldsymbol{\mu l}]}\end{array}$ & $\begin{array}{c}\text { Lysat }[\boldsymbol{\mu g} / \boldsymbol{\mu l}] \mathbf{x} \\
\text { Faktor 20 }\end{array}$ & $\mathbf{4 0} \boldsymbol{\mu g}$ Protein & $\begin{array}{c}\text { Vol. 10 } \boldsymbol{\mu l} \\
\text { Spalt-Puffer }\end{array}$ \\
\hline Colon & C 0 h & 0,2205 & 0,63 & 12,56 & 3,18 & 6,82 \\
Colon & D 0 h & 0,2431 & 0,69 & 13,85 & 2,89 & 7,11 \\
Colon & C 1 h & 0,244 & 0,69 & 13,90 & 2,88 & 7,12 \\
Colon & D 1 h & 0,2185 & 0,62 & 12,45 & 3,21 & 6,79 \\
Colon & E 1 h & 0,2757 & 0,79 & 15,70 & 2,55 & 7,45 \\
Colon & C 6 h & 0,2054 & 0,58 & 11,70 & 3,42 & 6,58 \\
Colon & D 6 h & 0,2483 & 0,71 & 14,14 & 2,83 & 7,17 \\
Colon & E 6 h & 0,2374 & 0,68 & 13,52 & 2,96 & 7,04 \\
Colon & C 24 h & 0,211 & 0,60 & 12,02 & 3,33 & 6,67 \\
Colon & D 24 h & 0,2031 & 0,58 & 11,57 & 3,46 & 6,54 \\
Colon & E 24 h & 0,2237 & 0,64 & 12,74 & 3,14 & 6,86 \\
Colon & C 96 h & 0,1856 & 0,53 & 10,57 & 3,78 & 6,22 \\
Colon & D 96 h & 0,1917 & 0,55 & 10,92 & 3,66 & 6,34 \\
Colon & E 96 h & 0,2582 & 0,74 & 14,71 & 2,72 & 7,28 \\
\hline
\end{tabular}

Tabelle 8 Proteinbestimmung für 10er Slot, Proben A und B

\begin{tabular}{|c|c|c|c|c|c|c|}
\hline Organ & Probe & Extinktion $(y)$ & $\begin{array}{l}\text { Protein }(x) \\
{[\mu \mathrm{g} / \mu \mathrm{l}]}\end{array}$ & $\begin{array}{l}\text { Lysat }[\mu \mathrm{g} / \mu \mathrm{ll}] \mathrm{x} \\
\text { Faktor } 20\end{array}$ & $40 \mu \mathrm{g}$ Protein & $\begin{array}{c}\text { Vol. } 20 \mu \mathrm{l} \\
\text { Spalt-Puffer }\end{array}$ \\
\hline Duodenum & $\mathrm{AOh}$ & 0,2302 & 0,66 & 13,11 & 3,05 & 16,95 \\
\hline Duodenum & $\mathrm{A} 1 \mathrm{~h}$ & 0,1476 & 0,42 & 8,41 & 4,76 & 15,24 \\
\hline Duodenum & $\mathrm{B} 1 \mathrm{~h}$ & 0,0751 & 0,21 & 4,28 & 9,35 & 10,65 \\
\hline Duodenum & A $6 \mathrm{~h}$ & 0,1318 & 0,38 & 7,51 & 5,33 & 14,67 \\
\hline Duodenum & B $6 \mathrm{~h}$ & 0,1399 & 0,40 & 7,97 & 5,02 & 14,98 \\
\hline Duodenum & A $24 \mathrm{~h}$ & 0,1536 & 0,44 & 8,75 & 4,57 & 15,43 \\
\hline Duodenum & B $24 \mathrm{~h}$ & 0,1705 & 0,49 & 9,71 & 4,12 & 15,88 \\
\hline Duodenum & A $96 \mathrm{~h}$ & 0,2621 & 0,75 & 14,93 & 2,68 & 17,32 \\
\hline Duodenum & $\mathrm{B} 96 \mathrm{~h}$ & 0,1942 & 0,55 & 11,06 & 3,62 & 16,38 \\
\hline \begin{tabular}{|l} 
Jejunum \\
\end{tabular} & $\mathrm{AOh}$ & 0,2345 & 0,67 & 13,36 & 2,99 & 17,01 \\
\hline Jejunum & $\mathrm{A} 1 \mathrm{~h}$ & 0,296 & 0,84 & 16,86 & 2,37 & 17,63 \\
\hline Jejunum & B $1 \mathrm{~h}$ & 0,2459 & 0,70 & 14,01 & 2,86 & 17,14 \\
\hline Jejunum & A $6 \mathrm{~h}$ & 0,212 & 0,60 & 12,07 & 3,31 & 16,69 \\
\hline Jejunum & B $6 \mathrm{~h}$ & 0,3036 & 0,86 & 17,29 & 2,31 & 17,69 \\
\hline Jejunum & A $24 \mathrm{~h}$ & 0,1586 & 0,45 & 9,03 & 4,43 & 15,57 \\
\hline Jejunum & B $24 \mathrm{~h}$ & 0,2288 & 0,65 & 13,03 & 3,07 & 16,93 \\
\hline Jejunum & A $96 \mathrm{~h}$ & 0,2267 & 0,65 & 12,91 & 3,10 & 16,90 \\
\hline Jejunum & $\mathrm{B} 96 \mathrm{~h}$ & 0,2678 & 0,76 & 15,25 & 2,62 & 17,38 \\
\hline Ileum & $\mathrm{AOh}$ & 0,2742 & 0,78 & 15,62 & 2,56 & 17,44 \\
\hline Ileum & $\mathrm{A} 1 \mathrm{~h}$ & 0,2827 & 0,81 & 16,10 & 2,48 & 17,52 \\
\hline Ileum & $\mathrm{B} 1 \mathrm{~h}$ & 0,253 & 0,72 & 14,41 & 2,78 & 17,22 \\
\hline Ileum & $\mathrm{A} 6 \mathrm{~h}$ & 0,2305 & 0,66 & 13,13 & 3,05 & 16,95 \\
\hline Ileum & B $6 \mathrm{~h}$ & 0,1991 & 0,57 & 11,34 & 3,53 & 16,47 \\
\hline Ileum & A $24 \mathrm{~h}$ & 0,1948 & 0,55 & 11,10 & 3,61 & 16,39 \\
\hline Ileum & B $24 \mathrm{~h}$ & 0,2141 & 0,61 & 12,19 & 3,28 & 16,72 \\
\hline Ileum & A $96 \mathrm{~h}$ & 0,2579 & 0,73 & 14,69 & 2,72 & 17,28 \\
\hline Ileum & B $96 \mathrm{~h}$ & 0,3251 & 0,93 & 18,52 & 2,16 & 17,84 \\
\hline
\end{tabular}




\begin{tabular}{|l|c|c|c|c|c|c|}
\hline Organ & Probe & Extinktion $(\mathbf{y})$ & $\begin{array}{c}\text { Protein }(\mathbf{x}) \\
{[\boldsymbol{\mu g} / \boldsymbol{\mu l}]}\end{array}$ & $\begin{array}{c}\text { Lysat }[\boldsymbol{\mu g} / \boldsymbol{\mu l}] \mathbf{x} \\
\text { Faktor 20 }\end{array}$ & $\mathbf{4 0} \boldsymbol{\mu g}$ Protein & $\begin{array}{c}\text { Vol. } \mathbf{2 0} \boldsymbol{\mu l} \\
\text { Spalt-Puffer }\end{array}$ \\
\hline Colon & A 0 h & 0,1219 & 0,35 & 6,94 & 5,76 & 14,24 \\
Colon & A 1 h & 0,1367 & 0,39 & 7,79 & 5,14 & 14,86 \\
Colon & B 1 h & 0,1136 & 0,32 & 6,47 & 6,18 & 13,82 \\
Colon & A 6h & 0,1436 & 0,41 & 8,18 & 4,89 & 15,11 \\
Colon & B 6h & 0,2163 & 0,62 & 12,32 & 3,25 & 16,75 \\
Colon & A 24h & 0,1056 & 0,30 & 6,01 & 6,65 & 13,35 \\
Colon & B 24h & 0,1010 & 0,29 & 5,75 & 6,95 & 13,05 \\
Colon & A 96h & 0,1364 & 0,39 & 7,77 & 5,15 & 14,85 \\
Colon & B 96h & 0,2087 & 0,59 & 11,89 & 3,37 & 16,63 \\
\hline
\end{tabular}

Tabelle 9 Proteinstandardkonzentrationsreihe und Steigung des Graphen

\begin{tabular}{|l|c|c|}
\hline Probe & $\begin{array}{c}\text { Konzentration } \\
\text { [g/l] }\end{array}$ & Extinktion \\
\hline Std. & 1,44 & 0,4744 \\
V1 & 0,72 & 0,2822 \\
V2 & 0,36 & 0,1685 \\
V3 & 0,18 & 0,0937 \\
V4 & 0,09 & 0,067 \\
\hline
\end{tabular}

\begin{tabular}{|c|}
\hline Steigung \\
\hline$y=0,35114 x$ \\
\hline
\end{tabular}

Tabelle 10 Verwendete Chemikalien und Kits

Acrylamid/Bis $30 \%$

Agarose electrophoresis grade

Ampuwa

APS

Borsäure

Bromphenolblau

$\mathrm{CaCl}_{2}$

Citronensäure

$\mathrm{CsCl}$

DEPC

DNA-Ladder

EDTA

Ethanol 99,9 \% vergällt

Ethidiumbromid
BIO-RAD Laboratories, Hercules, USA

Invitrogen Corporation, Carlsbad, USA

Fresenius Kabi, Bad Homburg, Deutschland

Ammonium Persulfat $10 \mathrm{~g}$, BIO-RAD, Hercules, USA

Merk KGaA, Darmstadt, Deutschland

Bromphenol Blue Na-Salt, Serva, Heidelberg, Deutschland

Calciumchlorid-Dihydrat, Merck KGaA, Darmstadt, Deutschland

Citric acid, Sigma ${ }^{\circledR}$, Steinheim, Deutschland

Caesium Chloride-Optical Grade, Invitrogen, Carlsbad, USA

Diethyl pyrocarbonate approx. 97 \% NMR, Sigma, Steinheim, Deutschland

123 bp DNA Ladder, Invitrogen, Carlsbad, USA

Tritriplex III, Merck KGaA, Darmstadt, Deutschland

DeRaSo, Dassel-Lauenberg, Deutschland

Ethidium bromide $10 \mathrm{mg} / \mathrm{ml}$, Sigma ${ }^{\circledR}$, Steinheim, Deutschland 
Glycerol

Guanidin

Hydrogen Peroxid 0,3\%

Isopropanol

$\mathrm{K}_{2} \mathrm{HPO}_{4}$

Kaisers Glyceringelatine

$\mathrm{KCl}$

Ketamin $10 \%$

Methanol

$\mathrm{MgCl}_{2}$

Mounting Medium

$\mathrm{Na}_{2} \mathrm{HPO}_{4}$

$\mathrm{NaCl}$

$\mathrm{NaCl} 0,9 \%$

Natriumacetat

Natriumcitrat

Natronlauge

NP-40

Paraffin

Paraformaldehyd

Pentobarbital-Natrium

Proteinase-Inhibitor-Cocktail

Proteinmarker WB

Reagenz A

Reagenz B

Salzsäure

Sarcosyl

SDS

SDS $10 \%$

Silan
Serva, Heidelberg, Deutschland

Ultra Pure TM Guanidine Isothiocyanate, Invitrogen, Carlsbad, USA

Dako Cytomation Peroxidase Blocking Reagent, Dako, Glostrup, Dänemark

Isopropylalkohol Ph.Eur., Chemie-Vertrieb Hannover, Deutschland

di-Kaliumhydrogenphosphat-Trihydrat, Merck KGaA, Darmstadt, Deutschland

Merck KGaA, Darmstadt, Deutschland

Kaliumchlorid, Merck KGaA, Darmstadt, Deutschland

Pharmanovo GmbH, Hannover, Deutschland

Merck KGaA, Darmstadt, Deutschland

Magnesium Chloride, Sigma ${ }^{\circledR}$, Steinheim, Deutschland

DePeX-Mounting Medium, GURR ${ }^{\circledR}$, Essex, Großbritannien

di-Natriumhydrogenphosphat, Carl Roth $\mathrm{GmbH}+$ Co. KG, Karlsruhe, Deutschland

Natrium Chlorid, Merck KGaA, Darmstadt, Deutschland

Isotone Kochsalz-Lösung 0,9\%, Braun, Melsungen, Deutschland

Sodium acetate, Sigma ${ }^{\circledR}$, Steinheim, Deutschland

Sodium citrat, Sigma ${ }^{\circledR}$, Steinheim, Deutschland

Sodium hydroxide solution, E. Merck, Darmstadt, Deutschland

Igepal CA-630, Sigma ${ }^{\circledR}$, Milwaukee, USA

Paraplast Plus Tissue embedding medium, tycon/healthcare, Mansfield, USA

Paraformaldehyde, Sigma ${ }^{\circledR}$, Steinheim, Deutschland

Narcoren, Merial GmbH, Hallbergmoos, Deutschland

Complete Mini EDTA-free, Roche Diagnostics, Mannheim, Deutschland

Precision Plus Protein TM Standard All Blue, BIO-RAD, Hercules, USA

Reagenz B Bio-Rad D Protein assay, BIO-RAD, Hercules, USA

Reagenz A Bio-Rad D Protein assay, BIO-RAD, Hercules, USA

Salzsäure $1 \mathrm{~mol} / \mathrm{l}$, Karl Roth $\mathrm{GmbH}+$ Co. KG, Karlsruhe, Deutschland

N-Lauroylsarcosine Sodium Salt, Sigma, Steinheim, Deutschland

Lauryl Sulfate,Sigma ${ }^{\circledR}$, Steinheim, Deutschand

Sodium dodecyl sulfate solution 10 B59 \%, Sigma ${ }^{\circledR}$, Steinheim, Deutschland

(3-Aminopropyl)triethoxy-silane, Sigma ${ }^{\circledR}$, Steinheim, Deutschland 
B-Mercaptoethanol

Temed

Tris

Tris-Base

Tris- $\mathrm{HCl}$

Xylazin $2 \%$

Xylol

\section{Verwendete Kits}

ACE-Kit

Apoptotic DNA-Ladder

DC Protein Assay Kit

Masson-Goldner-Färbekit

M-MLV RT-Kit

SYBR-Green-Kit

TUNEL-KIT

Western Blot Kit

Weigerts Eisenhämatoxylin Kit

Tabelle 11 Antikörperliste

ED1

$\beta$-Aktin

Bcl-2

Bax

Caspase 3

Caspase 3

Caspase 8

CD3

CD34
Merck KGaA, Darmstadt, Deutschland

BIO-RAD Laboratories, Hercules, USA

Carl Roth $\mathrm{GmbH}+$ Co. KG, Karlsruhe, Deutschland

Trizma ${ }^{\circledR}$ Base, Sigma ${ }^{\circledR}$, Steinheim, Deutschland

Trishydrochlorid, Carl Roth $\mathrm{GmbH}+\mathrm{Co}$. KG, Karlsruhe, Deutschland

Serumwerk Bernburg, Bernburg/Saale, Deutschland

Merck KGaA, Darmstadt, Deutschland

Chem Mate Detections Kit, DAKO, Glostrup, Dänemark

Apoptotic DNA Ladder Detection, 50 assays, BioCat, Heidelberg, Deutschland

BIO-RAD Laboratories, Hercules, USA

Merck KGaA, Darmstadt, Deutschland

M-MLV Reverse Transkriptase, Invitrogen, Carlsbad, USA

Platinum ${ }^{\circledR}$ SYBR ${ }^{\circledR}$ Green qPCR' SuperMix-UDG, Invitrogen, Carlsbad, USA

Dead EndTM Colorimetric TUNEL system, Promega Corporation, Madison, USA

Chemiluminescent Western Blot Immunodetection Kit, Invitrogen, Carlsbad, USA

Merck KGaA, Darmstadt, Deutschland

Mouse Anti Rat CD 68, AbD Serotec, Oxford, Großbritannien

ß-Actin mouse monoclonal IgG1, Santa Cruz Biotechnology, Santa Cruz, USA

Bcl-2 mouse monoclonal IgG1, Santa Cruz Biotechnology, Santa Cruz,USA

Calbiochem $^{\circledR}$ an Affiliate of Merck KGaA; Darmstadt, Deutschland

Rabbit Anti-Caspase-3 Polyclonal Antibody, Chemicon ${ }^{(B)}$ international by Millipore, Biierica, USA

Cleaved Caspase-3 (Asp 175) (5A1E) Rabbit mAb, Cell Signaling Technology, Boston, USA

Rabbit Anti-Caspase-8 Polyclonal Antibody, Chemicon ${ }^{(B)}$ international by Millipore, Billerica, USA

Polyclonal Antibody, Dako, Glostrup, Dänemark

Anti-CD34 monoclonal antibody, Immunotech, Marseille, Frankreich 
Tabelle 12 Geräteliste

ABI-Prism ${ }^{\circledR}$-7900-PCR-Cycler

Abiprism- Software

Bestrahlungsapparat

Biophotometer

Blotapparatur

Computerprogramm Mikroskop

CT-Scanner

Digitalkamara für Mikroskop

Digitalkamera für WB

Eppendorfpipetten

Filmentwicklermaschine

Gefrierplatte

Heizblock

Heizplatte

Kaleida-Graph- Software

Mikroskop

Mikrotom

Paraffin-Ausgießstation

Pipetboy comfort

Potter

Potter-Reagenzglas

Schüttler

Schüttler (im Kühlraum)

Spannungsgerät (Blot)

Spannungsgerät (Lauf)

Spekrophotometer

Tissue Lysec

Ultrazentrifuge

Vortexer
Applied Biosystems, Darmstadt, Deutschland

Applied Biosystems, Foster City, USA

Varian Clinac $600 \mathrm{C}$ accelerator, Palo Alto, USA

RNA/DNA Calculator, Gene Quant II Pharmacia, Biotech, Cambridge, Großbritannien

Trans-Blot ${ }^{\circledR}$ SD Semi-dry Transfer cell, BIO-RAD, Hercules, USA

Remote Capture 2.7, Canon Cananda Inc., Mississauga, Kanada

Somatom Balance, Siemens, Erlangen, Deutschland

Canon EOS D 60 Digital, Canon Cananda Inc., Mississauga, Kanada

Canon EOS 300 D Digital, Canon Cananda Inc., Mississauga, Kanada

eppendorf, Hamburg, Deutschland

SRX-101A, Konica minolta, Tokyo, Japan

Tissue Cool Plate COP 20, Medite Medizintechnik, Burgdorf, Deutschland

Thermomixer comfort, eppendorf, Hamburg, Deutschland

RCT basic, IKA Labortechnik, Staufen, Deutschland

Synergy Software, Reading, USA

Axioskop, Carl Zeiss, Feldbach, Schweiz

Reichert-Jung, Cambridge Instruments $\mathrm{GmbH}$, Nussloch, Deutschland

Leica EG 1160, Leica Microsystems, Nussloch, Deutschland

Integra Biosciences, Chur, Schweiz

Potter S, B. Braun, Melsungen, Deutschland

Sartorius, Göttingen, Deutschland

Köttermann ${ }^{\circledR} 4010$, Uetze-Hänigsen, Deutschland

Heidolph Polymax 1040, Schwabach, Deutschland

PowerPac 200, BIO-RAD, Hercules, USA

PowerPac 300, BIO-RAD, Hercules, USA

DU ${ }^{\circledR} 640$, Spectrophotometer, Beckmann, Corona, USA

QIAGEN GmbH, Hilden, Deutschland

Sorvall Ultra Pro 80, Sorvall Products L.P. Newtown, USA

MS1 Minishaker, IKA, Taquara, Brasilien 
Waage

Waage ( $\mu \mathrm{g}$-Bereich)

Wärmebecken

Wärmeschrank

WB Gel/Lauf-Apperatur

Zentrifuge

Tabelle 13 Verbrauchsmaterialien

Abdeckfolie für Lochplatte

Deckgläser

E-Cups

Entwicklungsfilm

Filterpaper

Halbmikro-Einmalküvette

Kryoröhrchen $2 \mathrm{ml}$

96-Lochplatte PCR

Mikrotom-Klinge

Nitrozellulosemembran

Objektträger

Petrischalen

Pipetten

Pipetten steril

Pipettenspitzen

Röhrchen 15 ml

Röhrchen $50 \mathrm{ml}$

Skalpell

Zentrifugenröhrchen
TE 612, Sartorius, Göttingen, Deutschland

BP 121 S, Sartorius, Göttingen, Deutschland

Störk Tronic, Medax Nagel GmbH, Kiel, Deutschland

Ehret BK 4029, Emmendingen, Deutschland

Mini-Protean ${ }^{\circledR}$ Electrophoresis Module Assembly, BIO-RAD, Hercules, USA

Centrifuge 5415 C, eppendorf, Hamburg, Deutschland

MicroAmp TM, Optical Adhesive Film, Applied Biosystems, Foster City, CA, USA

24 × 60 mm, Gerhard Menzel Glasverarbeitungswerk GmbH \& Co. KG,

Braunschweig, Deutschland

$1,5 \mathrm{ml} / 2 \mathrm{ml}$ Eppendorf-Nether - HinzGmbH, Hamburg, Deutschland

Lumi-Film Chemiluminescent Detection Film, Roche, Mannheim, Deutschland

Filterpapier Protean XL size, BIO-RAD, Hercules, USA

Cuvettes 100, Sarstedt, Nümbrecht, Deutschland

Schütt, Stadt, Deutschland, Deutschland

MicroAmp TM, Fast optical 96-well Reaction Plate with Barcode (0,1 ml), Applied Biosystems, Foster City, CA, USA

Microtome blades A 35 Type, Feather, Japan

Trans-Blot $^{\circledR}$ Transfer Medium $(0.45 \mu \mathrm{m})$, BIO-RAD, Hercules, USA

26 × 76 mm, Waldemar Knittel Gläserverarbeitungs $\mathrm{GmbH}$, Braunschweig,

Deutschland

NunclonTM Surface, nuneTM, Roskilde, Dänemark

$10 \mathrm{ml} / 25 \mathrm{ml}$ Cellstar ${ }^{\circledR}$, greiner bio-one, Frickenhausen, Deutschland

$10 \mathrm{ml} / 25 \mathrm{ml}$ Sarstedt, Nümbrecht, Deutschland

$10 \mu \mathrm{l} / 100 \mu \mathrm{l} / 1000 \mu \mathrm{l}$ epT.I.P.S. Reloads 0,5-20 $\mu \mathrm{l}$, eppendorf, Hamburg,

Deutschland

Cellstar $^{\circledR}$, greiner bio-one, Frickenhausen, Deutschland

Sarstedt, Nümbrecht, Deutschland

techno cut scalpel no. 4, HMD Healthcare Ltd., Hereford, Großbritannien

Beckmann Polyallomer Centrifuge Tubes, Corona, USA 
Tabelle 14 Sequenzen der Gen-spezifischen Primer für die quantitative RT-PCR-Analyse

Gene $\quad$ Primer Sequenz

\begin{tabular}{|c|c|c|}
\hline \multirow[t]{2}{*}{$\beta$-Aktin } & Sense: & 5'-ACC ACC ATG TAC CCA GGC ATT \\
\hline & Antisense: & 5'-CCA CAC AGA GTA CTT GCG CTC A \\
\hline \multirow[t]{2}{*}{ bax } & Sense: & 5'-ATG GAG CTG CAG AGG ATG ATT G \\
\hline & Antisense: & 5'-CAG TTG AAG TTG CCA TCA GCA A \\
\hline \multirow[t]{2}{*}{ bcl-2 } & Sense: & 5'-GCG ACT TTG CAG AGA TGT CCA \\
\hline & Antisense: & 5'-AGT TCA CCC CAT CCC TGA AGA G \\
\hline \multirow[t]{2}{*}{ cox-2 } & Sense: & 5'-TAC CCG GAC TGG ATT CTA CG \\
\hline & Antisense: & 5'-AAG TTG GTG GGC TGT CAA TC \\
\hline ED1 & Sense: & 5'- ATT GAA CCC GAA CAA AAC CA \\
\hline (CD68) & Antisense: & 5'- GCT TGT GGG AAG GAC ACA TT \\
\hline ED2 & Sense: & 5'-GCA GCA GCA ATA TCT CTC CA \\
\hline (CD163) & Antisense: & 5'-GCT GGC TTG TCT CTG TTT CC \\
\hline \multirow[t]{2}{*}{ HO-1 } & Sense: & 5'-CAA CCC CAC CAA GTT CAA ACA G \\
\hline & Antisense: & 5'-AAG GCG GTC TTA GCC TCT TCT G \\
\hline \multirow[t]{2}{*}{ HSP-27 } & Sense: & 5'-CGAAGAAAGGCAGGATGAAC \\
\hline & Antisense: & 5'-CGCTGATTGTGTGACTGCTT \\
\hline ICAM-1 & Sense: & 5'-TGC ACG TCC CTG GTG ATA CTC \\
\hline (CD54) & Antisense: & 5'-TGT CAA ACG GGA GAT GAA TGG \\
\hline \multirow[t]{2}{*}{ IFN-y } & Sense: & 5'-AGT CTG AAG AAC TAT TTT AAC TCA AGT AGC AT \\
\hline & Antisense: & 5'-CTG GCT CTC AAG TAT TTT CGT GTT AC \\
\hline \multirow[t]{2}{*}{$\|-1 \beta$} & Sense: & 5'-TAC CTA TGT CTT GCC CGT GGA G \\
\hline & Antisense: & 5'-ATC ATC CCA CGA GTC ACA GAG G \\
\hline \multirow[t]{2}{*}{ II-6 } & Sense: & 5'-GTC AAC TCC ATC TGC CCT TCA G \\
\hline & Antisense: & 5'-GGC AGT GGC TGT CAA CAA CAT \\
\hline \multirow[t]{2}{*}{ IL-8 } & Sense: & 5'-CCC CCA TGG TTC AGA AGA TTG \\
\hline & Antisense: & 5'-TTG TCA GAA GCC AGC GTT CAC \\
\hline \multirow[t]{2}{*}{ IP-10 } & Sense: & 5'-CTG TCG TTC TCT GCC TCG TG \\
\hline & Antisense: & 5'-GGA TCC CTT GAG TCC CAC TCA \\
\hline
\end{tabular}


MAdCAM-1 Sense: $\quad$ 5'-TTT CCT TTG CCT TGC TCC G

Antisense: $\quad$ 5'-ACT TGG AAG AGT GGA GTG CCC T

MCP-1 Sense: 5'-AGG CAG ATG CAG TTA ATG CCC

Antisense: $\quad$ 5'-ACA CCT GCT GCT GGT GAT TCT C

MIP-1 $\alpha$ Sense: 5 '-TTT TGA GAC CAG CAG CCT TT

Antisense: 5'-CTC AAG CCC CTG CTC TAC AC

MIP-3a Sense: 5'-CAA CTT TGA CTG CTG CCT CA

Antisense: 5'-TTC CAT CCC AGA AAA GCA TC

PECAM-1 Sense: 5'-TCA GCT GCC AGT CAG TAA ATG G

(CD31) Antisense: 5'-TCT GGA AGT TGC TCT TTG CTC TT

SMA Sense: $\quad 5$-GGC TCC ATC CTG GCT TCT CTA T

Antisense: 5 '-GGC GTG ACT TAG AAG CAT TTG C

TGF- $\beta \quad$ Sense: $\quad$ 5'-GCT GCT GAC CCC CAC TGA T

Antisense: 5 '-GCC ACT GCC GGA CAA CTC

Thy-1 Sense: 5'-TGA ACC CAG TCA TCA GCA TCA C

(CD90) Antisense: 5'-CAG TCG AAG GTT CTG GTT CAC C

TNF- $\alpha \quad$ Sense: $\quad$ 5'-ACA AGG CTG CCC CGA CTA T

Antisense: $\quad$ ''-CTC CTG GTA TGA AGT GGC AAA TC

VEGF Sense: $\quad$ 5'-CAA TGA TGA AGC CCT GGA GT

Antisense: $\quad$ 5'-AAT GCT TTC TCC GCT CTG AA

VEGF-R-1 Sense: $\quad$ 5'-GCC ACA GCC AGT GAG TAC AA

Antisense: $\quad$ '-GCT GCA TCC TTG TTG AGA CA 
Tabelle 15 Kriterien der Gewebeschädigung nach Radiotherapie mit Mittelwert (MW) und Standardabweichung (SD)

\begin{tabular}{|c|c|c|c|c|c|c|c|}
\hline Organabschnitt & $\mathrm{Oh}$ & $1 \mathrm{~h}$ & $6 \mathrm{~h}$ & $24 \mathrm{~h}$ & $96 \mathrm{~h}$ & 1.5 Monate & 3 Monate \\
\hline \multicolumn{8}{|l|}{ Duodenum } \\
\hline C & 1 & 1 & 1 & 4 & 4 & 1 & 1 \\
\hline D & 1 & 4 & 3 & 4 & 5 & 2 & 2 \\
\hline $\mathrm{E}$ & verstorben & 4 & 3 & 4 & 3 & 2 & 2 \\
\hline MW & 1,00 & 3,00 & 2,33 & 4,00 & 4,00 & 1,67 & 1,67 \\
\hline SD & 0,00 & 1,73 & 1,15 & 0,00 & 1,00 & 0,58 & 0,58 \\
\hline \multicolumn{8}{|l|}{ Jejunum } \\
\hline C & 1 & 2 & 4 & 4 & 3 & 1 & 1 \\
\hline$D$ & 1 & 2 & 4 & 4 & 4 & 2 & 1 \\
\hline $\mathrm{E}$ & verstorben & 1 & 4 & 4 & 4 & 1 & 1 \\
\hline MW & 1,00 & 1,67 & 4,00 & 4,00 & 3,67 & 1,33 & 1,00 \\
\hline SD & 0,00 & 0,58 & 0,00 & 0,00 & 0,58 & 0,58 & 0,00 \\
\hline \multicolumn{8}{|l|}{ Ileum } \\
\hline C & 1 & 1 & 5 & 4 & 5 & 1 & 1 \\
\hline D & 1 & 2 & 3 & 4 & 4 & 5 & 1 \\
\hline E & verstorben & 2 & 5 & 5 & 4 & 5 & 5 \\
\hline MW & 1,00 & 1,67 & 4,33 & 4,33 & 4,33 & 3,67 & 2,33 \\
\hline SD & 0,00 & 0,47 & 0,94 & 0,47 & 0,47 & 1,89 & 1,89 \\
\hline \multicolumn{8}{|l|}{ Colon } \\
\hline C & 1 & 1 & 1 & 1 & 1 & 1 & 1 \\
\hline$D$ & 1 & 1 & 1 & 1 & 1 & 1 & 1 \\
\hline E & verstorben & 1 & 1 & 1 & 1 & 1 & 1 \\
\hline MW & 1,00 & 1,00 & 1,00 & 1,00 & 1,00 & 1,00 & 1,00 \\
\hline SD & 0 & 0 & 0 & 0 & 0 & 0 & 0 \\
\hline
\end{tabular}




\section{DANKSAGUNG}

Ich danke meinem Doktorvater Herrn Prof. Dr. med. Dr. h.c. G. Ramadori für die Möglichkeit, diese experimentelle Doktorarbeit unter seiner Leitung anzufertigen.

Auch bei Herrn Prof. Dr. rer. nat. Dr. med. C. F. Hess bedanke ich mich, dass ich weitgehend die experimentellen Versuche in seinen Laboren durchführen konnte.

Mein ganz besonderer Dank gilt Frau Dr. med. S. Cameron M.A. für ihre engagierte Betreuung. Ihre stetige Ansprechbarkeit zur Evaluierung der Ergebnisse und zur wissenschaftlichen Diskussion haben mich wesentlich in der Ausarbeitung dieser Dissatation gefördert.

Weiterer Dank gilt PD Dr. med. R. Hermann und Prof. Dr. med. H. Christiansen für ihre sorgfältige Unterstützung bei der Planung der Versuche und der interdisziplinären Koordination mit der Abteilung Strahlentherapie.

Außerdem möchte ich Frau Dipl.-Biol. M. Rave-Fränk für ihre wertvollen Ratschläge zur Optimierung der Versuche und für die ausdauernde Bereitschaft zur inhaltlichen Auseinandersetzung mit der Thematik danken.

Ganz herzlich möchte ich mich auch bei Frau A. Bitter und bei Frau J. Kasten-Krapp für die zeitintensive Einarbeitung im Labor und die angenehme Arbeitsatmosphäre bedanken. Durch ihre zahlreichen Hilfestellungen während der Arbeit und ihren tatkräftigen Einsatz bei der Durchführung der Experimente ist es mir gelungen, die vielfältigen Methoden dieser Arbeit zu erschließen.

Des Weiteren bin ich den medizinisch-technischen Assistentinnen der gastroenterologischen Labore dankbar für ihre Mitarbeit und ihre hilfreichen Erfahrungen bei der Durchführung der Versuche.

Herrn Dr. rer. nat. J. Dudas danke ich für die unermüdliche Hilfe bei der Durchführung und Planung einiger Methoden.

Abschließend möchte ich mich bei Frau J. Colin bedanken, die maßgeblich an der Korrektur der vorliegenden Dissertationsschrift beteiligt war. 